\title{
Corporate decision-making for arts sponsorship
}

by

Kate Daellenbach

\begin{abstract}
A thesis
submitted to the Victoria University of Wellington in fulfilment of the requirements for the degree of Doctor of Philosophy
\end{abstract}

Victoria University of Wellington

2011 



\section{Abstract}

Sponsorship is a crucial revenue stream for many non-profit arts organisations. At the same time businesses appear to be viewing sponsorship and philanthropy as an ever more strategic activity, yet little is known about the actual decision-making processes these companies undergo in considering arts sponsorships.

Examination of sponsorship and philanthropy literature revealed that an opportunity existed to study these processes in more depth, and the research question was posed: How do companies make decisions when considering arts sponsorship? Literature from Organisational Buying Behaviour and Decision-making provided lenses by which these processes could be viewed, and a subsequent framework was developed to inform the research.

Multiple cases of positive arts sponsorship decisions from within New Zealand were examined. Responses from 24 in-depth interviews resulted in the identification of ten cases for which information was gathered from multiple informants on both sides of the relationship. In addition, ten interviews were categorised as "experts" on the topic of arts sponsorship more generally, and used as a secondary source of data. Within and between case analyses was combined with comparison of expert responses to yield initial results. Taking a theory-building approach, iteration between results, literature and theory served to develop the final findings.

This study revealed a number of key themes which characterise these decisions. Firstly, the expectations and perceptions of society, concerning sponsorship, influence stakeholders, companies and individual managers, and subsequently influence these decisions. Secondly, a co-existence of both commercial and philanthropic goals was found within decisions, suggesting that such decisions are not always categorized into one particular area. Thirdly, a key influential role was identified in these decisions as that of an advocate, being a manager who sees the benefit of the sponsorship and essentially makes it happen within the organisation. Fourthly, it was found that these decisions rely on and are influenced in part by individual intuition, based on personal and professional experience, and serving to pave the way for a type of informed 
happenstance, necessary for the decisions to progress. While three decision paths were noted in this study, a general decision process was proposed which would vary based on many of the characteristics above.

Overall, this study has contributed to sponsorship and philanthropy literature in revealing arts sponsorship decisions to be complex, with managers influenced by expectations and perceptions of society, commercial and philanthropic goals, individual and company frames, and intuitive and economic justifications. In conclusion, propositions and suggestions for future research are proposed, along with implications for managers in both arts organisations and sponsoring businesses. 


\section{Acknowledgements}

This thesis is completed in part because my family, supervisors, colleagues and friends believed I could do this, supported me, challenged me, and gave me feedback. I surely could not have done it alone, and I wish to acknowledge their support and input, and thank them.

Thank you firstly to my husband Urs, my son Seb and daughter Sophia, for your unwavering belief in me, your love and your wonderful reminder of what is really important in life.

My thanks and acknowledgements also go to my supervisors for their input, time and dedication. Peter Thirkell's tremendous intelligence, ability to listen, to provide insight and encouragement and to see the big picture has benefitted this effort. Lena Zander's knowledge, experience, insight, enthusiasm and ability to hold a skype session at $11 \mathrm{pm}$ have also proved invaluable.

Thank you also to my parents, sisters and their families, my husband's family, and our many good friends, for their support, encouragement and humour.

I also acknowledge the examiners, whose input I have appreciated and incorporated to the benefit of this thesis.

There have been many others whose ideas, support and coffees have certainly helped me in this research. In the early stages Val Lindsay and Nick Ashill helped me to get the process started, and I thank them for this. So many other colleagues and fellow PhD students within the School and Faculty have been part of this process, whether they knew it or not, and I thank them for their time and energy. 


\section{Table of Contents}

\section{1: INTRODUCTION}

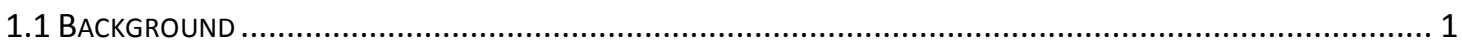

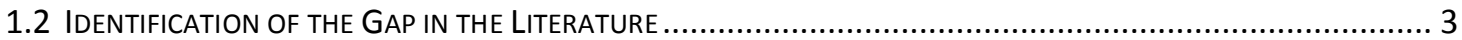

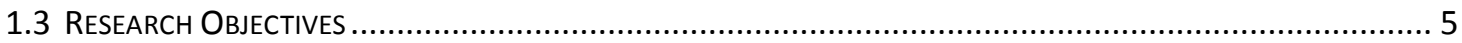

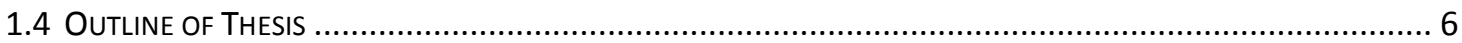

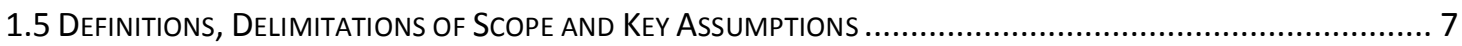

2: SPONSORSHIP AND PHILANTHROPY LITERATURE...............................10

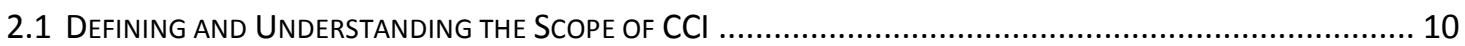

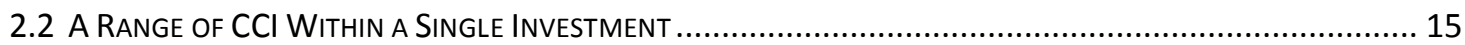

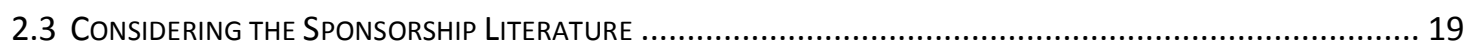

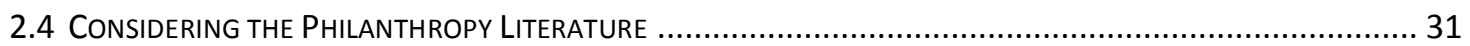

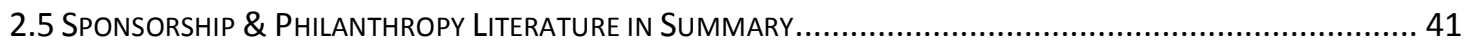

\section{3: CONCEPTUAL FRAMEWORK DEVELOPMENT: INTEGRATING} ORGANISATIONAL BUYING BEHAVIOUR AND DECISION-MAKING

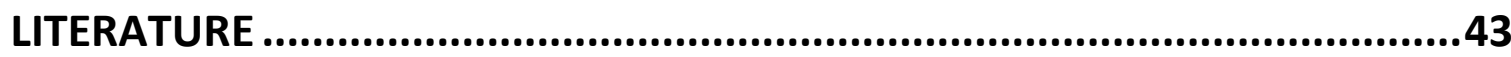

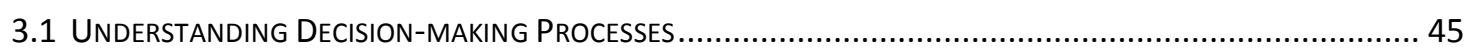

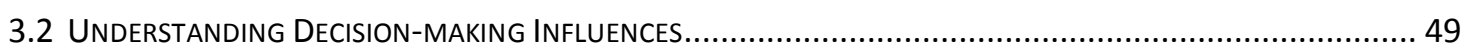

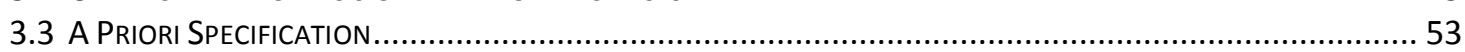

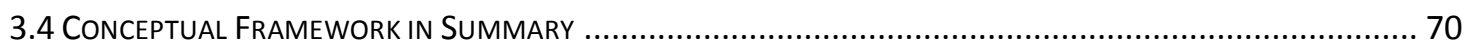

4: RESEARCH DESIGN AND METHODOLOGY ..........................................71

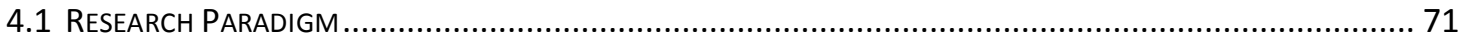

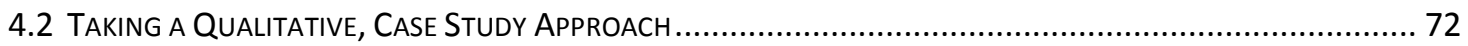

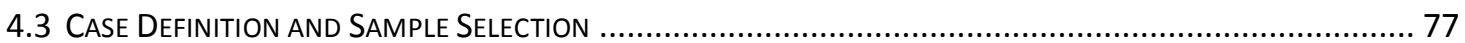

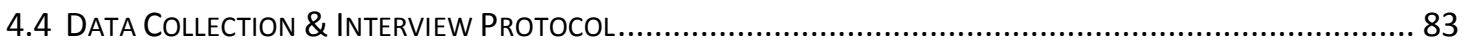

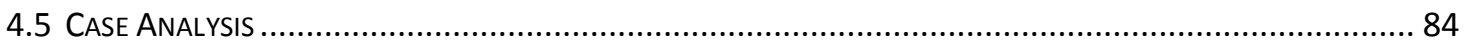

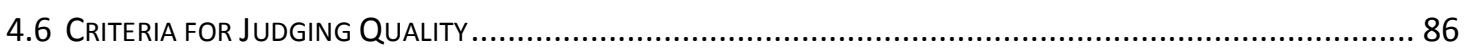

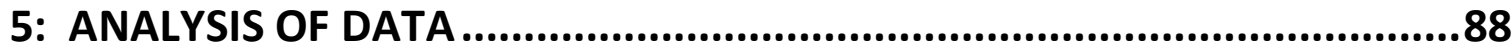

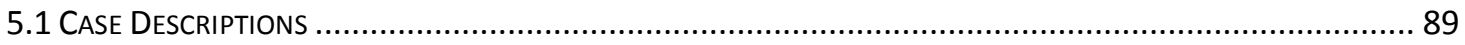

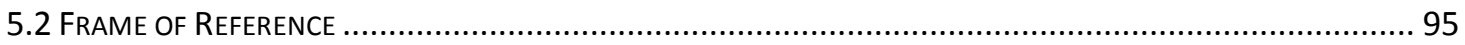

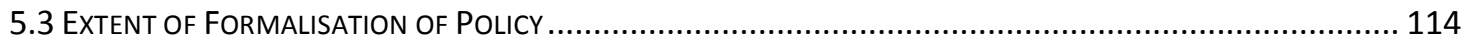

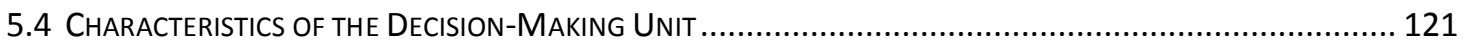

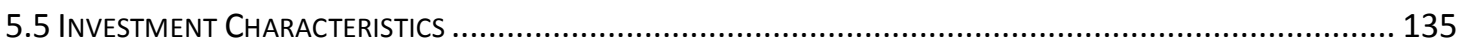

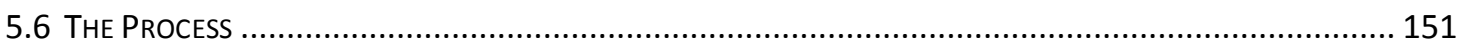

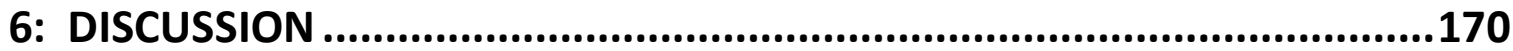

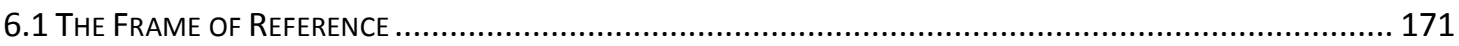

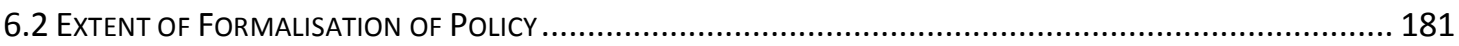

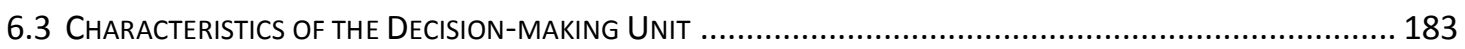

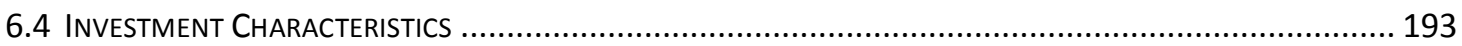

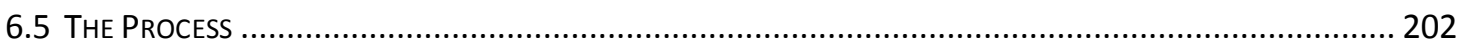

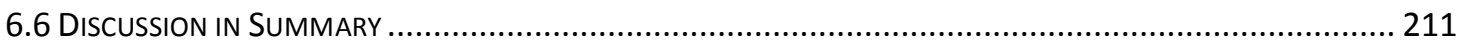

7: THEORY AND PROPOSITION DEVELOPMENT ....................................213 


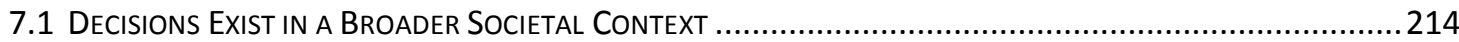

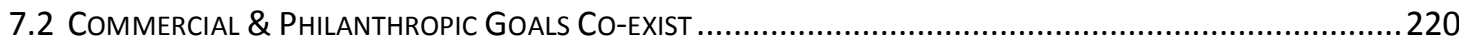

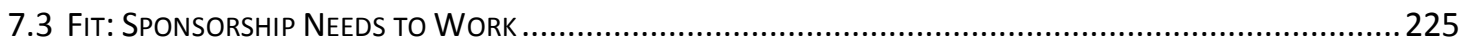

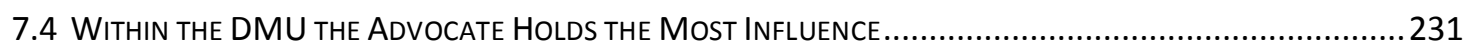

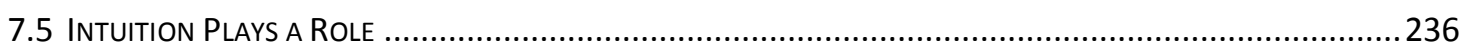

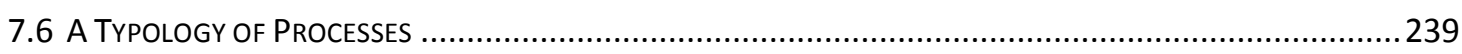

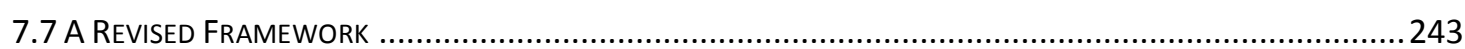

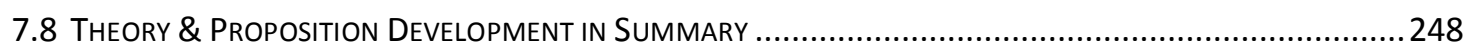

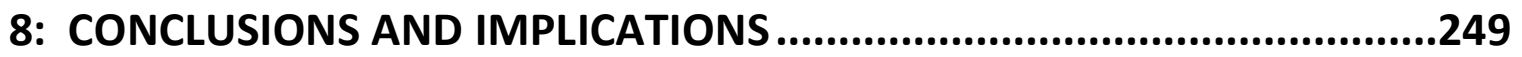

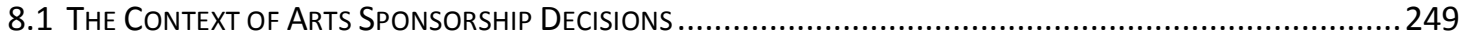

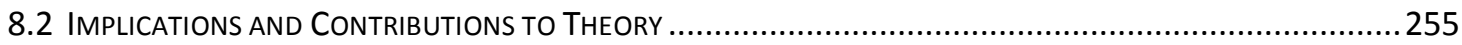

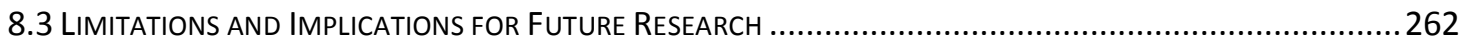

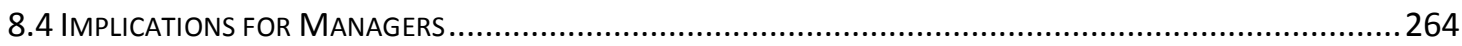

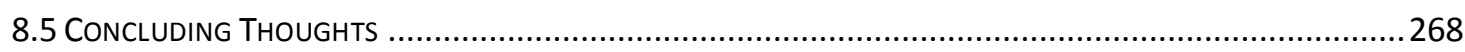

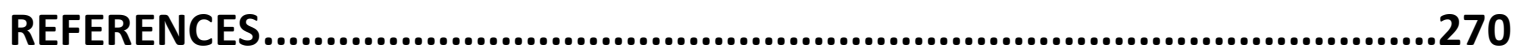

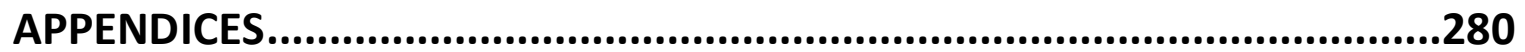

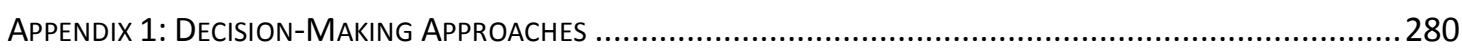

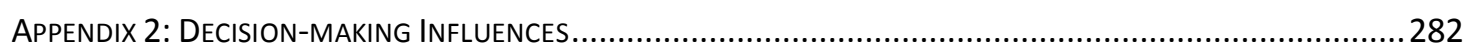

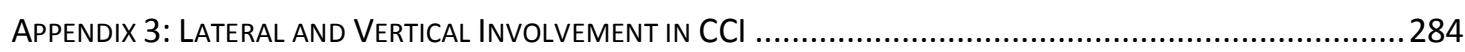

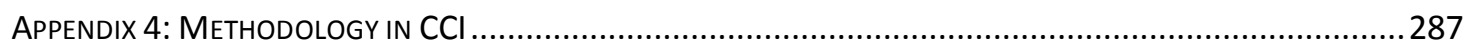

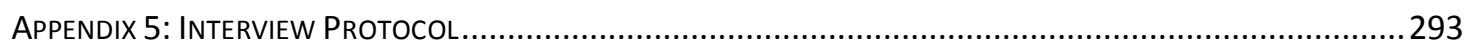

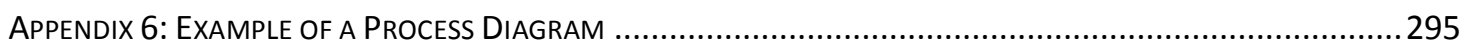

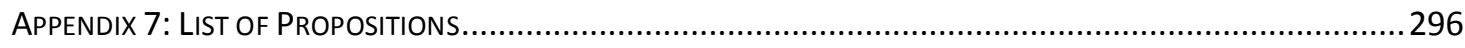




\section{List of Figures and Tables}

Figure 1.1 The Black Box of Arts Sponsorship Decision Making........................................

Figure 2.1 Map of the Literature Review ..........................................................................10

Figure 2.2 A Range of Commercial \& Philanthropic Goals ...............................................18

Figure 3.1 Development of a Conceptual Framework......................................................43

Figure 3.2 The Black Box of Arts Sponsorship Decision-making ….....................................54

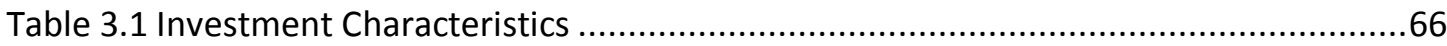

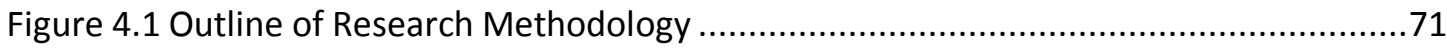

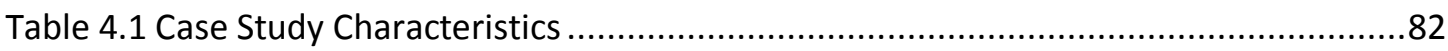

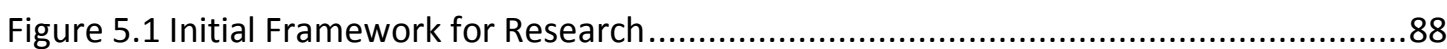

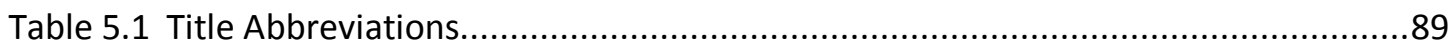

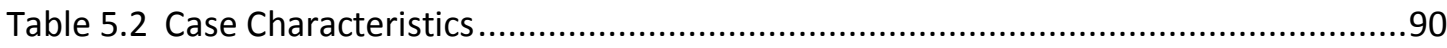

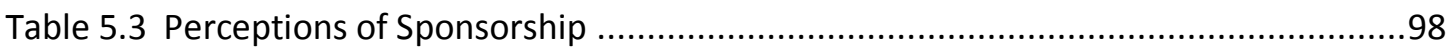

Table 5.4 Company Orientation to Commercial vs. Philanthropic Decisions........................105

Table 5.5 Formal vs. Actual Evaluation Criteria...........................................................117

Table 5.6 Roles in the Decision-making Unit...............................................................127

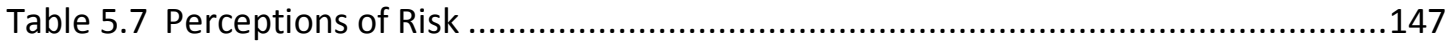

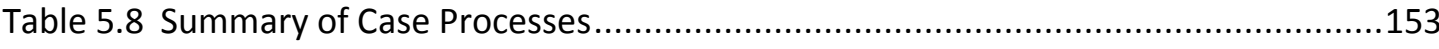

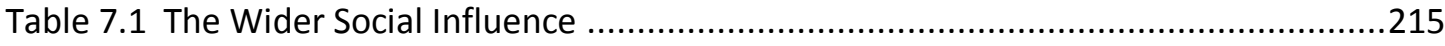

Figure 7.1 Cases Within a Commercial and Philanthropic Range.....................................220

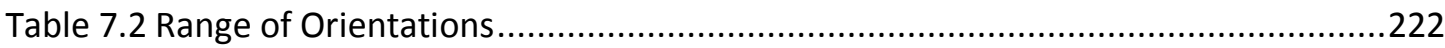

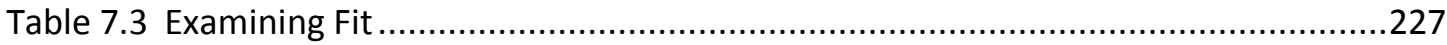

Table 7.4 The Advocate, Expert Power and Intuition .......................................................233

Table 7.5 Intuition and Knowledge in Decision Processes ..............................................238

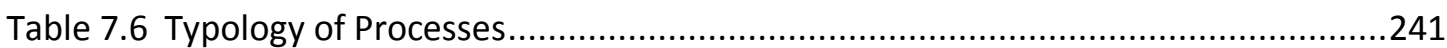

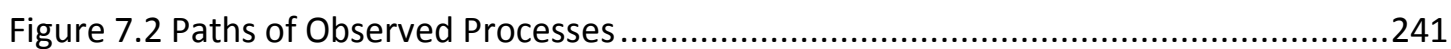

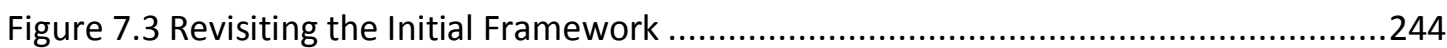

Figure 8.1 A Multilevel Perspective on Arts Sponsorship Decisions.................................254 


\section{List of Acronyms \& Abbreviations}

\begin{tabular}{|l|l|}
\hline Acronym & Full term \\
\hline BIT & Brand Image Transfer \\
\hline CCI & Corporate Community Involvement \\
\hline CFP & Corporate Financial Performance \\
\hline CSP & Corporate Social Performance \\
\hline CSR & Corporate Social Responsibility \\
\hline DMU & Decision Making Unit \\
\hline OBB & Organisational Buying Behaviour \\
\hline
\end{tabular}

\section{Titles of Respondents within cases}

\begin{tabular}{|c|c|}
\hline Abbreviation & Assigned role \\
\hline $\mathrm{ABM}$ & Arts Organisation Board Member \\
\hline $\mathrm{ACE}$ & Arts Organisation Chief Executive \\
\hline $\mathrm{CCE}$ & Company Chief Executive (of sponsoring company) \\
\hline CMM & $\begin{array}{l}\text { Company Marketing Manager: Individual within the sponsoring company } \\
\text { whose main role is assigned to the category of Marketing. Their role may or } \\
\text { may not include management of sponsorships. }\end{array}$ \\
\hline CSM & $\begin{array}{l}\text { Company Sponsorship Manager: Individual within the sponsoring company } \\
\text { whose main role is to manage sponsorship and sometimes broader CCI-related } \\
\text { investments. }\end{array}$ \\
\hline
\end{tabular}




\section{1: Introduction}

"the thing with sponsorship is that if there was a magic formula we would be sorting it out ... but because so much of it is basically based on people's thought processes and decision-making processes, you're always playing a guessing game about what that might be. Always trying to think about what they might want or what they might say or where they might be at.

\section{- Manager, Arts Organisation}

Gaining corporate sponsorship plays a significant part in the revenues of arts organisations around the world yet it remains something of a guessing game. Arts managers need to convince companies to engage in a sponsorship, and meet with varying success. The research in this thesis deals with this interchange, and specifically the decision processes these companies undertake. This research seeks to better understand how companies make arts sponsorship decisions. If arts organisations have greater understanding of these processes, they may have greater success.

The thesis consists of eight chapters. This first chapter introduces the study by providing background on the issue, introducing the gap in the existing literature, and setting out the research problem and objectives. An outline of the entire thesis will be provided along with an initial discussion of definitions and delimitations to provide clarity for future chapters.

\subsection{Background}

Increasingly non-profit organisations, including those in the arts, are seeking support from the business community. At the same time, businesses often take on a role in society whereby they invest in various causes. In the late 1980's authors noted a new phase of business response to societal expectations: "corporate social responsibility being viewed as an investment," or “doing better by doing good” (Stroup, Neubert, \& Anderson, 1987, p. 22). More recently, Seitanidi and Ryan (2007) put forward a list of relationships where companies provide support to non-profit organisations under the title 
“Corporate Community Involvement” (CCI), which included partnerships, sponsorships and corporate philanthropy, among others.

There is evidence that businesses around the world are making these investments in the community. A report of business giving in Australia estimated that donations more than doubled between 2000/01 and 2003/04 (Australian Government Department of Family and Community Services, 2005). Philanthropy New Zealand estimates that companies make up around $2.5 \%$ of the overall income for the non-profit sector, which would amount to around $\$ 80$ million (Robinson \& Hanley, 2005). Similar to Philanthropy New Zealand's estimate of $2.5 \%$, the Johns Hopkins Comparative Non-profit Sector Project estimated corporate gifts at between $2 \%$ and $2.9 \%$ of the income for the non-profit sector in the UK, US and France (Robinson \& Hanley, 2005). ${ }^{1}$ This $2-2.9 \%$ does not appear large, but for many non-profits operating on a break-even, even a small percentage is important.

Figures specific to the arts sector are difficult to come by. However LeClair and Gordon (2000) noted an increase in corporate support for the arts in the USA from $\$ 108.8$ million in 1980 to $\$ 243.6$ million in 1992. In the latest Arts Council Review (England), the council acknowledged the importance of corporate sponsorship and the impact of the economic downturn:

In April 2009, we took strategic action to maintain artistic excellence and courageous innovation during the recession by creating the Sustain fund. Sustain awarded $£ 47$ million to 146 arts organisations, enabling them to maintain the quality of their artistic output through the downturn and negating the worst of the decline in sponsorship and private giving. (Arts Council England, 2010, p. 3)

\footnotetext{
${ }^{1}$ Other studies suggest that New Zealand's non-profit sector has comparable characteristics with nations around the world. The Center for Civil Society Studies at Johns Hopkins University compared workforce and funding figures, illustrating that in these respects, New Zealand's sector bore similarity to patterns in the Anglo-Saxon cluster (including Australia, United Kingdom and the United States of America), and the Nordic cluster (Denmark, Finland, Norway and Sweden) (Sanders, O'Brien, Tennant, Sokolowski, \& Salamon, 2008).
} 
While organisations such as the Arts Council England have noted the importance of corporate sponsorship, the specific contribution to companies varies. For example, The Royal Shakespeare Company (England) reported their sponsorships and donations as $4.9 \%$ of their income (Royal Shakespeare Company, 2009), while the Chicago Symphony Orchestra reported its sponsorship and donations as $32 \%$ of their total revenue (Chicago Symphony Orchestra, 2009). In New Zealand, the percentage of revenue from business also varies. For example, The New Zealand International Festival of the Arts reported sponsorship at $31 \%$ of income (New Zealand International Festival of the Arts, 2004); and the Royal New Zealand Ballet reported sponsorship at 11\% of income (Royal New Zealand Ballet, 2004).

Certainly support from businesses is important to non-profits, including the arts sector, and businesses appear to be responding to the requests. From the sponsoring company's standpoint, the decision may or may not be regarded as an investment, but would certainly involve some sort of decision-making process. Arts organisations seeking sponsorship should understand these processes.

\subsection{Identification of the Gap in the Literature}

In seeking a better understanding of these processes, literature from both sponsorship and philanthropy appears most pertinent. In sponsorship, the literature has focused predominantly on sports sponsorship, with some attention to the arts. Sponsorship studies have considered objectives and motivations for sponsorship (Hoek, Gendall, \& West, 1990; LeClair \& Gordon, 2000; O'Hagan \& Harvey, 2000), as well as the roles and interplay of trust, commitment and communication within the relationship (Farrelly \& Quester, 2003a; Farrelly \& Quester, 2005b). In the philanthropy literature, which tends to have a focus on charities (i.e. not specifically arts), motivations have also been examined (Campbell, Moore, \& Metzger, 2002; Madden, Scaife, \& Crissman, 2006), as well as factors which influence the decision such as ownership, firm size and individual preference (Atkinson \& Galaskiewicz, 1988; Seifert, Morris, \& Bartkus, 2003; Wang \& Coffey, 1992). The literature in both areas notes how these "investments" may be and are used in the communications mix of sponsoring companies (Bennett, 1998; Cornwell, Weeks, \& Roy, 2005; McAlister \& Ferrell, 2002); however there is indication that the 
decisions are not confined solely to the marketing department (Bennett, 1998; Werbel \& Carter, 2002).

The literature also suggests that arts sponsorships are different to other sponsorships. Certainly the arts is different in nature from sport and charitable social causes. In addition, sports sponsorship offers attractive media coverage, while arts sponsorship cannot always offer this (Abratt, Clayton, \& Pitt, 1987, Farrelly and Quester, 1997). Partly as a result of this, arts sponsorships are linked to slightly different objectives, with less emphasis on objectives directly linked to profitability, and more emphasis of objectives which are less quantifiable, such as the objective of "providing a more enlightened image" (LeClair \& Gordon, 2000), and of objectives related to the interests of personal managers (Hoek, et al., 1990).

Together the sponsorship and philanthropy literatures illuminate a gap in better understanding the decision-making of arts sponsorships. The literature notes aspects which may surround a decision-making process. They highlight that companies may be moving towards making these investments more strategic and linked with their corporate objectives, brand image and/or more specific marketing goals. They note that individuals may play a part in the decision, although it is not clear who, to what extent and how. In sponsorship and philanthropy literature, the decision-making process of companies has not been examined in depth, especially in the case of arts sponsorship.

As noted by Daellenbach, Davies and Ashill (2006), viewing a sponsorship relationship using multiple frameworks or lenses enhances understanding of that relationship. Here, it is proposed that viewing sponsorship through the lenses of Organisational Buying Behaviour and Decision-making will shed light on processes, could highlight a novel way of looking at these decisions, and would contribute to the knowledge of this area (Eisenhardt \& Zbaracki, 1992; Kohli, 1989; March, 1994; Webster \& Wind, 1972b). This literature holds potential given that a sponsorship decision is an organisational buying activity, and involves a decision-making process. While there is some examination of the buying processes concerning socially responsible buying decisions (Drumwright, 1994), examination of decision-making processes specific to arts sponsorship are not apparent. 
Little study to date has specifically sought to gain insight into the processes which companies undergo when making decisions to sponsor the arts. If the decision process is viewed as a black box, there is little evidence that this box has been opened and examined to see what the processes are and what characterises these processes. This presents an interesting problem in that non-profits and specifically arts organisations are reliant on corporate support, yet these decisions are not well understood.

As outlined above, there are opportunities within the academic literature to develop theory concerning how companies make arts sponsorship decisions. A review of the sponsorship and philanthropy literature, combined with examination of theory within decision-making and organisational buying behaviour, leads to this conclusion. This study will therefore seek to make a theoretical contribution in developing a framework for understanding how companies make arts sponsorship decisions. A practical contribution is also sought, whereby this study will primarily assist non-profit arts organisations in better understanding their market, i.e. companies, when seeking sponsorship. The study will also assist sponsoring companies in gaining insight into their own and others' processes.

\subsection{Research Objectives}

This research seeks to identify and understand the decision-making processes of New Zealand companies as they consider sponsorship of the arts. Through multiple-case analysis of relevant participants in numerous decisions, this study develops a framework regarding the processes, their associated characteristics and resulting decisions.

The overriding question for this research is:

How do companies make decisions when considering arts sponsorship?

Specific research objectives are to:

- identify key influences and characteristics of decisions surrounding arts sponsorship, and

- develop an understanding of how these influences are connected. 
In order to meet these objectives, four aspects have been initially identified (illustrated in Figure 1) as influential and will be examined:

- The corporate frame of reference,

- The level of formalisation of policy,

○ The characteristics of the investment (the sponsorship initiative), and

- The characteristics of the decision-making unit.

The above have been developed based on an examination of the literature, and will serve to provide initial focus. However, it is important to note that this study will take a theorybuilding approach, and as such, the researcher must also be open to the possibility of other factors which may arise through the study (Eisenhardt, 1989).

Figure 1.1 The Black Box of Arts Sponsorship Decision Making

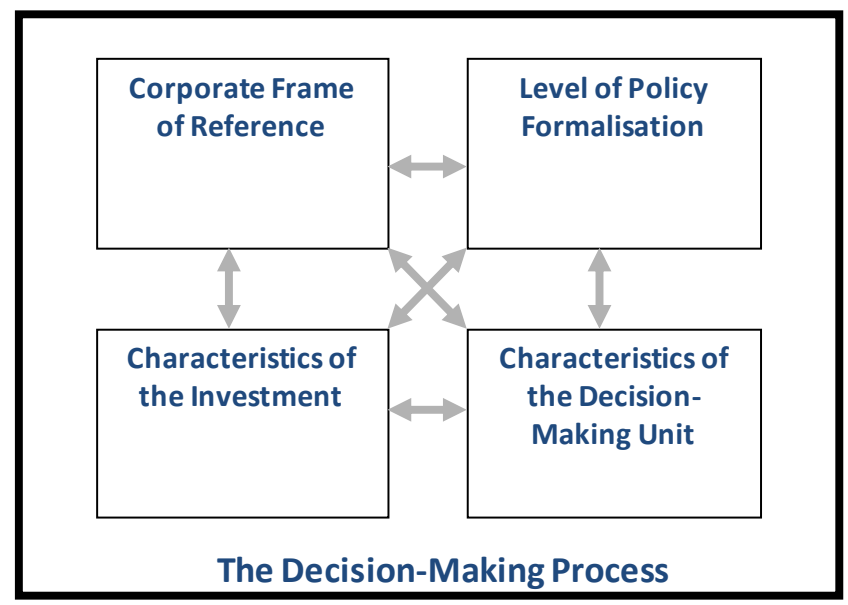

\subsection{Outline of Thesis}

This thesis is organised into eight chapters. The purpose of the present chapter is to give an introduction of the field to be investigated, describe the research problem, and orient the reader to the remainder of the thesis.

Chapter two comprises the literature review, examining literature from the field of Corporate Community Involvement (CCI) but in particular, sponsorship and corporate philanthropy. This literature review will assist in clarifying the field to be studied, will 
review academic discussions surrounding the managerial side of sponsorship and philanthropy, and will identify the research opportunity.

Chapter three incorporates literature from Organisational Buying Behaviour as well as Decision-making, in order to provide a lens through which to view arts sponsorship decisions, and to provide an initial conceptual framework.

Chapter four provides an explanation of the methodology used in this study. This will include a discussion of the researcher's philosophical base, a justification for case-study research, an explanation of the sample selection, and an explanation of the analysis used. A discussion of how the proposed methodology compares to methods in sponsorship and philanthropy research is included in this chapter.

Chapter five presents the results obtained through this study in terms of the initial framework. Matrices and quotations will be used to present the evidence gathered (Miles \& Huberman, 1994), thereby giving the reader better familiarity with the cases (Eisenhardt \& Graebner, 2007; Perry, 1998; Yin, 2003).

Building on the data presented in chapter five, chapter six will compare the findings with the literature. This chapter will therefore begin to draw out conclusions, highlight patterns, and note contributions.

Chapter seven takes the contributions and findings developed in chapter 6, into themes, propositions and a visual summary. In this sense, chapter seven provides the culmination of the theory-building process.

Chapter eight concludes the thesis with a summary of the insights, a discussion of limitations and implications for future research, along with implications for managers of both arts organisations and sponsoring companies.

\subsection{Definitions, Delimitations of Scope and Key Assumptions}

In order to provide greater clarity to the reader and a common understanding, this section addresses two areas which are important to note before the thesis progresses: (1) a 
number of terms will be defined as they will be used in this thesis, and (2) the delimitations of scope will be addressed.

Firstly, in this thesis, the term "Arts Organisation" will refer to non-profit arts organisations, registered as charitable companies.

The term "Company or Companies" will denote the sponsoring company; these are the companies who are making the decision.

The term Corporate Community Involvement (CCI) will be generally used to refer to the area of study linked to the managerial side of sponsorship, corporate philanthropy and Corporate Social Responsibility. This is not to redefine this term, but for ease of communication. Chapter two will note other areas of CCI and will further provide the rationale for limiting the literature to sponsorship and philanthropy/CSR.

The term "Arts Sponsorship" will be used throughout this thesis to identify the relationship between the company and the arts organisation. As will become evident, an arts sponsorship may take on many forms and be motivated by a variety of forces including philanthropy. Therefore, "arts sponsorship" will be used for ease of communication, but this is not meant to unduly restrict the discussion to the pure definition of sponsorship.

In conducting this study, certain decisions were made which provided boundaries around the research, but need to be recognised as delimitations (delimitations being within the researcher's control while limitations are beyond the researcher's control (Perry, 1998)).

Firstly, the selection of positive outcome decisions is one delimitation. This was purposeful in trying to determine how these positive decisions happened, and whether there were variations within these positive outcome decisions. Comparisons were thus sought between art organisations, companies and company characteristics, as well as the comparisons in the actual process, for positive outcome decisions. It is recognised that this leaves out the potential to contrast with decisions resulting in a negative outcome, and this will be later noted as a potential future research direction. 
A second delimitation was that the decisions had already been made. Although this may allow bias and post-rationalisation of respondents to enter into the study, it also allowed for decisions to initially be identified. This was important as decisions were sought which provided elements of difference required for literal and theoretical replication (noted in further detail in chapter 4). An additional advantage to selecting decisions which had already been made was that respondents were able to recommend respondents who could contribute to the case. This allowed for more effective snowballing within each case.

A third delimitation was that decisions were studied which occurred in New Zealand. In this study it was essential that face-to-face interviews were conducted, and that multiple informants for each decision were interviewed. It was therefore essential that some geographic boundary be established. As noted however, there is evidence of comparative characteristics of the non-profit sector between New Zealand and other countries. There are also shared elements in the needs of arts organisations seeking and relying on sponsorship for a portion of their revenue.

It is also of note that this study does not intend to select cases which would represent the population. Rather, cases were selected to offer comparison and to develop theory. This is in keeping with recommendations by authors on qualitative theory-building studies (Eisenhardt, 1989).

In closing, this chapter has provided a broad background to the problem to be studied and the literature to be included. The research question and objectives have been identified, and the structure of the thesis has been outlined. In addition, some early clarification of terms to be used and the acknowledgement of delimitations have been given. The purpose here has been to provide the reader with an orientation to the study. The following chapters will provide further justification, detail and conclusions. 


\section{2: Sponsorship and Philanthropy Literature}

Given that this study is oriented to theory-building, this literature review is designed to frame and inform the problem (Creswell, 2003; Eisenhardt, 1989). The goals are to provide a common base of understanding, evidence of the need for this study, and an initial direction for the research methods.

This review will proceed as illustrated in Figure 2.1. Literature will first be investigated to provide an understanding of the field of Corporate Community Involvement (CCI). Secondly, the sponsorship and philanthropy literature within CCI will be further examined to identify opportunities for research.

Figure 2.1 Map of the Literature Review

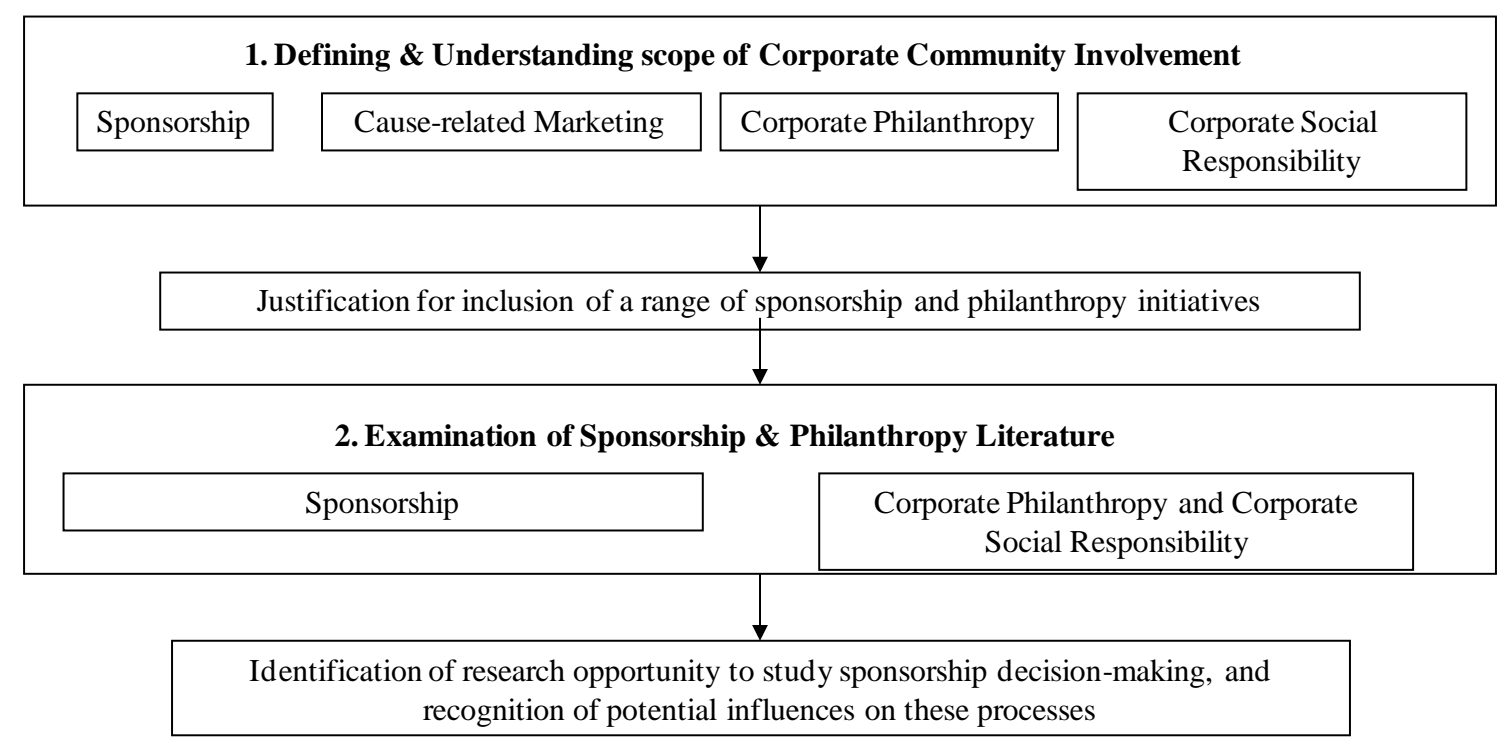

\subsection{Defining and Understanding the Scope of $\mathrm{CCl}$}

This literature review begins by recognising a range of literatures within the broader scope of Corporation Community Involvement (CCI). CCI is a term used by authors (Seitanidi \& Ryan, 2007) to encompass the various relationships companies may undertake when supporting and contributing to non-profit initiatives. Seitanidi and Ryan (2007) suggested that CCI might include charitable donations, benefaction, patronage, 
sponsorship, cause-related marketing or partnership. Consideration of one area solely would not represent the reality companies are operating within, and would unduly limit the literature considered. There is also evidence within the literature of an overlap between these approaches, especially philanthropy and sponsorship. This section will identify the differences and similarities in sponsorship, cause-related marketing, philanthropy and corporate social responsibility, and provide a rationale for considering sponsorship and philanthropy literature in particular.

To begin, sponsorship is one of the more commonly used terms when a company gives financial resources to an arts or non-profit organisation. The marketing literature points to sponsorship as a relationship of exchange between a sponsor and the sponsored organisation, where each receives a benefit from the relationship (Cornwell \& Maignan, 1998; Crowley, 1991; Erdogan \& Kitchen, 1998; Meenaghan, 1991a; Seitanidi \& Ryan, 2007; Witcher, Craigen, Culligan, \& Harvey, 1991). Most of the literature reflects "commercial sponsorship" defined as

... an investment, in cash or in kind, in an activity, in return for access to the exploitable commercial potential associated with that activity. (Meenaghan, 1991a, p. 36)

The commercial element is supported by many authors including Crowley (1991) who notes that

most definitions of sponsorship highlight the existence of a commercially relevant purpose as one of the key factors that separates sponsorship from other forms of corporate support. (p.11)

The commercial purpose and extraction of benefit from sponsorship is also apparent in the marketplace. A quick look at any website for most sporting or arts events contains a list of sponsors who we know will receive a commercial benefit, be it exposure, logo placement, tickets, client hosting opportunities or more.

Especially in terms of its commercial orientation, comparison is sometimes made between sponsorship and another element under the CCI umbrella, cause-related marketing. Cause-related marketing however, differs in that the arrangement requires a 
specific relationship between consumer purchases and corporate contributions. Noting the relationship to purchases and the social contribution of the company, Varadarajan and Menon (1988) proposed cause-related marketing be seen as "a manifestation of corporate philanthropy and enlightened business interest. It is basically a marketing program that strives to achieve two objectives - improve corporate performance and help worthy causes" (p.59). These authors went on to provide a specific definition of cause-related marketing as

the process of formulating and implementing marketing activities that are characterized by an offer from the firm to contribute a specified amount to a designated cause when customers engage in revenueproviding exchanges that satisfy organizational and individual objectives. (p. 60)

A well-known example of cause-related marketing was American Express's campaign to benefit the Statue of Liberty improvements. Under this arrangement, American Express donated one cent to The Statue of Liberty-Ellis Island Foundation for every purchase made on American Express cards (American Express, 2003). This example illustrates the link of consumer spending with the contribution, and illustrates cause-related marketing as a specific type of CCI, similar to commercial sponsorship in its motivation and profit orientation. McAlister and Ferrell (2002) also noted similarities between sponsorship and cause-related marketing in that both are linked directly with marketing, relate to specific target audiences, and have a goal of improving brand perceptions.

Continuing with the American Express example also illustrates the array of CCI options. In this case, as well as the cause-related marketing initiative noted, American Express also made a direct contribution to the Foundation, not tied to consumers' activities, and undertook efforts to raise awareness by funding a documentary on the statue. Therefore, in this and perhaps other cases, an initiative or investment may contain aspects of causerelated marketing, sponsorship and even philanthropy.

This brings the discussion to the third element of CCI, philanthropy, which, as noted in the above example, may enter into a company's support of a non-profit activity. Philanthropy has often been referred to as patronage, altruism, donations or benevolence, and is distinguished especially from commercial sponsorship in that there is no 
commercial element or expectation of a benefit. Seitanidi and Ryan (2007) referred to this type of relationship as asymmetrical, and similarly, Witcher et al. (1991) noted that with philanthropy "organizations make a financial or material contribution without the expectation of any commercial return" (p.14). Speed and Thompson (2000) also made this distinction stating that the "commercial motivation distinguishes sponsorship from altruism" (p.226). Cornwell and Maignan (1998) cited the definition from the Internal Revenue Service, which links a commercial sponsorship to advertising, and a more philanthropic arrangement to donations:

when the sponsor requires promotional benefits from the event organiser (e.g. in terms of media coverage or endorsement by the participant), the sponsorship is considered advertising by the Internal Revenue Service. ... If the sponsor does not require any marketing benefit from the event owner, the sponsorship is treated as a donation, and is not taxable. (p.15)

The inclusion of an exchange is the main difference between a philanthropic donation and a sponsorship investment. Donations are a financial gift for which the company does not expect anything in return, no quid pro quo (Burlingame, 2001), while sponsorship involves an exchange and expectation of benefit. Here, it is the company's expectation which is important. If a company gives financially or in-kind, and expects a benefit, then it is sponsorship; if they do not expect a benefit, then it is considered philanthropy. An example of a philanthropic transaction could be Contact Energy's 2005 donation to the Boxing Day 2004 tsunami relief efforts, which received no media exposure and was only quietly acknowledged in the company's annual report (Contact Energy Limited, 2006, p. 17).

Philanthropy is also often linked with the ideas of Corporate Social Responsibility (CSR), the final area of consideration within CCI. In particular, Carroll (1991) described philanthropy as to "be a good corporate citizen. Contribute resources to the community; improve the quality of life" (p.42). Carroll (1991) proposed that CSR could be viewed in a pyramid, its base and largest section being that of economic responsibilities, followed by legal, ethical and finally philanthropic. Philanthropy here, at the peak and the smallest portion of the pyramid, may be icing on the cake, but is nonetheless part of the cake and part of CSR. 
Hence, the above has pointed to four linked, but in many ways distinct, facets of CCI. However, it is also suggested here that these facets may not be so well defined in reality, and there may well be rather blurred lines between them. Returning to literature in CSR, a similar and related idea is Corporate Social Performance, which is identified by processes, policies and programs, as defined by Wood (1991):

a business organization's configuration of principles of social responsibility, processes of social responsiveness, and policies, programs, and observable outcomes as they relate to the firm's societal relationships. (p.693)

Thinking of this definition, it is feasible to think that a company may view a sponsorship, cause-related marketing activity or philanthropic contribution, all as part of what Wood describes as a "corporate social program." Similarly, the term "socio-sponsorship" is put forward by Seitanidi and Ryan (2007) as a sponsorship with the motivation being corporate social responsibility.

Further examples within the academic literature and industry cases illustrate situations where the differences are not clear-cut, especially between sponsorship and philanthropy. For example, in a survey of Norwegian firms, Thjømøe, Olson and Brønn (2002) gave their respondent companies two potential definitions of sponsorship to choose from: one wider view including philanthropy and the other not. The wider view was stated as sponsorship being "giving of financial support to an individual, organisation, or activity to support its good work without regard to whether or not we received publicity" (p.9). Their findings indicated that many organisations may consider sponsorship as financial support without obvious commercial benefit. In an analysis of arts organisations in the USA, LeClair and Gordon (2000) appear to focus on corporate donations (which would imply "philanthropy") yet they report that a key motivation is to improve the corporation's image - which suggests some level of benefit and therefore a more commercially oriented sponsorship. Simmons and Becker-Olsen (2006) moved away from a syntax argument, and refer to "corporate support of social causes" simply as "social sponsorship." In terms of definitions, then, there appears to be a grey area apparent. Speed and Thompson (2000) support this idea, in noting that the consumer may also see these issues as grey, finding that response to a sponsorship is stronger if the 
company is perceived to be sincere in their support, and suggesting that consumers "are sensitive to the potential philanthropic dimension that a sponsorship may have" (p.236).

There is also support for the view that philanthropy is not even a realistic term to use for corporate support of a non-profit. For some, "Philanthropy implies a certain amount of altruism in motivation, and with very few exceptions, if any at all, corporate support is motivated not by altruism but by corporate self-interest, as construed by management" (Smith, 1998, p. 252). Other authors take this one step further and suggest that companies should practise corporate philanthropy as a means of gaining competitive advantage (Porter \& Kramer, 2002). This line of thought is echoed by others as "strategic philanthropy" in which philanthropic activities are considered in light of the company's strategic capabilities (Bruch \& Walter, 2005; Collins, 1993; McAlister \& Ferrell, 2002; Ricks, 2005). The emphasis here is on the need for companies to justify their actions, be it on a social and/or economic basis (Kotler \& Lee, 2005; Valor, 2007). However, in this discussion it is important to note that based on our earlier definition of sponsorship and commercial sponsorship, and its distinction from philanthropy, the suggestion that the company use philanthropy to gain a benefit could be considered counter-intuitive to the definitions put forward by others in the literature.

The above discussion illustrates both the distinctions between various elements in CCI, but also that there is opportunity for overlap, or a blurring of the lines especially between ideas of sponsorship and philanthropy. The purpose here is not to criticise authors who discuss "philanthropy" or "commercial sponsorship" in ways which contradict definitions, but to lead us to the idea that there may well be a range of CCI which is considered by companies, even within a single investment/partnership with a non-profit organisation. The next section discusses this further.

\subsection{A Range of CCI Within a Single Investment}

The purpose of this section is to take the ideas above, of overlap and a blurring of lines, and to argue for this range of CCI to be considered in existence within a single 
investment. Clearly, there are differences between the above concepts. However, there is also the argument for overlap and even similarities in certain situations. While definitions might clarify distinctions, there appears to be value in an inclusive approach. Not only does this discussion suggest an inclusive approach in reviewing the literature, it suggests that companies themselves may not be making clear distinctions. To be more specific, if companies view these activities as similar, or even in the same category, then non-profits seeking support should approach their requests in the same spirit.

This orientation to an inclusive approach is in contrast to some authors, for example, Dolphin (2003) who noted "a request for a donation is different from the proposal for a sponsorship relationship; the goals are different and the language is different" (p.173). However, there are other authors who appear to support the view of less distinction. Already noted is that there are a number of relationships which companies might consider under the same "CCI" umbrella (Seitanidi \& Ryan, 2007). Kotler and Lee (2005) similarly proposed options for "doing good" including cause promotions, causerelated marketing, corporate social marketing, community volunteering and socially responsible business practices. Also, though under the label "strategic philanthropy", Ricks (2005) proposed a 2 × 2 schema which classifies giving on the basis of functional categories (either direct where the corporation targets a specific segment, or general), and strategic implementation (reactive or proactive). Under this classification, a proactivedirected activity would be similar to a cause-related marketing campaign, or a commercial sponsorship relationship. Wymer (2006) has also suggested that corporate philanthropy include "(a) corporate giving, (b) sponsorship, and (c) cause-related marketing" (p.1). Burlingame (2001) sums this up by noting that while it is useful to consider the differences, a greater understanding of all types of "transfers from companies to nonprofits" would yield greater understanding of the inter-connectedness between the sectors.

Varying treatment and an inclusive approach of companies in New Zealand and internationally is evident in annual reports and websites. Often sponsorship and donations appear under the term "community relations" or "community investment". Sometimes the term sponsorship is used as a distinct term, and sometimes it is used interchangeably with the terms such as "support". For one example, Telecom New Zealand's annual report lists sponsorship and community support together and including 
support of education, community/volunteer organisations, sports, innovation and arts (Telecom New Zealand, 2005).

An all-encompassing approach is also justified based on an examination of the inclusion of both sponsorship and philanthropy in the communications mix. Commercial sponsorship has been accepted into the integrated marketing communications mix (Dolphin, 2003; Meenaghan, 1998; Tripodi, 2001) both as a marketing tool, and also as a tool which, it is proposed, should make use of the other marketing mix elements (Cornwell, Weeks et al., 2005). The value of using sponsorship to build brand equity in particular is documented in the analysis of two sports cases: Adidas and the All Blacks (Motion, Leitch, \& Brodie, 2003) and Guiness and Hurling (Meenaghan, 2002). The argument for philanthropy to also be included in the communications mix is not as ubiquitous, but nonetheless is evident. Bennett found in a study of corporations in the United Kingdom, France and Germany, that corporate philanthropy is "set to become a crucial element of mainstream marketing communications" (Bennett, 1998, p. 472). Other authors have called for philanthropy to be incorporated into the communications mix, and to be part of marketing planning (McAlister \& Ferrell, 2002; Robinson, 2006). In this light then it would be conceivable that in a decision, a manager may well not separate "sponsorship" from "philanthropic" investments.

It is therefore proposed that an inclusive approach is a more accurate and potentially more powerful view of a single decision in CCI. In this discussion then a range of CCI will be adopted in which an individual investment may well be defined as containing an orientation more or less towards commercial or philanthropic goals. Figure 2.2 represents this range graphically. In this figure, the $\mathrm{Y}$-axis represents the orientation to commercial goals. A highly commercial investment would be justified and examined based solely on return-on-investment measures. The benefit to each party would be formally negotiated and the financial outlay would likely be accounted for as an advertising expense. The $\mathrm{X}$-axis represents the orientation to philanthropic goals, with a highly philanthropic initiative being anonymous altruism (a corporation gives time and/or money and requests anonymity and no benefit). Therefore, this figure suggests that it would be feasible to have a CCI investment, and even an arts sponsorship, which possesses characteristics of both commercial and philanthropic goals. 


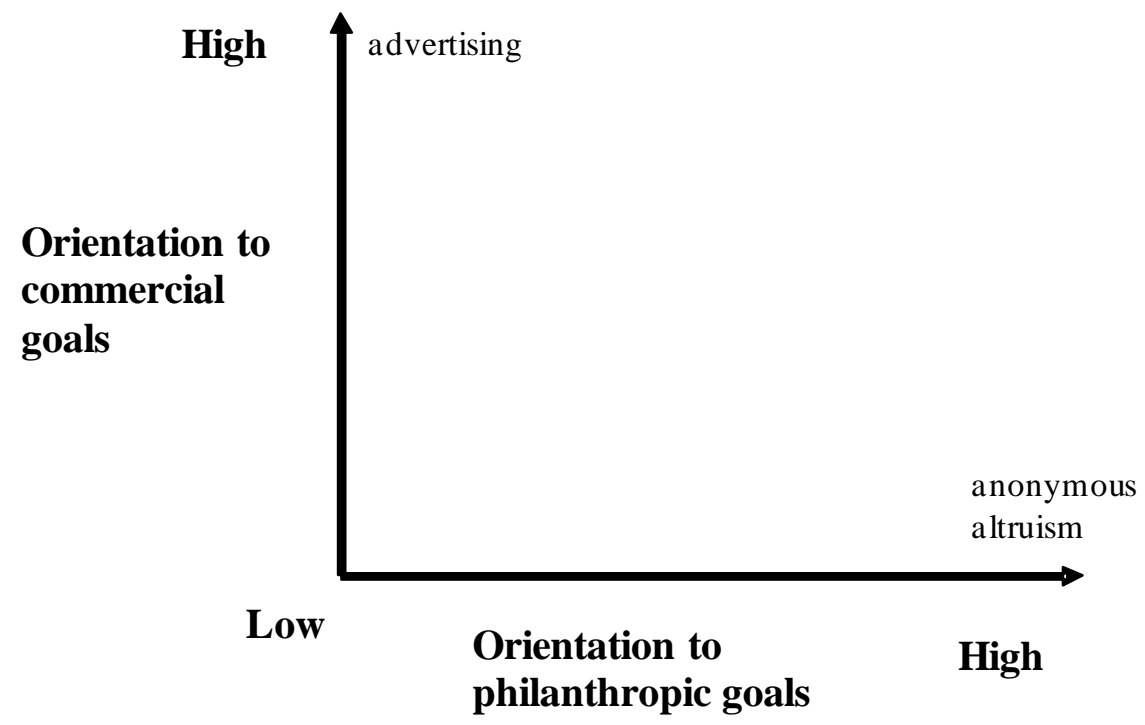

Similar approaches to this range have been alluded to in the literature. A twodimensional approach has been proposed by Wymer and Samu (2003) who place "nonprofit and business relationships" into a typology of relationships based upon (1) the extent to which businesses seek their own benefit, and (2) the proportion of power allocated to the business (vs. the non-profit). However, in terms of the sponsorship vs. philanthropy argument, most authors place these elements on a continuum. For example, Madden, Scaife and Crissman (2006) discussed the variety of CCI as a "continuum which runs from purely altruistic corporate philanthropy through to strategic, commercially based initiatives that are focused on direct return on investment to the company such as cause related marketing” (p.49). Saiia, Carroll and Buchholtz (2003) also suggested a continuum, proposing that strategic philanthropy exists at the "opposite end of the corporate philanthropy continuum from altruism” (p.170). Similarly Meenaghan and Shipley (1999) proposed a continuum ranging from philanthropy to advertising (although all categories were considered under "sponsorship"). A continuum, however, implies that to move along to philanthropy one must give up elements of sponsorship. The approach represented in Figure 2.2 differs in that it suggests that the two orientations may co-exist.

Adopting this perspective causes the question to be asked: do companies actually categorise $\mathrm{CCI}$ requests, making trade-offs between commercial and philanthropic objectives? With the exception of Thjømøe, et al. (2002), there is no evidence of 
literature to date which has sought to observe how companies view the distinctions. Furthermore, there is no evidence in the literature concerning the impact of this distinction to the company's decision-making process. Given this stance, theories and literature mainly from areas defined as sponsorship and philanthropy within CCI, will be integrated to better identify both the theoretical foundations and the research opportunities.

\subsection{Considering the Sponsorship Literature}

As noted, a significant and relevant literature stream is that of sponsorship. In this review, the term "sponsorship" will refer to commercial sponsorship. This is due to the fact that most of the sponsorship literature is oriented towards commercial sponsorship. This is not to disregard the idea of socio-sponsorship, and when such examples emerge they will be noted. It is important to note that the literature investigated is restricted to that related to the management and decision-making aspects of these activities within the company, rather than the consumer-oriented literature which considers issues such as how markets respond. To the extent that consumer response influences a company's decisions, this literature will enter into the discussion as appropriate. To this is added some reference to cause-related marketing, as both types of initiatives share the goal of commercial benefits. For purposes of this discussion, greater attention will be given to sponsorship, as the literature on cause-related marketing tends to focus on the consumer responses rather than the management of and decision-making pertaining to the relationship (Gupta and Pirsch, 2006b).

This examination of the sponsorship literature will firstly discuss some history of sponsorship, followed by a discussion of the objectives and motivations of sponsorship, sponsorship relationships, satisfaction associated with sponsorship, and sponsorship decision-making.

To provide some background, sponsorship, particularly of art and sport, has a long history. Sport sponsorship dates back 2500 years, to a time when wealthy Greek citizens made financial contributions for sports games, and in return received privileges and recognition from the public and/or government (Burton, Quester, \& Farrelly, 1998a). Although sponsorship has had a long existence, it only emerged as a corporate activity in 
the mid-1960's (Meenaghan, 1991b), and academic research on sponsorship began in earnest in the mid 1980's (Cornwell \& Maignan, 1998).

It has been suggested that sponsorship has undergone an evolution from its beginnings in philanthropy (Cornwell \& Maignan, 1998; Dolphin, 2003). According to Cornwell and Maignan (1998) "sponsorship as a communication tool and promotional activity is here to stay. ... A market-driven type of sponsorship has replaced philanthropic sponsorships, and has been accepted as business-related behaviour" (p. 18). Other authors have also noted the acceptance of sponsorship as a legitimate tool in the marketing mix (Dolphin, 2003; Tripodi, 2001). Although statistics are not easy to come by, a recently published report of arts sponsorship in Ireland revealed that companies have increased their sponsorship budget to the arts from 14\% in 2002 to $18 \%$ in 2004 (Amarach Consulting \& Onside Sponsorship, 2006, p. 5).

With sponsorship becoming more ubiquitous in practise and academic study, a number of streams of research have been identified. Cornwell and Maignan (1998) proposed five streams:

1. The nature of sponsorship, including how it is defined.

2. The managerial aspects of sponsorship, especially the motivations and objectives for a sponsorship initiative.

3. The measurement of sponsorship effects, and the effectiveness of the communications surrounding the sponsorship.

4. The strategic use of sponsorship, and ambush marketing.

5. Legal and ethical considerations including the tax constraints and implications of sponsorship related to tobacco and alcohol companies.

Similar streams were noted by Dolphin (2003), differing only in that the strategic use of sponsorship and ambush marketing phenomenon replaced consideration of sponsorship as an effective marketing tool.

These streams could be classified into two broad areas: literature oriented to consumer response to sponsorship, and the literature oriented to the management side of sponsorship. The consumer-related literature, such as how consumers respond to sponsorship (Cornwell, Weeks et al., 2005), and the measurement of sponsorship effectiveness, is clearly important to the growth of sponsorship. The fact that sponsorship 
is firmly entrenched in the communications mix means that the consumer perspective is linked to the management of sponsorship. However, the literature which examines the management perspective may be viewed as a separate stream. The literature on the managerial side of sponsorship includes the objectives and motivations for sponsorship, sponsorship as a partnership or relationship and some discussion of satisfaction. Specifically how companies make decisions to engage in a sponsorship has not been investigated in depth. However, elements of this decision-making process have been discussed at times. Each of these areas from the management side of sponsorship will now be examined.

\subsubsection{Objectives and Motivations for Sponsorship}

A well-explored theme in the sponsorship literature is the objectives and motivations for companies to engage in sponsorship. In this area, authors have found evidence largely supporting the objective of improving company image, but also some suggestion of objectives related to developing goodwill in the company network, meeting personal interests as well as "doing good" in the wider community.

The most frequent reason reported for engaging in sponsorship is to build and develop the company image, in order to increase consumer awareness. Meenaghan (1983) proposed a taxonomy of sponsorship objectives including broad corporate objectives, product-related objectives, sales objectives, media coverage, guest hospitality and personal objectives. As is evident, many of these are directly related to building and developing the company's image within the markets. For example, under "broad corporate objectives" comes corporate image building and increasing public awareness; under "product related objectives" comes the objective of increasing product or brand awareness, under sales objectives comes improved market perception and improved sales results; the achievement of media coverage as an objective has obvious image and sales implications. Others have studied and proposed similar groupings of objectives. Hoek et al.'s (1990) study of New Zealand firms revealed that companies felt the most important objectives in sponsorship, be it sports, arts or community related, were to improve goodwill, enhance corporate image and increase awareness of the company and/or its products. Similarly, Witcher et al. (1991) found that in the United Kingdom, promotion of image was seen as the top priority for sports, arts and community related sponsorship. This examination certainly reveals that image-building objectives are likely to be 
important. However the studies noted above relied on direct questions to the companies, rather than a method which would cause them to recall an actual decision. Therefore, while certain objectives are highlighted, it is difficult to tell to what extent these objectives influenced actual decisions.

The studies noted above also point to the particularities of arts sponsorship. Both Hoek et. al. (1990), and Witcher, et al. (1991) noted that while image building was most important, arts sponsorships also held more emphasis on community support and managerial interest-related objectives, than was the case for sports and communityrelated sponsorships. Further examination of now motivations may change depending on the nature of the sponsorship reveal differences especially in considering arts vs. sports sponsorship. Sports sponsorships tend to receive a greater emphasis on measurable results and profitability-related objectives (Hoek et al., 1990). Media coverage has been particularly identified as a measure and rationale for sports sponsorship (Abratt, et al., 1987). This emphasis on media coverage for sports sponsorship was echoed by Farrelly and Quester in their comparative analysis of sports and arts sponsorship in Australia (1997). Research by Cornwell, Pruitt and Clark (2005) linking announcements of major sports associations with increases in the sponsor's stock prices supports the view that exposure and measurable results may be attained via a sports sponsorship.

It would appear more likely that a major sports event will be broadcast, than a symphony orchestra concert. If media coverage is not a major motivation behind an arts sponsorship, what is? An analysis of arts-sponsorship studies in particular reveals that gaining awareness and building an image remains a high priority and rationale for sponsorship of the arts. In Ireland, O'Hagan and Harvey (2000) found that 75\% of the respondents indicated this was the most important objective. The importance of imagebuilding in arts sponsorship is also echoed in studies in New Zealand (Hoek et al., 1990), USA (LeClair \& Gordon, 2000), Canada (Turgeon \& Colbert, 1992), the UK (Witcher et al., 1991), the Netherlands (Hitters, 1996) and Japan (Kenichi, 1996). The image building associated with an arts sponsorship is perhaps less tangible than that associated with sports, but it has been noted that such sponsorship may provide "businesses with a means of projecting an enlightened image to potential customers" (LeClair \& Gordon, 2000, p. 239). 
Thus, the objective of image building is seen to be as important in arts sponsorship as sports sponsorship, however it is also noted that arts is less likely to achieve measureable results for decision-makers. In the business climate of today which demands measureable results, this raises some key questions for arts-sponsorship: How does one judge whether or not the company has achieved its goal of "projecting an enlightened image?" Does this difficulty in obtaining measureable results influence how arts sponsorship decisions are made?

Returning to the list of potential objectives, another motive which emerges in sponsorship studies is that of personal goals and interests of management. Cornwell and Maignan (1998) noted that in the past, a company's involvement in sponsorship was often more personal, perhaps motivated by personal interest in the cause. However, this motive does not appear completely confined to history. Especially in arts sponsorship, while image building remains the top motive identified, personal interests still appear as an objective. For example, Hoek et al. (1990) found that sponsors of cultural events put some emphasis on the interests of management and put less emphasis on the ultimate profitability of a sponsorship. This objective was similarly noted in other arts sponsorship related studies (LeClair \& Gordon, 2000; O'Hagan \& Harvey, 2000). Again, while this objective is noted, there is little evidence of how this objective may influence a decision. This is particularly relevant in the case of personal interests as motives: might an individual decision-maker overly influence a decision based on their interests?

A third category of motivation especially for arts sponsorship is that of developing goodwill within the corporate network (Kenyon, 1996) and supply-chain. This motivation would include sponsoring an event which would be of interest to employees or suppliers (referred to by O'Hagan and Harvey (2000) as “supply-chain cohesion”), or sponsoring events which would help strengthen and support networks in the environment in which the company operates (referred to by O'Hagan and Harvey (2000) as "rentseeking"), such as to improve lobbying success, or make political connections. This later network-based motive is emphasized in a practitioner's argument for arts sponsorship, where the author proposes that businesses should invest in arts sponsorship to attract key decision-makers in the community as well as demonstrate these attractive partnerships to politicians (Cowan, 2005). This area is also a point of difference for art sponsorship, but how this motive enters into the decision itself remains to be seen. 
Finally, there is the motive of "doing-good." As previously noted, Seitanidi and Ryan (2007) suggested that there may be commercial sponsorships and socio-sponsorships. Certainly, elements of social responsibility and "doing good" also emerge with objectives of arts sponsorship. In Argentina, 38\% of businesses giving to the arts included reasons of social responsibility for their actions (Goncebate \& Hajduk, 1996). In this case it was noted that the underlying reason for this was the falling state support. In Italy, arts related sponsorship is heavily weighted towards restoration, and viewed by the sponsors as an activity to confirm their social role in the community (Piperno, 1996). While previous discussions noted that sponsorship and philanthropy may overlay one another, it is also noted that as a reported objective, the idea of "doing good" does not appear to be the primary motive. One might ask the question as to whether this more community-oriented social approach does in fact enter into a decision, and if so, how?

Thus, the examination of key potential objectives in sponsorship both answers some questions, and raises others. It appears that in engaging in arts sponsorship, companies are most likely to seek the objective of improving brand image and awareness be it through exposure or more subtle development of an "enlightened image." However, other objectives are also at play - and more so than in sports or community-related initiatives. These other objectives may include the interests of management, desire to improve goodwill within the network, and the desire to contribute to social good. Questions also arise from this. Firstly, while companies may report on their desired objective, the question remains as to whether these precise objectives are actually used to evaluate a decision. Secondly, what does this imply for the process of decision-making and therefore to the request of the non-profit for sponsorship? If a company holds one objective higher than others, in what way might this affect the decision-making process? If an executive's interests are part of the rationale, how does this influence the decision? More broadly, we might ask, when organisations are faced with a multitude of sponsorship opportunities, how do they decide which, if any, to support? Could the process be characterised as systematic and related to established marketing objectives and image building, or being driven by other less well-defined objectives?

\subsubsection{Sponsorship as a Relationship}

A second major stream in the sponsorship management literature takes a relationship marketing perspective. This recognises that sponsorship is not a straight-forward 
purchase of materials for example, but involves individuals with their own views, power, negotiations, levels of trust, etc. As noted by Olkkonen (2002), "in order to understand the dynamics of a cultural sponsorship relationship, it is important to understand the interaction as a negotiation process between two kinds of organizational fields" (p.279). A range of authors have noted this complexity and have called for further analysis. Olkkonen, Tikkanen and Alajoutsijarvi (2000) in particular called for more actionoriented research to "paint a more in-depth picture of sponsorship as a social phenomenon" (p.14).

Consistent with this call, Olkkonen considered a series of cultural sponsorship relationships, using an interaction approach, and noted that these relationships are plagued by ambiguity. The ambiguity was largely a result of the fact that the company and the cultural organisation were vastly different in their needs and perspectives. The relationships developed, however, over time and the importance of the role of key individuals, their motivation and commitment to the sponsorship was significant (Olkkonen, 2002).

Similarly, Ryan and Fahy (2003) studied the case of the Galway Arts Festival and Nortel Networks, considered a range of constructs vis a vis this relationship, and proposed a theoretical framework. Their proposed framework found that trust was important for both parties, while for Olkkonen's study, trust was important but linked with formal controls. Time, in terms of its ability to facilitate the relationship, was important in both studies. Also for Ryan and Fahy (2003), "the perceptions, values and organisational mindset that each organisation brings to the relationship become important driving forces" (p.37); the organisational mindset referring to the belief within the organisation that the relationship would add value. Here Nortel Networks was noted as having a "strong relationship marketing mindset" evidenced in its relationship with the festival.

The studies above both emphasise the importance of the individual in these relationships, and raise questions concerning how individuals may influence these relationships. Ryan and Fahy (2003) noted the importance of one person in particular, referring to them as a "champion of the sponsorship" ( p. 37). Olkkonen (2002) proposed that there be "relationship promoters" on each side of the relationship, "persons who act as translators between two different organisational fields, who understand both parties' goals and needs, and who try to find the balance in the cooperation" (p. 284). In this sense, this 
literature points to the importance of personal relationships, and personalities, key individuals with their own beliefs and mindsets, as being important to the relationship. While these studies are over a longer period of time, the question arises here, as to whether these key individuals also played an important role if one were to take a smaller snapshot of the time in which an initial decision was made to engage in this sponsorship.

Other aspects of sponsorship relationships are revealed in a series of studies by Farrelly, Quester and Mavondo (Farrelly \& Quester, 2003a; Farrelly, Quester, \& Mavondo, 2003b; Farrelly \& Quester, 2003c). These studies, particularly in the area of sports sponsorship (Australian Football League) reveal the importance of trust and communication, along with market orientation and measures of commitment. These authors found that the sponsors' commitment was related to their own level of market orientation as well as their trust in the recipient organisation. They also found that the sponsor's level of trust was related to their perception of the property's (sports organisation) market orientation as well as the property's actual market orientation. In adding communication to the equation, the authors found that the results surrounding trust were ambiguous; there was no correlation between trust and the collaborative nature of the communication, suggesting that more than communication is necessary to build trust. In considering a sponsor's inclination to renew its commitment to a relationship, the authors found that again trust was not a strong indicator; however, the level of the sponsor's commitment was an important indication of their renewal (Farrelly \& Quester, 2003c). While these studies suggest evaluations are being made by the sponsor, of the sports organisation, it would be interesting to know how these evaluations wove their way through an actual decision process. In addition, with the knowledge that arts sponsorships are likely to be different, to what extent could these findings we carried through into this different sponsorship genre?

The results of the above studies have been carried forward into discussions of the advantages of developing a partnership-type relationship between sponsors and the sponsored companies, proposing the relationship be characterised as a "co-marketing alliance" (Farrelly \& Quester, 2005a), this partnership perspective being echoed by others (Seitanidi \& Ryan, 2007; Urriolagoitia \& Planellas, 2007). Certainly advocating for and seeking out a partnership-type relationship in sponsorship appears to be a focus both in sports and arts. Seitanidi and Ryan (2007), speaking more broadly of CCI, have also entered into this discussion, reinforcing many of the findings above. They have 
concurred that relationships between non-profits and corporations face limitations which may be overcome through more of a relationship perspective, and have advocated for more of an interactive and process-oriented approach, built on trust and the recognition of each partner's role. While these studies and discussions illuminate the importance of a partnership perspective, they do not inform us of how this is influential at the time of a decision. That is to say, if a company is initially making a decision to engage in a sponsorship, is there time to develop a relationship perspective? Are these ideas of partnership and relationship, of trust and commitment evident at the beginning of the relationship? And if so, what impact do they have?

Certainly, there is much to be gained from looking at sponsorship through a relationship lens, and looking at it in terms of an evolving partnership. This sheds light on the importance of organisational mindsets, individual players, perceptions of the company to be sponsored and perceptions of a partnership perspective. However, it is also evident that there remains a gap in the literature which focuses specifically on the decisionmaking process, and which focuses on arts sponsorships. Ideally, research in sponsorship should extend to the origins of relationships, and the extent to which insights gained from this exploration may be generalised in ways which assist arts organisations to initiate new relationships.

\subsubsection{Satisfaction with Sponsorship}

As previously noted, sponsorships are evaluated in part via measureable results, although arts sponsorship less so. The evaluation of sponsorship suggests an evaluation of whether or not the sponsors is satisfied. The satisfaction with a sponsorship relationship is likely to inform the company for future activities, and for the knowledge of the nonprofit organisation and their future endeavours. In some sense, satisfaction is discussed in the literature dealing with these partnerships as relationships (above). In addition, satisfaction is addressed in part in considering motivations; it was noted that for many sports sponsorship, measureable results (often related to media exposure) were sought. However, very little literature focuses on satisfaction as an outcome. This is partly addressed in the consumer literature, which considers and proposes means to measure the consumer response to sponsorship.

In terms of the managerial level of satisfaction, Cornwell, Roy and Steinard (2001) surveyed managers involved in sponsorship activities, and measured their perceptions of 
the success of the initiatives. They found that the managers perceived improved success if there was a long-term relationship between the two parties, if the company leveraged the sponsorship (that is, invested in its own promotional activities associated with the sponsorship), and if the managers were involved in the sponsorship. This study is an interesting examination indicating that the perceptions would likely influence a future decision, but it still does not answer the question of how decisions are made initially, and the impact of various processes on the levels of satisfaction.

\subsubsection{Making the Sponsorship Decision}

Given the research question: how do companies make arts sponsorship decisions, attention to the sponsorship literature vis a vis decision-making is necessary. In the above discussions are aspects of the decision process; certainly objectives will play a part, we also know believe that individuals are likely to influence decisions. However, the sponsorship literature which deals directly with the decision process is sparse. Turgeon and Colbert (1992) offered an early model of decision-making based on a content analysis of arts events. These authors proposed that the decision-making criteria may be grouped into five categories, including event-related, arts organisation related, market related, company-related and effect related (this last element being the most important). While this suggests that there are many facets to be evaluated, the model is based on a content analysis of reports, rather than personal impressions of the decisionmakers, and again, points to evaluation criteria rather than an actual process. More process was suggested in a life-cycle perspective taken on sponsorship by Urriolagoitia $\&$ Planellas (2007). These authors described the first stage of the life-cycle as formation, being a time in which the terms of the partnership are negotiated, the exchange of knowledge is beginning, and the structure of the relationship is based more on formal mechanisms. While this perspective is informative for these relationships, it does not look specifically at the manner in which decisions were made.

The absence of much research in sponsorship decision-making could be in part due to companies' historically haphazard approach to the decision-making process. Many have noted that the sponsorship decision-making process is not clear-cut and often not entirely rational. In 1978, Elicker, then President of SCM Corporation called for more organisations to integrate sponsorship into the corporate structure and set clear objectives. Pleas have been made for a more systematic approach to sponsorship 
decisions, noting a lack of professionalism, and calling for more reliance on market research and objectives, and a movement away from "gut instinct" (Abratt et al., 1987; Elicker, 1978; Meenaghan, 1991b; O'Hagan \& Harvey, 2000; Parker, 1991; Thjømøe et al., 2002). This begs the question: To what extent are decisions concerning arts sponsorship made via a systematic approach vs. gut instinct?

So what do we know of the decision-making process? In an interview concerning causerelated marketing, David W. Zucker, Senior Vice President of Porter Novelli stated that corporations should start with the mission statement for the cause, then move to their own core values and brand, followed by consideration of the target audience; next, identify priorities for causes to support, and develop a number of options (Higgins, 2002). These may be useful recommendations, but again do not study actual decisions made.

Part of the decision process is of course the "who" - who makes this decision? Who is involved? In terms of this question there is literature which addresses which department might play a role in the decisions. Although sponsorship is part of the communications mix and marketing would therefore play a crucial role, there is suggestion that public relations (which may or may not be part of marketing) and the chief executive office may also play an important role. Executive involvement is not uncommon, and was also found as important in other studies (Abratt et al., 1987; Thjømøe et al., 2002). However while these studies noted the importance of executive involvement, they also found that the department with the most influence in sponsorship decisions was in fact marketing. Other aspects of the "who" question of decision-making relate to the level of management involved. Here, variation in the management level involved is evident, based on the company's experience as well as the nature of the product. Burton, Quester and Farrelly (1998b) proposed that middle managers are more likely to be involved in the decision if the company has considerable experience with sponsorship. Lower level managers are also found to be associated with the decision more frequently in the case of a sports sponsorship (as opposed to arts) (Farrelly, Quester, \& Burton, 1997). However, is this the case for arts?

Certainly, there is indication that involvement of various levels of management may vary by the nature of the sponsorship (arts, sports or other), and the experience level of the company. Given the ongoing call for greater systemisation (Abratt et al., 1987; Elicker, 
1978; Meenaghan, 1991b; O'Hagan \& Harvey, 2000; Parker, 1991), and the variations noted, one might ask what other factors play a role in determining who is involved in sponsorship decisions? In one company, will it always be the same individual / managerial level influencing the decision? Is gut instinct important? How are these decisions actually made?

\subsubsection{Conclusions on the managerial side of arts sponsorship}

In reviewing literature in the management side of sponsorship knowledge of the motivations and objectives which managers seek to fulfil through this activity has been gained, as has knowledge of sponsorship as an ongoing, developing relationship between the two parties. Differences in the relationships and evolutions of relationships have been noted. The sponsored activity (arts vs. sports for example) will have an impact on the relationship, as will the experience of the company in sponsorship, and individuals. However, it is noted that arts sponsorship is different from sports sponsorship, and opportunity exists to explore actual decision-making processes for arts sponsorship, informed by the knowledge above.

In the context of this discussion, and the reference point of a non-profit arts organisation seeking support via sponsorship from a company, it seems essential that the non-profit understand the company they are approaching. While the literature relates to and illuminates aspects of decision-making processes, it has not been integrated, nor explicitly studied. There appears to also be opportunity to contribute to this discussion by taking a research approach which considers the dyad -- walking managers on both sides of the decisions, through actual processes. There are also still many unanswered questions in terms of decision-making: What is the decision-making process for arts sponsorship? How might it begin? Are the objectives and motivations noted as important, the ones which are in reality considered? How do the objectives influence the decision? Who, in particular, is involved in the decision and who is influential? How does this relationship begin? How do these decisions happen? 


\subsection{Considering the Philanthropy Literature}

As previously noted, there is value in considering literature from other areas under the umbrella of CCI, and in particular literature on corporate philanthropy. Corporate Social Responsibility (CSR) will be integrated into this discussion as there is general agreement that philanthropy is a component of CSR (Carroll, 1991; Seitanidi \& Ryan, 2007; Wood, 1991). Therefore, in examining this literature, discussions surrounding corporate philanthropy and philanthropy as part of a CSR program will be considered. Some articles which broadly consider CSR are also included where appropriate. However, those which focus on aspects of CSR separate from philanthropy (such as environmental responsibilities) have been excluded.

Similar to sponsorship, in the philanthropy literature, the issues surrounding a decision to give to a non-profit have received attention, while the details of actual processes have not been studied. Key themes which emerge on review of the philanthropy literature include (1) the discussion of whether or not firms should be engaging in philanthropy and if so, why, (2) the examination of strategic philanthropy, (3) motivations for engaging in philanthropy, and (4) factors which influence corporate philanthropy. Each of these will be discussed briefly, with reference to how this contributes to the proposed study.

\subsubsection{Justifying Corporate Philanthropy}

Authors, most notably Friedman (1970), have argued against philanthropy, claiming that the distribution of shareholder wealth should be left to the decision of shareholders. However many authors make the argument for corporate philanthropy on a number of levels. In 1991, Collins argued that corporate philanthropy is substantiated if companies take a long-term view to their activities, and that "profit and societal benefits need not be in exclusion" (p. 47). Collins' argument proposes that philanthropy be managed as a marketing function, and that the benefits from philanthropy will accrue to the company in this manner (again raising the question of whether this is "philanthropy"). Shaw and Post (1993) argued for philanthropy, noting that shareholders have a moral obligation to act in the interests of the public, and should therefore expect the company to do the same. Godfrey (2005) argued that CSR and philanthropy are justified as this will create positive 
moral capital, which will act as "insurance-like protection" for the company, should they require it. This in turn will contribute to shareholder wealth, and therefore reveals a profit motive for philanthropy.

Many questions arise from this ongoing discussion, particularly, while these are arguments, what view do the actual decision makers hold on the role of the firm in terms of philanthropy? In what way might this view influence the decision to engage in CCI? Why give at all?

Perhaps in the pursuit of evidence to justify a company giving to social causes, many researchers have looked to the relationship between Corporate Social Performance and Corporate Financial Performance (CSP-CFP). If firms operate primarily to increase the profits of shareholders, and even if one considers Carroll's CSR model, with economic responsibilities as a first priority, then perhaps this financial and profit-oriented language is the place to look for justification for corporate philanthropy. The literature which examines the CSP-CFP relationship has emerged with a range of results.

Orlitzky, Schmidt and Rynes (2003) conducted a meta-analysis, and found support for a positive CSP-CFP relationship, though with varying degrees. While they found bidirectional causality, the relationship which seems most of interest to managers is whether investment in a CSR program would yield positive results to CFP. Based on their analysis Orlitzky et.al. (2003) proposed that social performance has a positive effect on financial performance as it helps to build both a firm's external reputation, and internal support within the company.

The idea of moderating influences (for example, the firm's reputation) was also been proposed by Schuler and Cording (2006), who recommended that the CSP-CFP relationship be viewed with the stakeholders or consumers' decision-making processes in mind. Here, CSP activities are seen as being interpreted by stakeholders, having different effects on different stakeholders depending on the stakeholder's background, the information they receive and the activity itself. Choi and Wang (2007) brought in the influence of managerial values, and proposed that the benevolence and integrity of managers will influence their CSP and contribute to CFP via the relationship these managers have with stakeholders. In contrast, Seifert, Morris \& Bartkus (2004) found no support that philanthropy affects firm financial performance. However, based on the 
above discussion, it may be that intervening variables should be incorporated.

Considering Schuler and Cording (2006) and Choi and Wang (2007), while these authors recommend that stakeholder perceptions and managerial values influence the CSP-CFP link, these articles are proposing theory, rather than testing these relationships. Thus the question remains, albeit more informed, as to whether managers actually consider stakeholder perceptions and their own values, in their decision-making of social programs.

The other direction of the relationship, the effect of financial performance and profitability on CSP and philanthropy, has long been considered and found positive: the higher a firm's profits, the more likely they are to have discretionary funds, and the more likely they are to engage in philanthropy. A number of authors have found support for this relationship (McElroy \& Siegfried, 1985; 1986; Seifert et al., 2004), and it is acknowledged that the more resources a firm has available, the more likely they are to be able to make discretionary expenditures - which is what corporate philanthropy largely is considered.

Examination of the literature in the above areas then does suggest that there may remain a debate on whether "doing good" is appropriate for a firm, and if "doing good" does actually result. What is not answered here is whether this debate and these discussions enter into the decision-processes for companies considering art sponsorship. Do managers take into account a corporate "philosophy" regarding giving? Do managers consider arts sponsorship even to be part of the corporate philanthropy equation? Do managers consider stakeholder perceptions and their own managerial values in these decision processes, as is suggested in understanding the CSP-CFP relationship?

The next area of literature to be considered presents a variation on corporate philanthropy, and an argument for how philanthropy may meet objectives of doing good for society and for the company.

\subsubsection{Strategic Philanthropy}

Corporate philanthropy received something of a make-over when literature on Strategic Philanthropy began to emerge. This literature argues that a firm should give, but should 
do so on strategic grounds, inclusive of but broader than just marketing, with strategic thought underpinning the decision. Early in this discussion, Mescon and Tilson (1987) noted a move to more strategic thinking in terms of corporate "donations" and how they are publicised, focusing on the marketing of these activities to then benefit the firm. McAlister and Ferrell (2002) also suggested a strategic element in emphasising the promotion of philanthropic activities. While these authors point to the incorporation of marketing and promotions into corporate philanthropy discussions, the conversation surrounding strategic philanthropy moves beyond philanthropy as a communications tool.

Strategic philanthropy made its debut in an article entitled "The New Corporate Philanthropy" where author Craig Smith (1994) reported on philanthropic activities in major corporations which bore signs of strategic purpose. He noted that this new tack on philanthropy may give corporations a competitive advantage by providing marketing (name recognition) benefits, as well as "boost employee productivity, reduce R\&D costs, overcome regulatory obstacles, and foster synergy among business units" (p. 105). Porter and Kramer (2002) also called for companies to view philanthropy as a tool to improve the "competitive context - the quality of the business environment in the location or locations where they operate" (p. 58). The benefit to the firm overall looms large in this discussion, as seen in a definition proposed by Saiia, et.al. (2003) where strategic philanthropy was defined as "giving of corporate resources to address nonbusiness community issues that also benefit the firm's strategic position and, ultimately, its bottom line" (p.170).

The literature on strategic philanthropy notes the emergence of strategic concerns in philanthropic decision-making, and again points to the range of $\mathrm{CCI}$ in existence even within a single initiative, as noted earlier. However, the discussions here largely report on the trends, provide examples of strategic philanthropy in action, and offer methods of conceptualising or achieving it. How these decisions are actually made has not been studied, especially considering who is involved, and what role strategic concerns have in the decision process itself. The ideas of strategic philanthropy however, do point to the importance of setting objectives associated with philanthropy, which will return benefit to the company. Similar to discussions of objectives associated with sponsorship, this area is proposed to lend insight into how these decisions are actually made. 


\subsubsection{Motivations for Engaging in Philanthropy}

The concern for financial returns and strategic benefit are potential motivations for corporate philanthropy, as discussed above. However, in considering the philanthropy literature, more specific motives have been investigated and shed light. Specifically, motives related to image building, personal interests and a sense of social responsibility emerge in studies concerning objectives for corporate philanthropy.

While these themes are similar to sponsorship, corporate philanthropy studies appear to find objectives other than image building more prominent than in the sponsorship literature. Certainly, image building and awareness remains a motive for philanthropy, in part evidenced in the call for philanthropic investments to be included in the communications mix (Bennett, 1998; McAlister \& Ferrell, 2002; Robinson, 2006). However, image building does not consistently emerge as the main priority as it does in sponsorship. For example, Madden et. al. (2006) examined small to medium size enterprises in Australia, and concluded that three motives dominated these companies' motivations: (1) the expectation of the local community that the company donate or give; (2) the pursuit of a commercial/business benefit (such as developing image); and (3) a more personal desire of a manager to engage in philanthropic activities. This study raises the question again of expectations, and perhaps perceptions of stakeholders, as noted earlier. However, this study is also based on the reports of single-informants, and may suffer the same limitations as other studies noted, where actual decisions were not traced via multiple informants from both sides of the decision (i.e. dyadic).

Other authors in their examination of literature have noted the merging of commercial and community-oriented objectives. Valor (2006) proposed that in terms of philanthropy and in applying pro-social behaviour theory, giving may be the result of a combination of both "economic and moral reasons" (p. 25). Campbell, Moore and Metzger (2002) proposed motivations be categorised into four key areas: strategic, altruistic, political (broader environmental concerns) and managerial utility or personal influence of management. It is interesting to note that while a number of motivations are noted, Campbell, et. al. (2002) did not find clear evidence to support a dominant single motive. In addition, Valor provided a theory, but this remains largely untested. In considering the motivations and objectives for philanthropy, what remains to be seen is how motivations are considered in decisions, and if motivations influence actual decisions. 
Certainly, opportunity exists to gather further empirical evidence surrounding the objectives related to corporate philanthropy. In concluding their discussion on the motives of corporate philanthropy in the U.K., Campbell et. al. (2002) noted that "It may be that so little effort is invested in decisions on the level of donations that studies seeking patterns and explanations are rendered vacuous" (p.40). The authors go on to state "further research in the decision-making processes behind charitable donations may shed some light on this" (p.40).

\subsubsection{Influencing Factors on Corporate Philanthropy}

This brings us to the next stream of literature in corporate philanthropy - that concerning what does influence corporate philanthropy? A number of authors have moved away from the profit connection and motivations, towards other influences on corporate philanthropy. The main influences studied include efforts made to identify the presence or absence of a relationship between philanthropy and firm size, ownership, senior executive interests, industry effects and more. Each of these items will be examined briefly.

Firm size has been the subject of a number of studies and has been found to be an influential factor on corporate philanthropy. Amato and Amato (2007) conducted a quantitative analysis of US firms and found a cubic relationship, where smaller and larger firms tended to give more relative to total sales, while those in the medium-sized scale gave relatively less. Bartkus, Morris and Seifert (2002) found larger firms made larger gifts generally, and found a relationship between this and the characteristic of having a larger board and therefore greater ties to the external environment. The size of the company may also influence giving through other intervening factors. For example, Dunn (2004) found that larger firms were more likely to have professional donations programmes. In the USA McElroy and Siegfried (1986) found that the size of the firm affected the geographic locale of donations (smaller companies gave mainly to the headquarter locale), but as the firm size increased, greater percentages were allocated to operating locations. While the above studies suggest relationships, they are all large quantitative analyses which, while they are able to find relationships, are unable to say how this relationship may be played out in terms of an individual decision. 
Ownership of the firm is another influencing factor which has received some attention, and is often linked with the role of the corporation in society and agency theory. In an agency relationship, one party (being the principal) is dependent on the other party (the agent) to "undertake some action on the principal's behalf" (Bergen, Dutta, \& Walker, 1992, p. 1). In a corporate giving situation then, the agent is the manager or CEO, contracted by the owners or shareholders (the principals) to act in the interests of the principals. When the two have differing objectives, problems arise. Therefore, if the company is privately held, the principal and the agent are often the same, and conflict is less likely to arise. In addition, under this scenario, the principal is looking after themselves, and would theoretically seek profit maximization, which would not necessarily include philanthropic giving. On the other hand, if the firm is publicly held, it is more likely that conflict will arise.

There are a number of points to this theory related to philanthropy. Firstly, assuming individuals are seeking profits, and it is difficult to justify giving in terms of profits, one would presume that the more power the principal has, the less likely the firm is to make donations. Atkinson and Galaskiewicz (1988) found support for this when they found that as the percentage of stock owned by an individual or chief executive increased, the contributions decreased (although the relationship did not hold true for a corporate interest or family holding significant shares).

Secondly, under agency theory, one would presume that the shareholders as principals would try to increase their profits by seeking reductions in contributions made. Brammer \& Millington (2004a) supported this argument that stakeholders exert pressure but noted that managers then manage this pressure. That is to say, they found that if the firm perceives increased pressure from external stakeholders, then the management of corporate donations was less likely to be with top level executives, and more likely to be located with an externally-oriented department such as marketing or PR; "organisations appear to allocate responsibility for the management of donations to functional departments that have the capabilities to cope with the particular stakeholder pressures they face" (p.289). Similarly, Elms (2006) also suggested that the stakeholders (including owners/shareholders) should play an important role in CSR decisions; Elms argues that social responsibility should be understood as stakeholder responsibility - if stakeholders do not care, the corporation will not either. In this case we see that 
ownership has an influence on donations through management perceptions, and through the establishment of procedures or programmes.

Moving away from the concept of ownership and blockholders, Bartkus, Morris \& Seifert (2002), noted that the "number of powerful voices appears to be more important than the percentage of stock held by large blockholders" (p. 336). In other words, the influence of ownership may be subordinated by a collection of "louder," powerful individuals. However, who these individuals are, from where they derive their power, and how they make their powerful voices heard remains to be seen.

This idea of powerful voices brings us to the next influence, that of the individual manager or CEO exerting influence on philanthropy. While the manager may influence as an owner/shareholder, the majority of the studies here consider managers and board members not as owners seeking profits but as players in the decision-making process, with interests in non-profits.

So how might an individual emerge powerful in these decisions? As already noted, a motivation for corporate philanthropy was to be socially responsible, and authors note that this may well be an individual motive. To illustrate, in considering the giving history of S.P. DuPont, a corporate leader and American philanthropist, Kirchberg (2004) proposes that the emotional and personal interests of senior-level managers, especially as they relate to giving to the arts, may still be present underneath the layer of financial justification. Also considering decisions of corporate philanthropy, Jones (2007) brings together ideas of values, decision-making and philanthropy, and proposes a model in which the values of individual executives play a significant part in these decisions. Choi and Wang (2007) also argue for the consideration of the values of managers in the relationship between corporate philanthropy, and financial performance. Similarly, Valor (2006) notes that personal characteristics of decision-makers may play into these decisions. However, while the above note the potential influence of individual values, this influence has not been directly studied in decisions.

Relationships have been found however which suggest a single executive may be more influential in these decisions. Wang \& Coffey (1992) found that as the percentage of inside managers on a corporate board (which considers philanthropic giving) increased, corporate philanthropy also increased, indicating executive influence. Additionally, 
Brammer, Millington \& Pavelin (2006) surveyed UK managers responsible for corporate giving and found that CEO discretion was ranked the most important influence on the level of contributions. In addition, in terms of giving to the arts, LeClair \& Gordon (2000) noted that of the three most important rationales, one was "the personal interests of key executives" (p.230). Madden et al. (2006) also noted the importance of an individual, though in this case of a key individual on the non-profit side of the decision, able to open-doors. Again, however, while these studies lend support, they are limited in that they are not studying actual decisions, and with the exception of Madden et al. (2006), they do not suggest how the individuals exerted their influence.

Moving towards the "how" question, it has been suggested that individual interests may be moderated by institutionalisation or formalisation of a donations programme. Werbel \& Carter (2002) noted that CEOs' personal interests were associated with giving especially for arts and international groups; however, the CEO was not influential if the company had institutionalised the practise of giving. Therefore we see that individuals may be influential, but institutionalised practises may moderate this. This raises the question of how decisions are in fact carried out. Are processes and procedures carried out, thereby reducing an individual's influence?

The final noted influence on corporate philanthropy, is that of the industry in which a firm operates. In the US study conducted by Amato and Amato (2007), industry influences were found to explain roughly $20 \%$ of the variation in giving. More specifically, Brammer and Millington (2004b) argued that for consumer goods companies, donations were likely to be managed through PR departments, while highwage industries were not likely to manage donations in this manner. This however, relates to the management of the donations, rather than the decision-making. Industry norms on the other hand have been found to play a role in determining giving (Seifert et al., 2004); however somewhat contrary, another study suggested that competitors' contributions were perceived by managers as the least important influence on contributions (Brammer et al., 2006). In this sense, some indication of an industry influence may exist, but it is yet difficult to tell how influential this may be in a decision situation.

To consider this in more depth, a specific example of the interaction between industry and corporate giving is provided within a particular sector undergoing turbulence. In this 
case, Campbell and Slack (2007) looked at the giving behaviour of building societies at a time when their legal status was challenged. They found that the rate of giving increased dramatically for these companies when the sector "underwent increased social scrutiny ... and ... media attention" (p. 339). This suggested a relationship between what the industry was experiencing in the community, and managing community stakeholders through giving behaviour. This study further suggested that it may not be the industry per se, but the perception of or threats to the industry which may influence giving behaviour. Taking this further suggests that the wider environment in which the firm operates may have an influence on giving, however more cases, from more situations would naturally need to be considered.

\subsubsection{Decision-making in Corporate Philanthropy}

Given the research question for this study, particular attention was given to the literature and insights relating directly to decision-making in corporate philanthropy. As in sponsorship, studies directly related to decision-making were sparse. Two important models are evident however, and have been referred to above. These two models are those proposed by Jones (2007) and Valor (2007). Both of these authors propose potential models by which firms may engage in these decisions, but with very different focuses. Valor (2007) took a corporate decision-making view, and suggested a macro process by which firms may consider a strategic approach to philanthropy, and make these decisions in order to achieve both social and economic benefits. This conceptual model includes a process by which managers would make an environmental and internal corporate analysis, set objectives and monitoring procedures, establish a strategy, choose donation size and types, choose actual recipients of the donations, as well as communicate and measure the success of these donations.

At a more micro level, Jones (2007) looked at individual managers and the role their values may take in such decisions. In this article Jones also offered a conceptual model but one which highlighted the importance which personal values of senior-level executives may hold on these decisions. these two models take steps towards understanding decisions of corporate philanthropy, and highlight influences external to the company, within the company and with the individuals involved. However, these two models are conceptual and have not been tested. 


\subsubsection{Conclusions on corporate philanthropy}

The philanthropy literature which looks at the managerial side of corporate giving once again contains discussion surrounding the corporate decision, but not investigating actual decisions, and not specifically concerning the arts. The literature debates whether companies should engage in philanthropy at all, and contains discussions of the relationship between social and financial performance. The literature also notes that companies may seek broader strategic advantages (outside the realm of marketing specifically) through philanthropic activities. The motivations for philanthropy may include image-building, but may also include altruism, political motives, and personal interest of management. The literature points to the potential influence of individuals in the decisions concerning philanthropy. Finally, some authors propose models related to philanthropic decision-making; however these models have not been tested.

In considering this literature, pieces of the decision-making puzzle have been suggested, here, in terms of philanthropy more generally, rather than arts specific. While the literature points to aspects of these decisions which may be considered by decisionmakers. Many questions are also raised: Will companies have a philosophy concerning corporate philanthropy and will this influence the decision? Will values and opinions of stakeholder perceptions influence the decisions? To what extent might firm size or ownership influence the decision? Finally, how might a single powerful individual influence such a decision?

\subsection{Sponsorship \& Philanthropy Literature in Summary}

It is evident through the above discussion, that literature from both sponsorship and philanthropy areas may be integrated to inform this study. Both literatures provide insight into aspects of decision-making for sponsorship and philanthropy. However, there is little evidence of qualitative, dyadic study of arts sponsorship decisions. Both literatures suggest there is opportunity to develop greater understanding of how companies make decisions when considering arts sponsorship. Investigation around and outside the "black box" of these decisions has been taken, but the black-box remains unopened. While some conceptual models have been put forward to propose how companies could engage in philanthropy decisions (Jones, 2007; Valor, 2007), studies detailing how the decisions have actually occurred are not evident. This potential gap in 
the literature has been recognised by authors (Campbell et al., 2002; Margolis \& Walsh, 2003) who suggest that future research be conducted to develop a greater understanding of the actions of companies and for descriptive research to understand how companies respond to the needs of society.

This study therefore considers how companies make arts sponsorship decisions, within the range which includes elements of commercial and philanthropic orientations. The literature discussed in this chapter has both helped to formulate and inform this investigation. However, in constructing an initial framework, further literature needs to be examined. It is suggested in that in theory-building, the incorporation of other literatures and theories is essential (Eisenhardt, 1989). For this the study turns to literatures in Organisational Buying Behaviour, and Decision-making. Organisational Buying Behaviour (OBB) is drawn upon on the basis that an arts sponsorship decision is actually an organisational decision, and could be considered a purchase or investment by the company. Knowledge from decision-making literature is also drawn upon again, as these decisions are within the context of an organisation, and are often linked with strategic concerns, as identified especially within the philanthropy literature discussion. 


\section{3: Conceptual Framework Development: Integrating Organisational Buying Behaviour and Decision-making literature}

The preceding chapter identified a research opportunity in looking closely at the decision-making processes surrounding arts sponsorship. As there is little published literature in this area on which to base hypotheses and conduct theory testing, this study makes use of a theory building approach. In this approach, it is important to be informed but not limited by theory. As noted by Eisenhardt (1989), some theory is necessary to provide better focus for the efforts to follow. Therefore, to progress towards an initial conceptual framework to guide the research, it is necessary to draw on other literatures and theories, into which the arts sponsorship discussion may be woven. Specifically, the other literatures drawn upon include Organisational Buying Behaviour (OBB) and Decision-making. An illustration of this process is provided in Figure 3.1.

Figure 3.1 Development of a Conceptual Framework

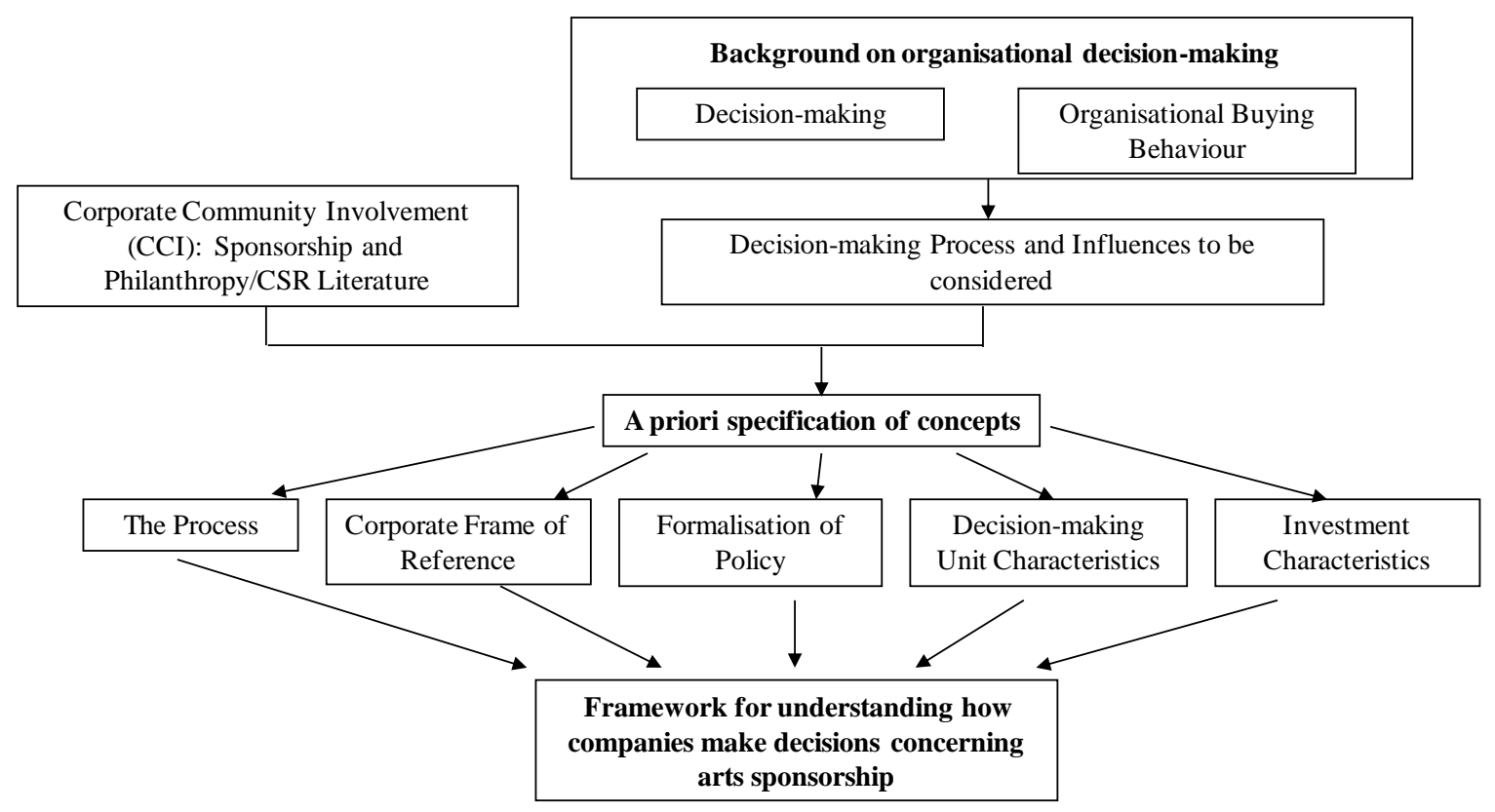


As noted, the incorporation of both Decision-making and OBB literatures are deemed to be worthwhile in this study, and to begin, some justification for including these literatures will be provided.

A first justification to include OBB and decision-making, rests on the idea that both areas focus on the decision-making processes within companies. This is appropriate within this discussion given that here too, we are concerned with a decision in the context of a company. Furthermore, in strategic decision-making, Eisenhardt and Zbaracki (1992) define a strategic decision as "one which is important, in terms of the actions taken, the resources committed, or the precedents set” (p.17). In the context of arts sponsorships, this discussion might refer back to sponsorships requiring significant resource deployment, or decisions which might be characterised as strategic philanthropy.

Discussion from OBB will also be incorporated, as this provides a focus on the organisation making a purchase or investment. The situation is very similar in the case of arts sponsorship, where a company is considering an investment in a non-profit organisation (and their activities). Furthermore, arts sponsorship decisions relate closely to Business-to-business marketing, in which businesses (here, the arts organisation) need to understand their customers (here the sponsoring company) and their customers' decision-making processes - something to which OBB or industrial purchasing literature is oriented.

Finally, the previous chapter lends to the inclusion of a new perspective. Given that sponsorship and philanthropic decisions are becoming ever more strategic or investment oriented (Stroup et al., 1987), that there are a myriad of objectives sought by $\mathrm{CCI}^{2}$, the discussions of "strategic philanthropy" and more specifically the legitimization of sponsorship and philanthropy in the marketing mix, putting this situation into a businessto-business and strategic context is not unrealistic. Furthermore, arts sponsorship decisions have not been investigated via the lenses offered in OBB or strategic decisionmaking. In this sense, these literatures will contribute to a conceptual framework to inform the study, will lend a new perspective, and will make a contribution to the arts sponsorship area.

\footnotetext{
${ }^{2}$ In this chapter, the term CCI, Corporate Community Involvement, will be used to represent the multiple types of relationships categorised here. However, for the most part there is an understanding that the literature reviewed covers mainly sponsorship and philanthropy.
} 
The following sections of this chapter will look more closely at two main aspects of decision-making: the processes and influences. Discussion will incorporate decisionmaking and OBB literature to generate a range of factors for consideration. This will then be synthesized with sponsorship and philanthropy literature previously considered to generate an initial framework for conceptualising arts sponsorship decisions.

\subsection{Understanding Decision-making Processes}

A number of approaches to the decision-making process are summarised in Appendix 1. While there are occasional variations to the process, the typical process may be summarised in Eisenhardt and Zbaracki's (1992) description of a rational model, which includes three main steps: problem identification, development and selection. Other processes have been identified which expand on these steps, such as that proposed in OBB by Robinson, Faris and Wind and noted again by Johnston and Lewin (1996). This process includes eight stages:

1. Recognise need,

2. Determine characteristics required of solution,

3. Establish specifications,

4. Identify potential sources,

5. Request proposals,

6. Evaluate proposals,

7. Select supplier, and

8. Evaluate the purchase.

The purpose of considering varying steps is to be aware of the potential stages which a company may work through. However, while these logical and incremental steps are presented in a "rational" manner, it is important in considering decision-making that limits of rationality are recognised.

Pure rationality assumes perfect and shared knowledge among the decision-makers concerning the alternatives and consequences, and that "the consequences and alternatives are defined by the environment” (March, 1994, p. 5). In reality, however, uncertainties exist and though individuals may intend to be rational, they will be limited 
in this. In March's words, this model of pure rationality "strains credulity as a description of how decisions actually happen" (1994, p. 5). Subsequently, bounded or limited rationality recognises that decision-makers face constraints of information, and make adjustments to their approach.

Eisenhardt and Zbaracki (1992) note that the debate between pure rationality and bounded rationality has died down and bounded rationality has been accepted, although there are many variations of theories which reside under the umbrella of bounded rationality. Three key conclusions these authors make in terms of these theories and the decision process include:

(1) ... the existence of cognitive limits to the rational model. Decision makers satisfice instead of optimize, rarely engage in comprehensive search, and discover their goals in the process of searching.

(2) many decisions follow the basic phases of problem identification, development and selection, but that they cycle through the various stages, frequently repeating, often going deeper, and always following different paths in fits and starts ...

(3) the complexity of the problem and the conflict among the decision makers often influence the shape of the decision path (Eisenhardt \& Zbaracki, 1992, p. 22).

So while there is a decision path, there may also be variations, iterations and complexity. This is perhaps in contrast to calls in sponsorship and philanthropy for more systemisation, but raises questions such as are decision-makers in arts sponsorship satisficing? Are there phases of the decision process? How complex are arts sponsorship decisions perceived to be? And does complexity influence the rationality of these decisions?

March further contributes to this discussion of bounded rationality by offering two perspectives, by way of "logics" on decision paths. One logic proposed by March (1994) is the "logic of consequence", where decision-makers make a choice based on answers to four questions:

- the alternatives, or what is possible, 
- the expectations or consequences combined with the associated likelihood of alternatives,

- the preferences or value of the consequence to the decision-maker, and

- the decision rule - that is, how the choice is made.

While the logic of consequences is essentially choice-based, March also proposes a "logic of appropriateness" which is rule-based. Under this logic, decision-makers consider three key questions concerning recognition, identity and rules:

1. recognition concerns what kind of a situation is this?

2. identity looks at what kind of a person am I and what kind of an organisation is this?

3. rules link the above questions asking "what does a person/organisation such as I am and such as this organisation is, do in this situation?

The above suggests decisions are unlikely to be purely rational, given cognitive limits of individuals, as well as the lack of perfect information about the alternatives which exist. Due to the characteristics of and potential conflict between individual decision-makers as well as the complexity of the problem, decision paths may well vary. While the "basic phases" of decision making may be problem identification, development and selection, decisions may be characterised as more based on the analysis of consequences or an analysis of the situation and rules which exist. In terms of arts sponsorship decisions, which have not been studied from these perspectives, one might ask about the influence a single decision-maker, with their cognitive limits may have, and whether a logic could be identified which would fit arts sponsorship decisions.

While the processes still may appear logical, it is also recognised that the decisionmaking process may not always run smoothly or logically. Part of the lack of logic may be attributed to conflict as noted by Sheth (1973). The introduction of conflict appears to sit closely beside Eisenhardt and Zbaracki's (1992) description of a political decision, where "the key assumption is that organisations are coalitions of people with competing interests" (p.23). Under this perspective the importance of conflict resolution and the use of power and political tactics come to the forefront. The choice process is not characterised as "intendedly rational with cognitive limits" as in bounded rationality, but as a "conflict of interests, dominated by powerful coalitions"(Eisenhardt \& Zbaracki, 1992, p. 32). These authors find acceptance within the literature that power, politics and 
conflict are important pieces of the decision-making puzzle. In terms of the earlier sponsorship and philanthropy discussions, this theory seems akin to studies of the role of the individual and the potential involvement of the CEO or higher levels of executives who possess a degree of power.

The final model reviewed by Eisenhardt and Zbaracki (1992) is the "garbage can model" in which organisations are viewed as "organised anarchies" with participation in the process as being "fluid", goals "ambiguious, shifting" and choice processes the "random collision of problems, solutions, participants and opportunities" (p. 32). While the authors find modest support for the model, and propose that the methodological validity in studies is "surprisingly soft" (p. 31), the model does point to the potential influence of chance or serendipity, something acknowledged in marketing as potentially influential (Brown, 2005).

The above highlights possible variations in processes, and many have suggested that while a decision-making process may be defined or categorised, it is likely to vary depending on the situation. Bunn (1994) noted that "organisational buyers use alternative decision processes for different situations" (p.38). Similarly in considering decisions specifically surrounding ethical issues, Rodgers and Gago (2001) proposed four elements to the process (perception, information, judgement and a decision), which may be combined together in any of 6 different pathways. Would then arts sponsorship be identified as a particular situation? Or even within arts sponsorship, could there by a variety of pathways which could be identified?

This discussion highlights a series of important points. Firstly, within the process of decision-making, there is likely to be a problem or need, an evaluation of possibilities and a final choice. The order in which these are played out varies, and not all steps may be followed. Underneath this process layer, there exists a series of variables which will both influence and characterise the path. Taken from the above discussion, these variables may include the following:

- Individuals, their associated power and politics, conflict resolution and/or their interpretation of the situation and their identity

- The information the decision-makers access and use

- The complexity of the problem 
- The context of the decision (for example whether or not the decisionmaking unit views the decision as a communications decision or not)

$\circ$ The decision rules (formal or informal) which are used and which seem to suit the situation; and

○ Chance.

While there are likely to be multiple potential processes, it may be possible to develop a number of prototypical approaches, as noted by Bunn (1994). This could be possible if a particular situation (such as arts sponsorship) was examined.

Therefore in developing theory associated with arts sponsorship decisions, the potential stages in decision-making should be noted. The process may be as simple as recognising a need, evaluating possibilities and making a choice, or it may be an expanded process. It may also be illogical, circular or haphazard. For CCI and arts sponsorship, examination of decision-making processes might lead to a series of questions as follows:

- Is there a range of decision-making processes for companies considering arts sponsorship? If so, what are the variations?

○ Individuals, information, problem complexity, decision context, decision-rules and chance have been identified as key influences on and characteristics of the process; to what extent and in what manner do these hold influence, and are there other influences which are important in the context of arts sponsorship?

As seen above, the process is a part of the puzzle, but there are also elements which influence and characterise the process. Further attention is now directed to these elements.

\subsection{Understanding Decision-making Influences}

A number of influences were noted above in examining the process. Within this same literature, a further range of key influences is also brought to light. A summary of these is included in Appendix 2. 
Perhaps the most encompassing of the approaches is that provided by Webster and Wind (1972a, 1972b), where these authors elaborated on the organisational buying process, and categorised the influences on this process into four broad areas:
○ environmental influences
$\bigcirc$ organisational influences
$\circ$ buying centre-related influences and
○ individual participant influences.

The importance of wider environmental variables on decision-making is supported by others within the OBB literature (Johnston \& Lewin, 1996; Sheth, 1973). These variables could include such elements as the social/cultural, economic, political, technological and legal (Webster \& Wind, 1972a). Similarly, in considering problem-solving, Ackoff (1981) notes that observation of the problem and the environment is a first key step.

The next level down according to Webster and Wind (1972a) is the organisational environment, including organisational technology, structure, goals and tasks and actors. Jocumsen (2004) finds that internal factors such as firm size and structure are important determinants of the decision-making process. Looking to bounded rationality as explained by March (1994), organisational characteristics are noted; specifically the organisational rules and the individual's assessment of the organisation's "identity" would play a key role following the logic of appropriateness.

The buying centre or decision-making unit (DMU) is next level down in Webster and Wind's model (Johnston \& Lewin, 1996; Webster \& Wind, 1972a). This category would include who the members of the DMU are, and their activities and interactions with respect to the decision. Johnston and Lewin (1996) acknowledge group characteristics as a key influence, but as an outcome of the purchase-related risk (which will be discussed momentarily). A component which could be included in this category would be conflict and conflict resolution, which would occur between parties within a unit, and is a key consideration in Sheth's model (1973). Conflict is also echoed in the bounded rationality model, where conflict among decision-makers may influence the process (Eisenhardt \& Zbaracki, 1992). Here, politics and power positions of individuals within the DMU are considered, which leads to the Political Model examined by Eisenhardt and Zbaracki where "central to the process is how conflict is resolved" (1992, p. 32). 
The examination of conflict and power suggests the importance of the individual. Even though the decision may be coined a "corporate" or "organizational" decision, the reality is that ultimately, individuals make decisions. This is emphasised in much of the literature considering characteristics of individuals as a key influence on decisionmaking. Webster and Wind (1972a) identified the individual participants' motivations, cognitive structure, personality, learning processes and perceived roles as part of their model. Similarly Sheth (1973) emphasised the "psychological world of decisionmakers" as an influence. Bounded rationality and political models consider the individual's cognitive limits and the individual's power and political tactics (Eisenhardt \& Zbaracki, 1992). In fact, March's (1994) discussion of the logic of consequences and the logic of appropriateness focuses on the individual and their perception and interpretation of consequences and situations. Hence the backgrounds, perspectives, roles, approaches and perceptions of individuals involved should not be underestimated.

Leaving the realm of the organisation, another key element of influence is that of the "product" or problem. Sheth (1973) notes that product-specific factors will be influential, and defines this as the perceived risk in the decision. The risk associated (or risk as perceived by the individuals) with the purchase is also at the core of the model proposed by Johnston and Lewin (1996). Associated with risk is the importance of the purchase and the uncertainty of the purchase task, two key elements identified by Bunn as influencing factors (1993), with the decision importance also noted by Jocumsen (2004). The above suggests that the complexity of the problem is seen to shape the decision path.

The final element, noted in the process discussion, but which must be reiterated here, is the element of chance. This is the central theme of the garbage can model (Eisenhardt \& Zbaracki, 1992). In considering chance, it is noted that this may not necessarily be random; Louis Pasteur has said "chance favours the prepared mind."

To summarise the discussion on decision-making influences, it is evident that through combining a series of literatures, a number of influences may be highlighted. These would include the following:

○ environmental factors

$\bigcirc$ organisational characteristics

○ characteristics of the decision-making unit (DMU) 
- characteristics of the individuals within the DMU

- perceptions of the product/purchase task, and

o chance.

However, as noted earlier, the perspectives presented here have not yet been utilised in an arts sponsorship context, and thus many questions remain. Specifically the extent to which the factors above influence arts sponsorship are yet unknown. Furthermore, arts sponsorship, potentially identified as a specific situation, may well have new and varying sub-categories for each factor identified above.

Thus, the understanding of arts sponsorship decisions, both the processes and influences, is likely to benefit from a decision-making and OBB perspective. In addition, this understanding may also contribute to greater knowledge of decision-making more broadly - changing our understanding of these processes and influences. While a leap into hypothesised processes and their characteristics would be too far a leap to take given the $\mathrm{CCI}$ literature reviewed earlier, there is enough evidence to provide some direction and develop a priori factors for consideration. 


\subsection{A Priori Specification}

In keeping with a theory-building approach, it is proposed that initial generation of $a$ priori constructs will assist in focusing further study. As stated by Eisenhardt (1989),

investigators should formulate a research problem and possibly specify some potentially important variables, with some reference to extant literature. However, they should avoid thinking about specific relationships between variables and theories as much as possible, especially at the outset of the process (p.536).

Therefore, this discussion considers elements identified in decision-making, combined with the CCI literature which has been investigated. This examination will specify $a$ priori factors, and also allow for the researcher to be attuned to other potential elements which may emerge.

The literature investigated from CCI has suggested firstly that it is useful to consider a range of relationships, and that range may well incorporate varying orientations to commercial and philanthropic goals. The literature has also suggested value in the study of the decision making process surrounding sponsorship of the arts. Finally, this literature has indicated key areas which may well influence the decision process: how the company views the sponsorship investment, the objectives being sought and the extent to which the investment meets these objectives, the individuals involved and their characteristics, and the departments involved. Considering this knowledge in terms of the decisionmaking/OBB literature suggests initial consideration of (1) the process itself, and (2) four key aspects, each of which would characterise and shape the process around a decision:

1. the corporate frame of reference

2. the level of formalization of policy

3. the investment, and

4. the Decision-making Unit (DMU). 
An initial framework is conceived in Figure 3.2, depicting the "black box of arts sponsorship decision-making." Here, the process itself is contained within the box, as are four elements which interact to influence and characterise the process.

Figure 3.2 The Black Box of Arts Sponsorship Decision-making

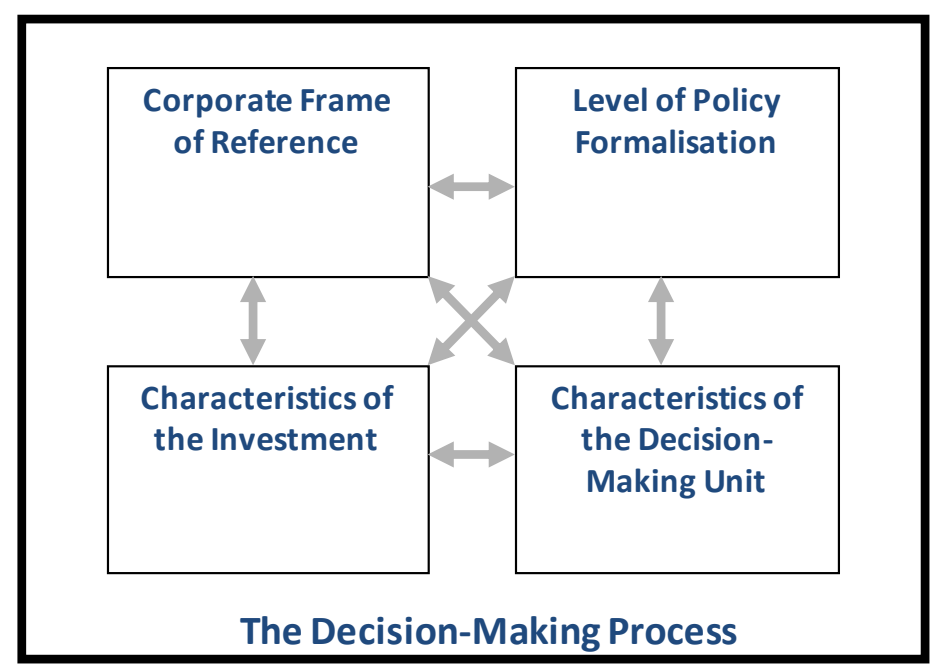

The remainder of this chapter will discuss each element, in terms of the theory and the literature investigated from CCI. This will therefore describe the influences and characteristics initially thought to play a role in arts sponsorship decisions.

\subsubsection{The Process}

Since opening the "black box" of arts sponsorship decision-making will reveal both processes and elements which influence and characterise the process, a first area for consideration will be the process itself. Through investigation into decisionmaking/OBB, potential processes have been noted along with the proviso that these processes are likely to vary with the situation. In the sponsorship literature, some investigation into decision-making has been conducted to a limited extent. Thjømøe et. al. (2002) revealed that processes may vary depending on how the firm viewed "sponsorship". Studies of sponsorship relationships have also revealed the importance of time, individual roles, etc., but not a specific process or decision path (Olkkonen, 2002; Ryan \& Fahy, 2003). 
To establish a starting point, taking the expanded eight step process provided by Robinson et.al. (as noted by Johnston and Lewin, 1996) and applying this to arts sponsorship, yielded a series of questions:

○ Recognising a need. Do companies recognise a need? This may well be reflected in their philosophy towards arts sponsorship and CCI generally. Do they see the need as part of their role in society? Or is it based on commercial motivations? Is it an integrated part of their marketing plan or not?

- Determining characteristics and specifications required. Do companies do this? Are they looking for specific tools/characteristics of an arts sponsorship?

- Identify sources and request proposals. Do companies undergo a search process, or is it more a case of sifting through the requests?

- Evaluate proposals. How is this done? Who is involved? On what basis are proposals evaluated? Is this directly related to objectives and motivations? Is this directly related to marketing objectives?

- Selection. Is this consistent with the evaluation?

- Evaluate purchase. Is this done and does this inform future processes?

While the process is a factor for investigation, it will be influenced and characterised by other factors, four of which have been identified in the initial framework. These will now be considered.

\subsubsection{The Corporate Frame of Reference}

Consistent with the logic of appropriateness, decisions may be shaped by the situation, and the individual's interpretation of the situation. The company/corporate frame of reference relates directly to a finding by Drumwright (1994) who found that a major factor which differentiated companies was whether or not socially responsible buying was "part of a deliberate corporate strategy" (p.6). The corporate frame of reference would reflect whether and to what extent CCI and arts sponsorship is considered part of a deliberate corporate strategy at the higher level, and would give an indication of the extent to which arts sponsorship decisions should be interpreted and dealt with as deliberate marketing strategies. This frame of reference will give individuals involved in the decision an interpretation of the situation, and therefore guidance as to what rules to apply. 
Through the corporate frame of reference, we are concerned with guiding values which the company holds with respect to CCI, and how senior management view the company's role in the community. This relates back to the overriding argument of commercial vs. philanthropic motives and the role of business in society. As noted earlier, arguments have been made for a moral basis for corporate giving (Shaw \& Post, 1993), and also that this giving does not need to be in disagreement with a profit motive (Collins, 1993; Godfrey, 2005, 2006). On the other hand, arguments have been made against altruistic giving, in favour of a link with strategy and commercial goals (Friedman, 1970).

As an example, in the 2004 Annual Report for Mainfreight, the company's Executive Director made a formal statement which would imply a more philanthropic orientation:

... no one should underestimate the usefulness of business working with society, both locally and internationally. Business and business people are the largest group seeking understanding of the cultures and ways of other countries and peoples in an endeavour to promote trade. That all countries have trade with each other may be the greatest chance for world peace (Mainfreight, 2004).

Within the literature there is indication that the industry influences the company frame of reference. In sponsorship, Crowley (1991) found relationships between the company's "audience orientation" and the benefits of sponsorship which were considered most important. For example, companies selling to the public ranked media coverage the most important valuation criteria for the investment. In philanthropy, Brammer \& Millington (2004b) found that for consumer goods companies, corporate donations are more likely to be managed through PR departments. This suggests that there may be consistencies in decisions within certain industry categories with respect to CCI.

Study of the corporate frame of reference will thus attempt to capture how the company as a whole views CCI and arts sponsorship, and how this might impact arts sponsorship decisions. Related questions may be asked such as, is there evidence that some companies are more oriented to a commercial perspective? Do some companies believe they play a strong role in the community and therefore justify more philanthropically 
oriented CCI? Essentially this frame may serve as an initial "rule" for situations, indicating where $\mathrm{CCI}$ requests may be directed, and how they are considered.

\subsubsection{Extent of Formalisation of Policy}

Formalisation concerns policies and procedures associated with CCI. For example, does the company have a formal policy/procedure? Is the procedure in place for all forms of CCI? Is the procedure followed? Naturally, formalisation may well relate to the size of the company - larger companies having a greater tendency to formalise as they have the resources and may receive a larger proportion of requests.

In terms of decision-making theory, the formalisation of policy would give greater boundaries to the alternatives to be considered, the interpretation of the consequences and the rules with which to evaluate the alternatives. It could also determine key players in the DMU and therefore power roles and potential conflict. The formalisation of policy could be considered part of Webster and Wind's (1972a) classification of "organisational goals and tasks" in which there may exist tasks, structure, technology and a buying centre. However, in this case the extent to which these structures are formalised and how this formalisation is played out is of most concern. Bunn (1994) incorporated this as "procedural control" noting that "for many buying decisions in the firm, actions are based on performance standards or established procedures" (p.161). Bunn noted that these controls could be formalised, or "rules-of-thumb" which managers have developed over time.

In considering cultural sponsorship, Olkkonen (2002) also noted that formal control can play an important role in the relationships. However the literature does not delve deeply into this area. In sponsorship and philanthropy the discussions stop at measuring the department which is involved - marketing or PR - but do not go into the policies which may be applied. Although Thjømøe et. al. (2002) studied decision-making processes for sponsorship in Norway, and measured commitments, definitions, goals, responsibility and integration, and measurement of effects, they did not measure formalisation. Similarly, Dunn (2004) considered professional donations programmes, defined as having a "set donation policy or guideline, a donation committee, and/or the public affairs department as the major authority for deciding which charities to support" (p.337- 
338). However, Dunn uses this to investigate the relationship between the programme and the level of giving rather than the process of giving.

Thus, it is suggested that the formalisation of policy could influence the decision-making process, both in the formal articulation of policy and procedure, but also via the extent to which these formal rules are followed.

\subsubsection{Characteristics of the Decision-making Unit (DMU)}

Bennett's (1998) study of philanthropic decisions in the United Kingdom, France and Germany, found that these decisions were most frequently made by groups. These groups of individuals are referred to in $\mathrm{OBB}$ as the buying centre or decision-making unit (DMU). The DMU has been examined as the group of individuals in the company involved in the purchase decision, although this does not always equate to a formal committee. In fact, the DMU is likely to contain those who are formally and informally part of the process. The characteristics of this DMU would include who is involved, what their positions are, what their influences are, and what roles they play during the process. This suggests examination of both the characteristics of the DMU and of the individuals involved. In terms of the DMU characteristics, roles, size and lateral and vertical involvement will be considered, followed by a discussion focusing on the individual within the DMU.

\section{DMU Roles}

DMU's are often described in terms of the roles involved. Literature from OBB is useful in this sense, including Webster and Wind's (1972b) identification of five key roles: users, influencers, buyers, deciders and gatekeepers. Others have added to this list including initiators and controllers (Dwyer \& Tanner, 2006), suggesting that the DMU may potentially be made up of the following roles:

- Initiators start the process. In terms of CCI, it may be the marketing, PR or CCE office who determines that the company may benefit from and should consider the initiative.

- Users are the ultimate users of the purchase and are likely to also be influencers. In CCI the users may be individuals in the marketing or PR department who will 
deal with the recipient organisation on an ongoing basis, developing leveraging ${ }^{3}$ tools, and making use of the benefits available to the company.

○ Influencers seek to affect the decision.

- Controllers set the budget and control financials. In CCI financial decisions may reside within a number of departments (such as marketing, PR or CEO).

○ Buyers hold the authority to actually make the purchase. The delegation of authority for decisions of CCI may also vary.

- Gatekeepers control the information flow to and from the DMU. In CCI this may for example be the PA to a CEO, the Marketing or PR Manager, or the Sponsorship Manager.

- Deciders make the final decision.

These roles may overlap, with perhaps the users also being the influencers, and the buyers also being the deciders. The important point is to be aware of the various players who potentially make up the DMU, rather than just paying attention to the buyers or deciders.

Returning to the literature, the importance of individuals and their roles in sponsorship relationships has been alluded to (Olkkonen, 2002; Ryan \& Fahy, 2003). However, there is no evidence that decisions have been considered in light of the roles, although there is indication that these roles exist within arts sponsorship decisions. For example, in examining large firms in the United Kingdom, Brammer, Millington and Pavelin (2006) found that the CEO was perceived to play a key role in the total amount of donations (suggesting "controllers" and "influencers"), but the management of the funds was delegated to an externally oriented department such as Public Relations (suggesting "users"). Attention to the roles also brings attention to other characteristics of the DMU, such as its size, lateral and vertical involvement.

\section{DMU Size}

DMU size has been noted in the literature as an influencing factor on the time it takes to make a decision, as well as the individual influence participants may have. Authors have found that as the number of individuals in the DMU increased, the time it took for

\footnotetext{
${ }^{3}$ Leveraging refers to the activities and related investments which companies make, beyond the sponsorship fee/request, to further promote their sponsorship association (Farrelly \& Quester, 2003a).
} 
decisions to occur also increased (Dholakia, Johnson, Della Bitta, \& Dholakia, 1993). Measures of DMU size, familiarity and viscidity (ability to work together) were combined by Kohli (1989) to determine the effect of these characteristics on the influence of the individual. Kohli found that the DMU size had an effect on the type of power most influential; specifically as the DMU size increased, if members worked well together and they were not under time pressure, expert power was the most influential form. In the CCI literature, there is no investigation into the size of the DMU although there is reference to the existence of committees (Brammer et al., 2006).

\section{DMU Lateral and Vertical Involvement}

DMU's may also be described in terms of their lateral and vertical involvement, that is, the representation of different departments (lateral involvement) and different managerial levels (vertical involvement). In their meta-analysis of OBB, Lewin and Donthu (2005) referred to lateral and vertical involvement as the DMU structure, and investigated the relationship between the purchase situation and the DMU structure and size. They concluded that although other studies found conflicting results, the DMU structure was related to the purchase situation; that is, it was related to the product type, and the risk, uncertainty, importance and complexity associated with the purchase.

Although these specific terms have not been used in the CCI literature. there is evidence of related investigation. In terms of lateral and vertical involvement, authors have asked the question of where the responsibility lies (see Appendix 3). Noted here is that the range of functional departments potentially involved in sponsorship decisions focuses on three areas: Marketing, Public Relations or the Executive /CEO. There tends to be agreement that sponsorship is highly associated with Marketing, being accepted as a key tool in the communications mix (Dolphin, 2003; Tripodi, 2001), while philanthropy's acceptance into marketing is still emerging (McAlister \& Ferrell, 2002; Robinson, 2006).

In sponsorship, Cornwell and Maignan (1998) noted the link with marketing, but also suggested the involvement of the CEO. A number of authors have pointed to a distinction in which departments are involved, according to the recipient of the sponsorship: sports sponsorship falling to Marketing, while arts sponsorships rest with public relations (Farrelly \& Quester, 1997; Farrelly et al., 1997; Witcher et al., 1991). There are also distinctions between who is prominent in the decision (the "decision- 
maker"), as opposed to who is prominent in the actual management of the arrangement (the "user"). For example, Witcher et al. (1991) note that Public Relations is prominent in decisions, but management of the relationship especially with sport sponsorship, tends to be carried out by Marketing. A slight contrast was found in a European study where Head Offices were noted to handle decisions of philanthropy, while the responsibility for managing the activity was with Marketing and/or Public Relations (Bennett, 1998).

In terms of vertical involvement, this discussion is mainly held in philanthropy, with some acknowledgement in sponsorship. The discussion surrounds the question of how much power upper-level managers or board members have. The importance of considering these upper-levels is examined by Hambrick and Mason (1984) who note how characteristics and experiences of upper managers will filter into decision making. In a related vein Smith (1994) recommends that companies appoint a senior-level executive to be the "philanthropy czar" for strategic philanthropy decisions.

As noted, the sponsorship discussion of vertical involvement is limited, but often alluding to the influence of personal interests of key executives as motivating factors (LeClair \& Gordon, 2000; O'Hagan \& Harvey, 2000; Thjømøe et al., 2002). However these studies are based on survey data of corporate objectives, and may not reflect the decision-making process, nor would they measure the extent or method of influence.

In philanthropy this discussion has received more attention, although it is not unanimous in its conclusions. Some authors have found no evidence that board members or senior managers influenced decisions (Bartkus et al., 2002; Navarro, 1988). Other studies suggest that senior-level managers and board members may play an important role in these decisions (Brammer \& Millington, 2004b; Dunn, 2004; LeClair \& Gordon, 2000; Wang \& Coffey, 1992; Werbel \& Carter, 2002). It may be safe to say that the involvement and influence of these individuals could depend on the situation, the individuals, the company and the request.

Therefore, the examination of the involvement of departments in these decisions points to potential involvement from three areas: Marketing, Public Relations, and the Executive Office. This clearly reflects elements of horizontal representation as well as vertical representation within the hierarchical structure of the company. 


\section{Key Individuals Within the DMU}

While roles and involvement of departments and levels have been considered to an extent, the potential for one key individual also merits further some examination. In particular, the question could be put, does a single individual influence an arts sponsorship decision? If so who might this person be, how much influence do they have? and how is this influence realised?

Quantitative studies which have tried to hone in on the possibility of one or two individuals having influence on philanthropy support the claim that senior level individuals in the organisation will influence giving decisions. In the United States, Werbel and Carter (2002) investigated how affiliations of CEOs with non-profit organisations influenced donations from the corporate foundation. They found that when a CEO held a membership role in the foundation, there appeared to be an influence. Looking at the board-level, Wang and Coffey (1992) found that corporate giving increased as the percentage of "insiders" (individuals who are employees of the corporation) vs. outsiders increased. They also found moderate support for the hypothesis that the presence of women and minorities on boards led to greater philanthropy. While relationships here are proposed, these are quantitative studies which test relationships, but do not explore how the influence is made.

An initial perspective on how a key individual may influence socially responsible decisions was given by Orlitzky and Swanson (2002) who suggested that a company may be more or less in tune with social needs and values, based on the executives. If the executives were receptive to social values, they would facilitate attunement (with social values) within the organisation. These authors noted that individual influence was moderated by special interest groups, and the presence (or absence) of trustful dialogue between the parties concerned. This picture presents the executive as a key influencer, monitoring the flow of information from society (specifically values) through to the organisation. The influence of the executive level on decisions was also examined by Hambrick and Mason (1984), who proposed that top managers will influence perceptions, strategic choices and outcomes, and that their influence and direction is related to their background characteristics, including career experiences. Jones (2007) borrowed ideas from Hambrick and Mason and others, and focused on the values of senior executives in terms of their influence on decisions of philanthropy, arguing that 
the values are "embedded in the being of the decision-maker" (p. 351) and would have a significant influence on these decisions.

In terms of sponsorship literature, qualitative studies also point to the important role of key individuals. Ryan and Fahy referred to a "champion of the sponsorship" (2003, p.37), and Olkkonen proposed there be "relationship promoters" on both sides of the partnership (2002, p. 284). This provides more insight and again suggests a single individual, however neither study is presented in terms of the time of decision.

Outside of CCI literature, numerous authors have put forward different roles as the key influencer, at the same time noting that it may not always be the executive:

- "Policy entrepreneurs" are noted by Drumwright (1994) as the individual who holds considerable sway on socially responsible buying decisions, but may not necessarily be the top manager.

- “Gatekeepers" are identified by Pettigrew (1975) as holding power in decisions via their control of information.

- The term "Boundary Role Person" (BRP) was used by Krapfel (1985) who noted the importance of information control for these individuals. Krapfel found that as the source gave greater information to the BRP, this improved the BRP's assessment of the source's credibility. In turn, the higher level of information and attributed credibility resulted in greater confidence of the BRP to serve as an advocate for the source.

- The "Linking Pin" is another role noted, in this case, by Wind and Robertson (1982) who identify Linking Pins as individuals who "exert leadership in their own group and maintain effective membership and influence in a higher level in an organisation" (p. 169).

- "Product Champion" is noted in innovation literature, as a person who informally emerges as an advocate for and active promoter of the innovation, eventually becoming a key factor in its success (Howell \& Higgins, 1990).

While it is likely that in a CCI decision, there may be a key influencing individual, a following question is how this individual gains their influence. Attention to Orlitzky and Swanson (2002), and Hambrick and Mason (1984) would suggest it is largely through the individual's status in the organisation. Pettigrew (1975) and Krapfel (1985) look more to the control of information. Kohli (1989) however, considered the individual influence in 
the context of the DMU and determined that expert power held the greatest effect on an individual's influence within the DMU. Here, expert power (borrowing from French and Raven's study in 1959) was defined as "the extent to which an individual is perceived by others as being knowledgeable about relevant issues" (Kohli, 1989, p. 52). Under expert power, it would not be the actual control of information, but the perception of the knowledge the person held. Kohli also found that expert power was moderated by variables, namely viscidity (expert power had a greater impact as the DMU worked more harmoniously together), and time (expert power was important when the DMU was under time pressure).

Therefore, a key individual may hold a greater influence within the DMU for an arts sponsorship decision. Who this person is and how they attain this influence (via information, perceived knowledge or political means, for example) is worthy of investigation. The authors noted above, both in CCI and OBB note the value in understanding a key influencing role, and also call for further research into these areas. An investigation from this perspective has not been conducted in terms of CCI or arts sponsorship specifically.

To conclude the discussion on the DMU, there are a number of points which have emerged. Firstly, examination of the DMU is an important part of the decision-making process but has not been investigated to date in terms of arts sponsorship. Secondly, the DMU may be described in terms of the various roles within the DMU, its size and the vertical and lateral representation, but in arts sponsorship decisions, this perspective has been given little attention. Thirdly, attention also needs to be given to the potential existence of a key influencing individual in the process, how they achieve their power and what influence they have. Fourthly, consideration of the DMU should also recognise that it is linked to the characteristics of the company - their frame of reference and the formality of policies and procedures. It may also be related to the characteristics of the investment under consideration, which will be discussed in the next section.

\subsubsection{Investment Characteristics}

Returning to decision-making and OBB literature, authors have noted the importance of the product characteristics in shaping decisions, which could be here equated with the sponsorship investment. March's discussion (1994) of bounded rationality focuses on 
the consequences decision-makers attribute to alternatives - the alternatives being here equated to the investment. In their review of OBB, Johnston and Lewin (1996) ranked purchase characteristics as a construct most frequently used to explain organis ational buying. More recently, Lewin and Donthu (2005) determined that the "purchase situation was the more frequently examined antecedent construct" in empirical OBB literature (p.1382).

While we tend to talk about product characteristics in Marketing, in the context of CCI it is more appropriate to talk about the product as the investment. Here, when considering the investment characteristics, the relevant question is particularly how individuals in the DMU perceive this investment. While there will be specific features of the investment, the associated benefits, consequences and risks perceived may also be important.

In the context of an arts sponsorship, this investment may hold slightly different qualities in each situation. To provide some boundaries, an arts sponsorship, as an investment, might be considered as follows:

(1) Being worth a certain amount of money. The arts sponsorship decisions considered here each involved a financial outlay (not just in kind/contra).

(2) Holding promotional / image building opportunities. Based on earlier discussions of the importance of brand and image building in motivations for sponsorship and philanthropy, an assessment of related opportunities is likely to come into play in defining the investment.

(3) Containing value in terms of alignment with the company's frame of reference. Based on earlier discussions there is likely to be some assessment of the value of this investment vis a vis the company. This may relate to promotional opportunities, to a higher level strategy, or to the value placed on this opportunity by a key individual.

(4) Including the managers involved in the arts organisation as key communicators. As this investment is likely to involve ongoing communication with the arts organisation, the managers involved - and specifically their ability to communicate and respond in a manner desired by the company - are likely to be considered "part of the package". 
With this description in mind, decision-making and OBB literature provides guidance to how the investments might be further characterised. These are summarised in Table 3.1.

Table 3.1 Investment Characteristics

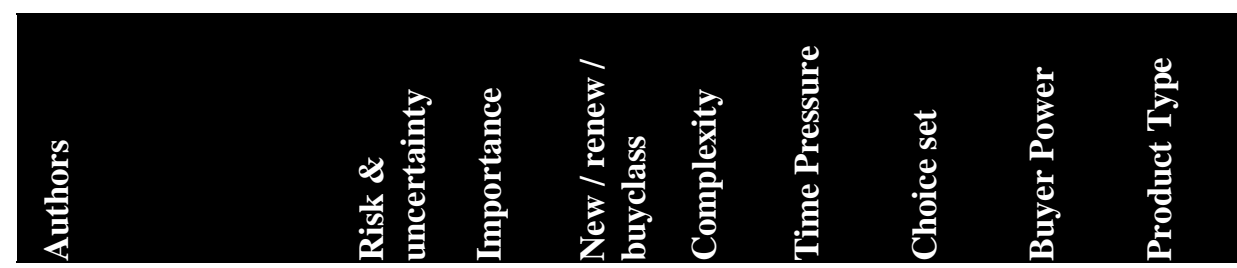

\begin{tabular}{llllllll}
$\begin{array}{l}\text { Lewin \& Donthu, } \\
\text { 2005) }\end{array}$ & $\mathbf{X}$ & $\mathbf{X}$ & $\mathbf{X}$ & $\mathbf{X}$ & & & $\mathbf{X}$ \\
$\begin{array}{l}\text { (Robinson, Faris, \& } \\
\text { Wind, 1967) }\end{array}$ & $\mathbf{X}$ & $\mathbf{X}$ & $\mathbf{X}^{4}$ & $\mathbf{X}$ & & & \\
\hline $\begin{array}{l}\text { (Johnston \& Lewin, } \\
\text { 1996) }\end{array}$ & $\mathbf{X}^{5}$ & $\mathbf{X}$ & & $\mathbf{X}$ & $\mathbf{X}$ & & \\
\hline $\begin{array}{l}\text { (Bunn, 1994) } \\
\text { (Sheth, 1973) }\end{array}$ & $\mathbf{X}$ & $\mathbf{X}$ & & & & $\mathbf{X}$ & $\mathbf{X}$ \\
\hline $\begin{array}{l}\text { (Anderson, Chu, \& } \\
\text { Weitz, 1987) }\end{array}$ & & $\mathbf{X}$ & $\mathbf{X}$ & & & & \\
\hline
\end{tabular}

Evident in Table 3.1, is that the level of risk (here associated with uncertainty), the importance of the product and the "new-ness" of the product are frequently noted as descriptors. Johnston and Lewin (1996) place risk at the core of their model, noting that "much of the variation in organisational buying behaviour appears to be related to the levels of risk associated with a given purchase situation" (p.8).

The importance, complexity and uncertainty of a purchase is likely to change with the type of purchase, which was given the term "buy-class" by Robinson, Farris and Wind (c.f. Anderson et al., 1987) in their buy-grid model which categorises the buying situation into a new task, modified rebuy or straight rebuy, based on the newness of the problem, the information requirements need to make a good decision, and the seriousness with which alternatives are considered. Anderson, Chu and Weitz (1987) tested this model and found support for the newness of the problem and the information

\footnotetext{
${ }^{4}$ Robinson, Faris and Wind incorporated the importance, complexity and uncertainty into the buy-class categories.

${ }^{5}$ Johnston and Lewin incorporated the importance, complexity, uncertainty and time pressure into their definition of risk associated with a given purchase situation.
} 
requirements as key factors; they also noted that the importance of the purchase was a missing factor. Bunn (1994), in developing a taxonomy of buying decision process, proposed the characteristics be referred to as "situational characteristics" which would include purchase importance and task uncertainty, as well as two more constructs external to the firm: extensiveness of choice set and perceived buyer power. More recently, Lewin and Donthu (2005) found that five constructs were frequently used to reflect purchase situation: buyclass, product type, purchase importance, purchase complexity and purchase uncertainty.

Obviously absent from the list above, but inherent in the product choice is that it will achieve the objectives the company desires. In an industrial purchase this would be the meeting of specifications, and would be a high priority characteristic. In terms of CCI this is restated as the investment's alignment with company objectives. Therefore, this element is added to the top of the list of investment characteristics which will shape and define the process, resulting in the following for inclusion in the study of arts sponsorship decisions:

1. the investment's alignment with company objectives

2. the task uncertainty surrounding the investment, including the new or renewing status

3. the purchase importance of the investment

4. complexity of the investment, and

5. perceived buyer power.

The following will elaborate on the above list in the context of CCI, in each case exploring this element with reference to OBB/Decision-making and in comparison to what has been studied in CCI. In doing this it will become evident that this perspective has not been taken in terms of arts sponsorship decisions.

\section{Investment's Alignment with Objectives}

Considering alignment with objectives as a component of the investment characteristics, the question is, to what extent do individuals in the DMU see this opportunity as consistent with the company frame of reference and/or specific marketing objectives? In organisational buying, products will be assessed on their ability to meet specifications. 
However, in CCI the investment's alignment with company objectives may not be so evident.

Alignment is also related to decision-making discussions. Returning to March's logic of consequence (1994), the decision makers consider the alternatives, their associated consequences and the value of the consequences - essentially in this last stage, the alignment of what the alternatives offer to what they value. The logic of appropriateness is also an alignment strategy - aligning the situation with the decisionmaker/organisation (March, 1994).

In CCI, alignment is concerned with the objectives the company is wishing to achieve. For example, a company would ask if the investment would meet the company's desire to gain awareness, promote the product, and/or be a good corporate citizen? Alignment is directly considered when managers are seeking out a positive fit between their brand and that of the arts organisation, which consumers will also perceive as logical and consistent (Becker-Olsen \& Hill, 2006; Smith, 2004). Alignment may also be something less direct or obvious, and possibly something assessed at a more personal level.

\section{Task Uncertainty Surrounding Investment}

Task uncertainty incorporates a number of variables identified earlier, and is likely to be a result of perceived risk, information and the newness of the investment. A definition for task uncertainty is provided by Bunn (1993) in defining this as "the buyer's perceived lack of information relevant to a decision situation" (p.45). The task uncertainty therefore also relates to the buy-class in terms of the newness of the problem and the information required for a decision. A new task would be likely to hold more uncertainty given that the firm would not have experience with the product. Presumably, the introduction of reliable information would then reduce the level of task uncertainty. Task uncertainty also reflects an element of risk as noted by Johnston and Lewin (1996), with greater uncertainties correlating to greater perceived risks.

There is little evidence of literature in CCI which deals with task uncertainty surrounding these investments. Seitanidi and Ryan (2007) highlighted the potential limitations of these relationships, which could be equated to risk. Other authors have noted the importance of trust, and developing trust within the context of these relationships 
(Farrelly \& Quester, 2003a; Farrelly et al., 2003b; Farrelly \& Quester, 2003c; Seitanidi \& Ryan, 2007). Authors have also noted difficulties in measuring CCI. This literature suggests an element of risk and uncertainty, but does not deal with this directly.

\section{Purchase Importance of Investment}

Purchase importance has been noted by authors as a key construct and element of the product characteristics (Anderson et al., 1987; Bunn, 1993, 1994; Johnston \& Lewin, 1996; Lewin \& Donthu, 2005). Bunn (1993) defines this as “the buyer's perception of the significance of the buying decision in terms of the size of the purchase and/or the potential impact of the purchase on the functioning of the firm" (p.45). In CCI it appears that the importance may be reflected in the financial commitment and/or potential public exposure (positive or negative) which may be realised during this relationship.

\section{Complexity of the Investment}

Complexity is likely to be in the eye of the beholder, but should be considered given that this will have an influence on the process. Lewin and Donthu (2005) suggest purchase complexity be associated with purchase importance, and it is arguable that these will be related, as will complexity be related to task uncertainty. However, some separate discussion of this is useful. Jennings and Plank (1995) offer an in-depth discussion on product complexity in light of purchases, proposing multiple dimensions of complexity (i.e. complex in terms of function, manufacturing, specifications, applications, transactions and politics). Although Jennings and Plank study aerospace which has its obvious complexities (to me anyhow), their conclusions are applicable here. They find that as the complexity of the product increases (excluding functional complexity), the likelihood of controls also increases. For CCI, the area of complexity has not been investigated, however it is suggested that the DMU's perception of a request as complex would influence the process.

\section{Perceived Buyer Power}

A characteristic associated with factors external to the firm, but nonetheless part of the product characteristics is that of the perceived buyer power. A definition for perceived buyer power is provided by Bunn (1993) in defining this as "the buyer's perception of the firm's negotiating strength in a particular buying decision situation" (p.45). This is included in the discussion of investment characteristics given that each investment or relationship will carry with it a certain amount of power for the company. Power has 
been discussed in more depth concerning the role of the individual and therefore as part of the DMU, however it may also be associated with the investment itself, where one investment could provide the company with more power and control than another. This has not been directly investigated in CCI literature to date.

Thus, the perceived characteristics of the arts sponsorship - i.e. the investment characteristics - are likely to influence the decision process. The extent to which the sponsorship is aligned with objectives, holds "uncertainty", is important, is complex and offers more or less power to the company are all potentially important aspects of the investment.

\subsection{Conceptual Framework in Summary}

This chapter has introduced a new perspective for understanding arts sponsorship decisions. Drawing on OBB and decision-making literature it is evident both that these perspectives will lend to better understanding these decisions, and that research in this vein has not yet been conducted. More specifically, in integrating OBB/decision-making along with findings from sponsorship and philanthropy, an initial framework is proposed including the following:

- The actual processes companies undertake, and

- The roles of the following in shaping the processes:

○ Company frame of reference

○ Formalisation of policy

- Characteristics of the decision-making unit, and

- Characteristics of the investment.

Before proceeding however it should also be noted that there may be other factors at play. This initial review and incorporation of a multi-disciplinary approach should therefore be seen as a tool designed to inform, but also sharpen the researcher's "capacity for surprise" (McCracken, 1988, p. 31). 


\section{4: Research Design and Methodology}

Having clarified the research question and developed an initial framework for the research, in previous chapters, this chapter will provide the rationale for and explanation of the research design and methodology. A summary of the discussion to follow is provided in Figure 4.1.

Figure 4.1 Outline of Research Methodology

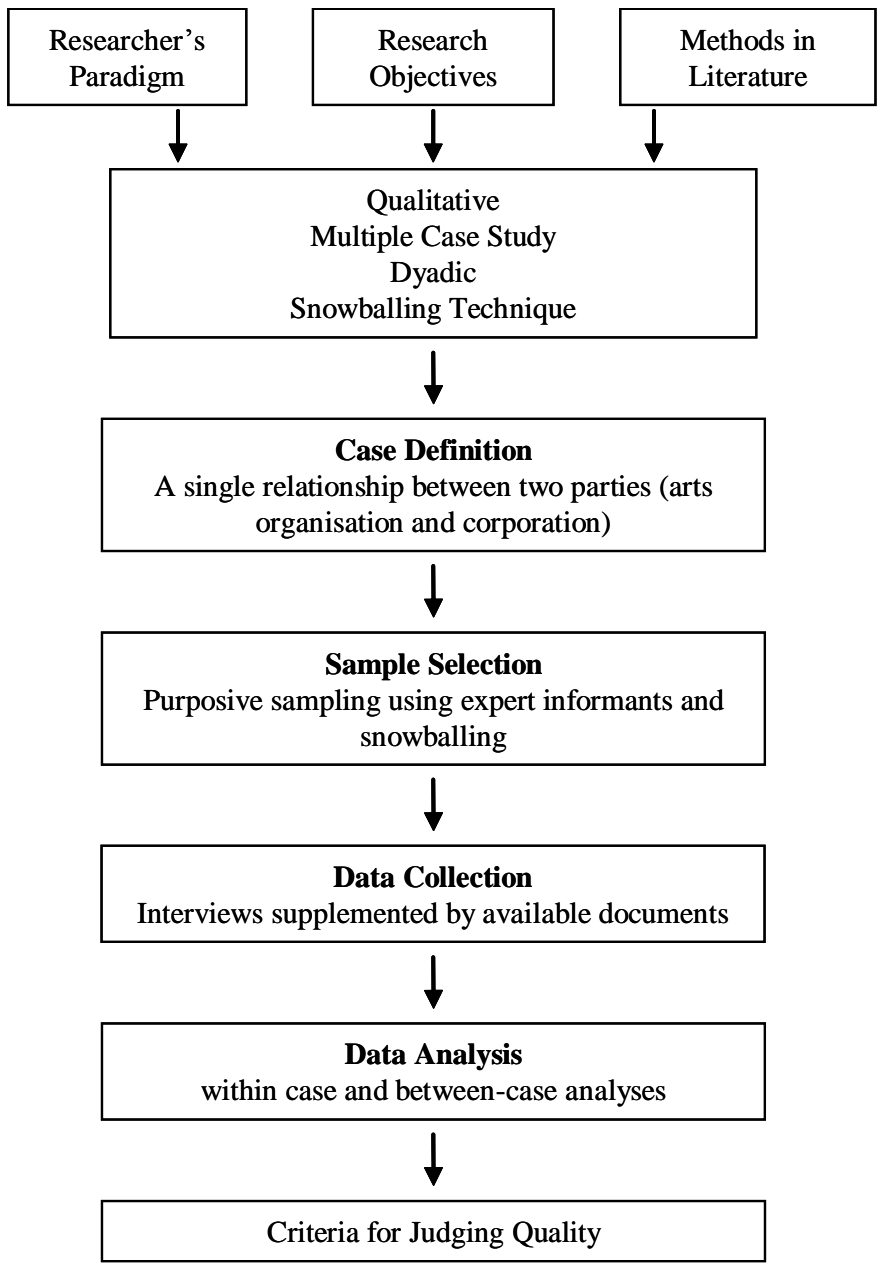

\subsection{Research Paradigm}

According to Denzin and Lincoln (2005), a paradigm is made up of three elements: the researcher's ontology, epistemology and methodology. These authors propose that adopting a paradigm will "shape how the researcher sees the world and acts in it" (p. 23). While particular paradigms may be appropriate in some research, this study took an 
approach similar to that suggested by Miles and Huberman (1994) and did not adopt a single, defining philosophy.

In terms of ontology (how a researcher views the nature of reality) the approach taken here is similar to postpositivism in that reality is seen to be imperfectly apprehendible, and researchers can only try to approximate it (Denzin \& Lincoln, 2005). The approach also shares similarity with critical theory where reality is seen as having multiple layers, with the observable layer on the surface, and further unobservable layers below this which may be better understood through research (Neuman, 2006).

In epistemology (how knowledge is viewed as it relates to limits and validity), the approach taken again holds similarity with postpositivism and critical theory, in that postpositivists seek internal and external validity, but view the findings as "probably true". For critical theory "facts require interpretation from within a framework of values, theory and meaning" (Neuman, 2006, p. 99) - a perspective which is echoed in this research.

Finally, a researcher's methodology describes how the knowledge is to be acquired. In this study, the research approach is similar to critical theory and interpretivism where the subjective nature of reality and the need to understand the social context are emphasised. Methodologies here make use of qualitative approaches and hermeneutics, and are more dialectical in nature - evolving and considering propositions and counterpropositions (Creswell, 2003; Denzin \& Lincoln, 2005).

In this study of decision-making within organisations, a qualitative approach will therefore be taken, to gather information on individuals' views and interpretations, and to attempt to gain insight into the unobservable layers of reality. Further discussion of this approach follows.

\subsection{Taking a Qualitative, Case Study Approach}

A qualitative case study approach was determined as most appropriate for this study given the paradigm discussion above, the research question and the literature examined. 
Qualitative research is distinct from quantitative research in that it positions the researcher within the context or natural setting, and through this develops an holistic, indepth picture. McCracken (1988) notes, "qualitative research does not survey the terrain, it mines it. It is, in other words, much more intensive than extensive in its objectives" (p.17). Creswell (1998) defines qualitative research as follows:

Qualitative research is an inquiry process of understanding based on distinct methodological traditions of inquiry that explore a social or human problem. The researcher builds a complex, holistic picture, analyses words, reports, detailed views of informants, and conducts the study in a natural setting. (p.15)

Denzin \& Lincoln (2005) put forward a similar definition, but bring the reader into the picture noting that through qualitative research, the researcher makes "the world visible" (p.3).

\subsubsection{Qualitative Research In Light of the Research Question}

As noted above, qualitative methods are most appropriate when exploring a social or human problem, and when an holistic picture is required to be painted for the audience. This is consistent with this study's purpose. The main research question for this study is: How do companies make decisions when considering arts sponsorship? It has been noted that organisational decisions may involve a number of people and therefore occur in a social setting. Greater understanding of this social situation and the intricacies of the decision will be best understood if the researcher directly enquires about the processes. In addition, the potentially complex processes of "how" companies make these decisions may only be understood well if an holistic picture is painted.

Authors have also given researchers more specific guidelines of when to conduct qualitative research. Creswell (2003) advises researchers to consider three things when making a choice: the research problem, their own personal experiences and the audience. In terms of the research problem, Creswell suggests qualitative research is appropriate especially when the question asks "how" or "what". This is in agreement with the research question concerned. Creswell and others also note that qualitative research is useful in theory building, as in this study. Qualitative research is useful when the topic 
needs to explored, when "variables cannot be easily identified, theories are not available to explain behaviour of participants or their population of study, and theories need to be developed" (Creswell, 1998, p. 17). Qualitative studies are "often mounted to explore a new area and to build or emerge a theory about it" (Miles \& Huberman, 1994, p. 90), and "they have often been advocated as the best strategy for discovery, exploring a new area" (p.12). As noted in the literature review, there is sufficient information to identify a gap and provide some direction for research, but there is not enough information to generate hypotheses. Based on this criterion, qualitative research is again supported.

Within qualitative research there are a number of methodologies which may be employed (Creswell, 1998), one of which is the case study. As a qualitative, multiple case study approach will be taken in this research, further exploration of case-study research now follows.

\subsubsection{Justification for Case-Study Research}

In this investigation a case-study approach was considered the best research method given the research question as well as the literature reviewed. Case-study research allows the researcher to investigate a situation, event or issue within a context and "focuses on understanding the dynamics present within single settings" (Eisenhardt, 1989, p. 534). Yin (2003) notes,

The case study method allows investigators to retain the holistic and meaningful characteristics of real-life events - such as individual life cycles, organizational and managerial processes, neighbourhood change, international relations, and the maturation of industries. (p. 2)

Yin further states that the case study method is preferred if the question is a "how" or "why" question, the researcher has no control over events, and when the focus is on a contemporary phenomenon within a real-life context. The study proposed here meets these criteria.

In terms of theory building, the use of case studies is also recommended by Eisenhardt and Graebner (2007). These authors propose that cases are more likely to generate novel theory and creative insight, more likely to result in theory which is "testable with 
constructs that can be readily measured and hypotheses that can be proven false" (Eisenhardt, 1989, p. 547), and more likely to generate empirically valid theory. Yin also notes the relevance of case studies to theory building and suggests that this should be the purpose of case studies:

Case studies ... are generalizable to theoretical propositions and not to populations or universes. . your goal will be to expand and generalize theories (analytic generalization) and not to enumerate frequencies (statistical generalization)" (Yin, 2003, p. 10).

Therefore, the case study is an appropriate method in this investigation on a number of fronts. Firstly, consistent with the argument for qualitative research, a case study approach allows for an in-depth examination of people and processes within their natural setting, here, the organisational context. Secondly, this study is theory building. While there is some knowledge on aspects surrounding arts sponsorship, there is not enough information to develop hypotheses. In this sense also, a case approach is useful.

It is also important to note the drawbacks and criticisms to a case study approach. Due in large part to the vast quantity of data which results from a case study, researchers are cautioned to be aware of developing overly complex theory which is rich in detail but lacking in simplicity; or, alternatively, theory which is too narrow (Eisenhardt, 1989). Recommendations are thus given to researchers to be rigorous, thorough and systematic in the literature review, research design, data collection and data analysis (Eisenhardt, 1989; Yin, 2003). Guidance and recommendations by these and other authors (such as Stake, 1995) have therefore been taken into account in this study.

Examining the existing sponsorship and philanthropy literature also suggests there is opportunity to approach this question using a qualitative case study method, especially in gathering data from multiple informants, from both sides of the dyad. A summary of these studies is contained in Appendix 4, and will be explored in the following.

In the sponsorship literature there is evidence of the benefits of a case study approach and in gaining responses from both sides of the relationship. Some studies have taken a similar approach, illustrating the value in this, although these studies concerned sports sponsorship (for example, Farrelly and Quester, 2003), or were concerned with a longer- 
term relationship rather than the initial decision (Ryan and Fahy, 2003; Olkkonen, 2002). However it is also noted that many studies in the sponsorship literature focus on the company rather than the dyad, many use surveys and secondary data, and the majority study sports sponsorship and use a single informant. This is understandable in many contexts, with difficulties acknowledged in seeking out multiple informants. However, this suggests that case-based research across the dyad and gathering data from multiple informants would be illuminating.

In the philanthropy literature there is a much stronger trend towards quantitative methods and the use of secondary data. Of the 25 studies noted, 20 were quantitative and 14 of these used secondary data such as income tax statistics. In addition, the focus in the philanthropy research has been to study the giving company, with only two studies having considered the dyad. Finally, when gathering data, researchers have tended to use single informants. Based on the philanthropy literature, interviews of the dyad, within a case approach and qualitative methodology appear to be lacking.

Therefore, the methodology selected here may also be justified based on the examination of studies noted in philanthropy and sponsorship literature. In terms of understanding a company's decision to support the arts, a deeper, richer picture needs to be painted, which may be achieved using a case approach and multiple informants from both sides of the relationship. This both addresses the question and addresses a methodological gap in the literature.

Given that this study is also informed by OBB literature, research from this area were also examined. Here again opportunity is evident for qualitative case study research. This is an approach suggested by Silk and Kalwani (1982), who called for more descriptive qualitative statistics in the industrial purchasing literature. These authors attempted to measure influence in organisational purchase decisions, and found conflicting results: they found that consensus was high for who was involved in the decision, but low for how much influence individuals commanded. Respondents tended to attribute more influence to themselves than other respondents did. This highlights a potential limitation in quantitative and/or single informant research, where respondents may misrepresent their or others' influence. This also suggests that rich data may be obtained through multiple informants. 
Wind and Thomas (1980) also call for research using multiple informants, suggesting specifically that research engage in circular sampling, where each interviewee indicates another person to interview, who is then interviewed and then may suggest another key informant. Multiple informants are suggested by these and other authors, and have been studied (Drumwright, 1994; Krapfel, 1985; Pettigrew, 1975; Wind \& Robertson, 1982), but there is little evidence of this approach within the CCI literature.

Given the research question, the suitability of the design and opportunity apparent within the literature, a qualitative study, using a case approach and gathering data via multiple informants from both sides of the dyad was designed. Multiple informants for each case were sought using snowballing. To further reinforce that such an approach could yield insight, a small selection of articles published in the Journal of Marketing were examined, each of which dealt with decision-making in an organisational context, cited Eisenhardt (1989), reported on a theory-building study and used qualitative methods (Drumwright, 1994; Gilly \& Wolfinbarger, 1998; Narayandas \& Rangan, 2004). These studies gave an indication of "acceptable numbers" but also illustrate the value and use of multiple informants to contribute a better understanding of organisational processes. ${ }^{6}$ The remainder of this chapter will explore this method in more detail, including the definition and selection of cases, the data collection process and data analysis.

\subsection{Case Definition and Sample Selection}

The importance of defining and bounding the case is a crucial component in any research design (Miles \& Huberman, 1994; Yin, 2003). In this study, each case was defined as a decision of arts sponsorship between a company and a non-profit arts organisation. As noted, all cases involved decisions which were in favour of engaging in the sponsorship. The cases were bounded in terms of time, by the start of the decision (asking informants when the process began), to the time just following the decision by the company to make

\footnotetext{
${ }^{6}$ Narayandas and Rangan (2004) used clinical field research over one year, to investigate buyer-seller relationships in mature industrial markets; they used a purposive sample of three dyads; within each relationship 5 - 18 managers were interviewed. Drumwright (1994) considered socially responsible buying (environmental concerns), and used an embedded multiple-case research design; the purposive sample included 10 organisations, with 21 buying processes studied in depth via 40 individuals interviewed. Gilly and Wolfinbarger (1998), in a grounded theory approach, studied 4 organisations within their purposive sample through group depth interviews (in total interviewing 40 individuals).
} 
an investment. The unit of analysis within each case was the group of individuals involved in the decision, who agreed to be interviewed.

The case definition proposed here, first relates to the fundamental research question: How do companies make arts sponsorship decisions? As Yin (2003) points out, "each case study and unit of analysis either should be similar to those previously studied by others or should innovate in clear, operationally defined ways" (p.26). This case and unit of analysis is similar to that proposed in organizational buying behaviour, but offers a point of difference to existing CCI literature.

In an early OBB paper, Wind and Thomas (1980) note the importance of selecting an appropriate unit of analysis, and propose that using an individual respondent is not enough:

The central sampling problem in research on organisational buying behaviour is the inability to select an individual respondent as an independent unit. It is necessary to select the individual in reference to the organisational structure.” (p.257)

There appears to be general agreement in OBB that single-informant studies are a sampling concern and studies should ideally use multiple informants (Bunn, 1993; Silk \& Kalwani, 1982). Furthermore, a number of studies in OBB are noted as having used multiple informants (Drumwright, 1994; Ghingold \& Wilson, 1998; Narayandas \& Rangan, 2004; Park \& Stoel, 2005). The case and unit of analysis definition here is viewed as similar to and following on from these studies.

In the CCI literature also, the use of multiple informants is not common, with reliance on single informants recognised as a limitation. Philanthropy literature is also more oriented to single-informant studies and the use of existing databases (Brammer \& Millington, 2004b; Dunn, 2004; Navarro, 1986; Wang \& Coffey, 1992). In sponsorship there are more multiple informant studies, especially in research considering the relationship aspect of sponsorship (Farrelly \& Quester, 2003a; Farrelly, Quester, \& Smolianov, 1998; Ryan \& Fahy, 2003). However the identification of these informants has not obviously employed a snowballing technique nor linked the informants with the roles they undertake in a decision. 


\subsubsection{Case Selection}

Two key questions determined the design with respect to case selection: the question of whether a single-case or multiple-case study should be employed, and the question of which cases to select.

In this study, multiple-case sampling was chosen over single case. The reasons for this relate to the research question and the desire to find a variety of processes which companies undergo. This could only be achieved through investigation into a number of relationships. Multiple-case sampling is also chosen in order to strengthen the study, providing greater confidence, reliability and stability in the findings (Miles \& Huberman, 1994; Yin, 2003).

In qualitative theory-building studies, authors are in agreement that the selection of cases should not be random, but purposive, and should consider following a replication logic whereby cases are "likely to replicate or extend the emergent theory" (Eisenhardt, 1989, p. 537). Yin (2003) proposes a replication logic whereby each case is selected "so that it either (a) predicts similar results (a literal replication) or (b) predicts contrasting results but for predictable reasons (a theoretical replication)" (p.47). Following this method, as Eisenhardt and Graebner (2007) note, the case study is like a laboratory experiment:

just as laboratory experiments are not randomly sampled from a population of experiments, but rather, chosen for the likelihood that they will offer theoretical insight, so too are cases sampled for theoretical reasons, such as revelation of an unusual phenomenon, replication of findings from other cases, contrary replication, elimination of alternative explanations, and elaboration of the emergent theory (p.27).

Yin goes on to note that achieving both literal and theoretical replication is the ideal situation. Therefore, cases were sought out which met certain criteria (a criterion sampling strategy (Miles \& Huberman, 1994)), which replicated findings within a group, and/or presented contrasting findings across groups. 
To guide this strategy, the CCI and OBB literature offered potential directions. Specifically, it has been noted that there are factors which are likely to influence the giving levels of the firm, including the industry (Brammer \& Millington, 2004b; Seifert et al., 2004), the buyclass - or specifically whether it is a "rebuy" or a new buy (Anderson et al., 1987), and the ownership of a firm (Atkinson \& Galaskiewicz, 1988). Cases were therefore sought in a number of industries; for both new and renewal situations, and for variation in ownership on the sponsoring company side of the equation.

Some characteristics were also sought in terms of the arts organisations studied. Similar to countries around the world, there are a variety of arts organisations in New Zealand. Some are professional, some are more community-based; some operate on a for-profit basis, while most operate as not-for-profits. Within not-for-profits there are also a range of funding levels, with some organisations receiving a large proportion of funding from the government, others from the private sector and others from audience support. In addition there are a range of genres of arts, including theatre, opera, orchestras, music ensemble groups, popular bands, visual arts, dance as well as festivals (be they multiarts festivals or a single genre festival). As noted, the cases included in this study were all with not-for-profit companies, who actively seek sponsorship; in addition, some variety of genre was sought.

With this strategy, it is also possible to turn to other questions to guide further case selection. Such additional questions included whether decisions were similar within a single company (hence multiple decisions within two companies are present), or similar as related to a single arts organisation (hence multiple decisions surrounding two arts organisations are present).

To identify cases, a purposive sampling strategy using expert informants and snowballing or chain sampling was employed. Expert informants were used to identify information rich cases (Miles \& Huberman, 1994). As cases were studied, additional cases were selected according to the criteria noted above and replication logic. Embedded within this was snowballing or "circular sampling" (Wind \& Thomas, 1980) within cases, to identify multiple informants. These strategies worked together to allow for cases which both met the criteria necessary and which were likely to be information rich. 
The total number of cases considered in this study is ten, with the information for each case primarily made up of responses from between 2 and 6 informed individuals. The results and analysis are largely based on these ten cases. However, in addition to this, ten individuals were identified as experts, and their responses served as a point of comparison for the findings. This number of cases examined is not dissimilar to other theory-building studies (e.g. Drumwright, 1994; Graebner, 2004).

It is important to consider the question of the number of cases deemed sufficient, in light of theory-building. As Eisenhardt and Graebner (2007) point out, when developing rather than testing theory, the cases need not be "representative" and theoretical sampling is appropriate. Similarly, Miles \& Huberman (1994) propose that this question should not be answered with statistics, but rather by considering how many cases will give the researcher confidence of analytic generalisations, and how in-depth each case is studied. Similarly Richards (2005) states:

\footnotetext{
Well-designed qualitative research projects are usually small, the data detailed and the techniques designed to discover meaning through fine attention to content of texts or images. These techniques take time and do not need large samples. (p.20)
}

In order to arrive at the final ten, as well as experts, a total of 31 individuals were interviewed in sessions ranging from $1-2 \frac{1}{2}$ hours, all of which were digitally recorded and transcribed. This allowed for the initial identification of 21 cases. Cases were then eliminated if information was only gathered from one side of the dyad and/or if the information was deemed insufficient. In total, 24 interviews contributed to 10 case studies. Each case study had responses from both sides of the dyad, with a minimum of two respondents, and a maximum of six respondents.

As noted earlier, ten interviews were further included as a panel of "experts." These interviews were from individuals who had considerable experience in the sponsorship field, working for a number of organisations over the years either in the role of senior management or as a board member. These interviews were distinguished by the range of examples of sponsorships, and insight into the decision-making process within multiple companies. The responses from this group of experts was used as a further but secondary level of analysis. 
A summary of the characteristics of the ten cases is provided in Table 4.1. As noted, there is representation of a number of industries, ownership structures, and decision statuses. In addition to these characteristics cases were sought in order to gather comparisons within companies and within arts organisations. In other words, some cases involved different sponsorship decisions within the same company, allowing for comparison to be made while keeping the company constant. Also some cases involved different companies making decisions on the same arts organisation, allowing for comparison to be made while keeping the arts organisation constant. Further details on each case will be provided in chapter 5 .

\section{Table 4.1 Case Study Characteristics}

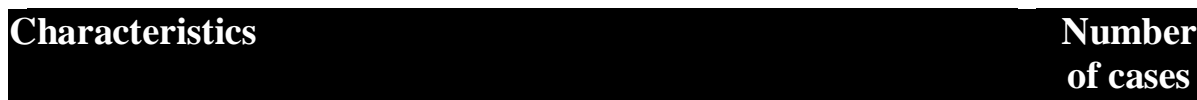

$\begin{array}{ll}\text { Industry classifications* for sponsoring } & \\ \text { companies } & 2 \\ \text { Electricity, gas, water \& waste services (Division D) } & 3 \\ \text { Transport, Postal and Warehousing ( Div I) } & 3 \\ \text { Manufacturing (Div C) } & 1 \\ \text { Professional, Scientific \& Technical Srvcs (Div M) } & 1 \\ \text { Construction (E) }\end{array}$

Ownership Status* for sponsoring companies

Publicly-held companies $\quad 5$

Privately owned 2

State-owned enterprises $^{7} \quad 3$

Genre for arts organisations

Multi-arts festival 1

Music-related 3

Theatre 1

Visual arts 2

Status of Decision (new or renewing)

New $\quad 8$

Renewing 2

* Industry categorisation is taken from the Australian and New Zealand Standard Industrial Classification, 2006 (Trewin \& Pink, 2006).

\footnotetext{
${ }^{7}$ State-owned Enterprises or "SOEs" were established in New Zealand from the mid 1980's as the country adopted free-market reforms, and the government saw advantages in the for-profit mode of operation. With this structure, government-owned services were 'corporatized.' These companies have CEOs and Boards of Directors installed, and are required to conduct arms-length management decision making (vs. political control). In addition to responsibilities later noted in this document, SOEs are required to pay tax, return a dividend to their sole shareholder (the NZ Government) and produce audited annual reports.
} 


\subsection{Data Collection \& Interview Protocol}

Initial case studies were identified using an expert informant. Based on the literature examined, and initial cases, further cases were identified in order to confirm and contrast findings according to the replication logic.

Once a case was initially identified data was collected from available corporate publications such as annual reports and websites. However, the main sources of data were face-to-face semi-structured interviews. This allowed the researcher to control the line of questioning and allowed participants to provide historical information (Creswell, 2003).

As respondents were identified either through an expert, or through a previous interview, contact was made via a telephone introduction. Following this, an e-mail was sent with further details of the project and a formal request for an interview. On occasion an interviewee would ask for additional information, which was then provided as appropriate. Some of the interviews were completed locally, while others required travel to other cities within New Zealand.

An interview protocol was developed (Appendix 5), and referred to prior to every meeting, to reinforce the main idea of the research, to provide a reminder of the required steps (such as ensuring a reference to the information sheet and consent form), and to provide a guide for the questions to be asked. The specific questions were designed to allow the researcher to be open to the emergence of new themes, while at the same time being informed by the literature.

Using a snowballing technique, multiple informants were interviewed for each dyad. In other words, during one interview, other key informants involved in the decision were identified. These individuals were then contacted and interviews arranged. Interviewees were sought from a variety of levels, from both sides of the decisions, and identified as being important informants for the decision. When interviews were collected from both sides of the decision, a good level of understanding was felt to be reached, and no further interviews were possible, the case was considered complete. Most cases contained interviews from 3 or more respondents. In two instances only two interviews were collected; however it was felt that these were of a sufficient depth that the decision was 
well understood. Interviews were digitally recorded and later transcribed verbatim. In addition notes were taken during the interviews.

When transcripts were complete, they were checked once more for accuracy against the recording, and then sent to the respondent for their perusal and comment. Small changes were requested on only two of the transcripts. Notes were also taken during the interview which were later referred to in the analysis, and served as a back-up reminder of key points.

\subsection{Case Analysis}

To facilitate the analysis, transcripts and additional information such as reports or e-mails supplied by respondents were imported into NVIVO. These sources of information were then coded prior to within and between case analysis (Eisenhardt, 1989; Miles \& Huberman, 1994).

An initial list of codes was developed prior to field work to provide guidance and a starting point. As quickly as possible following the transcription, the interviews were imported into NVIVO for coding. While the initial coding structure followed the framework identified in chapter 3, changes were made as new themes and patterns emerged, requiring new codes and/or coding structure (Creswell, 2003; Miles \& Huberman, 1994). As codes and coding structures were revised, memos were updated within NVIVO, to reflect these changes, and maintain a record of the analysis.

Once the coding was relatively complete, case analysis began, employing both a case and variable approach. According to Miles and Huberman (1994), these are two main approaches to cross-case analysis. The case approach focuses on the elements or intricacies within the case, followed by a comparison across cases. In contrast, they define a variable approach as follows:

[a] variable approach is conceptual and theory-centred from the start, casting a wide net over a (usually large) number of cases. The "building blocks" are variables and their intercorrelations, rather than cases. So the details of any specific case recede behind the broad 
patterns found across a wide variety of cases, and little explicit case-tocase comparison is done. (p.174)

These authors go on to suggest that a combination of the two approaches is most desirable, and this was sought in the analysis of the cases considered in this study. Cases were looked at in their entirety, with case summaries developed offering within case analysis. An iterative approach then was taken, with cases being subjected to further within and between case analyses.

The main component of the within-case analysis was the case summary. As data were entered and coded, and memos updated, individual case summaries were created for each case (Eisenhardt, 1989), similar to Yin's suggestion of developing descriptive frameworks for the cases. In this way a summarising document was maintained for each case throughout the initial iterative process of data collection and analysis (Yin, 2003). In situations where cases were from the same company or with the same arts organisation, this was noted, but the case summary remained distinct for each individual case. These summaries included thoughts on the case, details on the companies involved, matrices relating to the initial framework or new themes which had emerged, as well as a conceptual drawing of the decision (Yin, 2003). The case summaries were consistent in their format to allow for easier between-case analysis.

Between-case analysis occurred throughout the data collection phase, helping to inform the selection of further case studies, and further refine and inform codes and theme development. However, the bulk of the between-case analysis occurred once all case summaries were relatively complete. Between-case analysis comprised a number of tactics, and comparisons in order to "improve the likelihood of accurate and reliable theory" (Eisenhardt, 1989, p. 541):

- Looking for similarities and differences between cases, noting key themes that emerge. Matrices and tables were utilised for this process to enhance comparison.

- Explanation building (Yin, 2003): An initial proposition was put forward, then compared against cases, and revised iteratively.

- Logic models (Yin, 2003): A tentative model of how things work was developed and then the data was used to test against this. 
As is recommended for theory building, analysis was highly iterative. Continual movement between the data and the themes was characteristic of this process.

\subsection{Criteria for Judging Quality}

This study was developed with a mind to ensuring construct validity, internal validity, external validity and reliability (Yin, 2003). While reliability and generalizability (external validity) play what Creswell refers to as a "minor role" in qualitative studies, construct and internal validity "is seen as a strength of qualitative research" (Creswell, 2003, p. 195) and is used here to refer to the accuracy of the findings. Nonetheless, all four of Yin's proposed criteria are considered.

Construct validity refers to whether or not the indicator measures the construct. For construct validity to be present, multiple measures must operate in a consistent manner (Neuman, 2006). This is noted as potentially problematic in case research, but possible to attain through the use of multiple sources of evidence, establishment of a chain of evidence and having key informants review the draft report (Creswell, 2003; Yin, 2003). In this study, the use of multiple informants concerning each case study is a strength of the research, and contributes to construct validity. In addition, when available, additional information sources were used such as websites and annual reports.

As noted, providing informants with a draft report enhances construct validity. Consistent with this recommendation, a summary of findings was sent to respondents. This summary provided a short description of the study's purpose and methods, but focused on the themes found in the study to that point. This was completed in the final stages of the $\mathrm{PhD}$, although in enough time to incorporate responses. The summary was sent with a request for feedback; the main input sought was noted as whether they felt the report "rang true" to their experience. To date few comments have been received, although those received indicate the results resonate with respondents.

While internal validity is more important in case studies seeking causal relationships (Yin, 2003), Yin proposes that this be broadened to include consideration of inferences made in the research. The tactics here relate to the data analysis. Therefore, internal 
validity was achieved in this study through techniques including pattern-matching, and explanation building (Yin, 2003).

External validity, the ability to generalise findings to the wider world (Neuman 2006), was also addressed in this study through the use of a replication logic as noted above (Yin, 2003). It is important to note however, that the understanding of external validity or generalisability, as in quantitative studies, is very different to that in a case study (Creswell (2003, p. 195) suggests it takes only a minor role). Yin states this clearly noting that the "problem lies in the very notion of generalising to other case studies. Instead, an analyst should try to generalize findings to "theory"' (2003, p. 38). Here, the cases are selected to give a variety of results, and to generate theory, not to be representative of other cases. To achieve generalisation the theory must later be tested (Yin, 2003, p. 37).

In considering reliability the researcher wants to feel confident that another researcher, conducting the same study in the same manner would find the same findings. "The goal of reliability is to minimize the errors and biases in a study" (Yin, 2003, p. 37). This was achieved through careful documentation of the process, and adherence to procedures. The data collection was highly systematic, the protocol was documented and utilised, and a case study database (NVIVO) was present. All of these elements contribute to reliability (Yin, 2003).

This chapter has provided justification for and an explanation of the research design undertaken in this study. It has highlighted the appropriate selection of a qualitative, case-based approach, and has further elaborated on this, noting the selection of the cases as well as the selection and use of multiple informants from the dyad. This chapter has also detailed the process of data collection and analysis, noting the importance of a systematised and thorough approach. The following chapter will delve into the results of the research - a result of the application of the above research design. 


\section{5: Analysis of Data}

The purpose of this chapter is to provide an examination and analysis of the data, prior to the discussion and theory development (chapter $6 \& 7$ ). This chapter will give evidence of the depth of understanding of the cases, providing the reader exposure to the richness of the stories. This chapter lays the groundwork for chapter 6 in which the results will be discussed within the context of the literature. This structure is consistent with that proposed by Perry (1998) and other authors of theory-building from case studies. Authors have noted the trade-offs which may need to be made between orienting towards the theory and providing the richness of the story (Eisenhardt \& Graebner, 2007; Yin, 2003). Here, without the space restrictions of a journal article, attention is given to the data and the stories, to be followed by discussion in the context of the literature, and theory development.

This chapter will first provide an overview of the cases and the group of experts from which data was gathered. The analysis of the results will follow, according to the themes previously identified and as illustrated in Figure 5.1.

As noted, the data collected for this study are from arts organisations in New Zealand, and their New Zealand-based sponsoring companies. All of the cases examined are instances in which a sponsorship was agreed to, and the focus of the examination was the decision-making process leading to agreement.

Figure 5.1 Initial Framework for Research

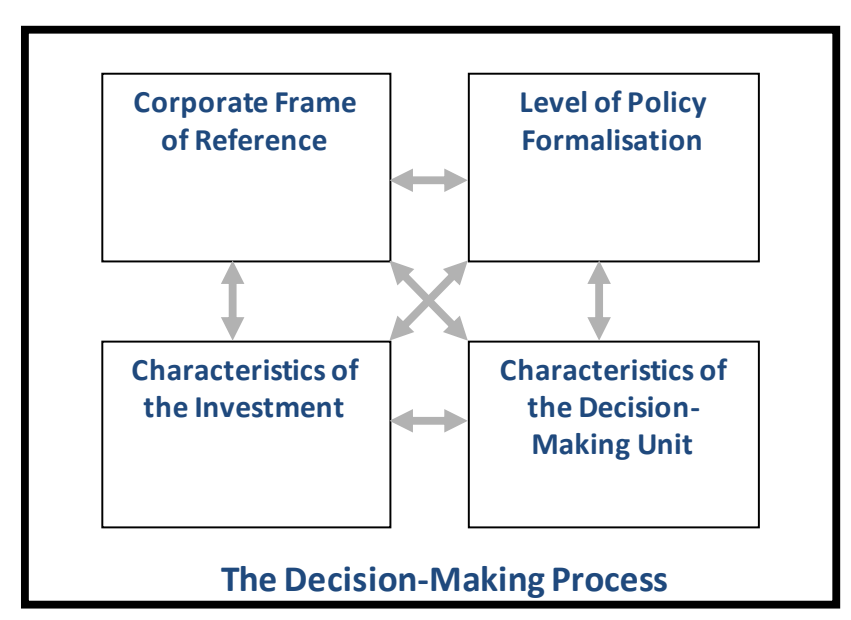




\subsection{Case Descriptions}

Ten cases were included in this study, each case being a story unto itself. In order to provide some element of the stories, while respecting confidentiality and avoiding repetition, a short description of each case is included in this section. In these descriptions, individuals will be referred to by a common role. As role descriptions and titles varied across companies, consistent titles were given to individuals with relatively consistent roles. These are summarised in Table 5.1. The group of experts will also be described. While the analysis focused on the cases, the responses of the experts were also used as a point of comparison.

As noted (chapter 4), respondents were sought via snowballing, aiming for rich cases to provide similarities and differences. All companies interviewed had made a positive decision to support an arts event, and cases examined included only those for which individuals on both sides of the decision could be interviewed. The resulting cases included new and renewing investments, with companies representing a variety of industries, company size and ownership patterns. While further detail follows in this chapter, a summary table of the cases and some of their characteristics is included in Table 5.2. ${ }^{8}$

Table 5.1 Title Abbreviations

\begin{tabular}{|l|l|}
\hline Abbreviation & $\begin{array}{l}\text { Assigned role } \\
\text { Company Sponsorship Manager: Individual within the sponsoring company } \\
\text { whose main role is to manage sponsorship and sometimes broader CCI-related } \\
\text { investments. }\end{array}$ \\
\hline CMM & $\begin{array}{l}\text { Company Marketing Manager: Individual within the sponsoring company } \\
\text { whose main role is assigned to the category of Marketing. Their role may or } \\
\text { may not include management of sponsorships. }\end{array}$ \\
\hline CCE & Company Chief Executive (of sponsoring company) \\
\hline ACE & Arts Organisation Chief Executive \\
\hline ABM & Arts Organisation Board Member \\
\hline
\end{tabular}

\footnotetext{
${ }^{8}$ Limited data on case characteristics are able to be provided given the relatively small population of New Zealand and the need to protect the confidentiality of the respondents and their organisations.
} 
Table 5.2 Case Characteristics

\begin{tabular}{|c|c|c|c|c|}
\hline Case & $\begin{array}{l}\text { Total } \\
\text { respondents } \\
\text { included in } \\
\text { analysis }\end{array}$ & $\begin{array}{l}\text { Respondents } \\
\text { from sponsoring } \\
\text { company }\end{array}$ & $\begin{array}{l}\text { Respondents } \\
\text { from arts } \\
\text { organisation }\end{array}$ & $\begin{array}{l}\text { Renewing } \\
\text { investment } \\
\text { or new? }\end{array}$ \\
\hline $\mathbf{A}$ & 3 & CSM & $\mathrm{ABM}, \mathrm{ACE}$ & renewing \\
\hline $\mathrm{B}^{\circ}$ & 3 & CSM, CCE & $\mathrm{ACE}$ & renewing \\
\hline $\mathrm{Co}^{\circ}$ & 6 & CSM, CCE & $\begin{array}{l}\mathrm{ACE}, \mathrm{ABM}, \\
\text { Other Arts } \\
\text { managers }\end{array}$ & new \\
\hline $\mathbf{D}^{\mathbf{a}^{\star}}$ & 3 & CSM, CMM & $\mathrm{ACE}$ & new \\
\hline $\mathbf{E}^{\square}$ & 2 & CSM & $\mathrm{ACE}$ & new \\
\hline$F^{\bullet}$ & 4 & CSM, CMM & $\mathrm{ABM}, \mathrm{ACE}$ & new \\
\hline $\mathbf{G}$ & 2 & CMM & $\mathrm{ACE}$ & new \\
\hline $\mathbf{H}$ & 4 & CCE, CMM & $\mathrm{ACE}$ & new \\
\hline$J^{\star}$ & 2 & CMM & $\mathrm{ACE}$ & new \\
\hline $\mathbf{K}$ & 3 & CSM & $\mathrm{ABM}, \mathrm{ACE}$ & new \\
\hline \multicolumn{5}{|c|}{$\begin{array}{l}{ }^{O} \text { Case } \mathrm{B} \text { and } \mathrm{C} \text { are within the same company. } \\
\square \text { Case D and E are within the same company. } \\
\text { Case B, F and } \mathrm{K} \text { share the same arts organisation. } \\
\star \text { Case D and J share the same arts organisation. }\end{array}$} \\
\hline
\end{tabular}

\section{Case A}

This case was a decision to renew an arts investment within a company which in the past had undergone significant change in terms of amalgamations and takeovers, and within a company which had limited experience in arts sponsorship. At the time of renewal the CSM had to balance other responsibilities, and time constraints, with the need for due diligence. In considering the investment, the main question seemed to be "should we keep the status quo?" The investment was seen as potentially helping the general reputation of the company within government, staff and the wider public, but more information was needed. The CSM sought out information on the quality of the investment via the media, informally sought opinions from staff but most importantly, held discussions and established a rapport with the ACE. Ultimately, the CSM felt this was a good investment, recommended it to her superior, and a further recommendation was made to the CCE and board which was approved. 


\section{Case B}

This case was another renewal decision, within a company holding a highly formalised and well-publicised approach to CCI generally, and with considerable experience in arts sponsorship. A long history between the two companies, had established a relationship between the arts organisation and the CSM as well as the CCE. However, when the CSM analysed the investment, she made a recommendation not to renew. At this point the CCE became involved, and encouraged the ACE to re-work the proposal to reflect greater value for money. The revisions followed and the CCE felt this better reflected the needs of the company. The recommendation was then made to the Board who approved the decision. Following approval, the CSM took on a greater role, negotiating benefits and leveraging with the arts organisation.

\section{Case $C$}

While within the same company as case B, this case was for a sponsorship investment new to the company. In this case, the ABM's local business knowledge led him to the initial idea that a sponsorship with this company would be mutually beneficial. The ABM informally proposed the idea to the CCE, with whom he had some rapport. The CCE immediately expressed interest and enthusiasm for the investment, feeling that it fit with the company's objectives and need to establish a presence in a particular location. At the same time the CSM had a rapport with the ACE, and open discussions and negotiations occurred between the two. Other arts managers became involved in helping the CSM to develop the case for support within her company. Eventually the CSM and CCE made a recommendation to the Board, which was approved.

\section{Case D}

This case was in a company deemed to have a highly commercial orientation to CCI, and a long history of arts sponsorship investments. Sponsorship requests were typically subjected to a defined evaluation process with clearly stated criteria in this company. While this specific investment was also subjected to this policy, the approach was initially informal, following a brief introduction between the ACE and CSM at a sports event. A formal proposal followed from the ACE, and the CSM saw the benefit. The CSM then worked to convince the appropriate marketing manager, who was at first not supportive. However, this manager was eventually convinced, and also became enthusiastic. Higher levels were involved and their support was sought. Once a general 
level of consensus was gathered, a "gentleman's agreement" was made between the CSM and ACE. A formal recommendation was eventually submitted to the CCE, and this was subsequently approved (much to the relief of the CSM).

\section{Case $E$}

This case was within the same company as case D and followed a similar pattern in many respects. The approach was made by the ACE directly to the CSM, following an informal meeting at a social function. The CSM again gathered support within the company based on the fit between marketing objectives and the sponsorship investment. Once the CSM felt that enough justification for the investment was present, the proposal was sent to higher levels. However, the CCE was aware of a shift in the brand strategy, and requested that the investment terms be renegotiated. A series of negotiations eventually resulted in the investment being approved, although not exactly to the terms desired by the ACE.

\section{Case F}

In this case, the company had clear procedures and policies with respect to sponsorship and CCI, and a firm belief that these activities were part of their role in society. Internally, sponsorships were managed by a CSM who sat within the marketing area. Prior to the decision studied, the ACE had approached the company unsuccessfully. In a last minute effort, the $\mathrm{ABM}$ made a second request directly to the $\mathrm{CCE}$, with whom a rapport had previously been established. Agreement was quickly secured. Following this agreement the CSM and CMM worked with managers in the arts organisation to ensure the benefits were adequate for the organisation.

\section{Case G}

This case took place in a privately-owned company where the CMM was responsible for sponsorship activities. Respondents noted that their CCI decisions stemmed primarily from a desire to give back to the community. The investment under consideration benefitted from the CMM's knowledge and interest in the arts sector, as well as his knowledge of the arts organisation in particular. At the time of the request, the company was looking to establish a greater presence in a particular geographic location, which involvement with the arts organisation would facilitate. While public relations experts 
recommended the company not engage in the sponsorship, the CMM felt that it would benefit the company by appealing to their customers. Informal discussions with other individuals within the company ensued and a final decision was made. The specific benefits to the company were developed post-decision. (Note that this company requested no direct quotes be replicated in this thesis, although the responses were certainly able to be thoroughly analysed.)

\section{Case $\mathrm{H}$}

This case occurred in a large publicly-traded company, with a strong sense of social responsibility, formally noted in company documents. Prior to the investment being put forward, the company had attempted other arts sponsorships, but felt they were unsuccessful. The initial pitch came via an ABM who also had a business relationship with the company, and felt the sponsorship would be beneficial. The ABM made an initial call to the CCE, followed by a short discussion between the CCE and other key managers. This discussion seemed to solidify the opportunity in terms of the fit and the value which they felt the company could bring to the arts event. A formal proposal by the arts organisation was made, and meetings with the arts organisation's project manager were felt to be important in assuring the company of success. However it appeared that decision had largely been made previous to these meetings.

\section{Case J}

This decision took place in a privately-owned company. The company and its owners had a well-known and strong view that part of their role as a company was to make a contribution to the community. The business that they were in was also acknowledged as one which at times suffered from a poor reputation in the public eye, and which relied on having good relationships with key decision-makers in the community. While this background was interesting in the case, more important was that there was an existing relationship between the ACE and the owners of the company. This relationship was at a business level, but had established a level of trust between the parties. The request was made from the ACE directly to an owner, who then approached other owners. The owners quickly agreed to the sponsorship, and with the decision made, authority was given to the CMM to develop benefits around the investment, including events suitable for hosting stakeholders. 


\section{Case $K$}

This case occurred in a highly commercially-oriented company, looking to gain presence in a particular geographic location. An ABM initially saw the opportunity between the company and the arts organisation, and made an initial pitch through managers at a second company integrated in the case company's operations. Hence, the idea came via an e-mail to the CMM, but not from the arts organisation at all. The CMM's personal experience of the arts organisation led them to feel intuitively that the opportunity was a good one. A commercial justification based on comparative advertising rates was made which further justified the investment. Considerable internal discussion was necessary to gain final approval within the company. These discussions benefitted from the CMM's strongly-held view of the benefits of the investment in terms of fit and value-for-money. Time was tight, but eventually approval was sought and the CMM managed the investment.

\section{Experts}

While interviews were held with individuals connected to the cases, some respondents had a greater amount of experience and knowledge concerning this topic than others. These were classified as a group of "experts". In addition to their wealth of experience in multiple investments, they also spoke about a variety of sponsorship relationships beyond identified cases. The profiles of these individuals varied, some of them held board positions with multiple arts organisations as well as corporate boards, some had been involved at the $\mathrm{CE}$ level with a number of arts organisations who had over time requested considerable sponsorships, and some were more oriented towards senior-management experience within the corporate sector, making decisions on allocating investments. The responses of these experts were thus coded to the themes and the case studies as appropriate, as well as a general node identifying them as experts, allowing their comments to be considered separately. While the analysis which follows focuses on the cases, responses from experts were also considered, though to a lesser extent.

The remainder of this chapter will discuss the results of the case and expert analysis. This analysis was conducted as identified in chapter four, with consideration of the initial framework, but also with an open mind to other emerging themes, topics, linkages, patterns and insights. Therefore, while the remainder of this chapter will be organised 
according to the themes in the initial framework, this is not intended to imply that a restrictive approach was taken. In addition, it is noted here that this chapter presents the results, but purposefully does not discuss the results in terms of the literature; this will be the subject of chapter six.

\subsection{Frame of Reference}

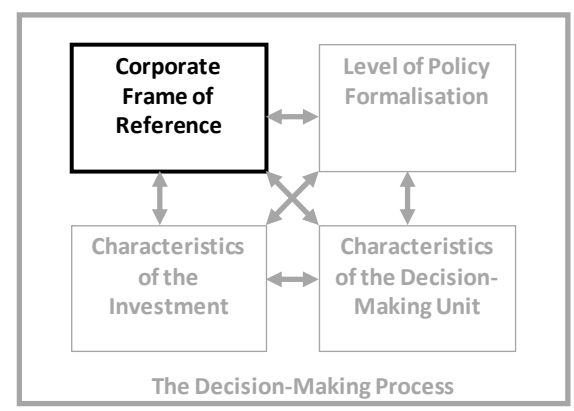

Decisions studied did not exist in a vacuum but were made within a wider context, which included individual perceptions of sponsorship or CCI broadly, the perceived acceptance of these actions by the community, and the more specific operations of the business. The frame of reference was an a priori theme included in the initial framework, proposed as loose "rules" for situations concerning CCI and sponsorship.

Information used to analyse decision-making with respect to the frame of reference centred on publicly available information, responses from individuals within the companies, and responses from arts organisation individuals relating to their perception of the sponsor's frame of reference. Three categories emerged from the analysis including statements reflecting the following:

(1) an external frame of reference, meaning acknowledgement of the context external to the company which played some part in the decision-making process;

(2) an internal frame of reference, referring to the specific context within the company which played a part in the decision-making process; and

(3) a personal frame of reference, meaning acknowledgement of a personal philosophy with respect to CCI and arts sponsorship. 


\subsubsection{External Frame of Reference}

The external frame of reference included forces external to the company, but which were observed as important for setting the stage for the decisions. The interviews suggested three areas were important in shaping decisions: (1) expectations of New Zealand society, (2) perceptions of sponsorship in the business community, and (3) industry characteristics.

\section{Expectations of Society}

In terms of the expectations of society, characteristics of the New Zealand business society were noted especially by the experts as important in shaping the climate of arts sponsorship decisions generally. Some respondents expressed that New Zealand does not have a strong culture of arts sponsorship (frequently compared to the United States), and attributed this to historic government support of the arts. They felt New Zealanders were accustomed to the government supporting the arts, and therefore would not see it as their role as an individual or as a company.

On the other hand, one respondent made a connection to New Zealand society vis a vis CCI, expressing that New Zealanders would be critical of companies which were too successful, but would be more comfortable with companies doing well if they were seen as contributing back to the community:

When you're owned by the people of New Zealand you need to be seen to be creating value in this country ... something deep in the New Zealand psyche that people and organisations don't mind you being successful providing they see you putting something back into the community.

These findings pointed to the importance of a generalised underlying philosophy within a society concerning CCI and arts sponsorship, with societal expectations filtering through to individuals, shaping decisions and strategy within the company. Therefore consideration was given to what knowledgeable and influential individuals thought of arts sponsorship. 


\section{Perceptions of arts sponsorship}

It was recognised early on in the study that a key underlying force for arts sponsorship decisions is the perception of sponsorship within the wider business community: how business people feel and think about sponsorship. The analysis suggested that respondents acknowledged sponsorship as difficult to measure, subjective, emotional, sensitive and discretionary. However, the analysis also revealed that respondents were aware of the positive benefits of sponsorship.

Firstly, a level of uncertainty towards sponsorship was noted, and was further queried to understand why, and what effect this had on the decision processes. Table 5.3 provides a representation of this analysis. As is evident, the statements settled into 2 main groupings (column 1) describing sponsorship as 1) sensitive and subjective, and 2) difficult. Further analysis suggested that the key reasons (column 2) for these perceptions included the difficulty of measuring tangible outcomes, the potential for decisions to rest with high level executives, and the concerns around the impact to the company's reputation. Additional comments which occurred less frequently were comments related to the complexity of the arrangements, the number of individuals potentially involved, and the historic perception of sponsorship as being a "hand-out." All of these opinions and statements combined to form a perception of sponsorship which then entered into the decision process.

Queries into the data of how these perceptions were viewed to impact the decisionmaking process revealed a number of effects (column 3) (note that these individual effects are not specifically tied to descriptors in column 1 and 2). The most common findings were that these characteristics were seen by company respondents to necessitate 
Table 5.3 Perceptions of Sponsorship

\begin{tabular}{|c|c|c|}
\hline $\begin{array}{l}\text { Described } \\
\text { characteristics of } \\
\text { sponsorship }\end{array}$ & $\begin{array}{l}\text { Why do they feel sponsorship has } \\
\text { this characteristic }\end{array}$ & Effects noted on decision-making \\
\hline $\begin{array}{l}\text { Sensitive and subjective } \\
\text { (4 respondents out of } 12 \\
\text { company respondents) } \\
\text {... there's an awful lot } \\
\text { of judgement. } \\
\ldots \text { there are just so } \\
\text { many feelings about it. } \\
\text {... people ... have } \\
\text { opinions... no one has } \\
\text { an opinion about an ad. }\end{array}$ & $\begin{array}{l}\text { Concern for reputation of the company } \\
\text {.. If a customer stopped using you, } \\
\text { people would be more ... generous } \\
\text { about trying to figure out why you } \\
\text { might have left their business or } \\
\text { something ... whereas in sponsorship } \\
\text { you kind of get slated because it's a } \\
\text { very sensitive area. } \\
\text { Negative associations with personal } \\
\text { decisions } \\
\text {.. a lot of sponsorship opportunities } \\
\text { are pursued through personal contacts } \\
\text { and networks and it's very important } \\
\text { to try and formalise those as quickly } \\
\text { as possible. } \\
\text { Change to a commercial focus from } \\
\text { philanthropic } \\
\text { Sponsorship has morphed a lot in a } \\
\text { short time ... some people still think } \\
\text { it's just philanthropy. And so they } \\
\text { want to know what the business is } \\
\text { being philanthropic about. }\end{array}$ & $\begin{array}{l}\text { Development of statistical / less } \\
\text { subjective analysis to show } \\
\text { accountability. } \\
\text { We have to be accountable for that } \\
\text { spend. We have to be able to go into } \\
\text { the [CCE] and say, hey, actually this } \\
\text { [amount of money] did deliver a } \\
\text { result. } \\
\text { Need to assess quality of arts } \\
\text { organisation } \\
\text { You have to be extremely careful } \\
\text { about the quality of the counter-party } \\
\text { and have some real assurance around } \\
\text { their ability to deliver. }\end{array}$ \\
\hline $\begin{array}{l}\text { Uncertain } \\
\text { (9 respondents) } \\
\text {.. sponsorship is a kind } \\
\text { of soft and squishy } \\
\text { science. } \\
\text {...the sponsor doesn't } \\
\text { have that much control } \\
\text { over everything and } \\
\text { therefore it is a slight } \\
\text { trip into the unknown. } \\
\\
\text {... it's very hard } \\
\text { actually top prove that } \\
\text { sponsorship works. } \\
\text {... you're dealing there } \\
\text { with intangibles. }\end{array}$ & $\begin{array}{l}\text { Difficulty of measurement } \\
\text { You can't do causal effect. . You } \\
\text { can't always quantify it in the way } \\
\text { accountants would like. } \\
\text { Involves more individuals } \\
\text { there is a whole team of people that it } \\
\text { takes to pull something like this } \\
\text { together. Whereas if you are placing } \\
\text { ads, it's easier } \\
\text { Lack of understanding \& skills } \\
\text { We're not taught how to think about } \\
\text { sponsorship. } \\
\text { There [are] very few companies that } \\
\text { actually have it as a core focus to } \\
\text { what they do ... [it's] discretionary. }\end{array}$ & $\begin{array}{l}\text { Need for someone who understands it } \\
\text { in DMU } \\
\text { those negatives tend to prey on } \\
\text { someone in the decision-making role } \\
\text { and they will say oh no we don't want } \\
\text { to do this we'll do that. They will } \\
\text { ignore all the positives and they'll just } \\
\text { find a little negative ... [there are] } \\
\text { people in the industry that ... } \\
\text { understand it. The majority of people } \\
\text { don't actually understand it. They } \\
\text { don't understand how they make it } \\
\text { work and they take the safe [option]. }\end{array}$ \\
\hline
\end{tabular}


the involvement of the Chief Executive and/or Board of Directors. The second most noted effect was that this perception meant there was greater pressure to demonstrate the commercial benefits of the sponsorship, ensuring a level of rigour in measurement and justification. The issue of quality also arose: in the context of a sponsorship arrangement, in which uncertainty may exist, some respondents felt that it was crucial to have an assessment of the quality, including the arts organisation's ability to deliver. Further discussion of quality is contained in section 5.5.

In terms of the positive perceptions, most respondents recognised and discussed the benefits of sponsorship. The benefits were typically noted in the context of discussing an evaluation stage in the decision process, and included sponsorship being described as good value for money, and providing both access to key decision-makers and image building opportunities. The presence of a positive view is not unexpected as all cases had agreed to engage in the partnership. Further examination of the perceived benefits will be examined in greater depth in section 5.5.

It was noted that especially at the CE level, some respondents were very positive of the benefits of sponsorship, and did not see any element of uncertainty. One respondent stated:

... how do we measure it? We've got no idea. We don't care. . we just make a judgment that we should be spending some of our money in these kind of spaces.

[interviewer:] Why is that?

because it makes a difference to society.

The statement above was not atypical. Firstly, the other respondent in the same organisation had a similar view, suggesting the influence of a company-specific frame. Similar views were evident in other companies expressing a more philanthropic orientation to their decisions; they noted uncertainties, but they were not very concerned about uncertainties.

There were also differences noted by level of respondent. In three companies (comprising 4 cases) interviews were captured from both the CCE level and the CSM/CMM level. In 
all of these cases, the CSM/CMM level managers focused more on the difficulties of measurement and uncertainty surrounding sponsorship, while the CCE's, although noting difficulties in measurement, unanimously expressed that this sponsorship was clearly justified as a positive contribution to society.

Another comparison of note is that these perceptions and views were largely taken from respondents within companies and the experts. Respondents within the arts organisations did not talk of sponsorship's uncertainty, difficulties or risks and sensitivities. This is not to say that these individuals did not see these perceptions, but suggests that this ambiguity was not top of mind, compared with company decision-makers.

Thus, a level of ambiguity associated with arts sponsorship appeared evident, and appeared to influence the decision process, especially in establishing the decision-making unit, and evaluating the investment. However, it was noted that the views of higher level managers and/or a company frame favouring a more philanthropic orientation may "trump" this uncertainty.

\section{Industry Characteristics}

In considering the frame as related to the industry, cases were categorised into industry classifications, according to the Australian and New Zealand Standard Industrial Classification (Trewin \& Pink, 2006). Cases were sought to seek replication within similar industries, as well as representation from a number of industries, resulting in the following categories being included:

C: Manufacturing (3 cases)

D: Electricity, gas, water and waste services (2 cases)

E: Construction (1 case)

I: Transport, Postal and Warehousing (3 cases)

M: Professional, scientific and technical services (1 case)

Analysis into the influence of an industry frame suggested that rather than industry being a determinant, the company strategy was the stronger influence. The following discussion provides further explanation leading to this conclusion. 
Membership in a particular industry was expected to lead to some similarities in decision-making. In industries in which the support of government was important, it was generally expressed by respondents that the sponsorship opportunity would not only fulfil their obligations to be a contributing part of society, but also allow the company to demonstrate its support of the community to government officials and leaders. One respondent stated:

the [arts event] allows us to target top tier, local government, and central government who are very important stakeholders to our company.

Another noted, "we have to communicate with [government] to say that we are fulfilling our mission."

Another group of decisions emerged for companies in which the customers were the key stakeholder group identified for sponsorship use. In these decisions, the sponsorship was evaluated more on the basis of how the arts event's market would match the target market of the company, and how the arts event brand would contribute to the company's brand. For example, one respondent noted:

whatever we associate ourselves with from a sponsorship perspective needs to be very aspirational for our target consumer. So that for us was absolutely key that the sponsorship proposal delivered to those key concerns that we had from a branding perspective.

Taking this into account, it was evident that if the industry had an influence on how the sponsorship was evaluated, it was likely to be based on which stakeholders were viewed as most important and most appropriately reached via sponsorship. In the results, a number of stakeholder groups were identified, including staff, media and business partners. However, government and customers were the two most frequently noted stakeholder groups, identified as potential markets to which the sponsorship should be linked.

In looking at the stakeholder groups vis a vis industry groupings, a clear delineation was not found. One company generally more concerned about government, shifted its 
evaluation to business clients, as the company strategy had taken a shift towards looking for greater presence in a single market. Another company, while categorised in an industry with government as a key stakeholder, clearly saw the customers as the most important stakeholder. Again, this company was also seeking out greater presence in a new market. This suggested that while the industry may dictate the stakeholders which they focus upon in terms of sponsorship, the company strategy at the time may well shift this emphasis.

The second element expected to be related to industry surrounded the idea of reputation. Three companies (4 cases) noted their concern for the reputation of their industry with the public:

\footnotetext{
I think that the perception [of the industry is that we are] making a quick buck, not contributing. ... [there are] those sorts of things in people's minds - so what are you really here for?"
}

In these cases respondents expressed that sponsorship may assist in putting the company in a better light. While this line of thinking was evident in a number of cases, in most cases the link with reputation management was not associated with arts sponsorship.

This discussion of reputation, does suggest a return to the emphasis on government stakeholders, and a consideration of the idea of CCI as a type of insurance. It was clear that respondents, in putting the sponsorship together with the emphasis on government stakeholders, were concerned about their reputation with the government, and felt that contributing to the community would make operations run more smoothly. The association made in a number of cases concerned with government stakeholders proceeded along the following lines:

(1) Sponsorship of the arts would demonstrate support of the community, which would assist in maintaining a positive reputation with the government.

(2) Sponsorship of the arts would demonstrate support of the community, which would then make the community more tolerant, allowing the business to function more smoothly. 
Therefore, these results suggested that the industry was not a large influence on the decision, but point to the importance of considering stakeholders and the use of sponsorship as a reputation management tool. In addition, this analysis suggested that the more important factor in considering sponsorship is the company's strategy. This is considered next, as part of the internal frame of reference.

\subsubsection{Internal Frame of Reference}

The internal frame of reference includes the characteristics of the company in which respondents are operating, and which appear to set the stage for decisions. Analysis of the interviews and additional documents led to a number of sub-categories:

(1) a company philosophy of giving;

(2) the effect of ownership; and

(3) the effect of the current context and strategies of the company.

\section{A Philosophy of Giving}

In trying to determine whether a type of company philosophy exists surrounding CCI and arts sponsorship, both formal statements and comments by respondents were considered. Formal statements made by the company, concerning CCI, or generally "good corporate citizenship", were considered to indicate an aspect of the frame of reference within which individuals operate. It was expected that the expression of a company as more oriented to commercial or philanthropic goals would influence the actions of individuals within the company considering sponsorship. For example, the following is a statement made on the website of a company not included in the study, reflecting a formally stated desire by the company to engage in community partnerships, for the benefit of the community and the company:

[our] success as an energy company depends on the support of people in many communities. We are determined to earn that support, not just through excellence in meeting our customers' energy needs, but also by playing an active and important role in community life.

As we develop partnerships in those situations where societal needs intersect with business objectives, powerful results become possible. 
And with strong results, come stronger communities from which we all benefit. (Petro-Canada, 2009)

The idea of good corporate citizenship, and the importance of contributing to society was expressed as part of a corporate strategy in all cases studied. This is not surprising given that all companies considered were engaged in this type of activity. Drilling down to the idea of sponsorship as part of "good corporate citizenship" the link was expressed as part of a strategy in all but one case. Further investigation revealed that most respondents felt that arts sponsorship in particular did contribute to good corporate citizenship.

While being a good corporate citizen was important for all of the companies, a range was evident in which companies could be categorised as relatively more oriented to commercial versus philanthropic goals in terms of their decision-making. The range is represented in Table 5.4, and described below.

As is evident in Table 5.4, three groupings of orientation were revealed: commercial, philanthropic and a commercial-philanthropic balance.

(1) Commercial orientation: Three cases appeared to be more commercially oriented (cases D, E and K; two companies). In each of these companies, formalised statements reflected commercial goals, and discussion of sponsorship as linked to "doing good" in the community was limited. This formal stance was echoed in the interviews, with respondents emphasising commercial goals such as brand exposure and return on investment. In terms of other characteristics, both companies were publicly held, and the decisions went through a process which could be characterised as highly formalised, with emphasis on the exposure generated, brand fit and return on investment. In addition, in these cases the Marketing Manager assumed a crucial role in the DMU (decision-making unit). 


\section{Table 5.4 Company Orientation to Commercial vs. Philanthropic Decisions}

\begin{tabular}{|c|c|c|c|}
\hline Case & Categorised as & Example statement & Characteristics of the decision(s) studied \\
\hline A & $\begin{array}{l}\text { Commercial \& } \\
\text { Philanthropic }\end{array}$ & $\begin{array}{l}\text { In most instances we do it purely to be philanthropic. To be a good } \\
\text { community, corporate citizen. } \\
\text {... But we also have to balance it out between a return to our } \\
\text { shareholders. }\end{array}$ & $\begin{array}{l}\text { Decision moved swiftly though may have } \\
\text { largely been due to the renewal/inheritance } \\
\text { status. Justification and support sought, and } \\
\text { recommendation made to progressively higher } \\
\text { levels. }\end{array}$ \\
\hline $\begin{array}{l}\text { B \& C } \\
\text { (same } \\
\text { company) }\end{array}$ & $\begin{array}{l}\text { Commercial \& } \\
\text { Philanthropic }\end{array}$ & $\begin{array}{l}\text { The decision-making process starts from a strategic perspective ... from } \\
\text { a consideration of our business and the needs of our business. } \\
\text {... [we also need to] be a good citizen and to take account of the needs of } \\
\text { the community. Having said that it also makes good business sense so } \\
\text { there's a coincidence between those two. I don't see them as there being } \\
\text { any dissonance between them. }\end{array}$ & $\begin{array}{l}\text { Structures in place for analysis of proposals. } \\
\text { Justification and support sought, and } \\
\text { recommendation made to progressively higher } \\
\text { levels. CCE has key role in large investments. }\end{array}$ \\
\hline $\begin{array}{l}\text { D \& E } \\
\text { (same } \\
\text { company) }\end{array}$ & Commercial & $\begin{array}{l}\text { I've got a little sort of decision tool that I developed. . . [it asks:] can we } \\
\text { leverage this event effectively, does it give us a platform? ... do we get a } \\
\text { sense that these people will deliver? Can we trust them? ... It's about } \\
\text { brand objectives, it's about brand strategy. It's about the cost. }\end{array}$ & $\begin{array}{l}\text { An attempt to make decisions objectively. } \\
\text { Decisions require input and support from } \\
\text { Marketing, and are highly related to objectives } \\
\text { of brand. Justification and support is sought, } \\
\text { and recommendation made to progressively } \\
\text { higher levels. }\end{array}$ \\
\hline $\mathrm{F}$ & $\begin{array}{l}\text { Commercial \& } \\
\text { Philanthropic }\end{array}$ & $\begin{array}{l}\text { we have commitment to giving back to the community ... but we also } \\
\text { have to be mindful of how that is spent. } \\
\text { Choosing a sponsorship property I think you've got to say does this } \\
\text { resonate with the audience? Do people think this is a good thing? }\end{array}$ & $\begin{array}{l}\text { Decision made swiftly by CCE, and then later } \\
\text { leveraged and justified internally. }\end{array}$ \\
\hline $\mathrm{G}^{*}$ & Philanthropic & $\begin{array}{l}\text { Approached it first from the standpoint of doing good in the community, } \\
\text { then sought to negotiate specific benefits. }\end{array}$ & $\begin{array}{l}\text { Swift apparently "easy" decision, aided by } \\
\text { knowledge of CCE. Justification and benefit } \\
\text { sought post-decision. }\end{array}$ \\
\hline
\end{tabular}




\begin{tabular}{|l|l|l|l|}
\hline Case & Categorised as & Example statement & Characteristics of the decision(s) studied \\
\hline $\mathrm{H}$ & Philanthropic & $\begin{array}{l}\text { [our company's] business philosophy ... is very much about trying to } \\
\text { make the world a better place. }\end{array}$ & $\begin{array}{l}\text { Quick decision made by largely CCE, in } \\
\text { consultation with others. Justification and } \\
\text { benefit sought post-decision. }\end{array}$ \\
\hline $\mathrm{J}$ & Philanthropic & $\begin{array}{l}\text { it's more of a philosophy ... it's probably nicer[than] those sponsorships } \\
\text { because you're not trying to figure out what you're leveraging you know. } \\
\text { it still fits but it doesn't have to be overtly commercial }\end{array}$ & $\begin{array}{l}\text { Based on rapport and relationship - easy } \\
\text { decision. Justification and benefit sought post- } \\
\text { decision. }\end{array}$ \\
\hline $\mathrm{K}$ & Commercial & $\begin{array}{l}\text { a lot of our sponsorship ... are based around what kind of rate card } \\
\text { value will we get. And even when we deal with charities sometimes we'll } \\
\text { say what are we going to get out of it? How much advertising are you } \\
\text { doing? what media plan do you have in place? where will our logo be? }\end{array}$ & $\begin{array}{l}\text { Noted that this decision was a commercial } \\
\text { sponsorship. Decision required much } \\
\text { negotiation internally, and justification based } \\
\text { on commercial return. }\end{array}$ \\
\hline
\end{tabular}

* not authorised to quote from case G. 
Two other cases shared these same ownership characteristics, but were not categorised as "commercial". In one case $(\mathrm{H})$ it was evident that the more important framing came from a strong global corporate culture of giving back to the community. In the second case (A) the respondent's statements suggested an orientation more towards philanthropic goals.

(2) Philanthropic orientation: Three cases (G, J, H; three companies) were characterised as decisions made in companies with a perspective more oriented towards philanthropy. In cases $\mathrm{G}$ and $\mathrm{H}$ this was assessed from formal statements made in the public domain. In case $\mathrm{J}$ little public information was available, yet the respondent was very clear on the company's stance. These respondents noted that the company's main focus for these decisions was to be a good corporate citizen. The benefits and use of the sponsorship was developed not as part of the decision, but following the decision. Interestingly the three cases do not share other characteristics. Two are privately-owned organisations, and one is publicly held. In each of these decisions however, the DMU was relatively small, with the key decision-maker being an owner or Chief Executive.

(3) Commercial and Philanthropic Balance: In 4 cases, (A, B, C, F; three companies) formal statements reflected a frame of reference which saw the two objectives appearing relatively equal in importance for the company. It was in these four that a balance was expressed as part of the frame of reference in making these decisions. Two of the three companies were State-owned enterprises (SOE's) ${ }^{9}$ which have a formal mandate to contribute to society.

In conducting the above analysis, it became evident that a company orientation impacted all decisions made by the company. In other words, for companies in which two cases were studied, both cases bore similarities reflecting the company orientation. It was also evident that while three categories are noted above, it was less of a strict categorisation and more of a range.

\footnotetext{
${ }^{9}$ The SOE Act reads: The principal objective of every State enterprise shall be to operate as a successful business and, to this end, to be - (a) As profitable and efficient as comparable businesses that are not owned by the Crown; and (b) A good employer; and (c) An organisation that exhibits a sense of social responsibility by having regard to the interests of the community in which it operates and by endeavouring to accommodate or encourage these when able to do so. (New Zealand Government, 1986, p. 6)
} 


\section{Ownership}

Ownership was another area of interest in considering the internal frame of reference. All companies but two noted the importance of ownership as helping to shape their sponsorship decisions. Ownership at times appeared to determine whether the company views sponsorship as more commercial or more philanthropic as in the previous section. Here, however, ownership was considered in terms of how the respondents made reference to the specific type of ownership and subsequent consideration of key stakeholders.

Discussions of ownership revolved around who specifically owned the company (private, public or SOE). Two companies, representing a total of four cases were identified as SOE's. In each of these companies, and consistently in the four cases studied for these two companies, the respondents noted that their status as a government owned enterprise was important in establishing their need to give back to the community. One respondent stated, "as an SOE we have a social obligation." This is not surprising given the SOE Act which stipulates that these organisations are required to contribute to the community.

Four companies (four cases), were identified as being publicly-traded companies, and while the expectation was that there would be more of a commercial focus, this was not the case. Two of these companies shared the need for extensive commercial justification of sponsorship, consistent with a wider company strategy. The third company expressed that the decision to sponsor an arts initiative was consistent with their culture being more oriented to "social good". The fourth case with a publicly-traded company was dominated by the context and time limitations, though had elements of both commercial and philanthropic considerations.

Finally, two companies ( 2 cases) were privately held organisations. Both of these organisations expressed a more philanthropic orientation towards sponsorship, and both of these decisions appeared to reflect more of the personal frame of reference of the owner or Chief Executive.

Based on the consideration of ownership as an internal frame of reference, it appeared that while ownership may have played a part in the company's orientation towards sponsorship, it was not a dominant consideration. Being an SOE gave companies a mandate to contribute to society, yet publicly traded companies also felt it was their role 
to contribute to society. Being publicly traded did not make for a consistent response either. While some publicly-traded companies were more commercially oriented, SOE's were not far behind, and it was clear that in one case, being publicly-traded did not deter the company from carrying a more philanthropic orientation. Where ownership did seem to make a difference was when the company was privately owned. In both of these cases the decisions appeared to happen quite easily, and on the basis of a smaller DMU, with an almost intuitive decision, and a more philanthropic orientation.

\section{Company Strategy}

Also within this internal frame and linked with the identification of key stakeholders was the company's strategy; its goals, needs and challenges. In this study, the current strategy of the company emerged as an important theme in setting the background or "frame" for the decision-making process. Firstly, it was evident in all cases, that for a decision to proceed there had to be some level of "fit" or congruence between the company strategy and the arts initiative. Related comments fell into two main areas: (1) a link with the corporate mission and culture, and (2) the need to connect with particular stakeholders.

In terms of a link with the mission and/or company-held values, respondents noted the role of sponsorship in helping to develop a vital community in which to operate, noting that development of the arts is part of developing a community:

if New Zealand isn't successful, then [our company] will not be successful. If New Zealand is successful and is growing and is dynamic and is diverse then we will be successful as well.

One case in particular expressed formally and via interviews that the global company had a strong desire to contribute to the community and that this was part of their corporate culture and values. In a second case (within a privately-held company) a strong culture of giving was noted, with this aspect of the culture clearly coming from the values held by the owners.

Further comments identified values such as quality, innovation and creativity as those which the company was interested in supporting via sponsorship: 
It's the [arts] organisation, their values and what they're trying to achieve and what their goals are, which we [the company] align to.

More generally, comments also noted that a sponsorship may help the company project a positive image to the community.

The second category included comments in which respondents noted that a key strategy was to connect with particular stakeholders in particular locations, for example, one respondent noted, "what we needed to do was introduce the ... name and brand into the region." Similar to earlier findings concerning stakeholders in industries and with ownership, the strategy appeared to determine the stakeholders who would be important in the use of sponsorship. Stakeholders included groups such as government, media, key business decision-makers, as well as the customer market.

The fit between the market and the sponsorship investment was the most common category of discussion, which highlighted that the existing company needs vis a vis their market, played a role in decision making. It was necessary that there be a fit between the company's target market, and that of the arts initiative. For example, one respondent remarked:

Is this the right kind of property for the kinds of customers? ... that's crucial. . It's a matter of getting things fitting right between the consumer and the property.

In four of the cases studied, this need for market fit translated into a need to reach a new geographic market, with companies looking to attain a greater presence in a particular location and using the arts initiative to help them achieve this.

The interviews posed some difficulty in trying to ascertain what criteria were applied to the evaluation, as opposed to the benefits the company realised later on. However, it was evident that the company strategy (goals, values and needs) set the stage for the approach by the arts organisation. It was also evident in all cases that a fit was necessary; a benefit to the company and a link between the two organisations had to be made, for an approach 
to be facilitated. Naturally, this fit came into play in the evaluation as well, but as will be discussed, this fit had to be there at the start.

This need for a fit between the company strategy and the arts event was clearly evident, pointing to the role of the strategy in establishing the frame of reference and almost a set of rules by which the sponsorship investment would be evaluated. Further evidence of this link appears in the analysis of the investment characteristics.

\subsubsection{Personal Frame of Reference}

Given that individuals are actually making the decisions, consideration of a personal frame of reference was crucial. That is to say, how did the individual in the DMU feel about sponsorship and CCI more generally? It was felt that this type of question would reveal more of a personal context for this subject, and a specific question near the end of the interview, was posed: "do you have a personal philosophy about the role of the company in society?" Interestingly, all respondents felt that the company had a role in contributing to society, and all linked sponsorship with this. There were however variations in how this was explained.

In responding to the specific question noted, seven out of 13 company case respondents expressed more of a philanthropic orientation, focusing on the need to engage in CCI and sponsorship as an obligation of the company in society. Four company individuals were more oriented towards commercial ends - noting the role of CCI and sponsorship as fulfilling ROI needs, and/or meeting a specific marketing objective such as changing perceptions of the market. While responses to this particular question resulted in a wide array of opinions, when other comments made by the respondents were considered, a more balanced view emerged. In other words, there was, overall, for individuals, an impression that both social and commercial goals existed, and could exist together.

Interview responses were then explored to see if there was a relationship between the individual frame and the decision-making process. Initially, it was thought that this individual frame would be linked with a company frame of reference: the "company's" philosophy of giving. This appeared only true in some instances - particularly those in smaller privately owned companies. 
Another finding noted previously was the difference in how CCE's expressed their views, compared with CSM/CMM's. CCE's were unanimous in expressing that companies have a role to play in contributing to society and part of this includes sponsorship. They spoke of an obligation to give back, as well as need to contribute to society. For example one CCE stated:

[when we make these decisions we ask] does it add value for New Zealand? for the country? ... basically we think in terms of what is of value to the country. What's the value to the nation?

This philanthropic-oriented view however, co-existed with the need to achieve commercial goals. The same respondent noted:

[we also ask] what is the value that this sponsorship might give to us? And that therefore relates to things like brand, fit and so on but what are we going to get out of it?

In contrast, and as related to the specific decision, most respondents in CSM/CMM positions spoke more frequently about the need for a market fit, the need for return on investment, and increased objectivity. Phrases such as "we have policy business rules", "a more objective ... way of thinking", and "we have to be really objective" were present for these respondents. Therefore, while these individuals appeared to share a philanthropic view overall, when speaking of specific decisions their discussion shifted to a more commercial orientation.

While a difference in approach and philosophy was noted in the decision, the next analysis concerned the effect of philosophies on the process. Findings firstly suggested that the philosophy of the CSM/CMM was not seen to hold a great influence over the decisions. In all decisions this role had to take a more commercial perspective, looking for the benefits and being aware of potential risks - either during the evaluation or postdecision. It was evident that while individuals at this level may have had an orientation toward philanthropy, the business objectives came first. 
A similar pattern was revealed for CCEs: while they may have expressed a personal philanthropic philosophy, they also expressed a role in ensuring business objectives came first. Particular attention was given in this analysis to six of the cases - all of which were characterised by relatively high CCE involvement. In most of these cases, it was found that it was not the CCE's personal philosophy of giving which played a part, but the individual's intuition, knowledge, judgement and position. Two CCEs noted that they simply knew it would work.

In two of the cases, although it was recommended to the CCE that the company not engage in the sponsorship, the CCE felt the link between the company and the arts initiative was strong, and essentially made a positive decision happen.

Discussion concerning the frame of the CCE in decisions was echoed in conversations with experts, most noting the need for someone in authority to understand the arts initiative and see the link with the strategy. Two expert respondents noted:

... [it is] always important to get to the key decision-maker. . . because they've got to have vision.

... what it needs is someone in a position of authority in that company who really wants to do it.

The influence of the CCE suggested further analysis in terms of the DMU, which will be discussed in more depth in section 5.4.

Based on the consideration of the individual frame of reference, the analysis suggested that the personal frame of reference influenced the decision when it was that of a highlevel individual, within the DMU, and that person felt strongly, based on their own experience, that the sponsorship would benefit the company. Analysis also suggested that the important frame is not so much how individuals felt about the role of the company in sponsoring the arts, but what they knew about the initiative and the ability for it to fit with the company needs. 


\subsubsection{Frame of Reference in Summary}

In examining the frame of reference, and its influence on the decision-making process, three levels were evident: an external frame of reference, an internal frame of reference and a personal frame of reference. Externally, it appeared that the general perception of sponsorship and its association with uncertainty fed into the process, often necessitating the involvement of high levels of management. While industry characteristics were considered, these were influential mainly as they related to the identification of stakeholder groups to be targeted with sponsorship. Considering an internal frame of reference, all companies in all cases expressed a need to be a contributing part of society, but what shaped the frame more dramatically was the company's strategy, and the need for the company to achieve a fit between the sponsorship and their operations - be it their mission, values or more specifically a market and/or brand fit.

Findings from examination of the personal frame of reference revealed an orientation both to philanthropic motives for CCI and sponsorship, along with the need to make commercially based decisions. The personal views concerning CCI did not seem to enter into the decision-making, except for the case of the high-level managers. For high-level managers, it appeared that rather than their philosophy, what was important was their knowledge and skill, allowing them a level of intuition about whether this investment would "work" for the company. In this way, these individuals did influence the decisions.

\subsection{Extent of Formalisation of Policy}

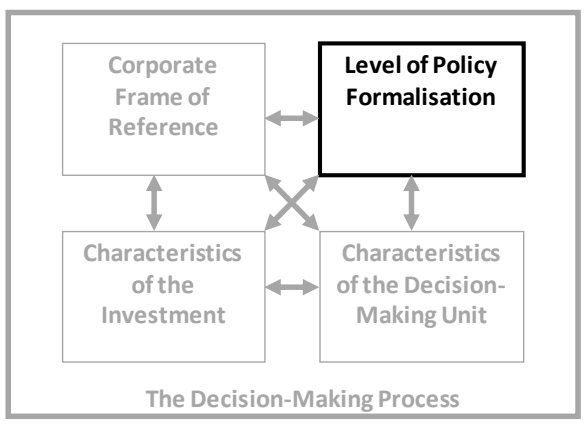

The formalisation of policy concerns the policies and procedures associated with the sponsorship. For example, did the company have a formal policy and formal procedures? Were the procedures followed? The formalisation of policy may give boundaries to alternatives considered, interpretation of the consequences, and rules with which to 
evaluate the alternatives. It could also determine the individuals in the decision-making unit and therefore determine roles and potential conflict. The formalisation of policy was regarded as influencing the decision process, firstly in the formal articulation of policy and procedure, but secondly, in the extent to which these formal rules are followed.

The extent of a formalised policy was ascertained in most instances via information on company websites. A direct question was also asked if the respondent had not already covered this in the course of the interview. Once the information was coded, nodes were reviewed, suggesting clear categories in terms of policy related to the objectives companies seek to fulfil in selecting sponsorship. Respondents also spoke of policy related to the procedures which requests are subjected to. In terms of the overall picture of the influence of a formal policy, three key questions were posed of the data:

1. To what extent did formal policies and procedures exist?

2. What was the relationship between the formal policy and the decision process? and

3. What seemed to affect the extent of formalisation?

\subsubsection{Variations in Policy}

The extent of policy formalisation, concerning sponsorship, varied among the cases, with a continuum evident among the cases ranging from no evidence of a formal policy, to highly formalised. At one end of the continuum, one case was categorised as having no formal policy but some informal, with no evidence of formal criteria noted either publicly or by the respondent, and information procedures largely resting with the decision of the owners of the company. At the other extreme, 5 cases were considered to hold a high level of formalisation, with specific criteria noted publicly, and processes clear, with multiple levels of the organisation formally involved in the decision-making unit.

In linking these groupings with other characteristics of the decision-making process, it was found that the existence of a formal policy was not a good indicator of how the process would unfold, especially in terms of the criteria applied. Instead, it appeared that there were "generally accepted" practices, which may or may not be formalised, but nonetheless, were expected to be undertaken. Specifically, it was "generally expected" that the sponsorship would have some benefit to the organisation. 


\subsubsection{Differences in Formal vs. Actual Criteria}

To explore the tendency towards generally accepted practises it was essential to consider the variation between formal policy and actual evaluation. The questions here concerned:

- What impact did the formally stated criteria have on the evaluation?

- To what extent were formal criteria followed or not? and in what circumstances were the criteria followed, or not?

To consider these questions, cases were examined, comparing statements related to formal criteria, against statements related to the characteristics of the investment which were actually considered. The resulting matrix presented each case, the criteria which were considered, and whether that criterion was either (a) formally noted but not evident in the actual evaluation; (b) formally noted and evident in actual evaluation, or (c) evident in evaluation but not formally noted. Table 5.5 provides a summary of this analysis.

The most commonly noted formal criteria were brand fit and the opportunity for exposure. Second most common was the opportunity for exposure followed by the evidence of the event's quality and/or reputation. In terms of the actual criteria applied, for the most part it followed the formal criteria with two key exceptions. Firstly, the importance of hosting opportunities was evident as a criterion applied in most cases, but only noted formally in four cases. Secondly, the fit with the company's market was noted in most cases, but only noted as a formal criterion in four cases. This suggests that while the formal criteria exist, there is room for movement, and different initiatives may suggest a different application of criteria.

In four of the eight cases with relatively specific criteria, it was evident that there was a "criterion of elimination." In these cases, notation was made in publicly available documents of what would not be considered. This acknowledgement of elimination was also present in interviews, and largely reflected the need to have a fit between the company and the arts initiative. For example, of the processes early on, one CSM stated:

typically, if a proposal comes in and it's not an immediate kind of misfit, depending on an initial sort of look at the organisation or the location and so on ... (author's emphasis) 
Table 5.5 Formal vs. Actual Evaluation Criteria

\begin{tabular}{|c|c|c|c|c|c|}
\hline Formal Criteria noted & $\begin{array}{r}\text { In how } \\
\text { many } \\
\text { co's? (/8) }\end{array}$ & $\begin{array}{r}\text { In how } \\
\text { many cases? } \\
(/ 10)\end{array}$ & $\begin{array}{r}\text { \# cases use this } \\
\text { as actual } \\
\text { criteria? }\end{array}$ & $\begin{array}{r}\text { \# cases formal } \\
\& \text { actual } \\
\text { match? }\end{array}$ & $\begin{array}{r}\text { \# cases criteria } \\
\text { actual but NOT } \\
\text { formal? }\end{array}$ \\
\hline $\begin{array}{l}\text { Hosting opportunities generally, including specifically to connect with } \\
\text { key markets for the company. }\end{array}$ & & 3 & 9 & 4 & 5 \\
\hline $\begin{array}{l}\text { A clear fit with the brand and associated benefits to the brand -- } \\
\text { includes the ability for the sponsorship to meet brand goals. }\end{array}$ & & 5 & 8 & 7 & 1 \\
\hline Opportunity for exposure for the company - advertising, media, etc. & & 5 & 7 & 5 & 2 \\
\hline A fit with the company's target market. & & 3 & 7 & 3 & 4 \\
\hline $\begin{array}{l}\text { Evaluation of quality of event/organisation - includes reputation and } \\
\text { evaluation of people, \& well managed. }\end{array}$ & & 4 & 7 & 4 & 3 \\
\hline No presence of risk that might impact company negatively. & & 2 & 4 & 2 & 3 \\
\hline $\begin{array}{l}\text { Evidence that arts organisation will make use of products associated } \\
\text { with corporation, enabling products/talents to be demonstrated. }\end{array}$ & & 3 & $\overline{4}$ & 3 & 1 \\
\hline $\begin{array}{l}\text { Evidence that there will be a win-win; benefits to both the company } \\
\text { and the arts organisation. }\end{array}$ & & 3 & $\overline{4}$ & 2 & 2 \\
\hline
\end{tabular}




\section{Formal Criteria noted}

Opportunity for the company to be able to work in partnership with the arts organisation. This includes leveraging.

Evidence that the sponsorship will somehow have a wider community benefit.

A fit with the company's broader values.
In how

many co's? (/8)

(1)

\# cases form

\# cases criteria

es use this

as actual

cases formal

actual but NOT

(/ 10)

criteria?

actual

formal?

2

3

4

2 2 0 0 3

Specific notation that the company wants value for money. 0 0

Provides benefit to staff.

2

2

Evidence of return on investment.

1

1

1

2

0

0

Links to good network of other sponsors.

1

1

0

0

0 
There were three cases when formal criteria were provided, but did not feature in the decision-making process. In these cases, while benefits such as a fit were in hindsight apparent, the negotiation of the benefits occurred post-decision. Two of these cases also had CCE high involvement, and in the third case time pressure necessitated minimal evaluation.

Another two cases also negotiated benefits post-decision. These companies were those who did not possess a formal statement of sponsorship criteria, with their decisions coming initially from more of a philanthropic perspective. The benefits sought (postdecision) were similar to those noted above for other cases - brand and market fit, exposure and hosting opportunities. Also, for two cases, it was evident that some level of analysis had occurred in the minds of the decision-makers concerning the fit with their brand/company - even though the exercising of this fit occurred post-decision. These findings also support that there was an element of generally accepted practice, and expected results, wherein the sponsorship must have some benefit to the company.

Overall, in considering the formal policy with respect to criteria, it was evident that when a formal policy exists, it served as a checklist - but not all boxes needed to be checked. In addition, what appeared more important than policy, was a generally accepted requirement that there needed to be a benefit that the company was able to see and make use of. In addition, the opportunity to host key stakeholders appeared to be an important part, but was not always explicitly itemised.

The above considers formal policy in terms of criteria, however this is incomplete without looking at the procedures.

\subsubsection{Formal Policy - Procedures}

The second aspect of formalisation is the process or procedure. Procedures were less well documented, but easily ascertained in the interview by asking both about the procedure for the specific case, as well as the formal procedures set by the company. It was clear here that decisions did not always follow the path intended. A general path most respondents noted as the "ideal" was as follows:

1. Applicants make contact and apply via the CSM/CMM. 
2. CSM/CMM assesses the sponsorship, and makes a recommendation, often in conjunction with either their superior or another person(s) in the company who will be affected by the initiative.

3. A recommendation is then presented to higher levels, and examined.

4. Approval (if given) is made at $\mathrm{CE}$ and/or board level.

Two interesting variations from this were observed concerning the involvement of highlevel decision makers. One variation was when a $\mathrm{CE}$ intervened at an earlier stage than expected. Another variation was in the initial approach, where applicants approached a high-level individual either directly or indirectly.

The first observed variation in procedure was when a decision would be made at a higher level and then would be "sent down". This was referred by respondents as "chairman's choice"; however, only one case was found which bore characteristics of this. In addition, in this case the formal process kicked in post-decision, with respondents noting the importance of giving the decision the necessary backing, engaging in negotiations and developing the benefits to ensure the sponsorship worked on the criteria the company had developed.

A second case had what could be called "early involvement" of the CCE, however in this case, it was viewed within the company as entirely appropriate, as this particular CCE had been previously involved in the arts initiative, and knew its benefits and its players. It is interesting that in both cases, the fit and benefit were evident in the approach, though not evaluated to the same extent as in the "desired" process. It appeared again that the CCE's intuition was present and influential in these decisions.

The second variation occurred in five cases, with respondents acknowledging that processes varied from the formal process in terms of who made the initial contact. Though websites request that proposals go through a sponsorship or marketing manager, it was acknowledged that often requests came in at the CEO or Board level. Again, the importance of the formal aspect of the policy came into play. One CSM stated:

The board may send one down to me for assessment. That often happens. You'll get board members being approached or one of your executives being approached. And what is really important is to have 
your processes in place and get buy-in from the exec about using these processes to avoid the "chairman's choice."

A big sponsorship often will come from further up the line. So you might get somebody who approaches our CEO or one of our directors directly or personally because they have a business relationship with them. And they'll chew their ear over a glass of wine or something and then it will come down to me and then it goes through a formal process.

In cases of the CCE or senior executives being approached it was evident that a fit with and benefits for the company remained a requirement early on. It was also clear in this second variation that existing relationships played a role in the initial ask. Thus, formal procedures, while useful and seen as important in many companies, appeared to serve as a guide - a guide to be followed when possible, but at times followed post-decision.

\subsubsection{Formalisation of Policy in Summary}

In conclusion, the analysis suggested that formal policy may be viewed as consisting of two aspects: criteria and process. With respect to the criteria, the policies were viewed as guidelines with emphasis remaining flexible, but also with an overriding view that there should be benefit to and fit with the company. With respect to the process, formal procedures were typically in place, and while circumstances and relationships at times shifted this to a post-decision process, the process was not eliminated entirely.

\subsection{Characteristics of the Decision-Making Unit}

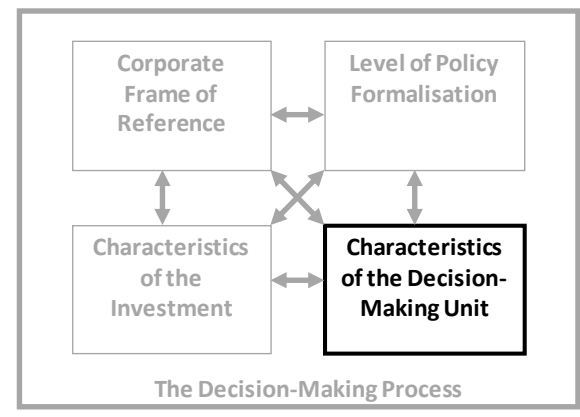

Decisions in companies are generally made as a group. This group is often called the decision-making unit (DMU), and has been examined in the organisational buying 
behaviour literature. The existence of a DMU does not mean it is a formal committee, but acknowledges that there are usually a number of people involved, with a variety of roles each contributing to the decision. In examining a decision process from the perspective of the DMU, examination would be given to who is involved, what their position is, what their influence is, and what role they play during the process. Two levels were thus considered, the characteristics of the DMU and the characteristics at an individual level.

Initial examination of this theme in the literature led to a number of categories of analysis: influences on the DMU, the roles, the size, the lateral and vertical involvement, and the importance key individuals. While the size of the DMU has been noted in the literature as an influencing factor on the time it takes to make a decision, as well as the individual influence participants may have, its relevance to the processes here appeared minimal. Therefore, more attention was given to the influences on the DMU, the lateral and vertical involvement, the roles and the influence of a key individual.

\subsubsection{Influences on the Decision-making Unit}

The main influences on the make-up of the DMU were the formal roles assigned, as well as the financial commitment sought.

A primary influence on the DMU, and one not unexpected, was where the company formally allocated sponsorship review and/or decision-making. In this study, a CSM was generally given the responsibility to review sponsorship applications ( 6 of the 10 cases). In one case the CMM held this role. In the final three cases the CCE or Owners were given this role. When the role was assigned, the individual was part of the DMU. There were often formal procedures demanding that approval be sought at a specific level, and naturally this also had an impact on the DMU.

In addition to acknowledging formal roles, most respondents indicated that a key determinant of the make-up of the DMU was the amount of money involved. The higher the amount, the more likely it would be that higher levels of management were involved. This was acknowledged to be the case due to the sensitivity around sponsorship, as noted by one CMM: 
Generally speaking my delegated authority is 250k. In sponsorships my delegated authority is $25 k$. Sponsorships are really interesting in that it gets elevated very quickly up the chain and very quickly it goes past me and requires a chief executive sign-off and very quickly it goes past him and requires board sign-off because it can be a highly sensitive area.

There were other reasons given for this elevation in the DMU, including personal interests of the board, and the fact that some of the sponsorships would require additional funds outside of the approved marketing budget. However, the majority of respondents agreed that sponsorship was moved up the ladder, and this was largely due to sponsorship's uncertainty. Important to note here, is that all cases were deemed "of importance" by the company, or "significant." Therefore, while exact amounts were not always available, it is not entirely surprising that higher levels of management were involved in these decisions. The following discussion needs to be considered in light of this.

\subsubsection{Decision-making Unit: Lateral and Vertical Involvement}

Consideration of a DMU's lateral and vertical involvement, examined the representation of different departments (lateral involvement) and different managerial levels (vertical involvement).

Most of the cases were vertically oriented, with a number of representatives from different levels, but few at the same level. However, two cases, both within the same company, had lateral involvement, and in each case, this was viewed as crucial to the decision-making process. In these two cases, the CSM actively sought support and involvement of a brand manager for the brand to which the CSM felt the sponsorship would be suited. In one other company this was noted as desirable, but did not eventuate.

One reason why this lateral involvement was not sought more frequently was explained by a CCE in terms of sponsorship serving to best promote "corporate brands", rather than an individual brand under the corporate umbrella. 
[sponsorship] is not about generating immediate sales action day-today it's all about enhancing the value of the brand and the brand doesn't belong to marketing it belongs to the chief executive.

This opinion appeared to move sponsorship to a higher level, initially to the level of a company marketing manager, and/or to the CCE. In this sense, it was evident that characteristics of the arts initiative, and where it was seen to fit under the company umbrella was a key influencing factor in the make-up of the DMU.

Regarding vertical involvement, the majority of the cases involved 3 or 4 levels within the organisation, including a CSM level, their superior, the CEO and sometimes the Board. While the presence of these levels appeared to reflect a formally established procedure, the decisions did not always progress in a "bottom-up" order. In some cases the CEO would be approached, but then it would be evaluated by the CSM or CMM, then return to the CEO and to the Board. In four cases only two levels were involved that of the CCE and the Board. In three of these cases the procedures had been established dictating that the CCE and Board would be involved. In the final case, the formal procedure was in fact to have more levels of involvement, however the relationship between the CCE and the arts organisation, and the time limits imposed on the decision seemed to necessitate a quick decision with a limited DMU. In this example, the circumstances surrounding the decision and available time appeared to have an effect on the DMU.

Also evident in this analysis was the involvement of the CCE level - consistent across all cases - and often the Board level. As noted this is seen to largely be a result of the ambiguity surrounding sponsorship, and the resulting desire for high level involvement. The group of respondents categorised as experts had a strong view of the importance of vertical involvement. In fact, a number of the experts felt that if a sponsorship fell into the hands of marketing, it was virtually doomed. Again, this appeared to relate to the particular difficulties in measuring sponsorship outcomes. One expert respondent stated:

... the tragedy is the modern educated marketer who is driven by textbooks will judge sponsorship completely dispassionately based on empirical data and decisions made by agencies. . the trouble is that 
agencies are anti-sponsorship because every dollar that is spent on sponsorship is a dollar that is not spent on advertising.

Others echoed this sentiment, noting that sponsorship could not be entirely judged on commercial criteria, which meant it would generally not hold up to a typical marketing evaluation. They felt that the involvement of a higher level executive was crucial as this person was more likely to understand sponsorship.

A final finding considering the vertical involvement within the DMU, was that the management of the relationship following the decision, was always carried out by the CSM or CMM position, although sometimes in addition to other individuals. This will be examined in more detail in the following section on roles.

This analysis therefore supported the suggestion that sponsorship decisions were made with the involvement of higher levels of management. While lateral involvement was brought into the process based on the arts initiative and how the company would use the sponsorship, vertical involvement was virtually a given, and was desired.

\subsubsection{Roles in the Decision-making Unit}

As expected, individuals within the DMU took on specific roles. The coding of interviews and subsequent analysis remained open to the multitude of roles potentially taken up by members of the DMU. Relevant statements were coded to categories including the role of users, influencers, gatekeepers, deciders and approvers. In addition the roles of "initiators" and "advocates" emerged. A representation of each case and the individual who occupied each role is presented in Table 5.6. Within this table, the individuals are also noted who were determined via the company's formal policy to occupy the roles of users, initiators and deciders. The discussion below elaborates on each role.

Users

[I was] coordinating with the guys ... finding out what the programme was and they had a bit of a PR programme going so [looking for] where we could help. 
Users were individuals who helped to manage the sponsorship and those who benefitted from the sponsorship after the decision was made. In terms of the management of the relationship, in each case it was either the CSM or CMM who was the key manager, unless this role did not exist, in which case it fell to the CCE. In terms of those who made use of the benefits, for example attending related events or inviting clients to events, this included a number of individuals from the company depending on the stakeholders identified to target. For example, a sponsorship which allowed for opportunities to connect with and socialise with clients/customers involved users in the sales areas. The involvement of other managers besides the CCE, CSM and CMM appeared to be a result of the advocate identifying who the users may be.

\section{Influencers}

I pitch my position as a professional person in my role and it gets challenged and evaluated and it gets sold in at a particular level.

- CSM, identified as an Influencer

Influencers sought to affect the decision, and as evident in Table 5.6, there were often multiple influencers. The most common individual in this role was the CCE or owner. Second most common was the CSM or CMM (in seven cases). This is not surprising as this was the person in these cases charged with the analysis and management of the sponsorship (also a user). When responsibility for these decisions formally remained with the CCE or owner level (in 2 cases), the CSM/CMM role was not present as an influencer. While levels of influence varied, in cases where a subordinate brand was involved (cases D and E), the appropriate marketing manager was present as an influencer. Evident in this analysis was that the influencers generally included the CCE, and influencers were often determined in formal policy or determined as appropriate to the situation in the case of subordinate brands. Also evident was that there were levels of influence, and in each decision a key person appeared to emerge. This was analysed further and will be discussed as the role of advocate. 
Table 5.6 Roles in the Decision-making Unit

\begin{tabular}{|c|c|c|c|c|c|c|c|}
\hline Case & User & Influencers & Gatekeeper & Decider & Advocate & Initiator & Approver \\
\hline $\mathbf{A}$ & CSM, Other Managers & $\begin{array}{l}\text { CSM, PA Manager, } \\
\text { CCE }\end{array}$ & CSM & CSM & CSM & $\begin{array}{l}\text { CSM } \\
\text { (renewal) }\end{array}$ & CCE \\
\hline $\mathbf{B}^{*}$ & CSM, CCE, Other managers & CSM, CCE & CCE, CSM & $\mathrm{CCE}$ & $\mathrm{CCE}$ & $\begin{array}{l}\text { CSM } \\
\text { (renewal) }\end{array}$ & Board \\
\hline $\mathbf{C}^{*}$ & $\begin{array}{l}\text { CSM, CCE, Other } \\
\text { managers }\end{array}$ & CSM, CCE & CSM, CCE & $\mathrm{CCE}$ & CSM & $\mathrm{ABM}$ & Board \\
\hline $\mathbf{D}^{\circ}$ & CSM, CCE, Other managers & $\begin{array}{l}\text { Brand Mgr, Other } \\
\text { CMM, CCE }\end{array}$ & $\mathrm{CSM}$ & $\begin{array}{l}\text { Brand Mgr, } \\
\text { CSM }\end{array}$ & $\mathrm{CSM}$ & $\mathrm{ACE}$ & $\begin{array}{l}\text { CCE, Exec } \\
\text { Team }\end{array}$ \\
\hline $\mathbf{E}^{\circ}$ & CSM, CCE, Other managers & $\begin{array}{l}\text { Brand Mngr, CMM, } \\
\text { CCE }\end{array}$ & $\mathrm{CSM}$ & $\begin{array}{l}\text { Brand mgr, } \\
\text { CCE }\end{array}$ & CSM & $\mathrm{ACE}$ & $\begin{array}{l}\text { CCE, Exec } \\
\text { Team }\end{array}$ \\
\hline $\mathbf{F}$ & $\begin{array}{l}\text { CSM, CCE, CMM, Other } \\
\text { managers }\end{array}$ & $\mathrm{CCE}$ & $\begin{array}{l}\mathrm{CCE} \\
\text { (formally should be } \\
\text { CSM) }\end{array}$ & $\mathrm{CCE}$ & $\mathrm{CCE}$ & $\mathrm{ABM}$ & Board \\
\hline $\mathbf{G}$ & Owners, CCE & $\mathrm{CCE}$ & $\mathrm{CCE}$ & $\mathrm{CCE}$ & $\mathrm{CCE}$ & $\mathrm{ACE}$ & Owners \\
\hline $\mathbf{H}$ & $\begin{array}{l}\text { CCE, Other Exec, } \\
\text { Marketing }\end{array}$ & $\begin{array}{l}3^{\text {rd }} \text { party, CCE, CMM, } \\
\text { Other Exec }\end{array}$ & $\begin{array}{l}\mathrm{CCE} \\
\text { (formally should be } \\
\text { CSM) }\end{array}$ & $\mathrm{CCE}$ & $\begin{array}{l}\text { CCE, } 3^{\text {rd }} \\
\text { party }\end{array}$ & $\mathrm{ABM}$ & $\mathrm{CCE}$ \\
\hline $\mathbf{J}$ & CCE, Owners, CMM & Owners & Owner & Owners & Owner & $\overline{\mathrm{ACE}}$ & Owners \\
\hline $\mathbf{K}$ & CMM, Other managers & Other Mktg & CMM & CMM & CMM & $\mathrm{ABM}$ & Exec Team \\
\hline
\end{tabular}

$*^{\circ}$ Case B and Case C are from the same company; Case D and case E are from the same company. 


\section{Gatekeepers}

I am the gatekeeper so even though [the CMM] might have been approached it will still come through me to make sure it goes through the right process.

- CSM, identified as a Gatekeeper

Gatekeepers controlled the information flow to and from the DMU. In eight of the cases, the individual charged with managing sponsorships became the gatekeeper. For six cases the CSM or CMMs were gatekeepers, and for two of the cases the gatekeepers were the owners or CCEs. In two cases the CCE took on the primary gatekeeper role due to an existing relationship between the arts organisation and that CCE. In another two cases there appeared to be two gatekeepers, the CSM and CCE; again, this related to previously established relationships between individuals. Also of note in examining the gatekeeper role, was that in all cases, the gatekeeper could also be described as a key individual or advocate, and that this later description appeared to be more appropriate for these cases.

\section{Deciders}

... the Board and/or [the CCE], depending on the level, will have the ultimate decision. So there could be instances where a sponsorship request will come to me, I'll need to do the thinking about whether it's best for the business and how much we're going to get out of it and I might say, no I don't think this is good, but for political reasons [the CCE] will still do it.

- CSM, speaking of the CCE as the Decider

Deciders were the individuals who appeared to make the final decision. Many times this final decision was put forward to the Board for approval, but in these cases it appeared that the decision had been made and no opposition was expected. In three of the cases, the deciders were the CSM or CMM, each noting that they felt they had enough evidence to support this decision, and when a recommendation was made to higher levels it was more of a "rubber stamp". For the other seven cases, the respondents agreed that the 
decider was at a higher level - typically the CCE. In some cases the actual decider appeared to be in contrast to policy which dictated that the Board would make the final decision. However acknowledgement was made that the Board had final approval, but, as one CCE pointed out, "the day to day management of the business is substantially delegated to me." Somewhat surprisingly, in two cases, both within the same company, the role of decider changed; for one case the CSM made the decision with the brand manager; for the other the CCE made the decision. In the second case in which the CCE was the decider it was apparent that the CCE was aware of a shift in strategy, leading to this individual's greater involvement. In looking at the decider in comparison to other roles, it also became evident that in four of the cases the decider was also a key advocate.

While the above roles revealed insights into the DMU, it was evident that there were roles such as that of advocates, approvers, and initiators which provided a more accurate representation of the DMU in these decisions. These emergent roles will now be discussed.

\section{Advocates}

I mean everybody over there actually refused. They were ready to, they said no, and it was only when I went back and I said I see value in this.

- CMM, identified as the Advocate

The advocates were the individuals alluded to in the above sections, as supporting the decision as it progressed. They often appeared as influencers, users, deciders and gatekeepers, and were initially noted as "key individuals" though this title evolved as their role became better understood. The advocates were the individuals who held considerably more influence on the decision than the others, and were often referred to as the people without whom the decision would not have happened. As well as holding more influence, the advocates also appeared to have greater knowledge, and a greater ability to generate enthusiasm within the company for the sponsorship.

In five of the cases, the person charged with managing sponsorships, usually the CSM or CMM, was identified as the key advocate. These individuals acted as gatekeepers, gathering information from around the company, from different departments or groups, in order to generate a firm justification for the sponsorship. But they went beyond the 
traditional gatekeeper role. In one case the advocate had a depth of information which others did not, and used this to help support the case. In two cases these individuals sought to convince others within the company in order to generate support. One CSM spoke of convincing a brand manager of the sponsorship's benefits:

I was quite excited about it quite quickly. I had to do a fair bit of work, the brand manager concerned was somewhat less enthused but in fact, having won her round, she's now sort of running round dragging me with her so that's really good.

In the other five cases, it was the CCE who took on this advocacy role. In one case, the ACE described the involvement of the CCE:

When it came down to the crunch and once the programme had been presented [the CCE] thought he wasn't getting value for money I got called down there and sat with him on my own and got told to shift it up a gear.

While in three of these cases it was viewed as the CCE's role to make these decisions, it was still essential that others within the company agreed, and it was the advocates who brought the necessary people together. The advocates thus provided and encouraged support and enthusiasm for the sponsorship.

In all cases, it appeared that without this advocate's support, the decision would not have happened. These individuals were information gatherers, who brought the "right" people together encouraging their support, and who then generated wider support, especially in presenting the case to higher levels.

In looking at the responses from the experts, having an advocate was identified as a necessary factor for a successful sponsorship agreement, but they saw the characteristics of this individual as being someone with both the authority and interest: "You need the person in authority who wants to do it" noted one expert.

Similar comments juxtaposed the need for authority and interest. One expert stated a sponsorship was not supported because 
“...he didn't really get it. I mean or he did and he wasn't influential enough in the firm."

Another expert spoke of the need for a key person to be involved:

...if it's not [the] CEO, it's got to be in the executive team. . at the senior level of management ... [and] you've got to have people that are genuinely interested in what you're putting on.

So, while there is a need for authority, this idea of having someone who "gets it" was evident with many of the experts. These individuals talked about the need to talk to people who "share your passion" and the need for a creative pitch that will generate enthusiasm.

It is evident from previous analyses that sponsorship may hold characteristics of uncertainty and intangibility for some. Experts expressed that this was one reason why arts organisations needed to generate enthusiasm or excitement. Case respondents also made comments suggesting that individuals involved did get "excited" about the investment. This however appeared to be more due to that individual's personal experience, rather than a stellar pitch.

This discussion has highlighted the importance of and need for an advocate within the company to drum up the right kind of support, with the right kind of people to develop a successful recommendation to those that will make the final decision. This individual had some level of experience and interest with the art-form, and was able to quickly establish in their mind how the investment would benefit the company. The analysis has also suggested that the advocate needed to either have the authority, or have a link to a "person in authority."

\section{Approvers}

The role of the Approvers represented those who considered the recommendation provided to them by Deciders. Some respondents referred to this as "rubber-stamping", and linked it to the approval of the Board or CE. Other respondents were adamant that 
this was not considered "rubber stamping" and recommendations passed up were vetted through discussion at higher levels, prior to approval.

This role did not appear when the company's formal policy was to have the decision made at the CE level (three cases), however, in the remaining seven cases, there was a distinct role of approver - being either a CE/Executive Team or Board of Directors who had to give the final approval, even if a decision appeared to largely have been made. In these cases, the other roles viewed their job to be to convince the approvers.

Respondents noted that the groundwork and homework had to be done prior to a recommendation going up to a higher level:

nobody puts anything up to the board that they think is going to cause a problem ... So going to the board - typically they're primed and they understand it and they've got quite a bit of background on it.

The Approver role was also linked to "robust debate," questioning the sponsorship, and ensuring it met with business needs. This appeared to be the case for all of the decisions, however in only one case did the approver actually challenge the decision put forward. In this case, the CE was aware of a change in strategy which would influence the use of the sponsorship, and therefore challenged the recommendation. This is not to say that "approvers" could not disapprove. Certainly respondents noted that cases such as this did happen.

\section{Initiators}

[he] could see that the two things could work together and that was it.

If [he] hadn't have been there it would never have happened.

- CCE speaking of the Initiator

The role of the Initiator, strictly speaking may not be a role within the DMU. However, this role emerged as crucial to the process, and having an influence on the DMU. The initiator was the individual who made the initial contact and sometimes made the request. The initiator was found to be the individual who first recognised the opportunity for a sponsorship between the two organisations. In all cases the initiator was connected with 
the arts organisation, making the initiator not "officially" part of the DMU, yet was influential and is therefore discussed in this section.

In six of the studied cases, the initiator was a manager from the arts organisation; in four cases they were from the arts board. What appeared to be more indicative than the level of the individual however, was the relationship between the initiator and the company being approached. Even "cold calls" have some basis already established; at minimum, there was a previous invitation from the arts organisation to an event where some rapport was established. Often it was a longer-term business relationship between the board and CCE. Three distinct scenarios were gathered in this study which had variations in the initiator-company relationship: (1) a renewing relationship, (2) an arts-board initiated ask, and (3) an arts management initiated ask.

For renewing sponsorships, the role of the Initiator was not as evident. It appeared that the decision to renew was initiated within the sponsoring company itself, by influencers or users, and in one case, was discussed at the end of the previous year's relationship.

For new sponsorships where an arts board member (ABM) made the initial link, the $\mathrm{ABM}$ was in the role of the initiator, and helped to open the door. In these cases (four cases) the ABM came up with the idea, felt the partnership would be of benefit, and made the initial contact. These board members were seen as knowing the right individuals to contact, and able to bring the right people together. In each of these cases the ABM made an initial contact at a high level within the company - either a CCE or a $\mathrm{CE}$ in a related company. However, generally this was not seen as a formal proposal, but rather the introduction. In all but one case, the actual pitch or more formal proposal was left to the arts managers.

For new sponsorships where the ACE was the initiator, the cases (four) were diverse. In two cases, strong existing relationships made it apparent that the ACE ought to be the person to contact the company directly. In two other cases, making these approaches was part of the ACE 's formal role. In addition, two of these four cases originated in the same arts organisation, for which the ACE held a relatively high profile in the community and was highly respected by respondents; this suggested that the ACE's contact would be just as convincing as that of a board member. Similarities within these 
four cases included the fact none of the related arts boards had a formal role in initiating sponsorship requests.

What may be said of the above analyses, is that the initiator was determined by what was appropriate. In arts organisations with boards who held some responsibility for seeking support, it was appropriate for them to make the initial ask. It was also deemed appropriate for them to contact individuals with whom they had some rapport, and at a level "equal" to their own. In addition to this, it appeared that a request was made in all instances with some initial introduction - relationships were used to open doors.

The ability of the initiators to open doors was not a small influence. In all four cases where board members were initiators, it appeared that the partnership would not have gotten off the ground otherwise. This effect was noted outright in two of cases, where it was suggested that without a board member making the link, seeing the opportunity and contacting the right person, the investment would not have been considered. However, it also appears and was expressed by many, that the initiator's status in the community or reputation did not mean an instant approval. Evaluation still occurred at some level, and there still needed to be a fit and benefit.

The analysis of the initiator role therefore suggested that this individual held important existing relationships, and knowledge concerning the operations of both the arts organisation and the company. As noted in the quote at the start of this section, the initiator was the individual who could see how the sponsorship could work.

\subsubsection{Decision-making Unit in Summary}

It is evident in the analysis of the cases and responses from experts, that vertical involvement within the DMU was a key characteristic of these decisions. Not only was it a characteristic of the decisions, but it appeared to be essential. Also important to these decisions was the existence of the advocate who believed in the benefits of the sponsorship for the company, and who had the ability to generate support within the

DMU. While the advocate was not always the CCE, involvement of the CCE was a consistent finding. Also evident was the role of Approvers, often a second level of decision, on occasions providing a "rubber stamp" while at other times subjecting recommendations to further debate. Finally, Initiators were noted as individuals who saw 
the opportunity and made the initial approach. While this was not a formal role in the DMU, it was important in that the initiators needed to have a way of opening the door, be it via a relationship and/or their own vision that the partnership would be a success.

\subsection{Investment Characteristics}

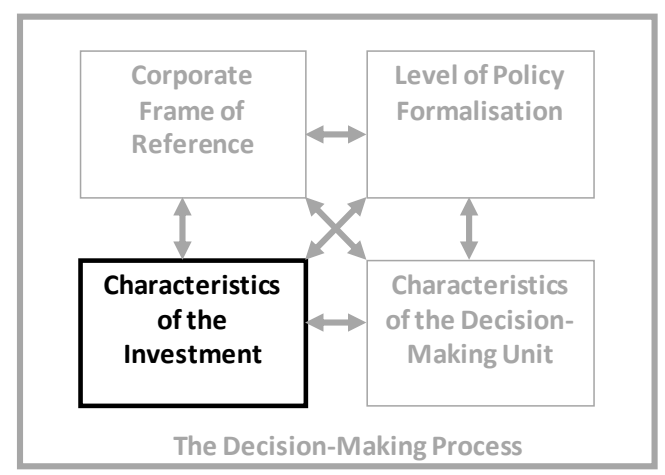

In this study, the "product" was the sponsorship itself, i.e. the event which the company was investing in. As the term "product" does not seem appropriate in this context, the term investment will be used here to refer to this. In analysing the interviews for indications of how the sponsorships were perceived, two main categories emerged (1) the specific characteristics of the investment deemed important to the DMU, and (2) how the investment was aligned with company objectives. These two areas led to further analysis into how sponsorship was viewed as best utilised, and ideas of quality, risk and trust. Each of these will be considered in turn.

\subsubsection{Specific Characteristics of the Investment}

Initial coding of responses revealed that the investment was described by respondents via characteristics of the event, the arts organisation and the arts managers. With respect to the event, the two most common characteristics were the financial commitment, and the longevity of the event. Characteristics of the arts organisations and the managers were also found to be important but were related to an assessment of quality, which will be discussed shortly.

The financial commitment was commented on in every case, and although actual amounts were not able to be gathered across all cases, the commitment was deemed 
"significant" by respondents. In particular, when speaking of the monetary request, a number of points were raised. Firstly, two company respondents noted the need for the amount not to be "out of the ballpark" in the initial ask:

if a sponsorship proposal comes in and it's way out of the ballpark, I mean we just don't even ... one naturally tends to think 'oh no, go away, I can't be bothered.

In three cases, the initial ask was too much, and this led to further negotiations. In these and other cases, reference to getting value for money, was evident: "[the event] is too expensive ... [so] they're adding a bit more value." The discussions also consistently noted the financial commitment beyond the initial cash outlay. This was referred to as leveraging, and represented the amount of money and resources the company might put into the investment (beyond the specific request) to ensure a benefit was realised by the company. This might include additional advertising to promote the partnership, or expenses associated with hosting events for example. All respondents noted leveraging, although for some it was more top-of-mind than others. The discussions of leveraging also related to other characteristics of the investment, particularly the ability to create a win-win situation, and to meet strategic needs.

The other event characteristic noted was the longevity of the event. In seven cases, respondents spoke of the length of time the event had been around, with a long-term event seen as desirable as it carried with it a certain reputation and assurance of the ability to deliver. The history of the event was also viewed as indicative of the potential to maintain a relationship over a long period:

the thing that really appealed to us was longevity... we could own it and with a name for years and years and years. And if you can own something, it builds up over time.

New events obviously did not have a history, and in these cases, the characteristics discussed related more to the need to be assured of the event's success. This appeared to be measured by the history and reputation of the organisation and its individual managers. The history, and reputation of the organisation and personnel, related to 
discussions of quality, risk and trust, key elements which will be examined in section 5.5.4.

\subsubsection{Investments' Alignment with Strategy}

As noted above and in earlier discussions, investments were evaluated and discussed in terms of their ability to fit with company strategy. Although objectives frequently overlapped, and multiple objectives were noted, the statements were initially coded into categories reflecting alignment with (1) company-wide objectives, and (2) marketing objectives.

\section{Company-wide Objectives}

Company-wide objectives were those which went beyond a discussion of the fit with a brand or a particular market segment. The most common company-wide objective noted was that the investment be related to the company's desire to establish a presence in a particular geographic location (evident in 6 cases). While this could be related to marketing objectives, the discussions went beyond a consumer segment. Here, respondents were looking at establishing greater networks in a community, linking with key decision-makers such as government, other business owners, and media for example. Respondents noting the importance of this talked of how the investment could help them gain more of an identity in this particular area, with particular groups or individuals. For example:

What we wanted in [the city] was a property that would provide us with opportunity to host key decision-makers and influencers in that community that would be seen as a quality, innovative but distinctly [city] property and which as I've said would have a broad appeal across the spectrum of [the city]

A related objective involved who the investment might appeal to (beyond the target market), and how this would assist the company in connecting with stakeholders. Groups identified here included government, staff, key decision-makers in an industry, media and other business leaders. 
Also observed was that the above was linked to how the investment would assist in reputation management - particularly with the stakeholders noted as well as with the general public and target segments. The desire for the company to have a sponsorship which they felt reflected company values (such as innovation, creativity and quality) was also apparent as is evident in this response by a company manager, talking about the arts organisation:

\section{It's the organisation, their values and what they're trying to achieve and what their goals are which we align to.}

The objective to have a return on investment was also present in conversations, especially for those companies with a more commercial orientation. However, for most, ROI was not as prominent, with respondents noting they felt it was an obvious part of the equation which would eventually be achieved, though not through sponsorship alone.

\section{Marketing-specific Objectives}

In all cases, sponsorships were linked to their ability to reach a particular market segment with a particular message. In terms of the message, this was oriented to a match between the brand image of the arts event and that of the company. Respondents spoke of this as "resonance" or "fit", one respondent in particular noting that having an obvious fit was crucial to the perception of the sponsorship:

I think if you don't have a fit between a property and the sponsoring brand, it becomes obvious, either immediately or over time, to the target audience at the other end, that there just is a lack of integrity in this relationship.

The need for a fit between the arts event and the company's brand also included the need for a match between market segments. This element, while more prominent in companies with a more commercial orientation, emerged in others as well. In commercially oriented companies, sponsorship was more integrated with the marketing department, in some cases handled by a marketing manager. Sponsorship investments here were discussed in terms of how they would work with the brand objectives, and the target consumer segment. 
The emphasis on the fit between the target segment and the sponsorship was especially crucial in five of the cases. Three of these cases had a strong orientation towards a commercial assessment for sponsorship. In these cases a target segment was identified, the respondents knew the profile of these segments, and knew that the sponsorship would work to appeal to these segments with the "right" message. In the other two cases, the discussion of the segment and the fit was not at the forefront of the conversation, but was deemed nonetheless important. In both of these later cases the decision appeared to have been largely intuitive, the decision makers knowing the investment would work for their market, without a formal evaluation becoming necessary.

In the remaining five cases, consumers were noted, but other stakeholders were clearly more important, such as political leaders and key decision makers in the business sector. These stakeholders were then talked about as a key market, and the investment was discussed in terms of how it would appeal to them, and help the company in getting the right message to these groups.

While these objectives were clearly a part of the decision process, the interviews allowed for a further level of analysis to be undertaken, related to the investment characteristics: how sponsorship was seen to assist in the above objectives.

\subsubsection{How Sponsorship Achieves these Objectives}

Querying the data to determine how respondents felt sponsorship would help meet the above objectives revealed that respondents felt sponsorship was useful via two key avenues: (1) hosting, and (2) brand image transfer.

\section{Hosting}

The ability to use hosting in sponsorship to benefit the company, was noted in nine of the 10 cases. Hosting was when the sponsoring company was able to use the arts event as the basis of a function to which they would invite guests. For example, a sponsored show might be preceded or followed by a cocktail reception. The ability to host key decision-makers, political leaders, and clients or customers was seen as a key tool in achieving both company-wide and/or marketing specific objectives. In terms of how 
respondents felt sponsorship could work for them via hosting, the common pattern proceeded as follows:

1. The event is of a high quality and is an exclusive experience;

2. therefore the event will appeal to key decision-makers / our clients / our staff;

3. therefore we have the ability to invite the identified groups/individuals;

4. the exclusivity of the experience will make them feel valued;

5. the informal (not business) nature of the experience will provide an opportunity to meet outside of a business context;

6. this will help to

a. establish a relationship;

b. demonstrate our commitment to the community;

c. solidify an association between the characteristics of the arts event and the company: quality, location/presence in a community, innovation

7. these individuals are more likely to feel good about their relationship with the company

8. this may influence their decisions at a later time.

Many respondents contributed to forming this pattern, and noted the importance of establishing and maintaining relationships at an informal level:

I think it works well for them just because they're getting something of value. They're getting it at an informal setting. It's with other people so it's not going to be a hard sell and it's not a hard sell. In fact it is just starting that relationship and like with all, you know with all businesses, do I like that person? do I want to do business with those people? and so it's the ability to do that. But without any of the stresses that are actually associated with organising a business meeting.

The above discussion of hosting raises an important point about quality of the investment. As evident, the quality of the event is at the top of the ladder as a key characteristic which will help attract the right people to the events initiated by the company. Further analysis of this characteristic was undertaken and will be discussed later. 


\section{Brand Fit}

In all cases studied, the desire for a fit between the company's brand and the arts event was apparent, and this was part of the evaluation of the investment. In three cases, this fit appeared to be evaluated subjectively or even intuitively. In another three cases the importance of the fit was at the forefront as described below:

[I] looked at the brand plan and the needs that were expressed for the brand in that plan and believed that the sponsorship was going to deliver to some of those needs for building, moving consumers on from awareness to some sort of experience with the brand. . trying to find vehicles to talk about ... the brand story, and being able to deliver an experience to those customers, a brand experience was really what we were hoping to do.

Related especially to these later cases, but drawing also on discussions from other cases, a common pattern here could be described as follows:

1. Information gathered concerning the segment suggests the segment wants a greater connection with the brand;

2. the sponsorship can develop that connection;

3. the sponsorship gives the consumer a greater connection;

4. this improved connection provides a unique association;

- association may be along the lines of a transfer of characteristics from the arts organisation/event, to the corporation, such as quality, innovation and/or fun;

5. improved associations improves top-of-mind;

6. this improves chance of consideration / purchase.

To summarise the above analysis, it was evident investments were subjected to an evaluation related to company-wide and/or marketing objectives, and that this was made in the context of how the individuals in the DMU saw sponsorship working. In addition, the characteristics considered may well also relate to a judgement on the ability of the arts organisation, and its people, to deliver on its promises. 


\subsubsection{Quality, Trust and Risk}

Quality, trust and risk has appeared in the above discussions and appeared as related concepts in the responses obtained. Common relationships found included the evaluation of an investment's quality being related to whether the company felt they could trust the arts organisation; in addition perceptions of quality and the existence of trust served to reduce the perception of risk in the investment.

\section{Quality}

... it also works for us because the event itself is seen as a high quality creative event and linking our brands to that event is helpful. - CCE

In analysing the transcripts, it was evident that quality was considered by the DMU considered, and that all companies were looking for something they deemed as "high quality" although the definitions of this varied.

In seven of the 10 cases quality was associated with the professionalism and reputation of the managers in the arts organisation. An assessment of the managers involved as being professional and organised, and holding a good reputation, seemed to suggest to managers that the event would be of a high quality. In one case, the CSM spoke of the ACE's reputation, and linked this to the evaluation of the investment, The CSM stated:

[the ACE] is an extremely genuine man and very well regarded ... for his personal integrity and his immense knowledge.

In two other cases it was evident that rather than the personal integrity, the respondents considered the professional approach and ability to deliver as important characteristics of the people, and therefore the investment. For example, a CCE spoke of the arts organisation as follows:

they had a [person] who had run it for years. And she ... knows how all the arty bit works and all we had to do was just make sure that she went in our direction... and so all we had to do was just floss it up a bit. 
A second relatively frequent measure of quality was the public perception or reputation of the event. If respondents felt the event was "seen as" a high quality event, they accepted this assessment as quality.

Other associations with quality included the range and quality of the artists, the longevity of the event (as noted earlier), and the link or fit with the company. With the last point, some respondents noted that quality would be relative and could only be assessed by considering what it was the company was looking to do.

In the respondents' discussion of quality then, multiple measures appeared, including the reputation of the managers involved and/or the event, the longevity, and the artists. In addition, this was interpreted through the frame of the company's goals and objectives. It was also evident that statements concerning quality were usually related to two other concepts: trust and risk.

\section{Trust}

[arts sponsorship is] a leap of faith. If you haven't got a video of the thing ... you need the trust, people that trust you - Expert

We do business ... with people that we like, most of us, or at least that's a foundation or platform and we can move on from there. People that we trust. - CSM

Trust appeared as an element in all cases, and was linked to both quality and risk. The assessed quality of the event appeared to help develop a sense of trust, which in turn reduced the perception of risk.

However trust did not only appear to be derived from a measure of quality. As noted in the opening quote to this section, trust was very much about the individuals involved. One CSM noted that the element of trust in individuals was a key criterion on which the investment was evaluated: 
do we get a sense, either objectively or subjectively, do we get a sense that these people will deliver? Can we trust them? - CSM

Many respondents stated that a past relationship had allowed them to build and develop this trust. Other respondents expressed that the longevity and reputation of the event, often assessed as a measure of quality, also helped to establish a level of trust.

In looking for patterns and the link between trust and the decision, trust was linked to an indication that there would be a partnership and ultimate success. One respondent noted that trust between individuals helped to open the lines of communication, which was seen as essential.

[the ACE and CSM] were able to talk very frankly to each other about the operational difficulties, about framing the sponsorship ... because we had these already established personal relationships we were able to be completely frank with each other. . . and I think that openness and honesty right at the start was important. - ABM

Others did not get as specific, but did note that if there was trust, they felt that they could work with the arts managers. Trust, was seen as a signal that there could be a partnership, to which the company could contribute, for which they could leverage their investment, and from which they could ultimately benefit.

\section{Risk}

In considering trust and quality, respondents were often looking for assurances to reduce risks. Risk did not seem to enter into these decisions overtly, but underlay them. However, a probing question was posed in all interviews to explore this area, given the emphasis on risk in the literature (Johnston \& Lewin, 1996) and the link implied in many cases with quality as noted above.

In response to the particular question on risk, most respondents stated that risk did not enter into the decision, but further analysis suggested this was either eliminated early on, or was sought to be reduced throughout the evaluation in a less obvious way. When respondents were asked to consider risk, they were able to identify areas for which they 
could see that risk may enter into the decision. Some of these areas are described in Table 5.7. The most commonly noted risk was the risk of being seen to be too elitist (noted in 5 cases). As a result, many respondents felt it was very important to align their company with an event which held popular appeal. This was further related to the company's mission and goals - if they were a company oriented to appeal to a wide community, these companies were more concerned with this risk. Other noted risks included the risk of being seen to be doing something political vs. something "businessrelated" ( 2 cases, 1 company), the risk of not getting the fit right ( 2 cases, 1 company), and the potential for a damaged reputation in exiting the sponsorship (1 case).

Further investigation showed how the perceived risk appeared to be alleviated. As noted, respondents did not enter into sponsorships which they felt may open themselves up to risk, However, in further analysis it was found that respondents took actions to reduce the chances of risk. In seven of the cases, a link could be drawn in the respondents' comments between the quality of the arts managers, a high quality event (for example, case A in Table 5.7).

Three cases $(\mathrm{A}, \mathrm{D}, \mathrm{E})$ specifically noted that they felt better about the investment having seen the company and the professionals within the arts organisation at work. In three other cases $(K, G, J)$ the risk appeared to be reduced due to one individual's personal knowledge of the event and those involved, coupled with this person's authority in the company. Other means of reducing the risk included reference to the event and organisation's reputation and history (some respondents sought out reviews to obtain a measure of quality which then reduced risk).

It was evident therefore, that company respondents were aware of a number of potential risks. If they felt that there was a level of trust with the arts managers, the risk seemed to be reduced. Also, if the event was assessed as a high quality event either via the event, organisation and/or staff, the risk again would reduce. This is of course in the context of the sponsoring company and their mission and objectives. One respondent noted that a company may in fact look for a "high-risk" controversial event, if this is what fits with their brand, mission and objectives. In this sense, risk then relates back to the company frame of reference. 


\section{New vs. Renewing Perspectives}

In querying the data for the above, it was evident that consideration should be given to the variations between new and renewing relationships, vis a vis quality, trust and risk.

Two of the ten cases were renewing-type relationships. As expected, in the case of a renewal, the extent to which the company was familiar with the arts organisation served to mitigate risk, and therefore it appeared less of a concern. However, there was not a strict division between the new cases vs. renewing cases. What appeared to be more important was the extent to which individuals knew one another and/or the arts organisation. For example, one respondent from a renewing case stated:

... being associated with a high quality event does have benefits and the [event] has been a very well organised, very professional and very high quality event, and I've no reason to think that [next year's event] won't be the same - $\mathrm{CCE}$

The above quote suggests that past experience of the individual was used to judge quality and make a judgement on the future experience. This is expected in the renewal case, but was not limited to this case. For example, a respondent in the case of a new sponsorship relied on his personal experience of the event, rather than a previous relationship with the arts organisation, but still made a judgement:

... because I knew about it I could go to the people I had to convince internally and say look this is a really good proposition for us. . . I knew that both from a PR perspective as well as from a straight marketing perspective that was going to be useful in terms of building brand awareness. - CMM 


\section{Case Description of risk and stage of process}

$\mathbf{A}$

CSM: Risk associated with controversy.

It would have to be with a reputable organisation. It would have to be something that wasn't controversial. - CSM

Risk considered early in the evaluation.
How was risk alleviated?

Evidence of professionalism and third-party assessment of quality

just meeting with the [arts organisation] and seeing how professional they were, and looking at reviews and seeing how well thought of they were. So we felt that we could safely continue with that sponsorship without it being of any concern to us. - CSM

we thought it was low risk. Because it is not controversial .... They had a really good reputation. They have a high standard in their performance. - CSM

\section{Alleviated in arts org programming}

they do some very demanding and challenging work but they also do a popular family show as well and they recognise that they have to appeal to all groups and my view, for [our company], that is not unimportant. - CCE

... a concern that they might be seen as elitist and that they're not necessarily available to everyone ... we want to be able to support community activity as well as high end refined art activity and that's been a key driver for us. - CCE

Risky projects were eliminated early in process.

company more risks because a new event ... the plan might not deliver the wonderful

Risk acknowledged. 
it really is a premium event, it has a reputation as a great event and is regarded as such in the public mind as a pretty special and well Risk assessed early in evaluation.

F $\quad$ CMM: exit and reputation risk

\section{CSM: elitist risk}

you have to be extremely careful about the quality of the counter-party and have some real assurance around their ability to deliver ... Sponsorship is by its very nature about profile and so if it goes sour it can make a huge impact negatively. ... The particular risk around sponsorship is exiting the sponsorship... When you sign up with somebody for three years usually, do you know how you are going to get out of it if it doesn't go very well at the end of three years or will you be dragged through the town and tarred and feathered because you dared to not give money to my favourite cause. - CMM

We need to be mindful of, particularly with arts actually, we're very mindful of anything that looks too elitist.... We want the public to feel as if we're giving something back to each and every New Zealander. So it's about our reputation and our image in the marketplace - CSM

Risk assessed early in evaluation.
Quality of arts organisation. Choose event carefully.

you have to be extremely careful about the quality of the counterparty and have some real assurance around their ability to deliver - CMM

CSM talks mainly about elitism - just don't sponsor things they think will develop bad publicity. 
CCE: risk of dull elitist association, and risk of not gaining benefit via naming.

There were two risks. One was that the event had gone down the tubes and part of that was because of [the artform] you know. ... So there was the risk that you know yawn, yawn, yawn. And the other risk was ... could we actually supplant [the past sponsor]. - CCE

Risk underlies decisions.
Confidence in people managing it and confident in their own ability to work with the event.

Now those risks were ameliorated because we thought [the arts organisation managers] can make this work, and we [the company] can convert it ... get over the risk that it's boring. And secondly we, we had the confidence that [our company] could make it.

[Interviewer:] ... How did you know that?

We're just innately confident. - CCE

I mean it's pretty hard to be nervous when you've got [a variety of art and celebrated artists] - CMM

we all knew each other so we didn't have to go through that, figure out how it was all going to work - CMM

$\mathbf{K}$

\section{Risk of elitism vs, brand}

[these arts events] can be a seen as a bit highbrow which is not necessarily [consistent with our company values] ... the risk would have been that the type of event wasn't going to match our brand values. - CMM

Risk underlies decisions.

\section{Respondent's own knowledge}

perhaps if there hadn't have been somebody like me sitting here who had [this experience with the arts event] they wouldn't have had an internal sponsor to push it any further. But because I knew about it I could go to the people I had to convince internally and say look this is a really good proposition for us. - CMM 
The above does not argue that there may be differences between new and renewing investment decisions. However it does illustrate that perhaps the more important influence in establishing quality, risk and an ability to trust, is the experience individuals may have with the event/organisation/staff - whether it is based on a past sponsorship relationship with the arts organisation, or not.

\section{How the Experts Put it Together}

The expert respondents agreed that assessments of quality and risk would need to depend on the company, and what their objectives were. However, there was agreement that an arts event had to be of a certain standard, and part of that standard was that the arts organisation be able to demonstrate an ability to deliver on its promises. One respondent stated that arts organisations need to operate with a commercial approach, which would then imply quality and reduce the risks. Part of this equation however, included reputation, and acknowledgement of the importance of an individual reputation was especially evident in experts whose experience was largely on the arts side. One such respondent noted,

\footnotetext{
if you perform well for a company then that person next time you come along to them and say look we've got a new opportunity here for you, they all say gee the last time it worked really well and we can trust this guy because he over delivers on what he promises and he's done it every time. - Expert
}

A specific comment made by a number of respondents was that the arts organisations needed to "under-promise and over-deliver." This was not noted as a contrived strategy, but rather a necessity, as sponsorship is by and large intangible.

\section{Arts vs. Corporate Perspectives}

Of note is that mention of quality and trust was less frequent in conversations with arts respondents as compared with company respondents. This is not surprising as company respondents tended to go into more detail about the evaluation process, while arts 
respondents had less insight into the actual evaluation. However, arts managers did note similar elements: specifically mentioning the need to demonstrate professional practices, to maintain a good reputation both individually and as an organisation, and not to appear too elitist. The differences between arts manager responses and company managers was that the company managers were better able to verbalise the links between these concepts, and were better able to drill down to the rationales, suggesting these ideas of risk, trust and quality were more top-of-mind for sponsoring companies.

\subsubsection{Investment Characteristics in Summary}

To conclude the discussion on the investment characteristics, and how they were evaluated, a number of key points have been raised. Firstly, investments were evaluated based on company-wide objectives, stakeholders, and specific marketing objectives, with a fit desired between what the investment could offer, and what the company needed. Secondly, how the sponsorship was to be utilised, especially in terms of hosting opportunities and brand fit, entered into the evaluation of the investment. In other words the investments were evaluated in terms of how the company perceived it would use of the sponsorship and how successful they thought this would be. Finally, it was clear that companies considered some risk associated with sponsorship, but this was alleviated by the perceived positive reputation and professionalism of arts managers and the event itself.

\subsection{The Process}

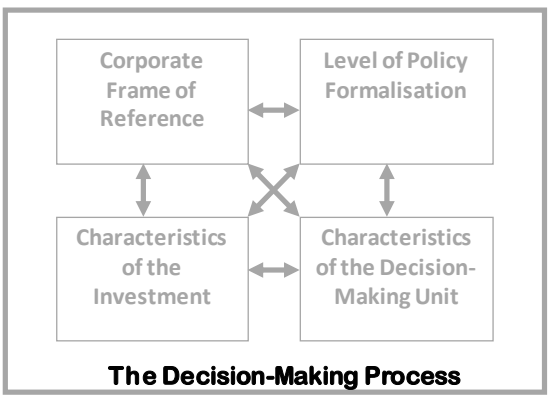

As outlined in the initial framework for this research, opening the black box of arts sponsorship decisions was proposed as revealing the elements which influence and characterise the process, as well as the process itself. The above discussions have provided results according to each of the elements initially put forward in the 
framework. This section will provide an analysis of the results as they pertain to the steps in the process of decision-making. As such there will be some overlap with elements in previous sections, but will be viewing these from a different angle.

Responses related to steps in the process were gathered and coded for all respondents in each case. Information on both sides of the decision was important to fill in areas which one person did not remember, or may not have been party to. The initial tree node structure for analysis of the decision process followed a framework including need recognition, evaluation, decision and post-decision. Two additional categories emerged from the analysis: initial source and process influences.

To assist in this analysis, a visual mapping approach was taken for each case, depicting the case as a process. This has been proposed as a method which assists in sensemaking, in terms of identifying patterns (Langley, 1999; Miles \& Huberman, 1994). An example of a map is located in Appendix 6. Using these maps, a temporal bracketing strategy was employed, meaning that each case was divided into phases which were then compared and contrasted. While the maps were useful for within-case analysis, cross-case analysis was facilitated with the use of matrices built for each of the phases. The above analysis suggested five phases of the process:

1. pre-approach context,

2. approach,

3. evaluation,

4. decision, and

5. post-decision.

A summary of the processes for each case, according to the above phases is included in Table 5.8 and will be discussed in following sections.

Throughout this analysis, earlier findings from earlier sections again came to the fore, although now given a "place" in the process. Therefore, to avoid too much repetition when findings re-emerge, earlier sections will be referred to when appropriate and evidence via quotations or matrices will not be repeated. 


\section{Table 5.8 Summary of Case Processes}

\begin{tabular}{|c|c|c|c|c|c|c|}
\hline & $\begin{array}{l}\text { Process } \\
\text { Category }\end{array}$ & Pre-approach context & Approach & Evaluation & Approval & $\begin{array}{l}\text { Post- } \\
\text { decision }\end{array}$ \\
\hline $\mathbf{A}$ & $\begin{array}{l}\text { low-level } \\
\text { driven }\end{array}$ & $\begin{array}{l}\text { The company inherited the } \\
\text { sponsorship in a takeover. The CSM } \\
\text { was charged with a review of the } \\
\text { sponsorship in relation to the } \\
\text { company's activities. The CSM } \\
\text { identified the company's priorities in } \\
\text { managing their reputation in the } \\
\text { geographic location in which the } \\
\text { sponsorship was based. }\end{array}$ & $\begin{array}{l}\text { In a type of renewal } \\
\text { process, the CSM } \\
\text { approached the ACE to } \\
\text { begin discussions, the } \\
\text { CSM being assigned this } \\
\text { responsibility. }\end{array}$ & $\begin{array}{l}\text { CSM reviewed fit and quality in } \\
\text { consultation with staff. Meetings } \\
\text { with ACE helped to determine } \\
\text { professionalism. CSM became a } \\
\text { strong advocate, made a } \\
\text { recommendation to CMM, which } \\
\text { was sent to the CCE. }\end{array}$ & $\begin{array}{l}\text { Internal } \\
\text { recommendation } \\
\text { by CSM to CMM, } \\
\text { then goes to CCE } \\
\text { for final approval. }\end{array}$ & $\begin{array}{l}\text { CSM } \\
\text { manages } \\
\text { with ACE. }\end{array}$ \\
\hline $\mathbf{B} *$ & high & $\begin{array}{l}\text { The company was faced with a } \\
\text { renewal of the sponsorship which in } \\
\text { the past was seen as "owned" } \\
\text { internally by the CCE. The company } \\
\text { had clear goals related to CCI, and } \\
\text { often used sponsorship to support } \\
\text { relationships with key stakeholders in } \\
\text { the location of the sponsorship. }\end{array}$ & $\begin{array}{l}\text { Approach happened } \\
\text { automatically at the end } \\
\text { of the previous year's } \\
\text { relationship. The CCE } \\
\text { and CSM were both } \\
\text { "asked" in conjunction. }\end{array}$ & $\begin{array}{l}\text { CSM's initial evaluation was not to } \\
\text { engage in sponsorship. CCE felt } \\
\text { opportunity existed for a good fit, } \\
\text { but the value was not evident. CCE } \\
\text { is advocate and negotiates with ACE } \\
\text { who returns with variation in } \\
\text { proposal. CCE accepts this and } \\
\text { presents recommendation to board. }\end{array}$ & $\begin{array}{l}\text { CCE made } \\
\text { internal decision, } \\
\text { then final } \\
\text { recommendation } \\
\text { put forward by } \\
\text { CCE/CSM to } \\
\text { board - approved. }\end{array}$ & $\begin{array}{l}\text { CSM further } \\
\text { negotiates } \\
\text { benefits and } \\
\text { manages } \\
\text { relationship. }\end{array}$ \\
\hline C* & 3rd party & $\begin{array}{l}\text { The company was looking for a way } \\
\text { to establish a presence in a particular } \\
\text { geographic location (location of arts } \\
\text { initiative). At the same time, many } \\
\text { personal links existed between the } \\
\text { company managers / executive and } \\
\text { the arts organisation. This company } \\
\text { also has clear goals related to CCI. }\end{array}$ & $\begin{array}{l}\text { The ABM initially opens } \\
\text { the door with the CCE, } \\
\text { but also making a link } \\
\text { with another ABM in a } \\
\text { related business. Once the } \\
\text { CCE expresses interest } \\
\text { the ABM lines up a } \\
\text { meeting with the CCE, } \\
\text { CSM and another ABM. } \\
\text { The approach is to gather } \\
\text { interest and get feedback } \\
\text { from the CCE. }\end{array}$ & $\begin{array}{l}\text { CSM and ACE met to develop ideas } \\
\text { further to capitalise on the fit. Other } \\
\text { arts managers helped to develop the } \\
\text { justification. Very open } \\
\text { communication and several meetings } \\
\text { occurred. CSM and CCE present } \\
\text { recommendation to the board. }\end{array}$ & $\begin{array}{l}\text { Felt that } \\
\text { CCE/CSM } \\
\text { together made } \\
\text { internal decision. } \\
\text { Final } \\
\text { recommendation } \\
\text { put forward by } \\
\text { CCE/CSM to } \\
\text { board - approved. }\end{array}$ & $\begin{array}{l}\text { CSM } \\
\text { manages } \\
\text { relationship } \\
\text { /leveraging. }\end{array}$ \\
\hline
\end{tabular}


CSM was advocate, working to

commercial orientation, with duties related to sponsorship falling to the CSM. The company also had a history of sponsorship relationships in the arts sector. Objectives and goals had just been set for a particular brand, for which a clearly identified market existed. The ACE had informally met the CSM at a function.

\begin{tabular}{|c|c|c|}
\hline $\mathbf{E}^{\circ}$ & $\begin{array}{l}\text { low-level } \\
\text { driven }\end{array}$ & $\begin{array}{l}\text { The company had a strong } \\
\text { commercial orientation with duties } \\
\text { related to sponsorship falling to the } \\
\text { CSM. The company also has a } \\
\text { history of sponsorship relationships } \\
\text { in the arts sector. Objectives and } \\
\text { goals had just been set for a } \\
\text { particular brand, for which a clearly } \\
\text { identified market existed. The ACE } \\
\text { had informally met the CSM at a } \\
\text { function. (same company and similar } \\
\text { circumstances as in case D. }\end{array}$ \\
\hline & high & $\begin{array}{l}\text { The company felt they have a role in } \\
\text { supporting the community, but also } \\
\text { have a commercial orientation. The } \\
\text { company had recently increased thei } \\
\text { operations in the locale in which the } \\
\text { sponsorship exists. ABM and CCE } \\
\text { are well-connected in the business } \\
\text { community. A previous approach to } \\
\text { this company by this arts } \\
\text { organisation was declined. }\end{array}$ \\
\hline
\end{tabular}

pitch/proposal initially to convince the Brand Manager of the the CSM

\section{The ACE made initial pitch via phone to the \\ CSM, followed by a} meeting with the ACE,

CSM and Brand Manager.

A formal proposal

followed.

The ABM approached the CCE individually. Time was limited as the arts event was approaching quickly. benefits. Brand Manager assessed based on brand objectives. Meetings held between BM.CSM and ACE sometimes others. Proposal developed by CSM and BM sent to CMM for approval, ultimately to CCE.

CSM was advocate, and sought support of Brand Manager who made an assessment based on brand objectives. Meetings held between BM, CSM and ACE. Proposal developed by CSM and BM sent to CMM for approval, then to CCE. (similar to case D). CCE reassesses and requests renegotiation based on a shift in brand strategy.

Evaluation appeared to be conducted based on intuition and personal knowledge of CCE.
CSM/Brand

Manager after bringing CMM into discussions, made decision -

"gentleman's agreement."

Ultimately sent to

CCE, but not until after the agreement was well on its way. CSM/Brand CSM /

Manager and CMM made recommendation to $\mathrm{CCE}$. CCE requests changes. Ultimately revised proposal is approved by CCE. Manager manages relationship/ leveraging.

CCE made

decision. Board approves.

CSM/CMM

negotiate benefits post-

decision. CSM/CMM manages relationship. 
This company is a smaller organisation, with the role of sponsorship decision-making falling to the CCE. The company had been in a business relationship with the arts organisation, and the CCE was knowledgeable on the art-form. The company was looking to establish greater presence in the locale of the arts organisation.

\begin{tabular}{|c|c|}
\hline $\begin{array}{l}\mathbf{H} \text { high / 3rd } \\
\text { party }\end{array}$ & $\begin{array}{l}\text { The company had strong and clearly } \\
\text { defined goals of being involved in } \\
\text { the community and "giving back." } \\
\text { Sponsorship as seen as an overall } \\
\text { brand management tool, } \\
\text { responsibilities falling to the } \\
\text { CCE/Executive. The company had } \\
\text { made unsuccessful efforts in the past } \\
\text { to enter into the arts sector. } \\
\text { Relationships existed between the } \\
\text { ABM and the CCE. }\end{array}$ \\
\hline J high & $\begin{array}{l}\text { This company is relatively small and } \\
\text { privately owned. The owners had a } \\
\text { strong sense of social responsibility } \\
\text { as well as a long-time relationship } \\
\text { and rapport with the arts } \\
\text { organisation. Individually the ACE } \\
\text { and one owner had a rapport. }\end{array}$ \\
\hline
\end{tabular}
organisation. Individually the ACE one owner had a rapport.
The CCE became aware of the opportunity via their business dealings. No evidence of a forma approach.
Evaluation conducted based on intuition and personal knowledge of CCE. CCE was advocate, holding informal conversations with other owners. Formal assessment and leveraging occured post-decision.

\section{ABM made informal} suggestion to CCE (Proposal entered in at evaluation stage.)

.
quick evaluation was made. A quick intuitive judgement was made of the arts organisation's ability to deliver benefits. CCE was advocate. Presentation and proposal by arts organisation was not seen as good, but executives were confident in the event.

ACE approached the owner who expresses interest. Owner then puts idea forward to other owners/CCE.

Owner is immediately advocate. Evaluation appeared to be conducted based on intuition and personal knowledge of Owners.

Formal assessment and leveraging
CCE made decision in conjunction with other owners, but felt very much a "done deal." CCE had responsibility at this level.
CCE works to extract benefit and manages relationship. occured post-decision.
Quick agreement made between owners and CCE. No higher level necessary for this company.

\section{CCE/COO made Marketing} decision early on. No board approval necessary. monstaff work with arts organisation to extract benefit and manage relationship. 
K low-level driven/ 3rd

This is a large organisation with a

commercial orientation. The

company was in process of entering

into a new locale in which the arts

initiative was present. The CMM

held responsibility for sponsorship

recommendations. The CMM also

held considerable personal

knowledge of the arts event. The

$\mathrm{ABM}$ had a rapport with executives

in company related to the company
ABM approached a 3rd

party in related business

who then made an e-mail

recommendation to the

CMM. This opened the

door and a forma

proposal was provided

later.

concerned.
CMM evaluated the investment on a commercial basis and also feel strongly

it will be successful for the company.

Internal negotiation was required in

putting the case to higher and higher

levels. CMM was advocate.
Approval achieved at

higher level following

internal

proposal/negotiations
CMM

manages relationship. 


\subsubsection{Pre-approach Context}

In analysis of the cases, the pre-approach context set the stage for the decision, and includes the context prior to an approach being made. In an organisational purchasing decision, the pre-approach context might include the recognition of a need, development of specifications, and a search for the appropriate product. It was quickly determined in the cases studied, that sponsorship processes were not pro-active, and a specific need for sponsorship was not evident. Decisions were not about searching for the right opportunity, but more about sorting through the pile of proposals. The analysis of this phase thus involved looking for underlying needs, as well as assessing what appeared to be important in the context prior to the approach. Three key findings were evident and will be reviewed:

1. the perception of sponsorship set the stage

2. decisions were considered in light of company objectives, and

3. existing roles and relationships mattered.

\section{Sponsorship Perceptions}

Firstly, in considering the cases, it was clear and has been noted in section 5.2 that the perceptions of sponsorship held by those in the DMU helped to set the stage for these decisions. The extent to which individuals found sponsorship ambiguous and uncertain (or not) influenced the remaining process, especially the evaluation. The extent to which individuals saw sponsorship's role as fulfilling a commercial and/or philanthropic role also influenced the remaining process.

In addition to individual perceptions of sponsorship, and also as in section 5.2, the company philosophy was important in the pre-approach. It was evident in all cases that the need to be a good corporate citizen, to support the community and "give-back" was related to sponsorship. However some companies held more of a commercial approach, while others were more extreme on their philanthropic approach. The range of orientations individually and at a company level helped to set the stage for the process, and also appeared influential in evaluation and decision phases. 


\section{Role of Company Objectives}

The second point evident in the pre-approach was the reinforcement of the role of the company-wide objectives - which related to alignment, as discussed in section 5.5.2. In looking at the pre-approach, all of the cases had needs or objectives which were later successfully filled via sponsorship. These objectives were not pre-defined "specifications" such as a need for an arts sponsorship in a particular city appealing to a particular market. Rather they were expressed as a need to be a contributing part of society, combined with a need to achieve the company's mission, to appeal to a particular market, and/or fulfil brand objectives. It was frequently in these objectives that the key stakeholders would be identified, at times as a consumer market, at times key industry and/or government decision makers. However these needs and objectives were not necessarily related to sponsorship in the pre-approach stage.

\section{Roles and Relationships}

Finally, roles and existing relationships were important characteristics of the preapproach. The formally assigned role of the individual in terms of sponsorship was crucial in four of the ten cases. In these four cases, the CSM or CMM was formally assigned the role of evaluating sponsorship decisions, and undertook this duty. In other cases the responsibilities appeared to be more fluid, with the CSM/CMM involved, but the CCE or other executives taking on more active roles. As expected the fluidity or rigidity of roles had an impact on the DMU which then influenced the evaluation.

Another perspective on roles in the pre-approach involved the existence of the advocate (see section 5.4). The advocate was the internal individual who supported the decision as it progressed, but was also within the company at the start. The idea of a person who internally "owns" the relationship was noted, and emerged again in this analysis.

The recognition of relationships was also very important in the pre-approach. As noted in 5.4.3, in considering the initiators, a relationship of some extent was always in existence in the cases studied. These relationships included ABM-to-CCE, ACE-to$\mathrm{CCE}$, and $\mathrm{ABM}$-to-other key individuals, but the relationships were existing prior to an approach. The next phase then involved the mobilisation of these relationships. 
The themes noted above - the perception of sponsorship, the existing company objectives and the existing roles and relationships - were the most commonly recurring themes in the analysis of the elements important in setting the pre-approach context. In addition, throughout this analysis it was clear that the "need" for a sponsorship is not something set down like specifications required in a product, rather there needed to be a happenstance, where the sponsorship fit with the company's context.

\subsubsection{Approach}

The next stage was that of the approach. This phase was determined as the time in which an action was made to make a request to the company on behalf of the arts organisation. At times this request was made via other parties, in which case the activities were traced back and included as part of this phase. For example, in one case the approach phase included the ACE contacting the CSM by phone, and later following this up with meetings and a proposal. In another more complex case the approach phase included the $\mathrm{ABM}$ contacting a third party, who then approached the CMM informally, followed by a more formal proposal by the ACE and others from the arts organisation.

Again, consideration of this phase found replication from previous sections. In particular, characteristics of this phase included the need for an alignment with the company's context and objectives, as well as the importance of the role of the initiator. Each of these will be addressed within the context of the process.

\section{Alignment with Company}

As noted, it was evident that there needed to be a fit between the company and the arts initiative. The idea of fit has been examined in section 5.5 in depth, however looking at this from a process point of view reveals that without an initial fit, the approach would not progress. Firstly, companies appeared to undergo an initial elimination process (section 5.3.2), culling those requests which did not immediately appear to fit the company context. In addition, requests which appeared to be out of the financial ballpark were also eliminated (see 5.5.1). On the "acceptance" side of the argument, many of the responses indicated that the potential for a fit was assessed and evident at the approach stage. In eight of the ten cases, it was evident that a judgement was quickly made on the fit, even if it was just by one individual. The remaining two cases moved more formally 
from the approach to the evaluation via negotiations, without evidence of anyone getting immediately enthused. In both of these later cases $(\mathrm{A}, \mathrm{E})$, the relationships between individuals were not well-established, and formal processes seemed to take precedence.

\section{The Initiator}

The idea of previous relationships being established was the next key component of this approach phase. As noted in the pre-approach, relationships may have existed but needed mobilising. As noted in section 5.4.3, the initiator was the individual who saw the fit, and made use of a relationship to get the approach started.

Apparent in the above is that while this phase is called the "approach" phase, there is evidence some amount of evaluation is going on. Initiators did their own evaluation they saw that this would fit and therefore began the approach. However in the approach, some cases had evidence of some evaluation within the organisation and in the approach phase. The extent of evaluation within the approach phase could be viewed on a continuum. At one extreme were cases in which a quick judgement was made at the approach stage, and the evaluation stage was virtually skipped (F,G, H). In these cases it was clear that the decision-maker was not only knowledgeable about the arts initiative, but had the authority to make the decision. At the other extreme were decisions in which potential was seen in the approach phase, but this then led to a rigorous evaluation stage. Here, companies tended to be more commercial in their orientation and the CSM played a more formal role in sponsorship evaluation.

\subsubsection{Evaluation}

The evaluation stage began after the approach, and was generally characterised by internal meetings, negotiations between parties and consideration of the request within the company. Analysis of this phase involved querying the data to consider how the evaluation was done, who was involved, and what the processes were within this stage. Key results included the following findings:

- alignment and risk was assessed in this stage if not assessed in the Approach;

- this stage often included an internal "sales pitch" up the company ladder;

- intuition, personal knowledge, instinct and subjective judgement often played a role in the evaluation. 


\section{Importance of Fit and Risk}

Given the importance of fit and risk, it was expected that these elements would feature strongly in this phase (see section 5.5). For both of these elements however, there was variation in how they were considered in this phase.

For alignment, it was noted earlier that an initial sense of fit was essential to move from the approach stage to evaluation, and this was expected to be further developed during evaluation. In all cases except one, there was evidence to support that the fit was considered at some level, and in many cases, this moved into detailed discussions of how to extract the benefits. Specifically, in six cases fit and benefits were focal points of the evaluation stage. In these cases respondents spoke of how the sponsorship would work with their plans for the brand/company and how it would be used. Such discussions considered the hosting opportunities, the similarity of markets etc., dependent on how they saw the sponsorship working with their company. However, in four of the cases, the evaluation of the fit with the company appeared to be done almost intuitively with most of the consideration in the approach phase. In these cases the assessment of fit was evident at the approach, and further evaluation of this seemed to be a judgement by a key individual. Negotiations around benefits and how these would be realised also did not occur in this phase for these last four cases.

A similar finding occurred for risk, with three cases evaluating the sponsorship with an eye to the quality of the arts event, and the reputation and professionalism of those involved - all elements discussed as serving to reduce risk (see section 5.5.4). At the other extreme, in four cases it appeared that the risk had been addressed and eliminated early on, based on personal knowledge of people and events. In these cases the evaluation was minimal. For the remaining cases, one had an entirely individual and quick evaluation for which the evaluation phase was difficult to unpack, and the other two fell between the two extremes, with some element of risk being considered in the evaluation phase, although not overtly. 


\section{Internal Processes and the DMU}

Another key finding in this analysis was the internal processes within the evaluation phase, involving high levels of executives and a strong presence of the advocates. These internal discussions involved a sub-phase of convincing others in the company of the benefits of the sponsorship. Again, there was variation in these processes. In the cases characterised with short evaluation phases, where intuition and individual judgement played a stronger role, the internal processes were minimal - in one case there was reference to a single meeting with others in the company, in another there was no reference to any internal discussions. In other cases the CMM or CSM developed their own proposal, to put forward to the next level of approval. One CSM also noted that they had to actively work to bring another manager on side.

As well as being a sub-phase of convincing others, the internal sales process stage included participation by up to 4 levels in the organisation, at times including managers in lateral departments, but more often than not vertical representation, always moving up the company ladder to higher levels. The involvement of higher levels of executives has been noted as a characteristic of these decisions (see section 5.4). In assessing the evaluation stage it was evident that in seven cases, if a high level executive was not already present from the approach phase, they became part of the DMU in the evaluation stage. In only 3 cases did the higher levels enter in at the decision/approval stage.

The other characteristic of the internal process phase was the role of the advocate (see section 5.4.3), the individual who believed in the benefits of the sponsorship and was able to convince others within the company. Often this individual had a higher level of knowledge concerning the investment, and could better justify the investment. In many cases it seemed that without this individual the investment would not have happened. As one advocate noted, “ [if] I didn't know about it I don't think it would have gone any further" (CMM).

\section{Intuition Plays a Role}

As evident above, some cases were notable in their lack of formal evaluation, and presence of individual judgement or intuition, where respondents commented that they 
just felt it was the right thing to do, or they knew the benefits, and did not need to detail them. In addition, it was often the advocate who held this intuition. In many of these cases the respondents noted that they felt there was opportunity there, and a decision was made at that stage. One respondent described the "evaluation" as follows:

So they came up, asked us, we said yep we can make this work, simple as that...

[Interviewer] Even though the proposal itself didn't grab you?

Oh it sucked. It was useless but that's alright we could see the possibility - CCE

For these cases, in which intuition played a strong role and "shortened" the evaluation phase, the discussion of specific benefits occurred post-decision. In addition, for three of these four cases the respondents expressed a relatively strong orientation to philanthropic goals.

Taking the idea of intuition further in the analysis, it was noted that even when the evaluation stage involved multiple steps and appeared to include an in-depth evaluation, this process still held an element of subjectivity. For example, one respondent in a case which went through a relatively rigorous evaluation phase, stated the following:

When we went through the process of evaluating the strategy ... we also developed a statistical model ... [but] it's all subjective, because it's always going to be, but [the statistical model] enabled us to relatively rank properties against one another.

... because I get so much information about who wants what, what's happening in the market, what other sponsors are doing, what businesses are doing, what our business wants to do, I know - I can actually get a good sense of what a proposal is kind of worth in terms of what they're offering or what they're reaching, and what all that sort of stuff is. - CSM 
This quote both notes the subjective nature and the importance of intuition based on knowledge. Certainly in the cases in companies deemed more oriented to philanthropic goals, intuition of senior managers played a part, but the finding above points to a level of intuition for other cases as well, and at other levels in the DMU. One respondent noted how instinct fit in with the process:

You just know instinctively it's a good fit for us. . you go through [the processes] and you make sure that ... you eliminate the risk that you can. But certainly there is a lot of instinct involved in our sponsorships. - CMM

\subsubsection{Decision}

The decision phase began at the point of someone in authority making a decision that the sponsorship should go ahead. As noted in the DMU results (section 5.4), there was often a decision internally, which was followed by final approval. In four of the cases studied, the "decision" appeared to be made at one level, followed by a formal approval at a higher level. In another four cases the decision and approval were conducted in one stage, at the level of the CCE/Owner. In the final two cases, comments pertaining to a final decision suggested that no decision was made until a higher level of discussion had ensued. Each of these scenarios will be discussed.

\section{Internal Decision Followed by Approval}

As noted, in four cases the decision phase had two elements. The first was that an internal decision had been made as a result of internal processes. The decision was then represented in a proposal document which was put forward to higher levels for approval. In these cases, respondents felt that the "homework" had been done and were confident that approval was relatively certain. However, most respondents also noted that they expected and would accept "robust discussion" at higher levels. In three of these cases the CSM or CMM made the recommendation and justification to the CCE, which was followed by Board approval. In one case the CCE "owned" the relationship, made the internal decision and then put it forward with the assistance of the CSM, for board approval. In all cases it was felt that the decision put forward was essentially a "done deal." 
The idea of a "done deal" was explored further in these cases. Questions such as why was this assumed, and in which cases was this assumed but did not actually eventuate, directed this analysis. The results pointed again to the level of fit with the company's mission and objectives. In these "done deal" cases the respondents felt confident in their justification of the fit with the company's objectives and goals, and the benefits of the sponsorship. In contrast, for one case an internal decision was made and felt to be a "done deal" yet approval was not in fact granted, and more negotiations resulted. In this case, the CCE held more information than others - and more than the Advocate -concerning the objectives and direction for the brand. Therefore the "fit" was called into question, as was the decision.

\section{Decision and Approval in One Stage}

In the second group of four cases, the decision and approval occurred concurrently. Each of these cases involved the CCE or owner making the justification and the decision. In all of these cases but one, this was viewed as the role of the CCE or owner, with two of these being partly due to the company being quite small. The outlying case was marked by a quick decision under time constraints and some political pressure, although postdecision justification and negotiations certainly occurred.

\section{Internal Decision Challenged}

The remaining two cases included the case noted above, where an internal decision was made, yet challenged at a higher level. In the final case the respondent (also the advocate), noted that they felt strongly that this was the right decision, but had to engage in considerable internal negotiations and convincing, such that they did not feel a decision had been made until it was approved at the higher levels.

Consideration of the decision phase then has suggested that a "decision" may or may not actually be the final decision. Even in the "done deal" cases, there was a chance the decision would be overturned. However the chance of this decreased as the confidence in the fit with the company increased. Also evident was that the decision phase appeared 
more straightforward if a high ranking individual held the formal role of evaluating these decisions. This discussion then links back to both the company frame of reference and investment characteristics in terms of objectives and fit, as well as the roles within the DMU.

\subsubsection{Post-decision}

Analysis of the post-decision phase considered comments referring to who managed the relationship, and what happened immediately after the decision was formally approved. This phase held consistent involvement of the CSM and/or CMM in managing the relationship, further developing and executing leveraging activities. However, in four cases noted above, in which a quick intuitive decision was made during the evaluation phase, the post-decision process became the key stage for negotiating benefits and developing the fit between company objectives and the arts event. While this in some cases was noted as not ideal, it was also acknowledged that this did not diminish the importance of the discussions. For three of these four cases this process was accepted and viewed as appropriate. Each of these three companies held a more philanthropic orientation, and felt that they saw the benefits early on, could make a decision, and were confident they could work out the details post-decision. For one case, this was however seen as less than ideal. In this last case it came down to timing, where the CCE made a quick albeit informed decision, and the CMM/CSM developed the benefits post-decision.

\subsubsection{The Process Overall}

While the above has taken each stage of the process apart, it is essential also to look at the flow of activities. In doing this, three groups of decisions were identified:

- High level decisions

- Decisions driven at a lower level, and

- Decisions in which a third party was involved

\section{High level decisions}

Four of the studied cases fell into this category where a decision was made relatively quickly at the CE/owner level, and then passed down to marketing to extract benefit. In one of these decisions, the process was uncharacteristic of the organisation, and 
could be deemed "personal" although respondents felt it was informed. However, for the remaining three, the decisions were with companies who had an orientation towards more philanthropic goals, and the CCE's were both involved in the decision and felt an amount of ownership towards it. In three of these cases the relationship between the arts organisation and the CCE/owner was well established prior to the approach, with a level of rapport present. One case was unique in that a third party known to both parties -- made the initial approach which was certainly seen as paving the way. In all of these cases, the fit was evident early on, and although a philanthropic orientation was noted, certainly commercial benefit was expected and developed post-decision. While the DMU appears to be relatively small, the number involved in post-decision negotiations reflected a similar DMU to that in other categories noted below.

\section{Driven at a lower level}

Another four of the studied cases could be characterised in this grouping, where the $\mathrm{CSM} / \mathrm{CMM}$ was the key driver, and in essence, pushed the request through to higher levels within the organisation. This was a common desired process, but as evident above, did not always happen. Within these cases there was less acknowledgement of an intuitive evaluation in discussing the process. Greater attention to measurement attempts and justification along commercial terms was evident in these cases, although the uncertainties around sponsorship were also acknowledged. In these cases the evaluation was more in-depth, involved larger numbers of individuals and a more purposeful and concerted attempt was made to gather support within the ranks, prior to going up for approvals.

\section{3. $3^{\text {rd }}$ party involvement:}

Three of the cases included in the study were characterised by a decision process in which a third party was involved. In these cases the idea was recognised by an arts board member. The board member saw the opportunity and the fit, and brought the appropriate people together. They made the initial introductions, but on a more informal basis. In one of these cases, the initial call was to the CCE, and the decision was then characteristic of the first group above. In the other two, the initial contact was made at a high level, but then the key driver of the process and decision became the CSM. 
Examining the above categories points to the importance of the role of the individual, as well as the fit and the company's orientation. In fact the above three categories are largely separated based on the "key individual."

Examination of the results in terms of the process has revealed a number of findings within the cases, many of which are consistent with previous findings.

Firstly, the pre-approach context set the stage for the decision and included consideration of the perceptions of sponsorship, company objectives, and key individuals. This phase highlighted that there may be some uncertainty concerning sponsorship, and a fit with company objectives was essential to counteract this uncertainty. In addition, the fit, along with a recognition of roles and existing relationships allowed the process to move to the approach phase. The Approach stage carried forward these roles and relationships, with an initiator putting the idea forward and showing the fit and benefits. The evaluation stage often took this fit further, although at times, the initial judgement shortened this phase considerably. The consideration of fit, along with risk varied significantly across the cases in this phase. Also important in the evaluation phase was the recognition that internal processes often emerged, and the importance of intuition.

The decision phase varied, from a two-step process driven by the internal discussions, to a more simplified single, informed individual, making the decision. Post-decision phases were consistent in that the CSM/CMM managed the relationship, although it was noted the more intuitive philanthropic-driven decisions tended to have more negotiation discussions in this post-decision phase.

The process overall was marked by both a need to fulfil commercial objectives and a desire to be a contributing part of the community; an acknowledgement that the decisions are largely subjective, and a need to back up a decision objectively; a desire to have input from a variety of people within the company, but the necessity of having one individual advocate who drove it forward.

The purpose of this chapter has been to provide the reader with a rich and in-depth understanding of how arts sponsorship decisions were made in the cases examined. The chapter has reflected the within and between case analysis undertaken, providing insight 
and elaboration on the elements identified in the initial framework. This discussion of results has also illuminated other facets of these elements, and a number of themes which appear to run through these decisions. The following chapter will next compare results from this chapter with the literature studied to date, to gain an even greater understanding of this area of research. Chapter 6 will therefore take these results one step further in order to enhance understanding of these decisions, and lead to stronger theory development. 


\section{6: Discussion}

The purpose of this chapter is to discuss the results in chapter 5, in light of the literature. This chapter will demonstrate how the results support themes in the study, and make a contribution to the literature (structure as suggested by Perry,1998). Through this examination, patterns will emerge which will be elaborated upon in chapter 7 .

This study was designed to identify and understand the decision-making processes of companies as they considered arts sponsorship requests. The overriding research question was proposed: How do companies make decisions when considering arts sponsorship? Specific research objectives were noted to identify key influences and characteristics of these decisions, and their inter-connections. A review of the literature suggested a conceptual framework and highlighted four potential influential aspects: company frame of reference, formalisation of policy, characteristics of the investment, and characteristics of the decision-making unit. The identification of the research problem not only suggested a qualitative, case-study approach, but also that theory building would be appropriate in addressing this issue.

Chapter 5 provided an exploration of the data, demonstrating that some elements were more relevant than others, and that linkages and patterns were present. For ease of communication and organisation, this chapter is structured around the initial framework. However, consistent with recommendations for theory building, this chapter moves beyond this structure, providing elaboration, highlighting patterns and suggesting themes, while comparing findings to the literature. As suggested, sponsorship and philanthropy may not be as distinct as sometimes presented, and a more inclusive approach will be taken here ${ }^{10}$. In the following, the term "sponsorship" will be used more frequently especially as it relates to the specific decisions being examined. This term is used as this was the language of the respondents, and is not meant to exclude ideas of philanthropy.

\footnotetext{
${ }^{10}$ In addition, CCI (Corporate Community Involvement) was introduced as the wider consideration of partnerships between business and non-profit organisations. This term will be referred to at times in this discussion as appropriate.
} 


\subsection{The Frame of Reference}

The frame of reference relates to March's (1994) discussion of the logic of appropriateness, where decisions are shaped by the situation and the individual's interpretation of the situation. In this study the situation was comprised of the external, internal company and the individual frames, with each influencing the decision. In this sense, the study found consistency with authors who propose that organisational buying decisions are shaped by influences at varying levels (Webster \& Wind, 1972a).

\subsubsection{External Frame of Reference}

The external frame of reference is similar to discussions of environmental variables (Johnston \& Lewin, 1996; Webster \& Wind, 1972a) which may impact on the decisionmaking processes. The results in this study pointed to more specific aspects of the external frame which were influential: the expectations of society concerning sponsorship, the perceptions of sponsorship in the business community, and industry characteristics.

In terms of society's expectations, authors have proposed that variables such as social/cultural characteristics will influence organisational decisions (Webster \& Wind, 1972a). Values held by society are likely to influence company decisions, and this appears to be the case in this study: "Corporations as organised groups of individuals formally espouse certain moral and social values" (Godfrey, 2005, p. 787). In CCI, discussion of the views of society, especially business society, go back to the debate on the role of the corporation in society. Arguments have been made for a profit motive (Friedman, 1970), for the interest of public good (Shaw and Post, 1993), and also for the two motives not to be in conflict (Collins, 1993; Godfrey, 2005, 2006; Valor, 2007). Authors in sponsorship have suggested that sponsorship has moved out of the realm of philanthropy (Cornwell \& Maignan, 1998; Dolphin, 2003), implying the prioritisation of the profit motive.

In this study, it was evident that some respondents felt that characteristics of New Zealand's business culture would be influential. Similarities in the profit/moral motive argument were evident, with some respondents emphasising that CCI (broadly speaking) for moral reasons were justified, others expressing the profit motive should reign, and still others proposing that the two motives are compatible (see section 5.2.2). Evident in 
the analysis of the external frame, was that philanthropy had not entirely "moved out" of sponsorship as suggested by authors. This is an important theme which will emerge again.

While the analysis suggested influence from society's expectations, a more specific focus on the perceptions of sponsorship was taken, where sponsorship was seen as perceived with uncertainty. This has been noted by authors, particularly in discussions clarifying the distinction between sponsorship and philanthropy (for example: Bruch \& Walter, 2005; Cornwell \& Maignan, 1998; Dolphin, 2003). Ambiguity and uncertainty is also noted by authors addressing difficulties in measuring the success of sponsorship (Cornwell, Weeks et al., 2005; Dolphin, 2003; Thjømøe et al., 2002). Similarly, Seitanidi and Ryan (2007) stated "it is becoming increasingly clear that the external environment in which partnerships are formed and managed is both complex and sceptical" (p.259). Given this environment, as well as the dual responsibility of contributing to the community and to stakeholders, Valor (2007) proposed that in decisions of philanthropy, companies should engage in a "continuous dialogue with all stakeholders" (p. 292). While the need to understand perceptions is thus noted as important, the effect of the perceptions and uncertainty, on the decision-making process has not been examined.

The OBB literature provides some guidance on the role of uncertainty in buying decisions. Uncertainty or risk appears in OBB as a product characteristic - a key determinant of organisational buying behaviour (Johnston \& Lewin, 1996). As noted in section 5.2.1, uncertainty emanated from concerns for reputation, concerns for a perception of philanthropic (vs. profit) rationales, difficulties in measurement, involvement of numerous people, and general lack of understanding. The implication here is that a sponsorship may be viewed as a product, carrying certain characteristics as perceived by the participants, which will then influence the decision process. This will be examined more closely in section 6.4.

Also in terms of the perceptions of sponsorship, was evidence of differing perceptions based on the level of the individual and the philosophy of the company. Chief Executives expressed less uncertainty, and more clarity on their desire to contribute to society as a motive. On the other hand, CSM/CMM's focused more on the profit motive. While the involvement of different managerial levels has been examined in sponsorship 
and philanthropy literature (Abratt et al., 1987; Burton et al., 1998b; Farrelly \& Quester, 2003a) the variations in perceptions have not been examined. These variations are not unexpected, and recognition of different mindsets and backgrounds based on levels of responsibility in the company is noted by authors such as Hambrick and Mason (1984).

The second point noted above was that perceptions differed based on the philosophy or orientation of the company. The finding was that companies deemed to hold a more philanthropic orientation seemed less concerned by uncertainties often associated with a sponsorship. This will be discussed in more detail in looking at the internal frame of reference.

The examination of the perception of sponsorship makes a contribution to the literature in suggesting the co-existence of both moral and profit motives for these decisions. Certainly the perception of sponsorship and possibly other CCI initiatives is an element of the external frame of reference, which appears to lend some uncertainty to decisionmaking situations. While the moral/profit argument and characteristic of uncertainty is consistent with the literature, the idea that both moral and profit motives may work together is not wide spread in the literature, nor is the influence of uncertainty on these decisions. This study then contributes to the literature by suggesting that there are a variety of perceptions of sponsorship, including moral and profit, philanthropic and commercial, and while this may lend itself to uncertainty, it also makes up a part of the "product" definition. Furthermore, in terms of perceptions, this study also suggests that the orientation of higher-level managers towards greater or lesser philanthropic motives may shift the uncertainty, thus impacting on the decision process. These ideas of dual motives and higher-level influence are both elements which will be further discussed.

Another feature of the external frame of reference was proposed as characteristics held within a particular industry. In the external frame, industry characteristics have been proposed by some authors to play a role in the selection and management of corporate giving. Studies have related certain industries to certain stakeholders, finding that these stakeholders are the main influence over selection and management (Brammer \& Millington, 2004b; Crowley, 1991). This study is in agreement with these authors that the stakeholders are a key influence, and that this may be determined by the industry. However the analysis also suggested that the company strategy may shift this focus, causing a new stakeholder group to emerge as more important. In addition, it was found 
that a single company may have different stakeholders in mind for different sponsorships. Therefore, the relationship is between the priority of stakeholder groups to be targeted and the sponsorship, rather than the industry and sponsorship.

Another aspect of the industry's potential influence in corporate philanthropy is in the area of reputation management. Godfrey suggests that philanthropy may act as “insurance-like protection", with firms engaging in more philanthropy if there is more industry-specific risk (Godfrey, 2005). This resonates with Campbell and Slack's (2007) study where companies used giving to "manage their community constituencies" (p.340) in response to an industry-specific threat. While industry-specific risk was noted in some of the cases, it was not generally linked to arts sponsorship in this study. However, the more general relationship between reputation and sponsorship was evident, with respondents linking the sponsorship, their reputation with stakeholders, and ultimate business success. The need for companies to acquire what Godfrey refers to as "positive moral capital" with stakeholders was certainly part of the equation.

Therefore, in considering the industry influence on arts sponsorship decisions, it is proposed that the industry itself may not have a direct influence on these decisions. However, the industry may define stakeholders, such as the company's need for government support and/or need to engage with customers. The identification of these stakeholders would then influence how the sponsorships were evaluated.

In the above discussion it is clear that respondents considered the external frame, particularly society's expectations and perceptions of sponsorship, and more specifically those of stakeholder groups. Importantly, managers considered this frame through the lens of their own company, with its particular needs. These findings suggest that the ideas associated with corporate legitimacy may shed light on these decisions.

Legitimacy theory notes that firms may take CCI actions in order to be seen as a legitimate actor in the business and wider community (Suchman, 1995). Chen, Roberts and Patton (2008) refer to "legitimacy gaps" which appear when there is a difference between what society expects, and the activities of the company. Similarly, LaFrance and Lehmann (2005) state that "a legitimacy problem arises when societal expectations for corporate behaviour differ from societal perceptions of corporate behaviour" (p. 220). 
These and other authors (Holmes \& Smart, 2009; Yaziji, 2004) note that actions such as engaging in a partnership with a non-profit organisation, will help to manage these gaps.

While this study was not designed around the ideas and theories of legitimacy, the findings suggest this is applicable. Section 5.2 noted many respondents' referred back to society and the community in discussing their decision, considering what society may think of sponsorship and the particular investment; in addition, views and philosophies of the company were also expressed in terms of the community. The application of legitimacy theory to this study therefore suggests that not only may managers be considering the "views" of society, but more particularly the expectations and perceptions society has of the company's CCI, including arts sponsorship.

This study has therefore contributed to the literature by identifying four key components of the external frame, which will influence arts sponsorship decisions. Firstly, moral and profit motives may co-exist in these decisions. Secondly, society's expectations and perceptions regarding business and CCI, including sponsorship, play a role. Thirdly, the extent to which society associates sponsorship with uncertainty and the extent to which society seems "okay" with philanthropic behaviour may hold a significant impact on the decision. Fourthly, the industry per se is not as important as the defined key stakeholders and managing the company reputation with these stakeholders.

\subsubsection{Internal Frame of Reference}

The internal frame of reference refers to the company's frame. This is similar to categories noted by OBB and decision-making authors: Webster and Wind referred to organisational influences (1972a), Jocumsen (2004) discussed firm size and structure, and March (1994) noted organisational rules and "identity." In this study, the influential sub-categories in the company's frame of reference emerged as (1) a philosophy towards CCI, (2) ownership status, and (3) company strategy.

In terms of the company's philosophy towards CCI, organisations have been noted to have a variety of rules, goals and tasks (Webster and Wind, 1972a), and these rules, goals and tasks are likely to influence the decision-making process. For example, in a study investigating socially responsible buying decisions, Drumwright (1994) found that a major factor differentiating companies was whether or not socially responsible buying 
was "part of a deliberate corporate strategy" (p.6). Looking at arts sponsorship, Ryan and Fahy (2003) found that "organisational mindsets" were important driving forces in the partnership. The idea of an organisational mindset, in part defined by a deliberate strategy, is referred to here as a philosophy towards $\mathrm{CCI}^{11}$.

Most of the companies studied had publicly available statements concerning CCI, which were considered reflections of philosophies towards CCI. What was evident was that all companies appeared to hold "good corporate citizenship" as important, and that there was a range of orientations within which companies appeared more or less commercially or philanthropically oriented.

This range was put forward in chapter 2 (Figure 2.2), building on discussions by authors in sponsorship and philanthropy who propose that there be a more integrative approach (Madden et al., 2006; Meenaghan \& Shipley, 1999; Moir \& Taffler, 2004; Ricks, 2005; Seitanidi \& Ryan, 2007; Wymer \& Samu, 2003). Similarly, but particular to sponsorship, Thjømøe et. al. (2002) found that managers expressed variation in their definition of "sponsorship" with some including an element of philanthropy. Literature in strategic philanthropy also suggests that giving decisions may include both commercial motives as well as motives related to social good (Porter \& Kramer, 2002; Smith, 1994).

Consistent with the proposed range of motives, this study found that three groupings could be identified: companies who were more commercially oriented, those with more of a philanthropic orientation and those in the middle. Moving beyond the literature however, this study suggested how these orientations may influence the decisions.

In the more commercially oriented companies, a more formalised process of evaluation was undertaken, focusing on return on investment and brand fit, with the Marketing Managers playing a crucial role in the DMU. This is consistent with literature finding more involvement of the Marketing role in commercial sponsorships (Abratt et al., 1987; Dolphin, 2003; Tripodi, 2001). In companies with more philanthropic orientations, decisions were made more rapidly, with benefit negotiations following the decision, and

\footnotetext{
${ }^{11}$ The broader term CCI (Corporate Community Involvement) is purposefully used here to reflect the company's philosophy to the broad range of activities.
} 
the CCE playing a crucial role. This is similar to studies, such as by Bennett (1998) who found that two-thirds of philanthropy decisions were made at a Head Office level.

However, while the literature makes a separation between commercial sponsorship and philanthropy, the current study found that the companies could be classified in a range including commercial and philanthropic. This study also found that these decisions tended not to exist in a particular category; for example, a philanthropic orientation was taken on what many would call a "commercial sponsorship." This suggests that companies may take a variety of views on arts sponsorship, and the profit/moral motives are difficult to separate. The third grouping included companies where decisions reflected orientations neither distinctly commercial nor philanthropic. This final group again supports the idea of a range of motives within a company and perhaps even a single sponsorship investment.

Thus, the suggestion in the literature that there be a more inclusive approach is echoed in this study, however greater meaning has been given to this. In particular, this study suggests that elements of both commercial and philanthropic goals may be evident in a single decision. Furthermore, while both elements may be present, there may be an orientation towards more commercial or more philanthropic goals, and this orientation will likely influence these decisions.

Moving on to the second key sub-category in the internal frame of reference, the importance of ownership was examined. This has been alluded to mainly in the philanthropy literature, with authors proposing that organisations who give more are characterised as having fewer large blockholders and a lower percentage of stock owned by institutional investors (Seifert et al., 2003). Similarly, Dunn (2004) found a positive relationship between privately-ownership and the existence of a professional donations programme.

In the study contained here, the relationship examined was not in terms of the amount of giving or the existence of a programme, but ownership as an influence on the decision process. In particular, it was found that the main differences occurred with privately owned companies. There was not a clear delineation between the decision processes in SOEs and publicly traded companies. However, in privately-held firms, the decisions were characterised as having a much smaller DMU, and greater reliance on the intuition 
of the Owner or CCE. This effect is reminiscent of agency theory, under which if the agent (the CE) and the principal (the owners/shareholders) are the same, less conflict is likely to arise (Bergen et al., 1992). Discussion of the role of the individual CCE/Owner was found to be significant in this study and will reappear in future discussion.

The final sub-category of the internal frame of reference was the company strategy. ${ }^{12}$ The cases in this study consistently demonstrated the need for a fit between the company's strategy and the sponsorship investment, be it congruence with a broader company strategy or a specific marketing strategy (section 5.2.2). In terms of process, the goals and objectives of the companies set the stage for the decision. The determination of a fit between the company and the arts initiative essentially facilitated an approach from the arts organisation. Naturally, this fit came into play in the evaluation as well, but it had to be there at the start.

The recognition of the importance of a fit with company-wide and marketing-specific strategies resonates with the literature, although this study provides more specific evidence to contribute to this knowledge. Sponsorship literature focuses on the idea of using sponsorship to improve image and goodwill, with emphasis given to building awareness in particular markets, especially consumer markets (e.g. Cornwell \& Maignan, 1998; LeClair \& Gordon, 2000; O'Hagan \& Harvey, 2000). Other markets are also noted however, such as investment markets in Cornwell, Pruitt and Clark's (2005) study of the influence of sponsorship on stock prices. Certainly, evidence was found in the cases studied, that fit with various markets was highly important, including consumers, and other stakeholders. However, evidence was also found to suggest an even broader view of "fit" is important, including a fit with values or with the community.

A broader assessment of fit is part of the argument for strategic philanthropy, through which companies view philanthropy as a tool to more generally improve their strategic position in a competitive environment (Porter \& Kramer, 2002; Saiia et al., 2003). Within this is a desire to do a community good, but with the recognition that improving the community will filter through to better business.

\footnotetext{
${ }^{12}$ Strategy is defined as "the direction and scope of an organisation over the long term, which achieves advantage for the organisation through its configuration of resources within a changing environment and to fulfil stakeholder expectations" (Johnson \& Scholes, 1999, p. 1067).
} 
Therefore this study is in agreement with the literature, that there needs to be an alignment between company strategies and the investment. The study also confirms that this alignment may be with the consumer markets and/or other identified stakeholders, it may be a fit with marketing-specific strategies or more broadly defined strategies.

In terms of the internal frame of reference, an important finding in this study is again the idea that a range of motives should be considered within a decision, rather than a delineation between "sponsorship" and "philanthropy". Decisions exist within this internal philosophical range, and this opens up a wider array of opportunities for the strategic fit which could be attained. This broader view of fit may go beyond the "target market" to other stakeholders and other goals. The importance and role of fit emerged more strongly in an evaluation of the investment characteristics, and will be discussed further in that section.

\subsubsection{Personal Frame of Reference}

The recognition of a personal component to organisational decision-making has been well documented. Webster and Wind (1996) propose consideration be given to individual motivations, cognitive structures, personality, learning and perceived roles; similarly Sheth (1973) emphasizes the decision-makers' "psychological world." Eisenhardt and Zbaracki (1992) note the role of individuals' cognitive limits, power and tactics as they play out in various decision-making models. In the cases studied, the individual played a key role, and the personal frame of reference was examined in this light.

Most respondents appeared to hold a philanthropic philosophy to CCI, where they felt that part of the role of the company was to make a difference to society. In considering the responses focused on specific decisions, CCE's were more comfortable taking this philosophy into the decision, while CSM/CMM's shifted to a more commercial view. This separation of philosophies is perhaps not surprising considering the role of these individuals. The CSM or CMM has the role of justifying, rationalising and measuring the sponsorship, and therefore will be more focused on these aspects (Moorman \& Rust, 1999). On the other hand, the CCE holds a broader more strategic role.

The acknowledgement of individual frames of reference influencing decisions was also made by Hambrick and Mason (1984), who argued that there is much to be gained in 
understanding decisions, if the values and cognitive biases of the "upper echelons" are considered. They noted, "complex decisions are largely the outcome of behavioural factors rather than a mechanical quest for economic optimisation" (p. 194), and that “managers' eventual perception of the situation combines with his/her values to provide the basis for strategic choice" (p.195). This argument suggests that the frame of reference particularly of the "upper echelons" may have considerable influence.

The ideas of Hambrick and Mason, along with others were incorporated by Jones (2007) who proposed a theoretical model which considers managers' values in corporate philanthropy decisions. Based on the literature, Jones proposed that "the influence of these personalised values on the decision-making process is of significance in the context of strategic decision-making and ... the corporation's decision to donate to philanthropic causes” (p. 352). In a similar vein, Orlitzky and Swanson (2002; Swanson, 1999), studying CSR, suggest that a company's "attunement" with social good is often influenced by the values of senior executives, with attunement being "the potential alignment of organisational behaviour with broad based social expectations of responsibility (Orlitzky \& Swanson, 2002, p. 120).

In addition to the ideas above, authors have also considered how values and background play a role. Returning to Hambrick and Mason (1984) the decision maker brings both a "cognitive base and values to a decision" (p. 195), with these elements influencing the perception of the situation. Similarly, Jones (2007) takes the view that values are "embedded in the being of the decision-maker... subconscious or 'passive participants' in all processes of thought" (p. 351). Jones' model sees the values subconsciously flowing through interpretations and perceptions as well as playing a role more consciously.

The results of this study support that the personal frame of reference impacts on decision-making. The greatest influence was noted with high-level individuals within the DMU, when that person felt strongly, based on their own experience, that the sponsorship would benefit the company. The emphasis here was on the cognitive knowledge and experience of individuals. However, it was also evident that individuals at the senior levels also held strong values supporting the role of the company in contributing to society through the sponsorship. 
Therefore, this study moves from the literature noted, to confirm that in these decisions, an important frame is that of the higher level individual, and that knowledge and experience are crucial to help determine the "fit". In addition, there is support that values play a role in setting an individual's frame. Finally, this study suggests that these individual experiences, knowledge and values may be at play not just in decisions categorised as "philanthropic" or CSR (subjects of Jones, 2007 and Orlitzky and Swanson, 2002) but also for decisions of sponsorship.

\subsubsection{Summing up the Frame of Reference}

The frame of reference has been described above in terms of both the literature and the cases studied. It appears that similar to OBB and decision-making literature, the environment in which the decision is being made is crucial. Particular to this study, the nature of the product (arts sponsorship), how it is perceived and what is expected are important elements which frame the decision. In addition, the strategies of the company are crucial as is the ability to establish a "fit" with these strategies. Sitting above these considerations is an overall company philosophy of CCI and views of how CCI fits into the company's role as a legitimate actor in society. These factors will influence the decision process - for example how the product is evaluated, and the more specific way in which "fit" will be sought. As well as external and company-level considerations, personal experience, knowledge and values play a role. Specifically, the knowledge and judgements of senior level individuals contribute to the frame within which these decisions are made. Overall, these findings are in agreement with decision making and OBB literature, but provide more specific insight and direction in terms of understanding arts sponsorship decisions.

\subsection{Extent of Formalisation of Policy}

The formalisation of policy gives greater boundaries to decisions, such as providing "organisational goals and tasks" (Webster \& Wind, 1972a), or providing "procedural control" (Bunn, 1994) be it formalised or more rules of thumb. March (1994) also referred to the existence of rules as forming a key part of decision-making processes. In this study information gathered to determine the role and influence of formal policy in arts sponsorship decisions led to two categories: 1) rules about the criteria and 2) rules about the process. 
In terms of the criteria, results suggested that when a formal policy existed, it served as a checklist, but not all boxes needed to be checked. What appeared more important than the policy, was a generally accepted requirement, that there needed to be a fit with and benefit to the company. These findings suggested that formal policy may exist but may not be strictly adhered to; at the same time however, the decision still needed to be able to be justified, and benefit to the company needed to be assured.

Particular to the process, formalised processes were evident, and as noted earlier, the uncertainty often associated with sponsorship appeared to lead to more transparent processes and greater "formalisation" existing within companies. Most companies studied had procedures and although the existence of these was not ignored, there was evidence that general rules of thumb, company needs at the time, and individual connections were more important. When it came to the actual decision, the formal procedures appeared to form the background, with the decisions oriented to being more behaviour and experience-driven rather than driven by formalised procedure. This coexistence of formal and informal elements in the process was very much evident in the examination of the formality accompanying the DMU, which will be discussed in greater detail in a following section.

In terms of the sponsorship or philanthropy literature which deals with the existence and use of formal policies and procedures, most of the discussion is less about criteria and more on motivations. Perhaps this is reflective of the characteristics of these decisions, which do not appear to be marked highly by formal control. In fact, O'Hagan and Harvey (2000) found that $41 \%$ of companies surveyed did not have a system of assessing arts sponsorship proposals, and calls for more rules in sponsorship decisions have been noted by these and other authors (for example, Thjømøe et al., 2002).

The findings in this study are consistent however with studies and theories in decisionmaking. Bunn (1994) for example noted that formal procedures may exist, but these controls may range from "rules of thumb" to more formalised rules. The idea that rules and procedures may exist, but decisions are not always purely rational echoes sentiments in strategic decision-making. For example, Eisenhardt and Zbaracki (1992) concluded that there are cognitive limits, and decision makers often end up satisficing rather than optimising. These authors and others also note that a variety of paths may be followed, which may depend on the situation (Bunn, 1994; Rodgers \& Gago, 2001). 
Similarly in this study, the formal existence of criteria and procedures played a supporting but not a lead role. The formal nature provided some basic rules, but what appeared more important was the situation, the context, the needs of the company, the happenstance. This idea of happenstance refers to a type of coincidence, here, that the company is looking to achieve something which the arts organisation can offer. It is the right time, right place and right offer. This happenstance seems to "trump" the formal checklists, and is a theme which will be revisited.

It is evident therefore that there is an acceptance and recognition of the need for formal policy, and this is seen as partly influenced by the external frame of reference. The formal policies may shape some of the criteria by which the investment will initially be evaluated, and may well shape roles within DMU. However, there also appears to be an acceptance and recognition that there is flexibility within and around the formal boundaries. That happenstance may in part redefine criteria and procedures, if the right opportunity emerges at the right time.

\subsection{Characteristics of the Decision-making Unit}

Sponsorship decisions occur within the context of an organisation, and involve a group of individuals referred to as the buying centre or decision-making unit (DMU) (Johnston \& Lewin, 1996; Webster \& Wind, 1972a). Sponsorship and philanthropy literatures have addressed aspects of this, though not with the lens of the DMU. Some authors in sponsorship discuss the involvement of various departments (Farrelly \& Quester, 1997; Thjømøe et al., 2002); similarly corporate philanthropy decisions have been noted as being made largely by groups (Bennett, 1998). In the study contained here, all decisions involved a number of individuals to varying extents, and therefore consideration was given to these decisions in terms of the DMU. Four main conclusions were drawn from the analysis of the DMU: 1) the vertical involvement, particularly of the CCE, was consistent; 2) the lateral involvement appeared to be controlled by the formal policies and decisions of the CSM/CMM; 3 ) the role of decider was often subject to a further "approval"; and 4) the presence and influence of an advocate was essential. 


\subsubsection{Vertical Involvement and the Role of the CCE}

As noted, a number of vertical levels were represented in the DMU's for these decisions, and the CCE was present in all DMU's. This is consistent with studies in corporate philanthropy, which note the involvement of senior executives to be prevalent (Bennett, 1998; Brammer \& Millington, 2004b; Brammer et al., 2006; Dunn, 2004). On the other hand, sponsorship studies emphasize the involvement specifically of marketing and public relations, and a movement away from Head Office involvement (Burton et al., 1998b; Farrelly \& Quester, 1997; Thjømøe et al., 2002; Witcher et al., 1991). While this study's findings may appear to contrast with sponsorship studies, there is more similarity when considering decisions within a commercial/philanthropic range. Specifically, while the CCE was always a part of the DMU, the decisions which were deemed to be oriented towards more commercial means (section 5.2.2) tended to have greater involvement of the marketing department. In decisions deemed more philanthropically driven the CCE took on a greater role in the DMU. This finding suggests that the company's philosophy of CCI plays a role in determining the DMU.

Also evident was the implication that the ambiguity associated with sponsorship partly determined CCE involvement. This is reminiscent of DMU studies from OBB. In particular, Lewin and Donthu (2005) concludes that the DMU structure is related to the "purchase situation," which includes the buyclass, product type, importance, complexity and uncertainty. Applying Lewin and Donthu's framework to the sponsorship decisions revealed many parallels. Taking sponsorship as a purchase situation, it was evident that the "newness", the importance and the uncertainty all related to who was in the DMU. Renewing sponsorships had established relationships, and the person most involved in this relationship was included in the DMU - in particular, renewing relationships determined the advocate. New sponsorships relied on a different type of relationship which then influenced the DMU. The idea of "product importance" also related to the DMU, with importance here related to the financial request. Specifically, larger financial requests were moved to higher levels in the company (see section 5.4.1). Uncertainty around sponsorship has also been shown to determine the presence of higher-level managers in the DMU. Further discussion of the characteristics of the investment will be undertaken in section 6.4, however the relationship between the "purchase situation" i.e. sponsorship - and the characteristics of the DMU appears important, especially in identifying the presence of higher executive levels in the DMUs for these decisions. 


\subsubsection{DMU Lateral Make-up}

The lateral involvement in a DMU refers to the inclusion of individuals from different areas within the company, but from the same hierarchical level. Studies in sponsorship and philanthropy have noted the involvement of Marketing and/or Public Relations departments, but examination beyond this is not evident. Consideration of lateral involvement revealed that this was an important part of the decisions, and appeared to be determined by the characteristics of the investment and the planned use of the sponsorship. For example, in two cases, the CSM sought out other appropriate Marketing Managers who would benefit from the sponsorship, and were crucial to moving forward. This point is an important finding in this study, suggesting that individuals involved in the DMU may be those who need to be involved - those who are affected, those who may benefit and those who see the benefit.

Brammer and Millington (2004b) make a related argument, noting that "organisations appear to allocate responsibility for the management of donations to functional departments that have the capabilities to cope with the particular stakeholder pressures they face" (p.289). In this argument, the company recognises the stakeholder pressures, and in turn, allocates responsibility to the departments which can best address this. In terms of the present study, the companies were noted as having particular goals and objectives, and a need to find a "fit". The fit may or may not be best handled solely by a Sponsorship Manager, Marketing Manager, or Public Relations Manager, and may be best managed by the CCE level. This study thus agrees with the findings of Brammer and Millington, but diverges from a number of studies particularly in sponsorship. Sponsorship studies have typically noted high levels of involvement from Marketing and Public Relations, and speak of sponsorship as a confirmed tool in the marketing mix (Dolphin, 2003; Tripodi, 2001). This study finds evidence to suggest that with sponsorship used to achieve numerous objectives within the company, it may be too limiting to prematurely restrict the decision and/or management to one specific area.

Related to this discussion is the notion that the group who makes the decision may well be different from the group who manages the relationship. So, while authors have noted that Marketing and Public Relations are commonly involved in the decisions and management of sponsorship (Cornwell \& Maignan, 1998; Dolphin, 2003; Tripodi, 2001), others have made a distinction. Specifically Witcher et.al (1991) suggest Public Relations 
is more prominent in decisions and Marketing more prominent in managing the relationship. Bennett (1998) found that corporate philanthropy decisions were typically handled by Head Office, with the management of the relationship resting with Marketing or Public Relations. Similarities with this literature were noted in this study. Firstly the common involvement of a senior executive level along with representation from Marketing and/or Public Relations was evident in the decisions. Secondly, while this study focused on the decisions themselves, it was evident that the management of the relationship typically fell away from higher levels, and moved into Marketing or Public Relations.

This study then is in agreement with the literature that there will be vertical and lateral representation in the DMU for support decisions, but provides a contribution in highlighting the CCE involvement, and in suggesting what may influence vertical and lateral involvement. The extent of the vertical influence, being the involvement of the CCE, may be determined by the orientation of the company to more philanthropic or commercial means, as well as characteristics defining the purchase situation. The vertical and lateral involvement is also likely to be determined by the recognition of which stakeholder groups will benefit from the relationship and who is best positioned in the company to manage these stakeholder groups.

\subsubsection{Roles in the DMU}

This study also looked at specific roles within the DMU. OBB authors have identified a number of roles including users, influencers, buyers, deciders, gatekeepers, initiators and controllers (Dwyer \& Tanner, 2006; Webster \& Wind, 1972a). Other authors have identified and described additional roles, such as "policy entrepreneurs" (Drumwright, 1994), "boundary role person" (Krapfel, 1985), and "linking pin” (Wind \& Robertson, 1982). In the sponsorship and philanthropy literature roles have been noted as they relate to sponsorship relationships (Olkkonen, 2002; Ryan \& Fahy, 2003), and authors have identified CEO's as potential controllers and influencers (Brammer et al., 2006) but this has not been brought into a decision-making context.

Within this study, support was found for the involvement of multiple individuals in the DMU who take on roles such as those above. Users, gatekeepers, influencers and deciders were easily identified as noted in the previous chapter. In addition, other roles 
emerged as deserving more consideration, in particular, Initiators, Advocates and Approvers.

Initiators are noted in the OBB literature (Dwyer \& Tanner, 2006), as individuals who start the process: "the initiator starts the purchase process by recognising the need" ( $p$. 101). However the idea of a separate initiator role is not commonly considered in OBB. In fact, Webster and Wind (1972b) note users and influencers as having a role in identifying the need. In this study, the idea of an initiator is borrowed, but based on the results, the role was adapted.

Here, the initiators are characterised as the individuals who see and act on the link between the company and arts organisation, rather than the individuals who see the need. These individuals were not within the company's DMU unless it was a renewing sponsorship; however initiators were very much a part of the decisions (see section 5.4). Initiators were connected to the arts organisation, and had knowledge of the arts initiative as well as the company to which a request was made. This connection and knowledge appeared to allow them to make the link and open the door. Their role in terms of the process will be further discussed in section 6.5.

The role of the decider also varied from the literature in this study. Webster and Wind (1972b) propose that "deciders are those members of the organisation who have either formal or informal power to determine the final selection of suppliers" (p.79). The results identified deciders as the individuals who appeared to make the decision. This was at times the CCE, and at other times a CSM or CMM. In this sense, the study agrees with the literature that there were deciders who have either formal or informal power to decide. However, in many cases there was another layer of approval, within which the formal power to decide was held, should the decider have informal power. Although it would seem logical that this effect may be related to the size of the company, the two levels were found in both large and small companies.

The role within this second layer of approval was termed the "approvers." The approvers were consistently high-level executives or board members, who considered the recommendation provided to them. Approvers emerged in decisions in which the decider held the informal power to decide. Looking back to the literature, this suggests that the role of deciders may be divided into an informal role and formal role, the formal role 
here being named "Approvers." The identification of the approvers represents a contribution to the literature. This role is not noted in OBB literature, yet justification appears in this study to suggest dividing the role of deciders to present a more accurate picture of these decisions. To some extent this is alluded to in the philanthropy literature, with authors considering the effect of board composition on the level of giving (Bartkus et al., 2002; Wang \& Coffey, 1992), however a direct acknowledgement of this second layer of decision has not been made. As well as bringing in the Approver role, this discussion implies that there may be an internal sales process, where the decision may have been largely made (by the deciders), but the approvers yet had to be convinced. This will be discussed further in terms of the process (section 6.5).

\subsubsection{Importance of the Advocate}

A final category observed was that of an advocate, being the person who internally supported the investment to a greater extent than others. The results indicated this person possessed a higher level of experience and knowledge with the arts initiative, saw how it would benefit the company, and had the power to be influential. The advocate was seen as the key individual within the DMU who made the decision happen.

The existence of a "key individual" is acknowledged in sponsorship and philanthropy literature. Some authors note the potential for the CCE in particular to individually shape these decisions (Brammer et al., 2006; Cornwell \& Maignan, 1998; LeClair \& Gordon, 2000; Wang \& Coffey, 1992; Werbel \& Carter, 2002). While this study also found that the CCE often held the advocate role, at times the CSM or CMM was the advocate. Therefore, the discussion will not focus on the position held by the individual, but the characteristics of the advocate.

Sponsorship and philanthropy literature particularly looking at relationships have noted the importance of having a key individual. For example, Ryan and Fahy (2003) observed a "champion of the sponsorship" (p.37). Olkkonen (2002) proposed "relationship promoters" in arts sponsorships being "persons who act as translators between two different organisational fields, who understand both parties' goals and needs, and who try to find the balance in the cooperation" (p. 284). While the above authors are talking about the management of the relationship rather than the decision, the similarity is 
evident, and this study is congruent with the suggestion that there is a need for a type of promoter or advocate.

Other authors have similarly proposed an advocate type role. In offering advice to companies wanting to develop strategic philanthropy, Craig Smith (1994) proposes that the company "empower a philanthropy czar"(p. 115). Authors in OBB have suggested key individuals, such as "policy entrepreneurs" (Drumwright, 1994), "gatekeepers" (Pettigrew, 1975), "boundary role person" (Krapfel, 1985) and "linking pin" (Wind \& Robertson, 1982). Another area which shares similarity is the discussion of a "product champion" in the innovation literature (for example Howell \& Higgins, 1990). In comparing the findings of this study with the roles noted above, similarities and differences emerge. These will be now be discussed.

Advocates in this study, were individuals who had the power or authority to hold influence, had more knowledge than others in the DMU concerning the investment, and had the enthusiasm and ability to generate excitement and a positive response within the company.

The idea of the advocate having power or authority suggests these individuals as gatekeepers, and in many cases their official roles involved this. Certainly for CSM/CMM's, formally assigned the responsibility of considering sponsorship proposals, these individuals were gatekeepers first. The role in this sense is similar to that defined by Webster and Wind (1972b): "gatekeepers are group members who control the flow of information into the group ... [they] exert their influence primarily at the stage of identifying buying alternatives" (p.80). The main difference in this study was that the advocates did not identify alternatives, but identified the arts initiative as being one to consider. That is to say, in these decisions not all advocates were faced with a number of alternatives at one time, but made an initial yes (consider it) / no (eliminate it) decision for a single sponsorship. This reinforces the significance of this role and also highlights an important distinction in these decisions which will be revisited in section 6.5 dealing with the process.

Moving beyond the identification phase, Pettigrew (1975) noted that gatekeepers may play an important part in the evaluation process. Similarly, evident here was that the 
advocate's influence went beyond the identification of potential within an investment, to play a significant role in the evaluation phase of the decisions.

An additional finding of the advocate role, and a rationale for taking the definition beyond that of a gatekeeper was that these individuals possessed a deeper understanding of the sponsorship than others in the DMU. As noted, they "get it". The idea of "getting it" relates to the requirement of knowledge and understanding, noted as existing with champions (Ryan \& Fahy, 2003), relationship promoters (Olkkonen, 2002) and philanthropy czars (Smith, 1994). Similarly, Drumwright (1994) refers to expert power "arising from extensive research [policy entrepreneurs] personally had done" (p. 37). The idea of expert power is defined by Kohli (1989) as follows:

the extent to which an individual is perceived by others as being knowledgeable about relevant issues. Others comply with such an individual because of their belief that doing so will lead to a better decision, not because compliance will lead to certain consequences independent of the decision or because of formal or informal obligations to comply. (p.52)

This definition of expert power coincides with findings that advocates had more knowledge than others. It further suggests that others may comply because they believed in the knowledge of this advocate/expert. It is therefore suggested that the advocates in these decisions were the individuals who possessed expert power.

Returning to the idea of knowledge, this study found that the advocate's knowledge was often unrelated to their business experience, but may have been personal knowledge built through experience with the artform. This is reminiscent of suggestions made by authors (Hambrick \& Mason, 1984; Jones, 2007) that personal values and experiences may influence business decisions. This further suggests that advocates may or may not get knowledge directly from a proposal, but will bring their background and experiences into these decisions.

The final characteristic noted of advocates was that they were able to create enthusiasm within the organisation. Again, this moves the role beyond the idea of a gatekeeper, and beyond the possession of knowledge. The ability to generate enthusiasm suggests the 
individual's own passion for the sponsorhip, similar to Ryan and Fahy's (2003) suggestion that a "champion of the sponsorship ...[have] a deep love of the arts and a deep understanding of their possible effect on people at a personal and professional level" (p. 37). It also suggests some personality traits such as those noted for "policy entrepreneurs" as individuals who "were usually facile at both motivating people and making the system work for them ... [who also had] tenacious persistence and high energy level. They were undaunted by resisters and operational problems" (Drumwright, 1994, p. 4).

The role definition of product champions in the innovation literature appears to ring true for the role of advocates in sponsorship decisions. This role is defined as follows:

[champions] manifest the personality characteristics of risk-taking propensity and innovativeness ...[they articulate] a compelling vision of the innovation's potential for the organisation, [and express] confidence in others to participate effectively in the initiative ... [they] appeal to larger principles or unassailable values about the potential of the innovation for fulfilling the organisation's dream of what it can be, [and through this] champions capture the attention of others. Moreover by providing emotional meaning and energy to the idea, champions induce the commitment of others to the innovation." (Howell \& Higgins, 1990, p. 336)

The detail in the above definition is beyond the data collected in this study, although it resonates with views of the experts noted in chapter 5. It is perhaps not surprising that the champion role for a product innovation bears similarity to advocates of arts sponsorship decisions, as both "products" may be viewed as holding elements of risk and uncertainty, and the extent of similarity deserves further investigation at another time.

To conclude the discussion of the advocate in these decisions, it is evident that there is benefit to be gained by considering this role in the DMU. While literature from a number of areas has contributed, the advocate in an arts sponsorship decision appears to require its own description. Within this description the advocate emerges as an individual who controls information, who possesses more knowledge and information than others, 
and who has the ability and motivation to generate enthusiasm for the initiation internally.

Therefore, this discussion has contributed to the literature in terms of the roles in arts sponsorship decisions, and specifically highlights the role of initiator, the decider/approver split, and the advocate. This study has both defined these roles, but also positioned them within the decision process, revealing more about the roles and their importance. Through this examination, the idea again of an internal sales process involving internal negotiations and discussions necessary to move the decision forward has also emerged. This final point will be further addressed in discussing the decisionmaking process.

\subsubsection{Summing up the Decision-making Unit}

The sponsorship and philanthropy literature has provided some insight into DMU's of arts sponsorship decisions, particularly in terms of departments potentially involved. However, the addition of an OBB lens has added to this knowledge. With this lens, it is evident that these decisions involve a DMU characterised as including a high-level executive, as well as representation from a Marketing-type department. It is also evident that there is a need to identify the roles of initiators, deciders vs. approvers and advocates, along with other more traditional roles within these DMU's.

Furthermore, this analysis suggests that there are a number of influences which are important for DMU's of these decisions. As well as those who may be assigned the responsibility, individuals within the DMU are determined in part by the uncertainty surrounding sponsorship, leading to a greater perception of risk and the necessity of someone in a higher role taking on more of the responsibility for these decisions. The DMU is also shaped by the company's orientation or frame of reference to such decisions being more commercially or philanthropically driven. The individuals within the DMU are also determined in part by the "fit" apparent between the arts initiative and the company - with the people brought in who are deemed to be appropriate and necessary given the determined fit. 
Finally, this analysis points to specific roles which appear necessary in these decisions. An initiator is essential in seeing the link and putting the two companies together, opening doors. The advocate is the individual crucial in the initial consideration and the internal selling of the sponsorship. Finally, the approver may sit at the end of the decision, giving final approval (or not) to the decision put forward. In conclusion, roles identified in OBB have been supported via this study, but additional roles and an expansion of role definitions in this particular context contributes to the literature.

\subsection{Investment Characteristics}

Literature from sponsorship and philanthropy tends to focus on objectives sought by the sponsoring company, rather than the investment's influence on the decision process. However the link has been made here between the idea of the "product" and a sponsorship. Furthermore, authors in decision-making and OBB have noted the importance of product characteristics in shaping decisions (Johnston \& Lewin, 1996), be it via determining elements such as risk (Lewin \& Donthu, 2005) or more generally making judgements about consequences which would then shape decisions (March, 1994). The sponsorship will be here referred to as the "investment", which reflects this product view, without going so far as to call sponsorship a "product."

Many authors in OBB have elected to "bundle" the investment characteristics. Johnston and Lewin (1996) refer to a purchase situation in which purchase risk is at the core, and a function of purchase importance, complexity, uncertainty of outcome and time pressure. Lewin and Donthu (2005) label purchase situation as a combined construct including buyclass, product type, importance, complexity and uncertainty (see section 6.4). Similarly in this study, it appears sponsorship investments hold a number of important characteristics, which may be described as a bundle including the financial request, the reputation of the event, organisation and people involved, the extent of fit with company objectives, and the perception of quality, trust and risk. 


\subsubsection{Financial Commitment}

As noted, the financial commitment sought was important in determining the decision making process. Findings in this category revealed that it was important the request was within a "ballpark" and that the specific financial amount requested would be augmented by the company through leveraging. The sponsorship and philanthropy literature notes the use of leveraging, but does not deal specifically with an analysis of the financial request. Even here, consideration of the exact amount was not obtainable in all cases. However the acknowledgment of the amount being important, and a "ballpark" existing does reinforce that the financial commitment is part of the bundle of characteristics which describe the investment.

In addition to the above, results indicated that there was often a lower threshold for sponsorships (compared to other marketing expenditures) at which decisions were escalated up the hierarchy. The amount requested thus impacts on the DMU. While this seems to be partly a formalised process, it is evident that this process would not be in place were it not for uncertainty associated with sponsorship. These findings are consistent with the OBB literature dealing with the influence of product characteristics (section 3.3.5). Specifically, the financial commitment could be likened to purchase importance (Johnston \& Lewin, 1996; Lewin \& Donthu, 2005). Returning to this study, it is evident that the perception of sponsorship as uncertain may attach more importance to a financial expenditure in sponsorship, rather than an expenditure in another area of marketing, such as a print advertisement. This also then relates to a perception of risk which will be addressed shortly.

\subsubsection{Longevity and Reputation}

A second aspect of the bundle was the history and reputation of the arts event, organisation and its management. Many respondents noted the desire to become involved with an event which had longevity and a successful history, and for which individuals involved in the event held positive reputations. This is an area which has been explored to some extent in the sponsorship literature in a series of related articles considering trust, communication and marketing orientation in sports sponsorship relationships (Farrelly \& Quester, 2003a; Farrelly et al., 2003b). These authors found that the sponsor's level of trust in the sports organisation was related to their perception of the sports organisation's market orientation; the authors going on to advocate for better communication and a 
partnership approach in sponsorship relationships (Farrelly \& Quester, 2005a; Farrelly \& Quester, 2005b). While these studies highlight the importance of the sponsee's marketing orientation as helping to build trust in the relationship, they do not look specifically at the beginning of the relationship and the decision. Furthermore, this study found that rather than a specific assessment of market orientation, a more general impression of reputation served to help develop trust. To an extent, the findings in this study agree that trust is important and may be developed through impressions of the arts organisation. However this study also points to the general reputation and longevity of the event as an initial characteristic considered important in the "product bundle."

Decision-making and OBB literature reveal elements related to reputation, including risk and uncertainty, along with the concept of the buy-class. Robinson, Faris and Wind's buy-class model (c.f. Anderson et al., 1987) relates organisational buying behaviour to the newness of the purchase, within which importance, complexity and uncertainty are contained. Newer investments are those which are perceived as holding more importance, being more complex and more uncertain. Similarly, the evaluation of the reputation of an arts event and/or managers appeared to be oriented towards reducing the uncertainty. In considering the findings and the literature, there is agreement that the reputation of an event/organisation/individual could be an important part of the investment bundle. In addition, there also appears to be a link between the reputation and reducing uncertainty associated with these investments.

\subsubsection{Alignment and Making it Work}

Evident in the previous chapter, was that investments needed to fit or align with the company's strategy, and this was also part of the product bundle. This could be equated to the idea of meeting specifications in terms of the OBB literature - and is perhaps an obvious requirement. However, specifications for sponsorship do not seem to be as easily laid out, as noted in the discussion concerning sponsorship's uncertainty.

Sponsorship and philanthropy literature deal with this area in examining the objectives managers seek to fulfil. As noted in chapter 2, numerous objectives have been given for these investments, including building awareness and image with a particular market, providing employee benefit, developing goodwill in the company's network, meeting 
expectations of a community, and fulfilling personal interests. This study found evidence of a similar variety of objectives within the decisions, but sitting above these objectives, was that the investment had to have some higher element of fit with the company more broadly. The investment needed to align with the company's strategy first, so that benefit could be realised. Part of this idea of alignment was how the sponsorship could be used to achieve benefit. Both the concept of alignment and the use of sponsorship are related and will be examined here.

In terms of alignment, respondents noted the need for the sponsorship to align with their strategy. This could occur at either the corporate-wide level and/or the marketing level. In fact, the results suggest that while marketing objectives may be sought, it appeared just as likely that achievement of broader company objectives would be sought through sponsorship investments. This finding is in agreement with the sponsorship literature which discusses the range of objectives sought via sponsorship, including image building, and developing brand awareness in key markets (Cornwell \& Maignan, 1998; Meenaghan \& Flood, 1983; Witcher et al., 1991), as well as improving the company image more generally, and developing goodwill within a business network more specifically (Hoek et al., 1990; O'Hagan \& Harvey, 2000). However, it is also suggested in the literature that the marketing alignment - the objectives related to developing awareness with a particular market - is the stronger of the motivations (O'Hagan \& Harvey, 2000). In addition, authors have noted commercial sponsorship's acceptance into the marketing mix (eg. Dolphin, 2003; Motion et al., 2003). While this study does not disagree that sponsorship is part of the marketing toolbox, alignment with marketing objectives was not consistently the strongest alignment sought.

Philanthropy literature also presents a list of alignments sought, including company-wide and marketing specific. Although there are authors who have noted the emergence of corporate philanthropy activities as part of the marketing mix (Bennett, 1998; McAlister $\&$ Ferrell, 2002), the philanthropy literature finds more emphasis of a wider array of strategic goals, including consumer/market oriented, political, altruistic, and related to managerial utility (Campbell et al., 2002). In fact, discussions of strategic philanthropy (Porter \& Kramer, 2002; Saiia et al., 2003; Smith, 1994) are oriented to aligning with company-wide objectives. 
In considering a commercial vs. philanthropic orientation, it might be expected that companies with a commercial orientation would first seek marketing alignment, and those with a philanthropic orientation would first seek corporate-wide objectives. This however was not always the case. While companies deemed to have a commercial orientation tended to look for marketing alignment, those characterised as having more of a philanthropic orientation, were sometimes oriented to marketing, and at other times to other broader goals.

This study thus agrees with sponsorship and philanthropy, that there needs to be alignment between the investment and the company strategy, and that this alignment may take the form of a fit with marketing or broader objectives. The findings however do not suggest that the market or consumer-oriented goals are always paramount in these investments, but that other stakeholders may be just as important. This is consistent with authors who find a range of motives, but do not find a single, dominant motive.

Another aspect to the alignment, was that investments were evaluated in terms of how this benefit to the organisation would be realised. Two activities were noted as prominent: benefit via hosting, and benefit through brand image transfer. Evident in the managerial side of sponsorship and philanthropy literature, is that this literature does not address the use of sponsorship or philanthropy to a great extent in the context of the decision-making process. However, some investigation into the consumer side of sponsorship contributes to this discussion.

The most frequently noted use of sponsorship in this study was through hosting. The cases examined here suggested that through sponsorship, hosting could be arranged allowing the company to realise benefits. Hosting then could relate to objectives such as business networking, and/or developing relationships with clients/customers. The pattern of how hosting would be used (section 5.5.3), points to the evaluation of the event's quality; whether it would appeal to the recipients of the hosting was crucial.

Hosting is an area of the literature which has received little attention in sponsorship or philanthropy. The lack of study may be related to the difficulty in measuring results associated with hosting. In addition there is some overlap between the idea of hosting and that of brand-image-transfer in that through both uses, a movement of meaning is desired. However, consideration of hosting in terms of OBB suggests that the use of the 
investment (for hosting) would determine the specifications (what is required). The use of the investment for hosting also relates to purchase importance, depending on the clients the company is hosting. Evidence here suggests there is opportunity for further study into hosting specifically as a use of sponsorship.

The second noted use of sponsorship focused more on brand fit, which has been examined in the consumer side of sponsorship literature. Smith (2004) describes this as Brand-image Transfer (BIT) being the movement of meaning, from one brand (arts event) to another (sponsor company). The idea that this may be an objective has been acknowledged in sponsorship and philanthropy, and numerous studies have been conducted which measure the impact of high or low fit in the minds of consumers (for example Barone, Norman, \& Miyazaki, 2007; Gupta \& Pirsch, 2006a; Nan \& Heo, 2007). These and other authors point out that the ability to transfer meaning is related to how closely the sponsor and arts organisation are perceived as "fitting" by the target market, with higher fit related to a greater transfer of meaning for the sponsor. The findings here support that BIT is a common use of sponsorship, and further illustrate that BIT may influence the evaluation stage, potentially making up the "specifications". In addition, as noted earlier, for many companies the extent to which this was evaluated favourably depended on whether or not the DMU perceived that BIT was possible.

The discussion of alignment and fit, through hosting and/or brand-image-transfer, also relates to ideas of legitimacy (section 6.1). Along with alignment to specific goals, these companies sought to establish a level of legitimacy with particular stakeholders. This is not to say that the companies were suffering from poor reputations, but as one expert put it, may have been looking for the "reflected glory" which sponsorship of the arts might offer.

Chen et. al. (2008) specifically studied charitable contributions of companies, and proposed that companies would seek to fill legitimacy gaps by either changing their own goals, changing the definitions of social legitimacy and/or "making an effort to identify or associate themselves with symbols, values or institutions that have a strong perceived image of social legitimacy" (p,133). It is this association with symbols, values and institutions which relates to sponsorship activities and the alignment sought. These authors found evidence that "on average charitable contributions appear to be used by corporates as a tool of legitimization" (p.141). While the study in this thesis did not 
undertake similar quantitative research, the statements of the respondents suggested that attaining legitimacy with consumer groups (via brand-image-transfer) and/or certain stakeholder groups (via hosting) was an outcome desired through their sponsorship.

In the above discussion, sponsorship decisions involve the investment being subjected to an evaluation related to company and/or marketing objectives, and an evaluation will be made in the context of how the individuals in the DMU see sponsorship working to achieve these objectives. This has also suggested that within these considerations, judgements will be made in terms of the investment's quality, its uncertainty or potential risk, and the extent of trust the company has in the investment. These later points will now be addressed.

\subsubsection{Quality Trust and Risk}

While key components of the sponsorship investment have been discussed above, three interrelated themes appear: quality, trust and risk.

Quality has been noted as being partly determined by the DMU's assessment of the event's reputation -the history of the event or reputation of the organisation and managers. Quality is also noted as important in assessing the investment's suitability for use in hosting. These assessments appear to be acting both to meet the "specifications" of investment, as well as to reduce potential uncertainty. The judgement of an investment's quality is recognised in the Organisational Buying process (Robinson et al., 1967), however, quality is not addressed in great detail in the sponsorship and philanthropy literature. To some extent this is implied in studies which consider sponsorship as a relationship. Ryan and Fahy (2003) examine constructs which indicate a type of quality, such as the willingness of the party to adapt, commitment, longevity and communication. In a series of studies looking at sponsorship vis a vis market orientation and trust, authors suggest that the sponsor's level of trust is related to their perception of the property as highly market oriented (Farrelly \& Quester, 2003a; Farrelly et al., 2003b; Farrelly \& Quester, 2003c). Quality then is likely to be part of considerations noted above, and was evident in this study. In addition, this study notes that quality is likely to be based mainly on the reputation of the event, organisation and/or managers, and that this assessment is likely to be related to the use of the sponsorship. Quality also 
appeared to have a role in establishing a level of trust and in reducing perceived risks, or product uncertainty.

Trust is noted as partly determined through an assessment of quality (related to reputation or a past relationship) and appeared as an important factor in the decisions. Although the decision-making process has not been examined to this extent in the literature, the idea of trust is evident. Ryan and Fahy (2003) noted the importance of trust for both parties in the relationship. Olkkonen (2002) saw trust as crucial and linked it with formal controls, in contrast to this study where it appeared more of a subjective judgement. Other authors relate trust to the company's perception of the property's market orientation (Farrelly \& Quester, 2003a; Farrelly et al., 2003b; Farrelly \& Quester, 2003c). In a similar vein, Seitanidi and Ryan (2007) propose that the development of trust between business and non-profit organisations is essential. Certainly there is agreement that trust is an important factor, and this study is in line with this. However this study also suggests that in the early stages of the relationship trust is assessed via subjective judgements by the DMU. Also the findings in this study link trust to the existence and establishment of more personal relationships, rather than a more formal assessment. Finally, this study suggests that trust is also linked to the concept of risk.

As noted in chapter 5, risk was not initially evident within responses, but seemed to lurk within the early stages of the decision process. The study found that risk was identified if the product did not "fit" the company's image or objectives, was seen as too political, too elitist, or was seen as something difficult to exit. These elements of risk appeared to be reduced early on in the process, with a quick rejection of proposals. The decisions that remained still seemed to hold some risk, primarily being the risk that the event would not be successful. This last risk was alleviated when the company could be assured of the reputation of the event, organisation and individuals - which brings us back to quality and trust.

While the sponsorship and philanthropy literature does not explore risk, OBB literature incorporates this in the idea of product or task uncertainty. While other authors have included product or task uncertainty in their set of factors determining buying behaviour (Bunn, 1994; Lewin \& Donthu, 2005), risk is at the core of Johnston and Lewin's model (1996) - where the level of risk associated with a purchase situation affects the DMU and 
determines a large part of the variation in OBB. Jocumsen (2004) also considers risk, but in terms of the personal risk tolerance of individuals involved in planning.

This study agrees with the OBB literature in that risk enters into and shapes the decision process. Risk is seen here as shaped in part by the company frame of reference. What the company's objectives are and who their stakeholders are will determine where the risk lies. How risk is defined then impacts on the evaluation process, usually early on in the decision and sometimes subconsciously or informally. Concurrently, the perception of risk may be alleviated by the reputation, track record and observed professionalism of the company, the event and the people involved. If the DMU feels they can trust the arts organisation, and deems it a high quality event, then the risk is reduced. In addition, the existence of a strong advocate, with both knowledge and power may change the risk perception.

In the above discussion, quality, trust and risk were explored separately, but these are clearly linked concepts, and concepts also related to the specific features of the investments. The study has noted that the financial commitment, the reputation, and ability to align with company objectives will all be elements which are assessed at some stage in the process. This study also suggests that these elements will contribute to the process in terms of how they indicate quality, trust and risk. Furthermore, it is proposed that the evaluation of these characteristics will be influenced by the company frame of reference and individuals within the DMU, and that these characteristics may at the same time influence the DMU.

\subsubsection{Complexity}

An additional element related to sponsorship as a product, is purchase complexity. Jennings and Plank (1995) considered complexity in terms of product decisions, and observed that as complexity increased, so too did controls. While the respondents in this study did not specifically identify investments as complex, some noted that sponsorships could be perceived as being complex, with multiple departments involved in implementation. Returning to the data revealed that in companies seen as more philanthropic oriented, respondents made comments suggesting that they did not perceive the investment in terms of its complexity. Furthermore, statements of higher-level executives tended to reflect a less complex evaluation of the investment. This suggests 
that the assessment of complexity in these instances is less of a formal assessment, and more of a personal perception, shaped by the company frame, and individual frame.

\subsubsection{Summing up Investment Characteristics}

The consideration of investment characteristics has led to a number of insights. Firstly, similar to OBB, the findings suggest there is a bundle of characteristics important in these decisions, which could be likened to the purchase situation (Johnston \& Lewin, 1996; Lewin \& Donthu, 2005). In the "sponsorship bundle", purchase importance is crucial and determined in part by the financial commitment sought and how sponsorship will be used, particularly as it pertains to stakeholder groups targeted. Perceptions of uncertainty, risk, trust and quality are also part of this bundle, and relate to the reputation of the event, its organisation and managers. Importantly however, these are perceptions and are influenced therefore by individuals - their experiences, knowledge, judgements and by the company frame of reference. Similarly, complexity may be in the sponsorship bundle but would be linked to the frame of the company and perceptions of individuals.

A crucial part of the bundle, obvious in OBB, but not so in sponsorship, are the "specifications" -i.e. what is this product being used for? Will it fulfil a company need? In OBB specifications are pre-determined. In sponsorships, the specifications are not as clearly laid out; the investment needs to fit, and align with company objectives, it needs to deliver a benefit in a manner which the company can see (hosting or BIT). Therefore the fit and use-pattern are both important parts of the sponsorship bundle.

In terms of the initial framework, this study then suggests elements which are important within the sponsorship bundle of investment characteristics. Furthermore, it suggests a 2-way interaction between investment characteristics and the DMU - the investment both influencing and being influenced by the DMU, and especially the advocate. Finally, it suggests that the perception of the investment will be shaped in part by the frame of reference.

\subsection{The Process}

As noted, the decision-making process itself has received little attention in studies of sponsorship and philanthropy. Theoretical models have been proposed based on literature (Jones, 2007; Valor, 2007) and while these lend support to this study, a step-by- 
step process of how companies make these decisions is not present. In this study, as noted in chapter 5 , the process identified included five stages:

1. pre-approach context,

2. approach,

3. evaluation,

4. decision and

5. post-decision.

These stages differ from OBB processes in that organisational buying processes generally include steps related to identifying the specifications and potential sources, and requesting proposals (Johnston \& Lewin, 1996; Sheth, 1973; Webster, 1965). None of the decision paths in this study were pro-active; in no case was a need pre-determined with noted specifications, and in no case did a company actively go out to seek opportunities.

Another finding concerned the fluidity or variation of the process. While the five stages could be related to each decision, there were variations. Some steps were almost skipped, or emphasis shifted. This is similar to findings of authors in OBB such as Bunn (1993) who proposed decisions may include a selection and combination of underlying activities.

The following discussion will work through the identified stages of the decision path found in this study, in terms of literature within sponsorship, philanthropy, OBB and decision-making. This process discussion is oriented to the sponsoring company, depicting the process the company works through. At the same time, the role of the arts organisation will be noted as appropriate. Concepts from previous sections may be revisited as they emerge important, and a closing section will revisit the overall process.

\subsubsection{Pre-approach Context}

The first stage identified was the pre-approach context and was essentially the scene setting. In this stage attention is given to the frames of reference within the company and for individuals. It represents the situation prior to the arts organisation making contact. 
This stage highlighted first the frame of reference of the company. The perceptions of CCI and sponsorship held within the company, the company's philosophy to CCI, and more specific objectives to which alignment could be sought via sponsorship were all important identifiers in this stage. In terms of the later objectives, while a "need" was not directly expressed, as is expected in OBB literature (Johnston \& Lewin, 1996), this stage reflected underlying needs, and the defining of a situation, reminiscent of the logic of appropriateness (March, 1994). Also in thinking of the company level, this stage considered the roles and relationships of individuals within the company who might potentially make up the DMU: who is in the formal role of reviewing sponsorship requests? who might be the advocate? for example.

This brings the focus to the individual, and the individual frame of reference making up a crucial part of the pre-approach stage. This element refers back to the perceptions, experiences, knowledge as well as formal roles for individuals who could potentially make up the DMU.

The results also point to the existence of a "happenstance" in the pre-approach stage, in which the initiator sees the potential in the investment. The idea of a "happenstance" was not so much about chance, as it was about individuals being well informed. Information in this stage about how the company viewed CCI and sponsorship, what objectives the company might be looking to achieve, and which individuals would be key in the decision, were particularly important in terms of moving to the approach stage. Importantly, in this stage the initiator needed to see the alignment or fit. This need for fit is in agreement with much of the sponsorship and philanthropic literature, however this study highlights the need for awareness of the company's needs prior to the approach. Certainly, a fit is necessary, but someone needs to see it from the start, and thus needs to be tuned in to the business environment.

Therefore, while the pre-approach stage differs from OBB literature in that a need is not specifically identified, for which a product is sought, it is similar in that there is an underlying need or objective which the company is trying to achieve. The extent to which the sponsorship may help to meet these objectives appears to be more of an idea by individuals, based on their own knowledge, experience and relationships. The ability then, to move from pre-approach to approach, is based on the extent to which the initiator feels a "match" is possible. 


\subsubsection{Approach}

The approach phase marked the initial approach of the arts organisation to the company. It was influenced by the pre-approach context, and was dominated by the initiator (section 6.3). In decision-making terms this is similar to the identification of a problem. The approach stage was when the fit and benefits were made apparent, or "pitched" to the company. Results indicated that there were variations in this stage according to who took the role of the initiator, suggesting different paths of decisions based on the approach phase.

On the company side, it was evident that in this stage, the advocate emerged as someone who progressed the decision forward - essentially not eliminating it and providing their support. Related to this, is that in this stage, some level of evaluation was undertaken by the company. Some cases in particular were notable in their inclusion of a quick evaluation during this stage, taking the place of the more formal evaluation phase.

This finding is reminiscent of sponsorship and philanthropy literature which suggests the decision-making process is less formalised and more personal (for example, Thjømøe et al., 2002). However, some OBB and decision-making literature suggests this is another path for decision-making. For example, Smith and Taylor (1985) propose four possible strategies in the industrial buying process including "computation" and "compromise", but also less certain processes of "judgement" and "inspiration". Certainly, in looking at the approach phase, individuals (the initiator on the arts organisation side, and the advocate in the company) appear to play a crucial role in providing some judgement and possibly inspiration. In terms of the fluidity of the process, Bunn (1993) suggests that there are a number of steps, but many possible arrangements. Similarly here there is evidence of evaluation occurring within the approach.

\subsubsection{Evaluation}

The evaluation of the opportunity is a phase noted and studied in OBB and decisionmaking literature. It could be linked with the phase of development, following problem identification (Eisenhardt \& Zbaracki, 1992), the evaluation of proposals (Johnston \& Lewin, 1996), or analysis and procedural control (Bunn, 1993). In this study, the 
evaluation considered the fit (if not already assessed in the approach), often included an internal sales pitch, and was highly influenced by the intuition of the advocate.

As noted, at times some evaluation was done at the approach phase, but in many cases there was a more defined evaluation stage. This stage held the assessment of fit and benefit to the company, an idea in agreement with the sponsorship \& philanthropy literature. Similarly although the "specifications" are not spelled out, the evaluation of benefit is in agreement with OBB literature.

An additional finding here was that an internal sales-pitch, led by the advocate, was often part of this stage. While it seemed this should relate to formalised processes, the formal process was not always followed (section 6.2). The existence of an internal sales pitch relates to findings in the DMU suggesting that vertical involvement is often necessary (section 6.3.1), and that the advocate may be the driver of this internal process. The idea of an internal sales pitch is not examined in the sponsorship or philanthropy literature, and is therefore a contribution to this area.

Furthermore, the analysis of this phase highlighted the link between the internal sales pitch, the advocate and intuition. Findings suggest that the knowledge and experience of the advocate was essential here; it allowed them a level of intuition which informed the process and drove the evaluation forward internally.

The importance of individual influence is noted by a number of authors, and is detailed in section 6.3.4 concerning the advocate. Consideration of the evaluation phase reveals that the advocate is highly involved in the evaluation, providing enthusiasm, knowledge and personal experience to the process. This focus on the individual and their role is in line with findings in OBB and decision-making literature. OBB authors note the importance of the individual's "psychological world” (Sheth, 1973; Webster \& Wind, 1972a), and similarly in decision making, the individual's cognitive limits, power, and politics are noted (Eisenhardt \& Zbaracki, 1992), along with the individual's perceptions and interpretations (March, 1994). Particularly in this study, the finding is that the knowledge and experience of a key individual is a crucial part of the evaluation stage of the process. 


\subsubsection{Decision}

The decision phase began at the point of someone in authority making a decision that the sponsorship should go ahead. As noted in the results pertaining to the DMU, there was often an informal decision, which was followed by final approval. At times the decision was considered a "done deal" especially as confidence in the fit increased. At other times, notably when the CCE or Owner made the decision, the decision and approval became one stage. Finally, at other times a decision deemed "done" was challenged. Evidence here suggests a range of decision/approval combinations, influenced by a variety of elements, but mainly by the knowledge held by individuals.

Again intuition is seen to play a role. Individuals who appeared to assess the relationship as delivering significant benefits, became such strong advocates that the decision and approval appeared as one stage. This is in contrast to literature in sponsorship and philanthropy calling for greater visible, measureable rationalisation, and a movement away from gut instinct (Abratt et al., 1987; Meenaghan, 1991b; O'Hagan \& Harvey, 2000; Thjømøe et al., 2002). However, OBB and decision-making literature recognises the important role of the individual's psychological world. In fact, returning to March's (1994) logic of appropriateness, under this logic decision-makers make individual interpretations of the situation, asking what kind of a situation they are facing, what kind of a person and organisation they are/they are within, and therefore, what may be appropriate?

In considering the decision phase it is therefore evident that roles and formal processes (such as approvals by higher levels) are important. However, what emerges as more important is the knowledge and experiences of individuals as they then interpret the situation.

\subsubsection{Post-decision}

The analysis of the post-decision phase yielded two results. Firstly, it was evident that the CSM/CMM generally managed the relationship, whether or not they had been an advocate or influencer in the decision. This finding supports sponsorship and philanthropy literature which notes that the management of these relationships typically falls to this level (Abratt et al., 1987; Brammer et al., 2006; Farrelly \& Quester, 1997). 
The second finding was that the post-decision phase was sometimes used as a time to post-rationalise the decision. This is, some companies evaluated and even negotiated the benefits of the sponsorship in this stage. This is not noted in sponsorship or philanthropy literature directly, and therefore the recognition of the potential for a post-decision evaluation is a contribution to this literature.

The variations noted above and in this last phase agree with a number of studies and articles in decision-making and $\mathrm{OBB}$, which propose that there may be many decision paths and variations which occur, and these are not always going to be linear and logical (Bunn, 1994; Eisenhardt \& Zbaracki, 1992; Rodgers \& Gago, 2001). In seeking out variations of paths in this study, further analysis was conducted, revealing three potential paths. Each of these paths will now be discussed.

\subsubsection{The Process Overall}

In attempting to group the variety of processes which emerged in this study, three categories were evident (section 5.6.6):

(1) High level decisions largely at the level of the CCE, with the CCE's intuition playing a role in the evaluation, and the formal evaluation taking place in the post-decision stage.

(2) Driven at a lower level, with the request being pushed upwards, supported by thorough evaluation and justification prior to a higher level presentation being made.

(3) $3^{\text {rd }}$ party involvement with the opportunity being identified and initially presented by a key $3^{\text {rd }}$ party.

The findings of the sections above along with the variety of decision paths support many conclusions made in the literature. It is evident that these processes are not aimed at solving a need or problem, but are perhaps more about satisficing rather than optimizing, and the players almost discover the goals in the process, as suggested by Eisenhardt and Zbaracki (1992). While there are phases of the decisions, the paths taken may vary (Eisenhardt \& Zbaracki, 1992). The paths may also vary by situation (Bunn, 1994), or vary by individuals (Rodgers \& Gago, 2001). 
In terms of decision-making literature, the process could be associated with March's (1994) logic of appropriateness. Under this logic the decision-makers firstly recognise the situation they are within: in this study it is a situation bounded by characteristics of sponsorship, and characteristics of the company. Secondly, the decision-maker considers their identity: what kind of a person am I and what kind of an organisation is this? Is this organisation oriented to commercial or philanthropic goals? What are our needs and objectives? What is my role and how do I feel about this opportunity? In terms of this study, these questions relate to the company frame, but also the individuals in the DMU and especially the advocate, along with their knowledge and experience. Finally, returning to the logic of appropriateness, the decision-makers ask, given this sponsorship opportunity, the nature of sponsorship and the nature of the company, what does a person such as I, within an organisation such as this, do?

The process overall suggests that these decisions may be characterised as a balancing act. Consistent with the range of orientations proposed, a company may be looking to balance their need to fulfil commercial objectives with their desire to be a contributing part of the community. There is acknowledgement that there is a subjective/objective balance: the decisions relied extensively on subjective judgement and personal experience, but needed to also be supported objectively. There is also a balance sought between achieving a "company" decision and an individual decision: a desire to have input from a variety of people within the company, but the necessity of having a single advocate to drive the decision forward. While the cases studied here varied in how they approached and achieved these balances, the existence of these factors was consistent throughout.

\subsubsection{Influences on the Process}

Throughout the examination of the stages of the process, key influencing forces appeared which could be grouped into three categories: the frame of reference, individual intuition and the idea of sponsorship as a product.

Firstly the frame of reference of individuals and the company were vital in setting the stage in the pre-approach context, but also influenced the process in determining the DMU. This idea of an environmental context is similar to models proposed by authors (Jocumsen, 2004; Johnston \& Lewin, 1997; Sheth, 1973; Webster \& Wind, 1972a), 
however this study has identified the more specific elements of the context which are important in these decisions.

Secondly, it is clear that individual knowledge and experience, leading to intuition, play key roles in the process, and most markedly in the evaluation and decision phase.

Certainly, individual characteristics, roles and judgements have been noted in OBB literature, but again, this study takes these ideas into a specific arts sponsorship context.

Thirdly, taking the perspective of sponsorship as a product/investment with its bundle of characteristics (per section 6.4) reveals the influence of this investment on the process. More specifically, perceptions of sponsorship as uncertain may influence the preapproach context, and the DMU in the approach and evaluation stage. The assessment of how the investment will fit with the company is influential throughout all stages in the process, through to the post-decision. Again, this agrees with OBB literature in determining a level of "purchase-related risk" (Jocumsen, 2004; Johnston \& Lewin, 1997; Sheth, 1973). This perspective however is not directly addressed in the sponsorship and philanthropy literature. Sponsorship has not been given attention from a "product" or investment perspective, with noted influences on the decision process; therefore, this is a contribution to this literature.

Hence, this study has contributed to the sponsorship and philanthropy literature, and potentially that considered in the broader range of CCI, by providing an in-depth view of these decision-making processes. The study has also contributed in its findings that an application of a modified OBB perspective along with decision-making is revealing. There are a number of reasons which might be suggested as to why CCI and sponsorship in particular have not been considered in these contexts. Particular to decision-making, much of this literature has been devoted to decisions in the area of strategic management, and decisions which are likely to have a greater impact on the company than a CCI investment might. However it is evident that this perspective has assisted in this study. In terms of $\mathrm{OBB}, \mathrm{CCI}$ and in particular sponsorship, is often linked to a marketing expenditure similar to advertising, which also has not received attention from an OBB perspective. In addition, the process which has been discovered here does not begin in the same way as many industrial purchases might begin (with specifications being defined and a search being undertaken). Finally CCI is difficult to measure, and 
therefore the idea of CCI as an investment or purchase for which ROI is expected may be a point of contention for some.

On the other hand, Webster and Wind (1972a), noted the particular perspective of OBB:

Industrial buying takes place in the context of a formal organisation influenced by budget, cost and profit considerations ... [it] usually involves many people in the decision process with complex interactions among people and among individual and organisational goals. (p.12)

The above explanation is consistent with the cases studied; these decisions took place within formal organisations, and involved a number of people with complex interactions. Furthermore this chapter has demonstrated that the application of this view has revealed much about these decisions. So, while this perspective has not been taken for sponsorship and philanthropy, these decisions are very much investments/purchases, and the application of both OBB and decision-making has revealed much insight.

\subsection{Discussion in Summary}

This chapter has highlighted a number of similarities and differences between the literature and the findings. Similar to literature in sponsorship and philanthropy we find that there are some uncertainties associated with sponsorship, that certain key individuals may hold more influence in these decisions than others, that the establishment of benefits and a fit is important in making the decision, and that each sponsorship will be evaluated on its fit, but also less well defined characteristics such as quality and trust. However this study has taken a specific point in time - the decision - and elaborated on each of these similarities, resulting in a richer understanding of these processes.

Unlike the sponsorship and philanthropy literature it has become evident here that the uncertainty surrounding sponsorship is about a wider societal perception, how companies may translate this into an orientation towards commercial and philanthropic goals, and how individual managers interpret this. This study has also suggested that while formal procedures and objectives exist, an amount of flexibility and happenstance is also at play. In terms of the roles that individuals play, more insight has been given to the group of 
individuals involved, the role of informed intuition, as well as the particular key individual, here called the advocate. These decisions have also been enriched through understanding sponsorship as a product with a deeper understanding of how the alignment or fit is viewed. In thinking about the process overall, this study has contributed to the sponsorship and philanthropy literature in identifying stages of the process, as well as a typology of processes.

In addition to the above, this study has also expressed similarities with decisions in OBB/Decision-making. They are influenced by a wider environment, rules, individuals, and the product/investment itself. Decisions may be characterised, but are likely to have variations, as certainly was the case in this study. In general, these findings are in agreement with $\mathrm{OBB} /$ decision-making literature, but the difference is that this study provides more specific insight and direction in terms of understanding arts sponsorship decisions.

This chapter, in comparing the findings with the literature, has revealed a number of insights and contributions, and has also suggested patterns and themes. The following chapter will build on this analysis and discussion, to highlight the key themes which emerged and to provide propositions. 


\section{7: Theory and Proposition Development}

Throughout chapter 6 , patterns and themes were evident. This chapter is devoted to drawing out these themes, and integrating key aspects of the decision-making story. Therefore, this chapter represents the next stage of the theory building process. In theory building, authors have agreed on the need for an iterative process, moving from the data, to a conceptual argument, back to the data, and tying in concepts from other sources (Locke, 2007; Siggelkow, 2007; Weick, 1989; Yin, 2003). Consistent with these recommendations, this study was subjected to systematic iterations, represented in part by chapters 5 and 6 . This chapter will build on these discussions to present key themes, put forward related propositions, and identify relationships between key constructs.

In answering the central research question, how do companies make decisions when considering arts sponsorship? themes identified were as follows:

- Decisions exist in a broader societal context, which includes views of stakeholders, consumers, and managers, all of which will impact decisions of support.

- Commercial and philanthropic goals co-exist within investments such that in a single decision, both elements play a part to varying extents.

- Fit: Sponsorship needs to work, meaning that there needs to be a fit between the company and the arts initiative.

- Within the DMU the advocate holds the most influence. While these decisions exist in a company, with a number of individuals present in the DMU, ultimately the advocate holds the most influence.

- Intuition plays a role. There is a strong intuitive element to these decisions, based on the knowledge and experience of individuals.

In the following, the themes above will be discussed, propositions presented (a summary of propositions is contained in Appendix 7), a typology of processes will be put forward, and the original framework will be revisited. 


\subsection{Decisions Exist in a Broader Societal Context}

The findings in this study, combined with an examination of the literature, suggest that these decisions need to be understood within the broader context of society. Society's expectations of companies, along with perceptions of a sponsorship, sponsorship of the arts, and CCI more generally, will have an impact on these decisions. Two main themes emerged here: the views of consumers and stakeholders, as perceived by managers, may influence the decisions, and the views held by individual managers were also influential. Table 7.1 provides case-by-case evidence of how respondents referred to the influence of the broader context.

To begin, the view of consumers and other stakeholders were acknowledged by respondents as influential. The idea that the sponsorship would help change the company image or manage legitimacy with stakeholders was present, be it to help the company be seen as more innovative (case A), relevant (cases B \& C) and/or part of the community $(\mathrm{F}, \mathrm{G}, \mathrm{K})$. Other cases were more consumer focused, looking at the sponsorship as potentially conveying a beneficial fit with their brand for consumers $(C, D, E)$. In all cases, consumers and other stakeholders were perceived by managers to hold views on sponsorship and CCI. The literature supports this, noting that individuals may mistrust companies who appear insincere in their actions (Bronn \& Vrioni, 2001), and/or may be more inclined to do business with companies who are actively involved in the community (Bloom, Hoeffler, Keller, \& Meza, 2006; Dacin \& Brown, 1997). In turn, this will affect the company's actions. For example, a company is more likely to be interested in social giving if managers perceive their consumers to be rewarding companies who give to social causes. Here it is evident that managers consider consumer perceptions of sponsorship, CCI more generally, and the more specific brand fit.

The above supports the intertwining of these decisions with perceptions and expectations in society. This is in agreement with ideas of legitimacy (chapter 6), suggesting that managers are likely to consider a number of questions: "What are the expectations of our stakeholders/consumers?" "What are their perceptions of our company?" "How then, will our stakeholders/consumers feel about this sponsorship?" "Will our consumers and/or stakeholders respond to this positively?" This leads to the first proposition: 
Table 7.1 The Wider Social Influence

\begin{tabular}{|c|c|c|}
\hline case & evidence from interviews & link to decision \\
\hline & $\begin{array}{l}\text { "[This sponsorship] allows us to target top tier, local government, and central government who are very important } \\
\text { stakeholders to our company... we were seen as a very staid [company]... So what we have been trying to do ... [is to] } \\
\text { transform the perception of our company both internally and externally... [so that we become] one of the more sought } \\
\text { after companies to work for... if you're seen as a company that is very innovative, very "out there", to stretching the } \\
\text { boundaries, then that means that you will attract some high -calibre staff." (CSM) }\end{array}$ & $\begin{array}{l}\text { The perceptions of government, } \\
\text { employees and potential } \\
\text { employees regarding the } \\
\text { sponsorship is influential. }\end{array}$ \\
\hline B & $\begin{array}{l}\text { "I also have a huge belief that if you want a creative society ... then you have to support the creative people within the } \\
\text { society. And so those two -- they're not on any checklist but that's a very strongly held personal view that I have which } \\
\text { fortunately for me I suppose I think my entire board share at varying levels." (CCE) } \\
\text { "Well perceptions are everything and so we're trying to influence perceptions of who we are and whether or not we're } \\
\text { relevant... Generally we want people to think we're relevant and have a future." (CSM) }\end{array}$ & $\begin{array}{l}\text { The CCE's philosophy of the } \\
\text { company's role in society plays a } \\
\text { part in decision. } \\
\text { The perceptions of stakeholders } \\
\text { and whether they see the } \\
\text { company as relevant is } \\
\text { influential. }\end{array}$ \\
\hline $\mathrm{C}$ & $\begin{array}{l}\text { (Same company as B above). } \\
\text { "[the sponsorship] worked extraordinarily well at an influencer level, very, very well... it is part of a wider strategy to } \\
\text { raise our profile in [this specific geographic region]." (CSM) }\end{array}$ & $\begin{array}{l}\text { The perceptions of stakeholders } \\
\text { in a particular region influences } \\
\text { the decision. }\end{array}$ \\
\hline $\begin{array}{l}\mathbf{D} \boldsymbol{x} \\
\mathbf{E}\end{array}$ & $\begin{array}{l}\text { "I think if you don't have a fit between a property and the sponsoring brand, it becomes obvious, either immediately or } \\
\text { over time, to the target audience at the other end, that there just is a lack of integrity in this relationship." (CSM) }\end{array}$ & $\begin{array}{l}\text { The perceptions of the } \\
\text { sponsorship in the minds of } \\
\text { consumers influences evaluation. }\end{array}$ \\
\hline $\mathbf{F}$ & $\begin{array}{l}\text { "We need to be mindful of, particularly with arts actually, we're very mindful of anything that looks too elitist ...We } \\
\text { want the public to feel as if we're giving something back to each and every New Zealander. So it's about our } \\
\text { reputation and our image in the marketplace and, ultimately, the other thing is in this political environment, if you get a } \\
\text { huge backlash of customers unhappy with [our company] ... that is unsettling in the political environment because we } \\
\text { are nervous that any change in government or any massive backlash from the public could result in [changes to the } \\
\text { market], which completely changes us as a company." (CSM) }\end{array}$ & $\begin{array}{l}\text { The perceptions of any } \\
\text { sponsorship in the minds of the } \\
\text { public and also government } \\
\text { influences these decisions. }\end{array}$ \\
\hline
\end{tabular}


Company documents link their CCI to enriching the community in which they operate. Respondents in this case felt that a part of their brand was to be seen as a participating part of the community. Respondents also noted the desire to position themselves in the minds of potential customers within a specific geographic location.

G*

CMM expressed personal view that corporations need to do more than just generate profit.

"it makes a difference to society... you get a richness of society... But we need to have a rich, a rich society in terms of breadth of things that are going on and so part of that is building an image globally that goes beyond just being a farm and a nice scenic place to visit, it's why would you live here? It's partly because there's a kind of richness of culture and all sorts of things. ... [The company's] business philosophy ... is very much about trying to make the world a better place." (CCE)

"more companies need to be getting involved in the community sponsorship... You're using the community to generate profit so it makes sense that maybe at some point you should be looking at what you can do to give back." (CMM)

J [the company] I would say are really cutting-edge in terms of good corporate citizenship ... Who really have ... a real sense of community responsibility in terms of everything they do." (ACE)

K "[the objectives were] to increase brand awareness and to get [the people of the region] on our side ... we need to show [the community] that we're supporting their community if you like and something that's of value to them. " (CMM)
The perceptions of the sponsorship in the minds of the community influences evaluation. The views of CMM influence decision.

The views of managers relate to the company involvement in society. Improving society is part of the "company philosophy" and influences decisions.

The views of managers are in accordance with the "company philosophy" of giving back to the community, and this influences decisions.

How the sponsorship would be perceived in the minds of the community, and that it was seen "of value" was important in this decision.

* Case $\mathrm{G}$ requested no direct quotations be used. 


\section{Proposition 1}

In considering arts sponsorship decisions, managers are likely to be influenced by their interpretation of perceptions and expectations held by consumers and other stakeholders with respect to sponsorship and the specific investment.

The decisions of arts sponsorship therefore are positioned within the broader context of society, and societal views of CCI, sponsorship and sponsorship of the arts. Decisionmakers consider the perceptions of consumers and stakeholders - what they expect of companies, how they might perceive sponsorship generally, and how they might perceive the specific relationship. In considering findings regarding intuition, it may be that these questions are considered in a conscious and systematic manner, or this may be part of an intuitive response. In either case, it appears managers will reflect on the broader context.

The second idea noted within this understanding of the broader society, is the acknowledgement that companies make these decisions within an environment which may hold sponsorship as a somewhat uncertain tool. As one respondent noted, "It is a slight trip into the unknown". That is to say the uncertainties which society, business, consumers and stakeholders may attach to sponsorship may influence the decisions.

Throughout this study, some uncertainty about sponsorship was noted as existing in the business community, and was evident from participants (see Table 5.2). Sponsorship was sometimes seen as difficult to measure, having a reputation of being an inappropriately personal choice, and carrying elements of risk for the company's reputation. This uncertainty appeared to feed through to the process, at times making the decisions seem more complex, impacting on the DMU and also on the evaluation process. The uncertainty was associated with higher level executives being established in the DMU than might otherwise be expected. In addition, greater emphasis on commercial justification was often sought for sponsorships which were difficult to quantify on a commercial basis.

While this uncertainty was a theme, not all sponsorships were met with suspicion. In fact there was significant variation in uncertainty, expressed at varying levels across cases, with differences often related to the individual respondents. The more senior the manager, the less concerned they appeared to be about the uncertainty of sponsorship. 
This is congruent with ideas that senior managers have a very different role than $\mathrm{CSM} / \mathrm{CMM}$, and the ability to make decisions amid some uncertainty is a feature of being the CCE (Hambrick \& Mason, 1984). It is also evident that the role of the $\mathrm{CSM} / \mathrm{CMM}$ required these individuals to take a more critical evaluative stance. Therefore, a view of uncertainty concerning sponsorship may be present, but also may vary within the company depending on the individuals involved. This leads to the next topic under the broader context: the views of individuals.

It was found here that the views of individual managers may cause them to be more inclined towards commercial justification, or to make decisions based more on philanthropic rationales. Their views may also directly influence the evaluation of the investment. For example, two cases in particular were noted for an individual manager's confidence in making quick decisions on the basis of "doing good for society," and the negotiation of commercial benefits following the decision.

Noted earlier was the idea that the CCE-level held a different view than CSM/CMM's. This suggests that the formal roles and responsibilities of individual managers have implications on their views and subsequently the decision. This is in agreement with the literature (Hambrick \& Mason, 1984; Jones, 2007; Orlitzky \& Swanson, 2002). More than the formal roles however, the authors above also suggest that knowledge, experience and values-based ideas may play into these decisions. This is supported in the findings, with the input of background knowledge playing a role in the evaluation stage of the process. In addition reference to values was evident with senior-level executives (cases B,C,G,H, Table 7.1). Hambrick and Mason (1984) point out that experiences and values of senior managers are especially important in complex decisions. Similarly in sponsorship decisions, there was indication that they may be seen as complex, and the uncertainty which may exist would add to this complexity.

The study here supports that the background of executives has an influence, and this background is shaped in the "broader context of society" as well as by individual experiences with the arts and with sponsorship. These experiences may or may not have an influence on the organisation as a whole, but appeared to influence the extent to which managers perceived sponsorship with uncertainty, and therefore certainly influence the decision related to the arts initiative. This leads to the next proposition: 


\section{Proposition 2}

Positive experiences and values in support of arts sponsorship held by a senior level executive are likely to reduce the perception of uncertainty surrounding the use of sponsorship.

Examining the idea of uncertainty, within society but also as perceived by individual managers, specific relationships with the decision were noted. Firstly, in cases where sponsorship was perceived as more uncertain, the DMU tended to include higher levels of management than might otherwise be expected. In addition, perceptions of uncertainty tended to be related to more extensive and commercially-oriented evaluation phases. Therefore the following propositions are made:

\section{Proposition 3(a)}

The more managers feel that sponsorship carries with it uncertainty, the more likely the decision-making unit is to include senior levels of management.

\section{Proposition 3(b)}

The more managers feel that sponsorship carries with it uncertainty, the more likely the evaluation phase is to be extensive and commercially-oriented.

These propositions suggest that sponsorship decisions need to be viewed within this broader context. It is also clear that some elements of the context may now be clarified: specifically that managers consider how society, consumers and stakeholders perceive sponsorship, that sponsorship may be viewed with some uncertainty, that this uncertainty will influence the decisions, but also that individual managers with their own background and experience, may mitigate this influence. 


\subsection{Commercial \& Philanthropic Goals Co-exist}

A second theme which emerged was that within a single decision, both commercial and philanthropic goals were evident, and influenced the decisions. The literature also suggests a range of CCI, but classifies individual initiatives as commercial sponsorship, cause-related marketing or philanthropic giving for example. This study finds that within a single decision, there may be elements of commercialism and philanthropy. The fact that both commercial and philanthropic justifications appeared suggests that philanthropy has not entirely moved out of arts sponsorship decisions.

The range of commercial and philanthropic orientations was found for companies and/or even individual investments (see Figure 2.2), suggesting each might be characterised as being more or less philanthropic and commercial. Figure 7.1 replicates the earlier illustration with a rough representation of where the cases were positioned.

Figure 7.1 Cases Within a Commercial and Philanthropic Range

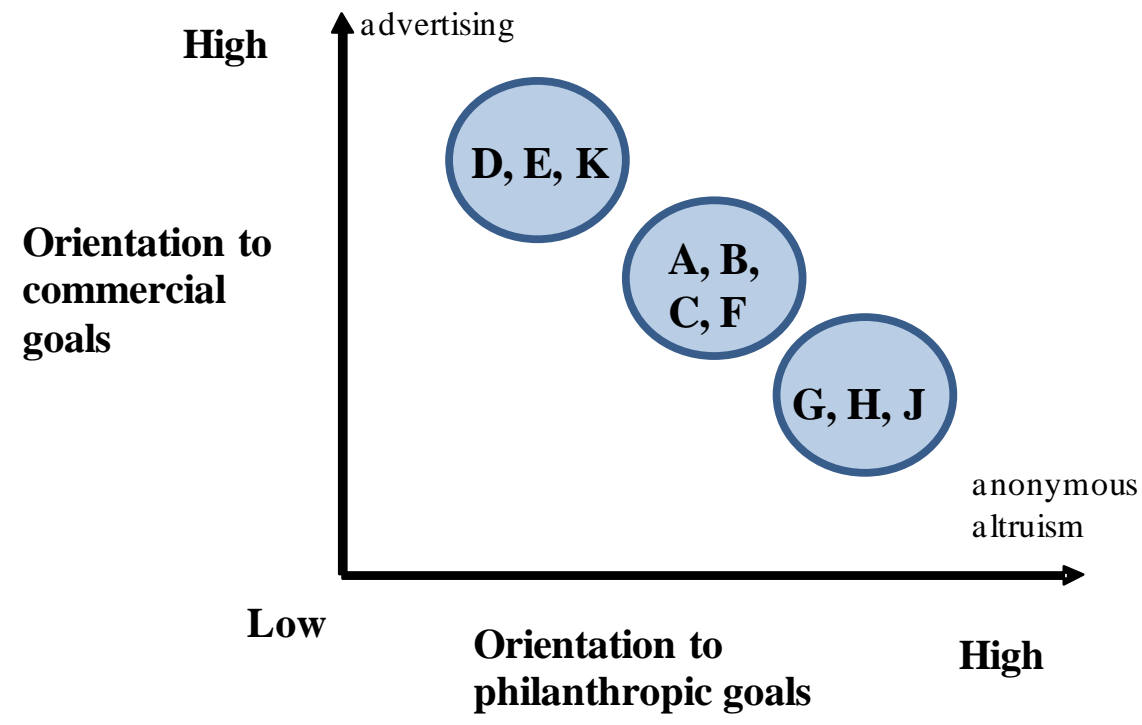

Note that cases D and E were within a single company, as were B and C.

While the study focused on individual cases, the results suggest that companies could be characterised as displaying certain orientations along these lines. Findings were most clear for companies within the extreme categories, being more commercial or philanthropic. Evident in the analysis and discussion is that all decisions held elements 
of both philanthropic and commercial goals. That is, in each decision there was an element of a desire to do good in the community, as well as to benefit the company on a commercial basis. This leads to the next proposition:

\section{Proposition 4}

- Regardless of whether a company is more philanthropic or more commerciallyoriented, arts sponsorship decisions are likely to include goals related to philanthropy along with commercial gain.

Previous discussions explored this range in terms of the literature, noting that the orientations appeared to be related to aspects of the decision process including the formal policy, advocate, evaluation, approval and post-decision negotiations. Table 7.2 provides an examination of these elements for each case, providing further evidence of the differences especially between the two extreme categories.

The category of "more philanthropically oriented" is reminiscent of Drumwright's (1994) reference to companies having an intentional corporate strategy. In companies with a more philanthropic approach, the respondents expressed the deliberateness of this, and this mindset appeared to facilitate the process. Managers in companies with a more philanthropic orientation viewed sponsorship with less scepticism than other companies, suggesting that their orientation gives them the "freedom" to make these decisions without the need for measurement and hard facts. However, a return from their investment was still understood to be expected. This suggests the following proposition:

\section{Proposition 5 (a)}

Managers in companies who approach sponsorship from a more philanthropic orientation are less likely to perceive uncertainty involving the use of sponsorship.

In looking at processes, more philanthropically oriented companies $(\mathrm{G}, \mathrm{H}, \mathrm{J})$ tended to have fewer formal policies related to these decisions, and evaluation relied more heavily 
Table 7.2 Range of Orientations

\begin{tabular}{|c|c|c|c|c|c|c|c|c|}
\hline Case & Orientation & $\begin{array}{l}\text { Existance of } \\
\text { formal } \\
\text { policy } * *\end{array}$ & Advocate & $\begin{array}{l}\text { Characteristics of } \\
\text { evaluation }\end{array}$ & $\begin{array}{l}\text { Primary } \\
\text { stakeholders } \\
\text { targetted with } \\
\text { sponsorship }\end{array}$ & $\begin{array}{l}\text { Overall fit sought at } \\
\text { what main level? }\end{array}$ & Approval & $\begin{array}{l}\text { Post- } \\
\text { decision }\end{array}$ \\
\hline $\mathbf{A}$ & Both * & Moderate & CSM & $\begin{array}{l}\text { Concern for quality and } \\
\text { professionalism of arts } \\
\text { organisation. }\end{array}$ & $\begin{array}{l}\text { Government and } \\
\text { industry key } \\
\text { decision makers }\end{array}$ & $\begin{array}{l}\text { Corporate Strategy Fit } \\
\text { with key decision- } \\
\text { makers in geographic } \\
\text { location }\end{array}$ & $\begin{array}{l}\text { Internal } \\
\text { recommendation } \\
\text { goes to CCE. }\end{array}$ & $\begin{array}{l}\text { CSM } \\
\text { manages } \\
\text { with ACE. }\end{array}$ \\
\hline B* & Both & High & $\mathrm{CCE}$ & $\begin{array}{l}\text { Renewal, CCE does main } \\
\text { negotiation to ensure } \\
\text { "value-for-money". }\end{array}$ & $\begin{array}{l}\text { Government and } \\
\text { industry key } \\
\text { decision makers. }\end{array}$ & $\begin{array}{l}\text { Corporate Strategy Fit } \\
\text { with key decision- } \\
\text { makers in geographic } \\
\text { location. }\end{array}$ & $\begin{array}{l}\text { CCE makes } \\
\text { internal } \\
\text { decision, put } \\
\text { forward to } \\
\text { board. }\end{array}$ & $\begin{array}{l}\text { CSM further } \\
\text { negotiates. }\end{array}$ \\
\hline$C^{*}$ & Both & High & CSM & $\begin{array}{l}\text { Process of establishing fit } \\
\text { and benefits for company. }\end{array}$ & $\begin{array}{l}\text { Government and } \\
\text { industry key } \\
\text { decision makers }\end{array}$ & $\begin{array}{l}\text { Corporate Strategy Fit } \\
\text { with key decision- } \\
\text { makers in geographic } \\
\text { location }\end{array}$ & $\begin{array}{l}\text { CCE/CSM } \\
\text { together make } \\
\text { internal } \\
\text { decision, put } \\
\text { forward to } \\
\text { board. }\end{array}$ & $\begin{array}{l}\text { CSM } \\
\text { manages } \\
\text { relationship. }\end{array}$ \\
\hline $\mathbf{D}^{\circ}$ & $\begin{array}{l}\text { more } \\
\text { commercial }\end{array}$ & High & CSM & $\begin{array}{l}\text { CSM drives internal } \\
\text { "pitch" to Brand Manager, } \\
\text { evaluates fit with brand } \\
\text { and market. }\end{array}$ & $\begin{array}{l}\text { Specific consumer } \\
\text { market }\end{array}$ & $\begin{array}{l}\text { Consumer Market } \\
\text { Oriented / Fit with Brand } \\
\text { Objectives }\end{array}$ & $\begin{array}{l}\text { Gentleman's } \\
\text { agreement put } \\
\text { higher. }\end{array}$ & $\begin{array}{l}\text { CSM \& } \\
\text { Brand } \\
\text { Manager } \\
\text { manage. }\end{array}$ \\
\hline $\mathbf{E}^{\circ}$ & $\begin{array}{l}\text { more } \\
\text { commercial }\end{array}$ & High & CSM & $\begin{array}{l}\text { CSM drives internal } \\
\text { "pitch" to Brand Manager, } \\
\text { evaluates fit with brand } \\
\text { and market. CCE } \\
\text { challenges. }\end{array}$ & $\begin{array}{l}\text { Specific consumer } \\
\text { market }\end{array}$ & $\begin{array}{l}\text { Consumer Market } \\
\text { Oriented / Fit with Brand } \\
\text { Objectives }\end{array}$ & $\begin{array}{l}\text { CSM / Brand } \\
\text { Manager put } \\
\text { forward to } \\
\text { higher levels } \\
\text { and CCE. }\end{array}$ & $\begin{array}{l}\text { CSM \& } \\
\text { Brand } \\
\text { Manager } \\
\text { manage. }\end{array}$ \\
\hline $\mathbf{F}$ & Both & High & CCE & $\begin{array}{l}\text { Evaluation appears to be } \\
\text { based on intuition and } \\
\text { knowledge of CCE. }\end{array}$ & $\begin{array}{l}\text { Government and } \\
\text { industry key } \\
\text { decision makers }\end{array}$ & $\begin{array}{l}\text { Corporate Strategy Fit } \\
\text { with key decision- } \\
\text { makers in geographic } \\
\text { location }\end{array}$ & $\begin{array}{l}\text { CCE makes } \\
\text { decision. Board } \\
\text { approves? }\end{array}$ & $\begin{array}{l}\text { CSM/CMM } \\
\text { negotiate } \\
\text { benefit and } \\
\text { manage. }\end{array}$ \\
\hline
\end{tabular}

* ${ }^{\circ}$ Note Cases B \& C share the same company; cases D and E share the same company. 


\begin{tabular}{|c|c|c|c|c|c|c|c|c|}
\hline Case & Orientation & $\begin{array}{l}\text { Existance of } \\
\text { formal } \\
\text { policy } * *\end{array}$ & Advocate & $\begin{array}{l}\text { Characteristics of } \\
\text { evaluation }\end{array}$ & $\begin{array}{l}\text { Primary } \\
\text { stakeholders } \\
\text { targetted with } \\
\text { sponsorship }\end{array}$ & $\begin{array}{l}\text { Overall fit sought at } \\
\text { what main level? }\end{array}$ & Approval & $\begin{array}{l}\text { Post- } \\
\text { decision }\end{array}$ \\
\hline $\mathbf{G}$ & $\begin{array}{l}\text { more } \\
\text { Philanthropic }\end{array}$ & Low & $\mathrm{CCE}$ & $\begin{array}{l}\text { Evaluation based on } \\
\text { intuition and knowledge } \\
\text { of CCE. }\end{array}$ & $\begin{array}{l}\text { Specific consumer } \\
\text { market }\end{array}$ & $\begin{array}{l}\text { Consumer Market } \\
\text { Oriented / Fit with Brand } \\
\text { Objectives }\end{array}$ & $\begin{array}{l}\text { CCE makes } \\
\text { decision in } \\
\text { conjuction with } \\
\text { other owners. }\end{array}$ & $\begin{array}{l}\mathrm{CCE} \\
\text { negotiates } \\
\text { benefit and } \\
\text { manages } \\
\text { relationship. }\end{array}$ \\
\hline $\mathbf{H}$ & $\begin{array}{l}\text { more } \\
\text { Philanthropic }\end{array}$ & Moderate & $\mathrm{CCE}$ & $\begin{array}{l}\text { Evaluation made on } \\
\text { knowledge and intuition. }\end{array}$ & $\begin{array}{l}\text { Specific consumer } \\
\text { market }\end{array}$ & $\begin{array}{l}\text { Both levels: Corporate } \\
\text { Strategy Fit and } \\
\text { Consumer Market } \\
\text { Oriented / Fit with Brand } \\
\text { Objectives }\end{array}$ & $\begin{array}{l}\mathrm{CCE} / \mathrm{COO} \text { make } \\
\text { decision. }\end{array}$ & $\begin{array}{l}\text { Marketing } \\
\text { negotiate } \\
\text { benefits and } \\
\text { manage. }\end{array}$ \\
\hline $\mathbf{J}$ & $\begin{array}{l}\text { more } \\
\text { Philanthropic }\end{array}$ & Low & Owner & $\begin{array}{l}\text { Evaluation made on } \\
\text { knowledge and intuition. }\end{array}$ & General community & $\begin{array}{l}\text { Corporate Strategy Fit } \\
\text { with key decision- } \\
\text { makers in geographic } \\
\text { location }\end{array}$ & $\begin{array}{l}\text { Quick } \\
\text { agreement made } \\
\text { between owners } \\
\text { and CCE. }\end{array}$ & $\begin{array}{l}\text { Marketing } \\
\text { negotiate } \\
\text { benefits and } \\
\text { manage. }\end{array}$ \\
\hline $\mathbf{K}$ & $\begin{array}{l}\text { more } \\
\text { commercial }\end{array}$ & High/Mod & CMM & $\begin{array}{l}\text { Evaluation based on facts } \\
\text { and return, along with } \\
\text { CMM's knowledge. }\end{array}$ & $\begin{array}{l}\text { Specific consumer } \\
\text { market }\end{array}$ & $\begin{array}{l}\text { Consumer Market } \\
\text { Oriented / Fit with Brand } \\
\text { Objectives }\end{array}$ & $\begin{array}{l}\text { Approval } \\
\text { achieved at } \\
\text { higher level } \\
\text { following } \\
\text { inernal } \\
\text { proposal/negotia } \\
\text { tions. }\end{array}$ & $\begin{array}{l}\text { CMM } \\
\text { manages } \\
\text { relationship. }\end{array}$ \\
\hline $\begin{array}{l}* \text { Both } \\
* * \text { Exis }\end{array}$ & $\begin{array}{l}\text { No obvious ten } \\
\text { nce of formal }\end{array}$ & $\begin{array}{l}\text { Low } \\
\text { Modey: } \\
\text { High }\end{array}$ & $\begin{array}{l}\text { orientation } \\
\text { ittle eviden } \\
\text { ate: Some fo }\end{array}$ & $\begin{array}{l}\text { ver the other. } \\
\text { mal policies at a broad leve } \\
\text { mal policy, but rules }\end{array}$ & thumb apply & & & \\
\hline
\end{tabular}


on the personal experience and intuition of the advocate. High-level executives featured as the advocates in these decisions, and this was their assigned role. In addition, the post-decision phase for these companies was different than others in that it included the bulk of the negotiation of benefits. Although these decisions could be characterised as more philanthropically oriented, the expectation of some commercial benefit was still there. Based on the above, further propositions may be made concerning decisions in more philanthropic-oriented companies:

\section{Proposition 5 (b-d)}

Philanthropic-oriented companies are likely to

(b) have fewer formal policies associated with arts sponsorship decisions.

(c) make arts sponsorship decisions relying heavily on the intuition of the advocate.

(d) negotiate the benefits of arts sponsorships following the decision.

At the other extreme, the more commercially-oriented companies tended to have high levels of formal policy, had the CSM/CMM as the Advocate, and this was their assigned role. The CSM/CMM drove the decision process with a significant internal sales effort directed to higher levels in the company. This internal process emphasised the fit with the company's needs and ultimate benefit to the company. However, even though these companies were characterised as being more commercially oriented in their decisions, they maintained that they held a role in contributing to society. This then leads to propositions concerning more commercially-oriented companies:

\section{Proposition $6(\boldsymbol{a}-\boldsymbol{c})$}

Commercially-oriented companies are likely to

(a) have more formal policies associated with arts sponsorship decisions.

(b) make arts sponsorship decisions with emphasis on the commercial justification, including the formally evaluated fit and benefits to the company.

(c) negotiate benefits associated with an arts sponsorship during the evaluation phase of the decision process.

The above highlights the two extreme categories, and naturally there is a middle group, categorised mainly on the basis that the cases did not fit into either extreme. The respondents expressed the need to achieve both goals, policy tended towards moderate or high, the advocate was at times the CCE and other times the CSM, and the negotiation of benefits sometimes occurred following the decision. This middle group then, while not sharing consistent characteristics with either extreme noted above, does support the 
overall view that investments are viewed with both commercial and philanthropic goals in mind.

\subsection{Fit: Sponsorship Needs to Work}

$$
\begin{array}{r}
\text { "If you've got a sow's ear, it's not going to work" } \\
-\quad \text { Arts Board Member }
\end{array}
$$

Companies make arts sponsorship decisions while holding the sponsorship as a type of product in which they are investing and which is expected to work -- i.e. deliver benefits promised. This theme of sponsorship as an investment is partly evident due to the application of OBB theory. Previous literature has taken the view of sponsorship more as a tool in marketing, and it is evident that an OBB perspective yields insight. The view through this lens revealed sponsorship as a particular purchase situation, in which benefits were sought but not necessarily identified at the outset, and as a situation holding some risk which would need to be alleviated.

Within this purchase situation, a strong theme was that a fit between the company and the arts initiative was essential. The fit could take on different guises, depending on company needs, but it often came down to assurance of success. The fit was also something which was essential to communicate early on in the process, determining whether the process would continue, and often who was included in the DMU.

A summary of the results regarding fit is provided in Table 7.3. The table first provides a description of the situation or need which each company faced, and which was eventually matched to the sponsorship. Related to the situation was the stakeholder group(s) which they sought to influence, and a way of making use of the sponsorship (use-pattern). Also noted is how the opportunity was initially recognised, whether additional research was undertaken, and a comment on the apparent concern for quality within each decision. The evidence in this table, combined with the following discussion highlights four subthemes of fit, which will be explored:

1) fit is considered alongside use-pattern

2) a "good fit" is ok, but will it work?

3) someone needs to "get it" and

4) the advocate is crucial to the evaluation of fit. 
Firstly, as noted previously, fit had to be seen within a context of how the fit would be communicated or used, and two "use-patterns" were identified: hosting and brand-imagetransfer.

Hosting involved the company using the sponsorship as an opportunity to directly connect with stakeholders, so the arts initiative had to be seen as something which would appeal to these stakeholders, and which would present the desired image. In brandimage-transfer the company was interested in consumers transferring associations with the arts event to the company and its brand. For this, the initiative needed to match the profile of the targeted consumers, and deliver a desired image. As evident in Table 7.3, the possibility of engaging in a sponsorship for both purposes was evident. This leads to the following proposition:

\section{Proposition 7}

A sponsorship needs to provide benefits to the company which are likely to be realised through hosting and/or brand-image-transfer.

As well as the importance of the alignment and use-pattern, it was evident that the arts initiative had to prove it would succeed. Part of this process was that the initiative be seen to be high quality, and would deliver benefits promised. Beyond the establishment of a fit was a need for the company to feel that the sponsorship would be successful. In other words, would it work? would it deliver to the objectives of the company? The benefits which are ultimately derived from these partnerships may be planned but cannot always be guaranteed and sometimes the benefit of "reflected glory" for example is difficult to measure. The relevant question here is how do decision-makers determine that the investment will deliver the benefits? 
Table 7.3 Examining Fit

\begin{tabular}{|c|c|c|c|c|c|c|}
\hline case & related company situation & stakeholder groups & use-pattern & $\begin{array}{l}\text { who saw } \\
\text { opportunity }\end{array}$ & $\begin{array}{l}\text { research } \\
\text { effort } \\
\text { required }\end{array}$ & concern for quality \\
\hline $\mathbf{A}$ & $\begin{array}{l}\text { looking for continued presence } \\
\text { with government and key } \\
\text { decision-makers }\end{array}$ & $\begin{array}{l}\text { government, employees, } \\
\text { potential employees, } \\
\text { community }\end{array}$ & hosting & $\begin{array}{l}\text { inherited } \\
\text { relationship }\end{array}$ & Yes & $\begin{array}{l}\text { would they deliver? Would it } \\
\text { appeal? }\end{array}$ \\
\hline B* & $\begin{array}{l}\text { looking for continued presence } \\
\text { with government and key } \\
\text { decision-makers }\end{array}$ & $\begin{array}{l}\text { business leaders, } \\
\text { government }\end{array}$ & hosting & renewal situation & $\begin{array}{l}\text { no - } \\
\text { knowledge }\end{array}$ & $\begin{array}{l}\text { not evident: arts organisation } \\
\text { well known to company }\end{array}$ \\
\hline $\mathbf{C}^{*}$ & $\begin{array}{l}\text { looking to expand presence in } \\
\text { local region }\end{array}$ & $\begin{array}{l}\text { business leaders, } \\
\text { government }\end{array}$ & hosting & $\begin{array}{l}\text { ABM made } \\
\text { connection }\end{array}$ & $\begin{array}{l}\text { no - } \\
\text { knowledge }\end{array}$ & $\begin{array}{l}\text { would it attract the right } \\
\text { people? }\end{array}$ \\
\hline $\mathbf{D}^{\circ}$ & $\begin{array}{l}\text { looking for way to connect with } \\
\text { specific consumer market }\end{array}$ & consumer group & brand image & $\begin{array}{l}\text { Approach by ACE; } \\
\text { CSM made } \\
\text { connection }\end{array}$ & Yes & $\begin{array}{l}\text { would it deliver brand } \\
\text { message correctly? }\end{array}$ \\
\hline $\mathbf{E}^{\circ}$ & $\begin{array}{l}\text { looking for way to connect with } \\
\text { specific consumer market }\end{array}$ & consumer group & brand image & $\begin{array}{l}\text { Approach by ACE; } \\
\text { CSM made } \\
\text { connection }\end{array}$ & Yes & $\begin{array}{l}\text { would it deliver brand } \\
\text { message correctly? }\end{array}$ \\
\hline $\mathbf{F}$ & relocating to local region & $\begin{array}{l}\text { business leaders, } \\
\text { government }\end{array}$ & $\begin{array}{l}\text { hosting \& } \\
\text { brand image }\end{array}$ & $\begin{array}{l}\text { ABM made } \\
\text { connection }\end{array}$ & $\begin{array}{l}\text { no - } \\
\text { knowledge }\end{array}$ & not evident \\
\hline $\mathbf{G}$ & $\begin{array}{l}\text { looking for way to connect with } \\
\text { specific consumer market }\end{array}$ & consumer group & $\begin{array}{l}\text { hosting \& } \\
\text { brand image }\end{array}$ & $\begin{array}{l}\text { CMM saw } \\
\text { opportunity }\end{array}$ & $\begin{array}{l}\text { no - } \\
\text { knowledge }\end{array}$ & $\begin{array}{l}\text { not evident: arts organisation } \\
\text { well known to company }\end{array}$ \\
\hline $\mathbf{H}$ & $\begin{array}{l}\text { looking for way to connect with } \\
\text { specific consumer market }\end{array}$ & consumer group & $\begin{array}{l}\text { hosting \& } \\
\text { brand image }\end{array}$ & $\begin{array}{l}\text { ABM saw } \\
\text { opportunity }\end{array}$ & $\begin{array}{l}\text { no - } \\
\text { intuitively ok }\end{array}$ & could the staff deliver? \\
\hline $\mathbf{J}$ & $\begin{array}{l}\text { strong social orientation; looking } \\
\text { to connect with community }\end{array}$ & $\begin{array}{l}\text { community, business } \\
\text { leaders }\end{array}$ & hosting & $\begin{array}{l}\text { Approach by ACE; } \\
\text { Owner made } \\
\text { connection }\end{array}$ & $\begin{array}{l}\text { no - } \\
\text { knowledge }\end{array}$ & $\begin{array}{l}\text { not evident: arts organisation } \\
\text { well known to company }\end{array}$ \\
\hline $\mathbf{K}$ & $\begin{array}{l}\text { looking to expand presence in } \\
\text { local region }\end{array}$ & consumer group & brand-image & $\begin{array}{l}\text { ABM made } \\
\text { connection; CMM } \\
\text { agreed }\end{array}$ & $\begin{array}{l}\text { no - } \\
\text { knowledge }\end{array}$ & $\begin{array}{l}\text { not evident: known event to } \\
\text { CMM. }\end{array}$ \\
\hline
\end{tabular}


A first finding for this question was related to experience. As managers had more positive experiences with sponsorship they were more likely to be able to see that benefits would be delivered, and they perceived less uncertainty and risk in the partnership. This relates to the views of individual managers. A second finding was that the reputation of the arts organisation was crucial in this judgement. A positive reputation of the arts managers, event and/or arts organisation assured decision-makers that the partnership would work. This also relates back to the previous idea of experience; for many managers, the trust and establishment of an arts manager's reputation was often gained through their own experience with the manager/organisation. This suggests the following proposition:

\section{Proposition 8}

The more positive experience managers have had with sponsorship, the arts organisation and/or related arts managers, the more likely they are to perceive that the sponsorship will deliver benefits to the company.

Certainly, individual experiences paved the way for a perception of success, and in some cases this was enough to forge an initial agreement. However this question, "will it work?" was also related to the perception that specific benefits would be realised.

The specific benefits of course relate to the initiative itself, and the use-pattern(s) which the organisation elected. Therefore, the question "will it work?" was typically answered for hosting based on whether managers felt their key stakeholders would attend the hosted event. This related to the managers' perceptions of whether the event would appeal to the stakeholder group. For example, one respondent stated, "if ... you think [key stakeholders] are not going to come to that because it's just not going to be seen as a high enough quality event, then that's not going to work for us." Thus, the question "will it work?" is subject to the stakeholder groups being identified, as per the company objectives. Secondly, the question is answered by considering the perceptions and expectations of the noted stakeholder group(s), with respect to the sponsorship. The following is therefore proposed: 


\section{Proposition 9 (a)}

If a company is seeking hosting opportunities, a successful outcome for the company is likely to be perceived when the event is judged to appeal to the company's identified stakeholder group $(s)$.

The other use-pattern was brand-image transfer, where managers assessed a sponsorship as more likely to be successful when the consumer markets matched, and if the qualities inherent in the arts event were qualities desired for their brand. Again, this goes back to the objectives the company is seeking to fulfil, their identification of the consumer market and identification of the message they wish to convey. This also relates to the company's judgement of how that market will perceive the partnership, and their assessment that the sponsorship will help to reach and appeal to these consumer markets in the way intended. Therefore the following proposition is suggested:

\section{Proposition 9 (b)}

If a company is seeking brand-image-transfer, a successful outcome for the company is likely to be perceived when the arts event's audience and brand image is consistent with the company's target market and desired brand image.

These propositions bring together the importance and means of establishing a fit between company objectives and the initiative, and highlight that fit is evaluated based on the expectation of benefit to the company. As benefit is anticipated, success is perceived, and the sponsorship is seen as something which "will work."

Also apparent is that individual experiences influence these decisions. It was noted that someone within the company needed to see that the sponsorship would deliver benefits to the company. This ability to see that it would work is here referred to as "getting it." It could be a hunch, it could be a shared passion, but ultimately it was about seeing that the sponsorship would be successful for the company.

As noted, within the sponsorship purchase situation, specifications are not initially laid out such that companies present a request for proposals. Rather, proposals are presented and the company sifts through them, looking to eliminate those which simply do not fit, 
and to consider in more depth those which may have benefit. This puts the responsibility on the arts organisation to demonstrate the fit and benefits to the company. In all cases studied someone connected with the arts organisation first needed to see the opportunity (in the pre-approach phase). However, in presenting the opportunity to the company, there also needed to be someone within the sponsoring company, who could clearly see the fit and potential benefits. Importantly, this fit/benefit needed to be evident at the approach phase in order for the process to continue. One expert noted the challenge of finding someone internally and having them "get it":

I needed capital and the only way to do it was largely to try and engage with people and try and have them share your passion for what you're doing. And to see the wisdom of getting into it.

As is evident in Table 7.3 opportunities were often initially seen by a member of the Arts Board or the Arts Chief Executive. This was then communicated to someone within the corporation, usually the CCE or CMM/CSM. It was at this stage of communication that the ability for a company manager to "get it" - to see how it would work - was essential. It was crucial that how the sponsorship would deliver on the company's goals was instilled in this individual's mind. Whether it was a connection with business leaders or with consumer groups, an individual in the DMU had to be able to see how it would work for the company. As well as the fit and potential benefits needing to be evident and adopted by this individual, they needed to be evident at the approach phase, so that the process would move forward. This leads to the following proposition:

\section{Proposition 10}

The decision-making process is more likely to move forward when an arts representative is able to communicate and instil a strong sense of the benefits to the company within a key individual within the DMU.

As well as recognising the importance of communicating the fit and benefits at the approach phase, the above discussion highlights the importance of a single individual in this phase. This single individual was referred to in chapter 6 as the advocate. The influence of the advocate was a strong theme in this study, and will now be explored. 


\subsection{Within the DMU the Advocate Holds the Most Influence}

This study clearly found that arts sponsorship decisions are influenced by an informed and influential advocate. Each decision hinged on a single individual's contribution to the process. In each of these decisions a single person - the advocate - believed that the sponsorship would work (saw the fit/benefits), and moved it forward within the company. Without this advocate the decision would not have happened. These individuals appeared to buy in to the proposal, felt it would be positive for the company, and saw how it would work. Furthermore, they then proceeded to take on the role of convincing others within the company of the benefits. In some cases they developed their own pitch for an internal sales process, which was at times a rigorous process. The presence of an advocate was a consistent finding in this study, leading to the following:

\section{Proposition 11}

In successful arts sponsorship decisions there is likely to be an advocate within the sponsoring company who supports the sponsorship internally.

Further analysis and evidence related to the advocate role is presented in Table 7.4. As may be seen, at times the advocate was the individual who was assigned the task of reviewing sponsorship proposals. This suggests that they were doing their jobs, acquiring knowledge and developing support for the investment (cases A,C,D,E,G, K). However, these individuals did not advocate for all sponsorships put forward, and in other cases the advocate emerged from a higher level even though others had been formally assigned this responsibility $(\mathrm{B}, \mathrm{F}, \mathrm{H}, \mathrm{J})$. This suggests that the advocate role is better defined by the expert power these individuals held, their subsequent actions to support the sponsorship and their formal role, as opposed to a definition entirely related to the formal role.

The concept of expert power proposed that advocates gain expert power through knowledge as well as the belief by others that they are knowledgeable. It is evident, and depicted in Table 7.4, that advocates may derive their power through knowledge they have gained previous to the sponosrship being proposed $(\mathrm{B}, \mathrm{C}, \mathrm{G}, \mathrm{H}, \mathrm{J}, \mathrm{K})$. At other times, the advocate derives their knowledge and subsequent expert power through the research conducted post-approach $(\mathrm{A}, \mathrm{D}, \mathrm{E})$. 
Thinking back to the importance of an individual who "gets it," it was noted that these individuals often understood the opportunity due to their previous knowledge and experience. This is not an unusual finding, given the discussion concerning the importance of a personal frame of reference, and experience playing a role in decisions, especially those of the upper echelons. However, it is a finding which is in contrast to discussions of justifying sponsorship more on the basis of hard facts and measureable outcomes. This then suggests further propositions concerning the advocate:

\section{Proposition 12 (a)}

Individuals are likely to become advocates for a sponsorship through the expert power they hold.

\section{Proposition 12 (b)}

The expert power of an advocate is likely to be derived from that individual's personal views and past experiences with the arts and the specific arts initiative, as well as their more formal role to acquire knowledge pertinent to the investment.

A further related pattern was that as advocates held greater amounts of knowledge on the arts initiative and sponsorship more generally, the level of intuition and subjective judgement which entered into the decisions appeared to increase. In other words, these individuals in possession of knowledge, were at liberty to apply it. This leads to the next proposition:

\section{Proposition 13}

The more expert power the advocate holds the more likely intuition is to play a strong role in the decision. 
Table 7.4 The Advocate, Expert Power and Intuition

\begin{tabular}{|c|c|c|c|c|c|c|c|c|c|}
\hline case & Advocate & $\begin{array}{l}\text { Formal } \\
\text { advocate } \\
\text { role }\end{array}$ & $\begin{array}{l}\text { Advocate's } \\
\text { source of } \\
\text { sponsorship } \\
\text { knowledge }\end{array}$ & $\begin{array}{l}\text { Advocate's } \\
\text { pre-approach } \\
\text { knowledge of } \\
\text { arts initiative }\end{array}$ & $\begin{array}{l}\text { Advocate's } \\
\text { post- } \\
\text { approach } \\
\text { knowledge }\end{array}$ & evidence & category & $\begin{array}{l}\text { level of } \\
\text { knowledge } \\
\text { held by } \\
\text { Advocate }\end{array}$ & $\begin{array}{l}\text { level of } \\
\text { intuition } \\
\text { involved in } \\
\text { decision }\end{array}$ \\
\hline $\mathbf{A}$ & CSM & $\mathrm{CSM}$ & role & little & $\begin{array}{l}\text { research, } \\
\text { discussions } \\
\text { with company } \\
\text { staff, and } \\
\text { impressions } \\
\text { on meeting } \\
\text { with ACE. }\end{array}$ & $\begin{array}{l}(\mathbf{C S M}): \text { "[we got] some feedback from the } \\
\text { organisation, and also did a bit of research } \\
\text { externally." }\end{array}$ & $\begin{array}{l}\text { post- } \\
\text { approach } \\
\text { research and } \\
\text { experience } \\
\end{array}$ & low & low \\
\hline B* & CCE & CSM & $\begin{array}{l}\text { past } \\
\text { experience }\end{array}$ & $\begin{array}{l}\text { considerable - } \\
\text { thought to } \\
\text { "own" } \\
\text { relationship in } \\
\text { the past. }\end{array}$ & $\begin{array}{l}\text { past } \\
\text { sponsorship } \\
\text { relationship } \\
\text { with company } \\
\text { and personal } \\
\text { interest. }\end{array}$ & $\begin{array}{l}\text { (ACE): "[this] sponsorship relies heavily on } \\
\text { the fact that [X is] the CEO ... he has such a } \\
\text { passionate interest in it." (CCE): } \\
\text { "[the previous CCE] is a well established } \\
\text { enthusiast for the arts and has a personal } \\
\text { passion for it. I share that view." (CSM): } \\
\text { "In this particular instance the key } \\
\text { relationship that's held is actually with our } \\
\text { CEO." }\end{array}$ & $\begin{array}{l}\text { personal } \\
\text { views and } \\
\text { past } \\
\text { experience }\end{array}$ & high & high \\
\hline$C^{*}$ & CSM & CSM & role & $\begin{array}{l}\text { considerable - } \\
\text { through } \\
\text { personal } \\
\text { experience of } \\
\text { arts initiative } \\
\text { and other } \\
\text { sponsorships. }\end{array}$ & $\begin{array}{l}\text { Personal } \\
\text { relationship } \\
\text { with ACE, } \\
\text { and role- } \\
\text { related } \\
\text { knowledge }\end{array}$ & $\begin{array}{l}\text { (ABM): "the very close friend of [ACE, was } \\
\text { CSM ... they] were able to talk very frankly } \\
\text { to each other about the operational } \\
\text { difficulties, about framing the sponsorship." } \\
\text { (CSM): "because I get so much information } \\
\text { about who wants what, what's happening in } \\
\text { the market, what other sponsors are doing, } \\
\text { what businesses are doing, what our business } \\
\text { wants to do ... I can actually get a good sense } \\
\text { of what a proposal is kind of worth in terms } \\
\text { of what they're offering or what they're } \\
\text { reaching." }\end{array}$ & $\begin{array}{l}\text { personal } \\
\text { views and } \\
\text { past } \\
\text { experience }\end{array}$ & high & high \\
\hline
\end{tabular}




\begin{tabular}{|c|c|c|c|c|c|c|c|c|c|}
\hline case & Advocate & $\begin{array}{l}\text { Formal } \\
\text { advocate } \\
\text { role }\end{array}$ & $\begin{array}{l}\text { Advocate's } \\
\text { source of } \\
\text { sponsorship } \\
\text { knowledge }\end{array}$ & $\begin{array}{l}\text { Advocate's } \\
\text { pre-approach } \\
\text { knowledge of } \\
\text { initiative }\end{array}$ & $\begin{array}{l}\text { Advocate's } \\
\text { post- } \\
\text { approach } \\
\text { knowledge }\end{array}$ & evidence & category & $\begin{array}{l}\text { level of } \\
\text { knowledge } \\
\text { held by } \\
\text { Advocate }\end{array}$ & $\begin{array}{l}\text { level of } \\
\text { intuition } \\
\text { involved in } \\
\text { decision }\end{array}$ \\
\hline $\mathbf{D}^{\circ}$ & CSM & $\mathrm{CSM}$ & role & $\begin{array}{l}\text { little - only via } \\
\text { reputation of } \\
\text { ACE. }\end{array}$ & $\begin{array}{l}\text { from ACE via } \\
\text { proposal and } \\
\text { discussions. }\end{array}$ & $\begin{array}{l}\text { (CSM): [The ACE] and his people wrote a } \\
\text { proposal and sent it to us ... we had meetings } \\
\text { to talk about that, about the potential and the } \\
\text { ideas that we had and the ideas that they had } \\
\text { and I think it was probably a little bit like } \\
\text { falling in love. It builds over time, it's not } \\
\text { love at first sight, but you work at it and } \\
\text { something grows. }\end{array}$ & $\begin{array}{l}\text { post- } \\
\text { approach } \\
\text { research and } \\
\text { experience }\end{array}$ & med & low \\
\hline $\mathbf{E}^{\circ}$ & CSM & CSM & role & $\begin{array}{l}\text { little - only via } \\
\text { reputation of } \\
\text { event. }\end{array}$ & $\begin{array}{l}\text { from ACE via } \\
\text { proposal and } \\
\text { discussions, } \\
\text { plus past } \\
\text { experience. }\end{array}$ & $\begin{array}{l}\text { (CSM): "We had some communications, and } \\
\text { then [ACE] ended up hosting [me and the } \\
\text { brand manager] at the [arts event] ... Then ... } \\
\text { there was a meeting ... Both myself and [the } \\
\text { brand manager] had perceptions of the event." }\end{array}$ & $\begin{array}{l}\text { post- } \\
\text { approach } \\
\text { research and } \\
\text { experience }\end{array}$ & med & low \\
\hline $\mathbf{F}$ & CCE & CSM & unsure & $\begin{array}{l}\text { some - via past } \\
\text { dealings with } \\
\text { event and } \\
\text { reputation } \\
\text { (event well- } \\
\text { known) }\end{array}$ & role-related & $\begin{array}{l}\text { (CMM): In that particular case it was [the } \\
\text { ABM's] direct approach to [the CCE] that } \\
\text { brought it through. (CSM): "[The CCE } \\
\text { has] the ultimate say at the end of the day and } \\
\text { he will go 'yes, we're going to do this } \\
\text { because it's going to keep certain people } \\
\text { happy." }\end{array}$ & $\begin{array}{l}\text { personal } \\
\text { views and } \\
\text { past } \\
\text { knowledge } \\
\text { assumed } \\
\end{array}$ & & \\
\hline G* & CMM & CMM & role & $\begin{array}{l}\text { considerable - } \\
\text { through past } \\
\text { busines dealings } \\
\text { with arts } \\
\text { organisation and } \\
\text { own personal } \\
\text { interest. }\end{array}$ & $\begin{array}{l}\text { business } \\
\text { dealings and } \\
\text { personal } \\
\text { interest/knowl } \\
\text { edge. }\end{array}$ & $\begin{array}{l}\text { (CMM): Statement noted that the company } \\
\text { knew the arts organisation well through past } \\
\text { business dealings. (ABM): [the company is] } \\
\text { fantastic and that depends upon there being } \\
\text { inside [the company] a few people who really } \\
\text { think it matters and one of them is [the } \\
\text { CMM]. }\end{array}$ & $\begin{array}{l}\text { personal } \\
\text { views and } \\
\text { past } \\
\text { experience }\end{array}$ & high & high \\
\hline
\end{tabular}

${ }^{\circ}$ Case B and C share the same company.

* For case G direct quotes were not authorised. 


\begin{tabular}{|c|c|c|c|c|c|c|c|c|c|}
\hline case & Advocate & $\begin{array}{l}\text { Formal } \\
\text { advocate } \\
\text { role }\end{array}$ & $\begin{array}{l}\text { Advocate's } \\
\text { source of } \\
\text { sponsorship } \\
\text { knowledge }\end{array}$ & $\begin{array}{l}\text { Advocate's } \\
\text { pre-approach } \\
\text { knowledge of } \\
\text { initiative }\end{array}$ & $\begin{array}{l}\text { Advocate's } \\
\text { post- } \\
\text { approach } \\
\text { knowledge }\end{array}$ & evidence & category & $\begin{array}{l}\text { level of } \\
\text { knowledge } \\
\text { held by } \\
\text { Advocate }\end{array}$ & $\begin{array}{l}\text { level of } \\
\text { intuition } \\
\text { involved in } \\
\text { decision }\end{array}$ \\
\hline H & $\begin{array}{l}\mathrm{ABM} / \mathrm{CC} \\
\mathrm{E}\end{array}$ & $\mathrm{CCE}$ & role & $\begin{array}{l}\text { little - some } \\
\text { knowledge via } \\
\text { event's } \\
\text { reputation }\end{array}$ & $\begin{array}{l}\text { via } \mathrm{ABM}(3 \mathrm{rd} \\
\text { party), past } \\
\text { experience in } \\
\text { arts generally }\end{array}$ & $\begin{array}{l}\text { (CCE): "[the ABM] said you guys should } \\
\text { consider this." } \\
\text { "So we, we looked at it and looked at their } \\
\text { proposal and basically my memory of it was } \\
\text { that it was a crap proposal. ... so that's when } \\
\text { we came back to our ... questions." "we were } \\
\text { sort of blundering around trying to have } \\
\text { something that we liked in the arts." }\end{array}$ & $\begin{array}{l}\text { personal } \\
\text { views and } \\
\text { past } \\
\text { experience }\end{array}$ & low & high \\
\hline $\mathbf{J}$ & OWNER & $\begin{array}{l}\text { OWNER } \\
\text { /CCE }\end{array}$ & $\begin{array}{l}\text { past } \\
\text { experience }\end{array}$ & $\begin{array}{l}\text { considerable - } \\
\text { through } \\
\text { personal } \\
\text { experience of } \\
\text { arts initiative } \\
\text { and other } \\
\text { sponsorships. }\end{array}$ & $\begin{array}{l}\text { personal } \\
\text { experience } \\
\text { with arts } \\
\text { organisation } \\
\text { and long-term } \\
\text { knowledge } \\
\text { and rapport } \\
\text { with ACE. } \\
\end{array}$ & $\begin{array}{l}\text { (CMM): "[the owners] have a huge } \\
\text { background with the [arts organisation] ... So } \\
\text { the [owner] is one of the patrons and a big } \\
\text { supporter." }\end{array}$ & $\begin{array}{l}\text { personal } \\
\text { views and } \\
\text { past } \\
\text { experience }\end{array}$ & med & high \\
\hline $\mathbf{K}$ & CMM & CMM & role & $\begin{array}{l}\text { some - own } \\
\text { personal } \\
\text { knowledge and } \\
\text { experience of } \\
\text { event. }\end{array}$ & $\begin{array}{l}\text { personal } \\
\text { knowledge } \\
\text { and } \\
\text { presentation / } \\
\text { facts from arts } \\
\text { organisation }\end{array}$ & $\begin{array}{l}\text { (CMM): "because I knew about it I could go } \\
\text { to the people I had to convince internally and } \\
\text { say look this is a really good proposition for } \\
\text { us. . I mean if I hadn't have lived in [the } \\
\text { city] and I didn't know about it I don't think } \\
\text { it would have gone any further." }\end{array}$ & $\begin{array}{l}\text { personal } \\
\text { views and } \\
\text { past } \\
\text { experience, } \\
\text { AND post- } \\
\text { approach } \\
\text { research }\end{array}$ & med & med \\
\hline
\end{tabular}




\subsection{Intuition Plays a Role}

Previous discussions have noted that someone (the initiator) needs to initially see the sponsorship opportunity in order to put it forward to a company; in addition, within the company someone has to "get it" (the advocate). The idea of intuition and knowledge playing a role in these decisions was also noted. Furthermore, the idea of chance or happenstance playing a part in sponsorship decisions was discussed. However, it was suggested that these decisions did not come about purely due to chance, but more of an informed happenstance. On examination of the patterns, it appears that knowledge and intuition play a significant role in these decisions, in identifying opportunities, and in seeing how the opportunity might fit, or, in providing this "informed happenstance." Evidence in this study suggests that rather than chance and serendipity playing a part, the more important factors are those of knowledge and intuition which allow individuals to take advantage of opportunities, and put the "right" parties together, thus facilitating a positive decision.

Hodgkinson, Sadler-Smith, Claxton and Sparrow (2009) provide a three-part definition of intuition as comprising

- a capacity for attaining direct knowledge or understanding without the apparent intrusion of rational thought or logical inference;

- neither the opposite of rationality, nor a random process of guessing, intuition corresponds to thoughts, conclusions and choices produced largely or in part through non-conscious mental processes;

- affectively charged judgments that arise through rapid, non-conscious and holistic associations. (p.280)

This definition highlights the cognitive knowledge and rational thought as well as the non-conscious processes involved in intuition. These authors use the term "informed intuition" and argue that "informed intuition is as essential to the competence portfolio of hard-pressed decision makers as many of the analytical skills that feature in contemporary business school curricula" (p. 278).

Informed intuition rings true in the study contained here. Although the extent of nonconscious activity was not measured, there were individuals in the decisions who appeared to simply "know" the sponsorship would work for the company - they "got it". 
In many cases this was the $\mathrm{CCE}$ who was approached, and their ability to see the fit enabled the decision to progress swiftly. In other cases this person was a third party or arts board member who could see that the sponsorship would "work." In some cases it was a lower level manager, who knew that the initiative would fit with company objectives. In each case however, it was evident that these individuals were knowledgeable about the company, the initiative and how the partnership would deliver benefit. They had experience which led to knowledge, which in turn took different forms. For some it was knowledge of the business climate - what company was doing what - along with the knowledge of the arts organisation. For others it was the previous, more specific knowledge of the arts initiative. Still others held knowledge on sponsorship as a tool for use. In all cases the knowledge was related to the individual's experiences. The idea of experiences and knowledge being an important part of intuition is noted by Hodgkinson, et. al. (2009):

neither insight nor intuition occur in a cognitive vacuum or in an 'unprepared mind', rather, learning and experience constitute the substances on which such associative processes operate. (p.279)

Similar in some respects is the observation made by Hambrick and Mason (1984) that more complex decisions involve behavioural factors rather than a pure economic justification. Whether or not individuals in the DMU's considered these decisions complex was not always apparent, however the input of behavioural factors and intuition was evident.

Table 7.5 provides detail on the role of knowledge and intuition in the cases studied. In six of the cases intuition played a role in the pre-approach phase, meaning that someone, based on their own knowledge, was able to see that the opportunity would fit. At other times intuition appeared to play a role in the approach, in which an individual who was approached immediately saw that the opportunity would fit. Finally, intuition appeared to play a role in the evaluation, especially in how the sponsorship would fit with the company brand. 
Table 7.5 Intuition and Knowledge in Decision Processes

case individual intuition from ... decision stage within which intuition is evident

A n $\quad$ post-approach research

past experience experience with past relationship - knows arts initiative sees how it will work for the company

business connection/expertise ABM knows company and arts organisation.

$D^{\circ}$ CSM brand knowledge knows brand and what the company is seeking to do.

\begin{tabular}{lll}
$\mathbf{E}^{\circ}$ & $\mathrm{CSM}$ & brand knowledge knows brand and what the company is seeking to do. \\
\hline & business connection/expertise ABM well connected in business community
\end{tabular}

$\begin{array}{lll}\mathbf{E}^{\circ} \quad \mathrm{CSM} & \text { brand knowledge knows brand and what the company is seeking to do. } \\ & \text { business connection/expertise } \mathrm{ABM} \text { well connected in business community }\end{array}$ F $\quad$ ABM $\quad$ - sees opportunity

G CMM past experience CMM knowledgeable on artform and knows it will work.

business connection/expertise $\mathrm{ABM}$ well connected in business community

H ABM $\quad$ - sees opportunity

$\begin{array}{ll}\mathbf{J} \text { Owner } & \text { past experience past experience with art org \& ACE } \\ & \text { business connection/expertise \& past experience ABM well connected in }\end{array}$

$\mathrm{ABM} / \quad$ business community - sees opportunity. CMM past experience with arts

K $\quad$ CMM initiative.

* ${ }^{\circ}$ Cases B \& C share the same company; cases D and E share the same company. evaluation: owner felt it would work

evaluation: learned knowledge of arts organisation helped to shape recommendation.

evaluation: The CCE felt that this sponsorship would work and took negotiations over.

approach: ABM saw opportunity and felt it would work.

evaluation: CSM sees fit based mainly on brand knowledge. evaluation: CSM sees fit based mainly on brand knowledge. approach: ABM saw opportunity and felt it would work. approach: CMM knew of opportunity and felt it would fit. approach: ABM saw opportunity and felt it would work. CCE felt it would work

approach: ABM saw opportunity and felt it would work. evaluation: CMM felt it would work. 
The above leads to the following propositions:

\section{Proposition 14 (a)}

Informed intuition concerning sponsorship of the arts is likely to be fostered via the experiences and knowledge of individuals.

\section{Proposition 14 (b)}

Arts sponsorship decisions are likely to be influenced by the informed intuition of individuals within the DMU.

Based on the above, arts sponsorship decisions are now seen as existing in a broader social context, incorporating elements of commercial and philanthropic goals, requiring a fit with company objectives, and requiring the informed intuition of key individuals. The following section continues to bring the results and discussions of this study together, and brings the themes noted above together, but does so by focusing in on the decision process itself.

\subsection{A Typology of Processes}

This study has considered arts sponsorship decisions, their influences, and also the process itself. In previous discussions, three paths of process were identified. While this was an initial finding, supported by and contributing to the literature, it remained a consistent typology to which to return as the analysis progressed. This section will further examine these decision paths as a typology of processes found for arts sponsorship decisions. The three paths are summarised in Table 7.6, and visually depicted in Figure 7.2.

\section{Path 1: High and Intuitive}

Evident in cases B, F, G and J was a path which could be characterised as "high and intuitive." These decisions tended to occur in companies with more of a philanthropic orientation, however the decisions appeared to follow this path mainly due to existing relationships and knowledge held by the parties concerned, making this the path which most relied on informed intuition. Specifically in the pre-approach context for these 
decisions, the important factor was a relationship enabling extensive knowledge between the parties and especially knowledge and experience of the arts initiative by the advocate. Another aspect of the established relationship was that it was appropriate to initially speak with a high-level manager - a factor which characterised the approach. Also in the approach phase, a fit appears to immediately have been recognised, partly due to the manager's own personal experience of the arts initiative/company. Knowledge and experience also appears to facilitate the perception of success and reduce any concern for risks associated with the relationship. Therefore, in this phase of this path, the application of informed intuition is clearly evident. The evaluation phase in these cases was relatively short. In fact, for three of the cases, the intuition used in the approach essentially meant that the evaluation was "skipped" and a decision was made. Therefore the more detailed negotiation of benefit tended to come post-decision.

\section{Path 2: Lower-level Driven Decisions}

The second grouping was the lower-level driven process. These decisions (cases A, D, $\mathrm{E}, \mathrm{K})$ were categorised here due to their more commercial orientation and formalisation of processes. The processes and commercial approach necessitated that the person contacted initially was the CSM or CMM. In most of these cases it was the ACE who contacted the company, making a request, which was then subject to a rigorous evaluation to determine the extent of fit and potential benefits. Certainly the intuition of the CSM/CMM played a role at times, being knowledge of the company brand or knowledge developed via research. In one case, the CMM's personal experience played a critical role, giving them the expert power to drive the process on. For the cases following this path it was the CSM/CMM who took on the role of the advocate, and it was in these cases where an internal sales process, driven by the CSM/CMM, was most evident. Due to the more formalised processes, theses advocates however were still required to submit their evaluation and recommendation "up" to higher levels for approval. Unlike path 1 , in each of the cases under path 2 , the negotiation of benefits was part of the evaluation phase - preceding the decision. Post-decision activity involved the management of the relationship and benefits, led by the CMM/CSM. 
Table 7.6 Typology of Processes

\begin{tabular}{|c|c|c|c|c|c|c|c|c|c|}
\hline case & $\begin{array}{l}\text { process } \\
\text { group }\end{array}$ & Orientation & new/renew & $\begin{array}{l}\text { opportunity } \\
\text { identified }\end{array}$ & relationship & advocate & evaluation & approval & post-decision \\
\hline $\mathbf{A}$ & $\begin{array}{l}\text { low-level } \\
\text { driven }\end{array}$ & Both & renew & $\mathrm{n} / \mathrm{a}$ & assigned & $\mathrm{CSM}$ & $\begin{array}{l}\text { result of } \\
\text { research } \\
\end{array}$ & $\begin{array}{l}\text { approval at CCE } \\
\text { level }\end{array}$ & $\begin{array}{l}\text { CSM works } \\
\text { wth ACE }\end{array}$ \\
\hline $\mathbf{B}^{*}$ & high & Both & renew & $\mathrm{n} / \mathrm{a}$ & $\begin{array}{l}\text { well established } \\
\text { at multiple levels }\end{array}$ & $\mathrm{CE}$ & $\begin{array}{l}\text { CCE made } \\
\text { judgement } \\
\text { early on }\end{array}$ & sought but felt done & $\begin{array}{l}\text { CSM further } \\
\text { negotiates } \\
\text { leveraging }\end{array}$ \\
\hline $\mathbf{C}^{*}$ & 3rd party & Both & new & $\begin{array}{l}\text { by ABM - connected } \\
\text { in business } \\
\text { community }\end{array}$ & $\begin{array}{l}\mathrm{ABM}-\mathrm{CCE} \text { and } \\
\mathrm{ACE}-\mathrm{CSM}+\end{array}$ & $\mathrm{ABM} / \mathrm{CSM}$ & $\begin{array}{l}\text { CCE made } \\
\text { judgement } \\
\text { early on }\end{array}$ & sought but felt done & $\begin{array}{l}\text { CSM } \\
\text { manages }\end{array}$ \\
\hline $\mathbf{D}^{\circ}$ & $\begin{array}{l}\text { low-level } \\
\text { driven }\end{array}$ & Commercial & new & presented by ACE & brief intro & $\mathrm{CSM}$ & $\begin{array}{l}\text { CSM made } \\
\text { judgement } \\
\text { early on } \\
\end{array}$ & up to CCE - says ok & Mktg / CSM \\
\hline $\mathbf{E}^{\circ}$ & $\begin{array}{l}\text { low-level } \\
\text { driven }\end{array}$ & Commercial & new & presented by ACE & little - some intro & CSM & $\begin{array}{l}\text { result of } \\
\text { research }\end{array}$ & $\begin{array}{l}\text { CCE agrees to } \\
\text { change }\end{array}$ & Mktg / CSM \\
\hline $\mathbf{F}$ & high & Both & new & $\begin{array}{l}\text { by } \mathrm{ABM} \text { - connected } \\
\text { in business } \\
\text { community }\end{array}$ & $\begin{array}{l}\text { political / } \\
\text { personal }\end{array}$ & CCE & $\begin{array}{l}\text { CCE made } \\
\text { judgement } \\
\text { early on }\end{array}$ & CCE agrees & $\begin{array}{l}\text { CSM/CMM } \\
\text { post- } \\
\text { rationalisation } \\
\text { / leveraging } \\
\end{array}$ \\
\hline G & high & Philanthropic & new & $\begin{array}{l}\text { existing business } \\
\text { connection }\end{array}$ & $\begin{array}{l}\text { companies in } \\
\text { business } \\
\text { relationship }\end{array}$ & CCE & $\begin{array}{l}\text { CCE made } \\
\text { judgement } \\
\text { early on } \\
\end{array}$ & $\begin{array}{l}\text { CCE and some } \\
\text { informal discussion } \\
\text { ok }\end{array}$ & $\begin{array}{l}\text { CCE work to } \\
\text { extract } \\
\text { benefits }\end{array}$ \\
\hline H & $\begin{array}{l}\text { high / 3rd } \\
\text { party }\end{array}$ & Philanthropic & new & $\begin{array}{l}\text { by } \mathrm{ABM} \text { - connected } \\
\text { in business } \\
\text { community }\end{array}$ & $\begin{array}{l}\text { ABM also does } \\
\text { bus with CCE }\end{array}$ & $\mathrm{ABM} / \mathrm{CCE}$ & $\begin{array}{l}\text { CCE made } \\
\text { judgement } \\
\text { early on }\end{array}$ & already done & $\begin{array}{l}\text { mktg to } \\
\text { manage / } \\
\text { work with }\end{array}$ \\
\hline $\mathbf{J}$ & high & Philanthropic & new & $\begin{array}{l}\text { existing business } \\
\text { connection }\end{array}$ & $\begin{array}{l}\text { existing strong } \\
\text { rapport }\end{array}$ & $\begin{array}{l}\text { OTH / } \\
\text { OWNER }\end{array}$ & $\begin{array}{l}\text { Owner made } \\
\text { judgement } \\
\text { early on }\end{array}$ & done & $\begin{array}{l}\text { mktg to } \\
\text { manage }\end{array}$ \\
\hline $\mathbf{K}$ & $\begin{array}{l}\text { low-level } \\
\text { driven/3rd }\end{array}$ & Commercial & new & $\begin{array}{l}\text { by } \mathrm{ABM} \text { - connected } \\
\text { in business } \\
\text { community }\end{array}$ & $\begin{array}{l}\text { business } \\
\text { relationship }\end{array}$ & CMM & $\begin{array}{l}\text { CMM sees } \\
\text { potential - } \\
\text { need to } \\
\text { justify. }\end{array}$ & $\begin{array}{l}\text { approval at higher } \\
\text { level }\end{array}$ & $\begin{array}{l}\text { CMM } \\
\text { manages }\end{array}$ \\
\hline
\end{tabular}

$*{ }^{\circ}$ Cases B \& C share the same company; cases D and E share the same company.

Figure 7.2 Paths of Observed Processes 


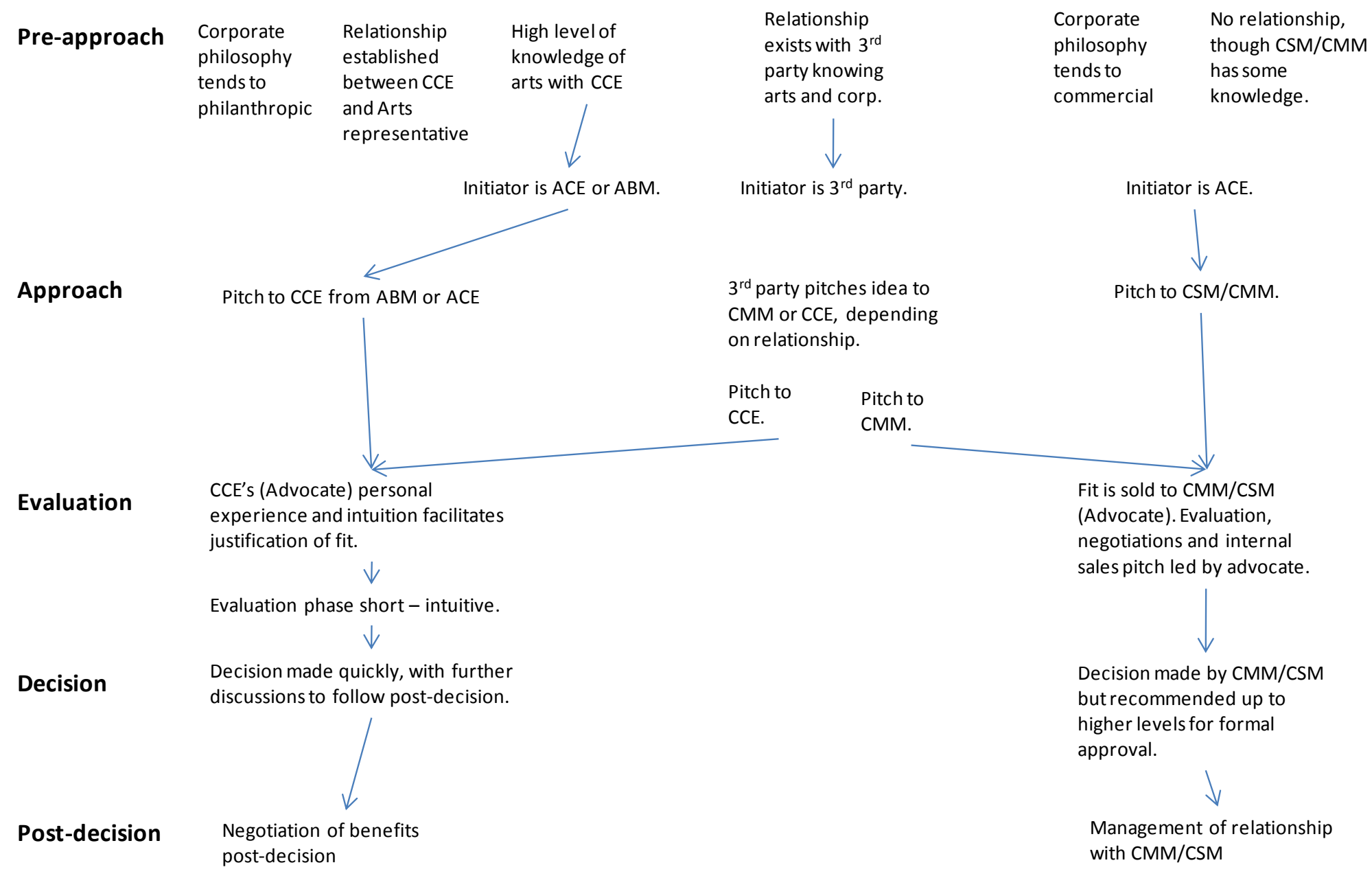




\section{Path 3: Third Party Decisions}

The final identified group was that of $3^{\text {rd }}$ party involvement, with cases $\mathrm{C}, \mathrm{H}$, and $\mathrm{K}$ ( $\mathrm{K}$ holding characteristics of two paths). As is evident in Figure 7.1, this path joined with either Path 1 or Path 2, but differed in the early stages of the decision. In the preapproach, these decisions were driven initially by an individual not directly employed by the arts organisation or the company. In these decisions, an individual knowledgeable in and connected to the business sector saw the opportunity, and was able to put the two parties together. These $3^{\text {rd }}$ parties were the initiators who intuitively knew the partnerships would benefit the company. In addition, these individuals had relationships established which they could use to open the door for the approach. Here, the intuitive judgement of the $3^{\text {rd }}$ party was crucial to the process moving forward. As one CCE stated, without this $3^{\text {rd }}$ party "it never would have happened." Once the opportunity had been recognised, the $3^{\text {rd }}$ party individual pitched the idea to the individual with whom a relationship was established, essentially opening the door. In two cases this was the CCE, and hence the decision joined Path 1 . In one case the idea was pitched to the CMM, and the decision joined Path 2.

The identification of the three paths in this research supports the previously identified themes - the range of philosophies and inclusion of commercial and philanthropic orientations, the importance of the recognition of a fit and benefit, as well as the role of the advocate and the role of intuition. Less directly is this underlying theme of the broader frames of society, the company and individuals. The following will present these themes in terms of a revised framework.

\subsection{A Revised Framework}

The initial framework for this study served to alert the researcher to potential elements of this "black-box" of decision-making. These ideas were examined in the results and discussion, which highlighted patterns and relationships, and suggested new themes. This examination leads to the development of a revised framework, which is presented in Figure 7.3, and will be elaborated upon. 
Figure 7.3 Revisiting the Initial Framework

Initial Conceptual Framework

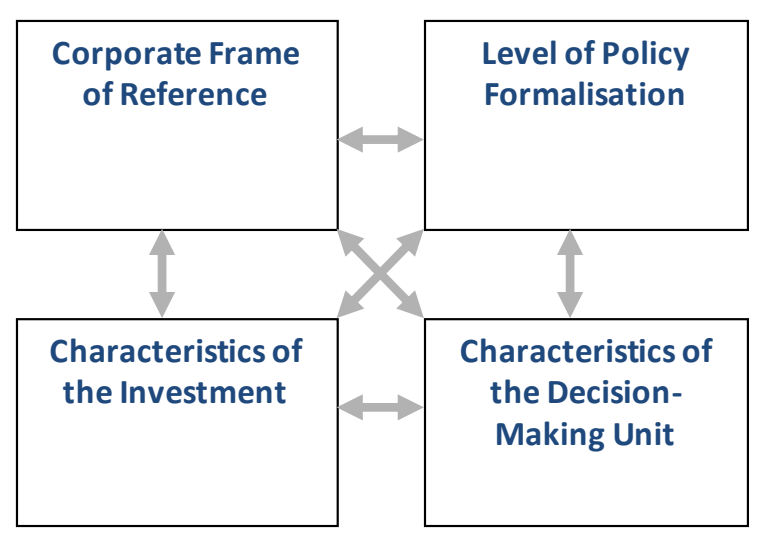

The Decision-Making Process

Revised Framework: Corporate Decision-making for Arts Sponsorship

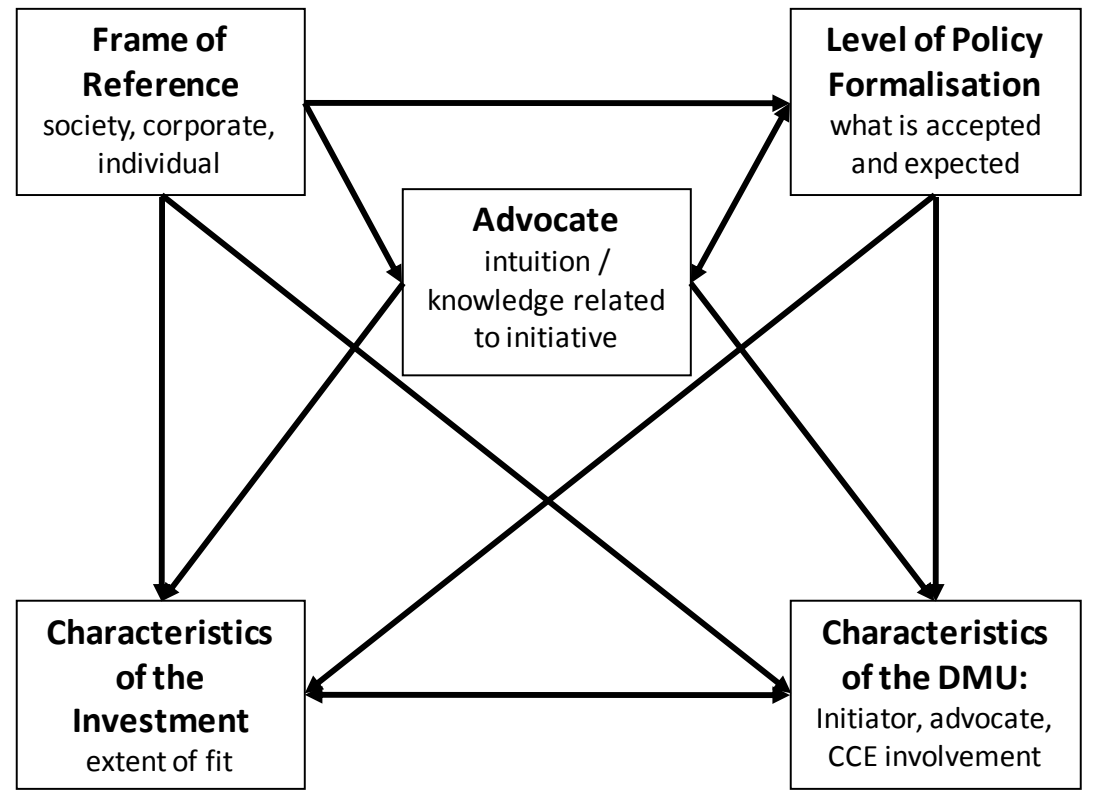

The Decision-Making Process

Pre-approach $\rightarrow$ Approach $\rightarrow$ Evaluation $\rightarrow$ Decision $\rightarrow$ Post-decision 


\section{Frame of Reference}

The frame of reference refers back to the idea of a broader context, but here is defined in terms of its three levels. Firstly, society provides an indication of accepted and expected modes of operation for companies. This informs the level of formalisation within the company, and filters through to consumers and stakeholders, defining their expectations and perceptions, thus influencing the extent to which the sponsorship is seen as a fit for the company. Secondly, the frame of reference of the company indicates how they see themselves operating with respect to arts sponsorship. Is it part of their accepted and expected activity? What is the balance expected within the company of commercial justification vs. intuition? The answers to these questions influence the make-up of the DMU, and the ability of an advocate to make use of their informed intuition in justifying the sponsorship. Within the company frame objectives and markets are also recognised. This frame therefore has a critical influence on how the investment is evaluated with respect to its fit with the company. Thirdly, the individual frame identifies the roles, beliefs and knowledge of individuals involved, thus having an impact on the decision, especially if that individual happens to be the advocate.

\section{Policy Formalisation}

In the revised framework, policies and procedures exist, but the extent to which they are followed vary, being characterised as what is generally expected, given the situation. Here, the extent of "rule following" is influenced by societal, corporate and individual frames of reference. Specifically, more philanthropic oriented companies are less concerned about "ticking the boxes." Also, less procedure is followed when the fit is highly evident and the advocate is confident of the benefits. Therefore, both the frame of reference and the advocate were seen as strong influences on the extent to which formal policy is followed, but each of these forces were also affected by the arts initiative and its apparent fit with and benefit to the company.

Policy however tended to also influence other elements, including the initial make-up of the DMU, especially in determining the formal roles of individuals and their presence in the DMU. In addition, policy held some influence on the evaluation, reflecting 
something of a balance between the economic vs. intuitive judgement, and providing some guidance of criteria, but not firm and fast rules.

\section{Characteristics of the DMU}

The revised framework suggests that the key characteristics of the DMU are better itemised as the existence of an initiator and advocate, and the presence and influence of a higher level of manager. The DMU is influenced by a number of elements in this model. Firstly, formal policies may necessitate certain individuals being present. However, this is in part highly influenced by the frame of reference. The extent to which managers perceive uncertainty in the use of sponsorship, seems to demand formal and informal policies with respect to having higher levels of management in the DMU. The company frame, specifically goals and objectives may also dictate the individuals involved in the DMU. In addition, investment characteristics, including the finances requested and the way in which the sponsorship might be used, will influence the DMU. Also, the knowledge of a key individual, with respect to arts sponsorship and the arts initiative itself may cause this individual (the advocate) to become a part of the DMU.

In turn, the existence of the advocate within the DMU will have an influence on the evaluation. The main influence here is the advocate's knowledge with respect to arts sponsorship and the initiative in particular. If that individual is comfortable with arts sponsorship, has experience of arts sponsorship generally, is knowledgeable and has a favourable opinion and experience of the arts initiative, the evaluation process is likely to proceed more smoothly. It is noted that while the advocate is part of the DMU, their role has also been presented as its own element, central to the framework, and further examination of the advocate will be provided.

\section{Characteristics of the Investment}

In this revised framework, the main characteristic of the investment is the extent to which it fits with the company's goals and objectives. "Fit" now, however has a more specific meaning; the investment needs to meet objectives defined by the company, needs to appeal to the right stakeholders/consumers in the right way, and needs to provide some assurance of success. Therefore, the characteristics of the investment are highly 
influenced by the frame of reference of the company especially, but also of the individual managers in how they view the opportunity. The DMU's ability to see the fit and "get it" is also going to influence the evaluation, primarily via the advocate.

\section{The Advocate}

While the advocate is clearly part of the DMU, based on this study, it is a more accurate depiction of these decisions to give this element greater emphasis. The advocate role was partly related to formal process, but the extent of their advocacy was due more to informal processes. These individuals emerged as an advocates due to their own knowledge and experience - or their informed intuition - their frame of reference, their subsequent expert power. It was this background that allowed them to take a lead role in the DMU, using their expert power to enthuse and convince others of the fit and benefits concerning the investment. Thus they were both a part of and an influencer of the DMU. Whether the decision was evaluated more on philanthropic or commercial grounds, the advocate also played a role in giving interpretation to the characteristics of the initiative. In doing this they also influenced the extent of rule following. For example in cases under Path 1, advocates felt so strongly that the investments would benefit the companies, that the evaluation phases were virtually skipped. The presence of an advocate does not make these decisions solitary, or an individual "chairman's choice" decision, but the centrality of this role and the understanding of this role in these decisions is a key finding here.

\section{The Process}

While recognising that the path may vary slightly, and variations were often a result of the elements noted above, the general process noted in these decisions consisted of five phases: pre-approach, approach, evaluation, decision and post-decision. The preapproach was largely marked by the frames of reference within society, the company and individuals, including the advocate. The approach was characterised not as a response to requests by the corporation, but as an informed individual making the connection and therefore making the contact. The evaluation phase occurred next, and demonstrated the most variation, as some decisions involved quick intuitive evaluations and others involved lengthy internal discussions and negotiations. The decision phase also held variation, with some decisions subjected to a second level of approval, and others able to 
be made immediately. Finally, the post-decision phase was important to consider, as in some decisions it was in this phase that the negotiation of benefit occurred.

The revised framework presented is viewed as better reflecting corporate decisions of arts sponsorship. Key findings include the importance of the advocate, the less significant role of policy and procedure, and modifications to the characteristics of the DMU and the arts initiative. In addition, this framework highlights interconnections and relationships among the elements and the process itself.

\subsection{Theory \& Proposition Development in Summary}

This thesis has revealed numerous findings, detailed in Chapter 5, and examined in chapter 6 . These previous chapters presented this "accumulating body of evidence" referred to in the opening of this chapter. While previous chapters have perhaps made the reader aware of the multitude of findings, chapter 7 has sought to bring more focus and order to these findings, by presenting key themes, subsequent propositions, and a summarising framework.

This theory-building process has therefore revealed much about arts sponsorship decisions. It suggests that there may be a typology of processes which companies will follow, but how these processes play out will be dependent on many factors. It has also suggested factors which will influence these decisions, and the manner in which they will influence the decisions. This chapter has also revealed complexities around these decisions, in balancing commercial and philanthropic goals and formal and informal processes. Finally this chapter has made specific propositions to which further research may be attuned.

The following chapter will further synthesise the findings, will bring the ideas presented here into implications both for theory as well as for managers, and will conclude the thesis. 


\section{8: Conclusions and Implications}

This thesis has taken the reader on a progressive journey through the study of arts sponsorship decisions. To review, chapter 2 examined literature from Corporate Community Involvement, revealing that the "black box" of decision-making in arts sponsorship had not yet been opened, and opportunity existed for a theory-building approach to this area. Knowledge from Organisational Buying Behaviour and Decisionmaking was applied to develop an initial framework in chapter 3. The literature, framework and the research question then led to the methodology (chapter 4), of qualitative case-based research, using multiple informants from the dyad. The results of the research were presented in chapter 5, revealing the richness of individual cases and the cases in combination. These results took on more meaning in chapter 6 as they were examined and discussed in light of the literature. Patterns emerged from this examination, which were expanded upon in chapter 7, where themes were highlighted, propositions offered, and a framework for understanding these decisions was presented.

This final chapter will conclude this journey. Firstly, the broad findings will be revisited to enhance the picture of these decisions. This will be followed by a summary of contributions and discussion of limitations. The thesis will be concluded by providing managerial implications, and suggesting future research.

\subsection{The Context of Arts Sponsorship Decisions}

Evident throughout this study was that there are a number of factors influencing and forming these decisions: the broader societal context, the range of commercial and philanthropic orientations, the fit, the advocate, and intuition. In examining and building on these themes it is evident that these decisions could be viewed as influenced by multiple contexts: specifically the social, stakeholder, company and individual contexts.

\section{The Social Context}

Art sponsorship decisions are influenced by the social context within which stakeholders, the company and individual managers operate. With this view we see that society has certain expectations of companies in terms of CCI and in particular, arts sponsorship. 
Society will also have perceptions of what companies are doing with respect to CCI and arts sponsorship. In considering arts sponsorship, managers interpret these expectations and perceptions, asking themselves what individuals in society are expecting and how they might perceive the sponsorship. Some indication was given in this study that CCI may be used to manage legitimacy gaps: gaps between expectations society has of the company, and perceptions society has of the company's behaviour. This context relates to the societal frame of reference, but also to the interaction with stakeholders and frames of the company and individuals. In understanding these decisions then, arts managers must try to understand this broader context and how it may be interpreted by managers in companies considering sponsorship.

\section{The Stakeholder Context}

Sponsorship needs to provide benefits to the company by appealing to specific stakeholders. While the stakeholders are identified by the company, they are external to the company and function within wider society. However they are a defined group or groups, and their specific context is considered in these decisions. The stakeholder groups may be a consumer market, key business leaders, government representatives or media for example, but they will be identified by the company in relation to the sponsorship. Much like in the social context above, managers will consider expectations and perceptions of stakeholders, they will make a judgement on what stakeholder groups expect of the company, how they might perceive the behaviour of the company, and how they might perceive the sponsorship. Of specific interest is the extent to which stakeholders would find the arts initiative appealing, and/or the extent to which stakeholders would make the desired link between the company's image and the image of the arts initiative. Examining the stakeholder context thus relates to the frame of the company, the fit and use of the sponsorship. Clearly, consideration of this context is essential for arts managers to understand in approaching a company for sponsorship.

\section{The Company Context}

Arts sponsorship decisions are also influenced by the company context. Firstly, the company will have goals and objectives which the sponsorship needs to address in order to be considered. These goals may be marketing specific such as appealing to a target market, or more broad corporate objectives such as establishing a greater presence in a 
business community. These goals, the stakeholders and the sponsorship need to work together, in essence forming the "fit" between the company and the arts initiative. Secondly, the company context takes into account the company's orientation within the range including philanthropic and commercial goals. Whether a company tends to be more at ease with philanthropic rationales, or more tuned towards commercial justification, will have an influence on the extent of formal policies employed in these decisions. The orientation also impacts the extent to which individual intuition is applied, and whether managers appear comfortable with intuition over economic rationale. Finally, the company context includes the past experience and knowledge of the company with sponsorship and the arts organisation. This helps to establish whether there is an existing relationship between the two parties, and the amount of knowledge the company has about the arts organisation. Considering arts sponsorship decisions in light of a company context reveals many influences on these decisions from the company level. This relates to the company frame of reference, but also the need for a fit, and the importance of intuition. Understanding the company context also suggests links with the social, stakeholder and individual contexts.

\section{The Individual Context}

The importance of the individual context in arts sponsorship decisions has arisen particularly related to the initiator and the advocate. The initiator is external to the company, and has the knowledge and experience to see that the sponsorship will in fact "fit." Therefore initiators are the people without whom the sponsorship would not have been put forward to the company. Their knowledge, experience and understanding of the company and the arts initiative is therefore a crucial context in these decisions.

However, once the proposal has been put forward, it is the role of the advocate which is most important, being the individual with the knowledge and experience to see that the sponsorship will work for the company, and who in turn advocates for the sponsorship. Advocates are determined by their expert power, partly due to a formal role, but also related to their knowledge and experience, essentially forming their ability to "get it" - to understand how this relationship will work and benefit the company.

Considering the individual context in these decisions certainly suggests understanding the backgrounds of individual managers, but this study has suggested the contexts of the initiator and the advocate to be the most important in these decisions. In arts sponsorship 
decisions therefore, the individual context is highly influential, and crucial for arts managers to understand.

\section{A Multilevel Perspective on Arts Sponsorship Decisions}

The above gave emphasis to the multiple contexts within which arts sponsorship decisions occur, and how these contexts overlap, interact, and impact on decisions. This examination bears similarity to that of a multilevel model, and suggests that looking at these decisions in terms of a multilevel model may assist in better understanding organisations and these decisions. Management authors have proposed that a multilevel perspective may result in better understanding organisations: "using a multi-level lens reveals the richness of social behaviour; it draws our attention to the context in which behaviour occurs and illuminates the multiple consequences of behaviour traversing levels of social organisation” (Hitt, Beamish, Jackson, \& Mathieu, 2007, p. 1385).

In this multilevel view, the contexts noted above would be considered the "levels." Some levels would therefore be nested in others (such as the company nested within a societal level), and interactions could be represented between the levels. Applying this thinking to the study contained here led to the development of Figure 8.1. This figure illustrates the contexts discussed earlier and their interactions, which, with further elaboration to follow, yields a rich perspective for these decisions.

In Figure 8.1 the nested arrangement of these contexts is evident, where stakeholders, the company and individuals are all contexts which sit within and are influenced by the social context. There is also an overlap between stakeholders and the company, with the company identifying these particular groups, and providing interpretation as to their expectations and perceptions. In addition, the individual context sits partly within that of the company context, representing the combination of an individual's background, knowledge and experience from both their personal and their business/company lives, as well as their formal role within the company.

Relationships and influences are also noted via the arrows in Figure 8.1. In this, we see the stakeholder context interconnected with the company in its definition and interpretation: the company defines and determines who the stakeholders are. Individual managers and particularly the advocate also provide interpretation to this stakeholder 
context: the advocate determines whether they see the initiative appealing to stakeholders. The company and individual also share an interconnection, with company goals, objectives and philosophies interpreted by individuals, but also individual experiences shaping the company's experience. These are relationships evident within this multilevel context, but there are also clearly connections to the decision process itself.

The decision process column depicts the stages identified in this study, and influenced by this multilevel context. The process is therefore seen as consisting of a pre-approach stage, followed by the approach, evaluation, decision and post-decision stages. While variations are expected within this process, consistent questions characterise each stage. In the pre-approach, is the opportunity identified? In the approach, is the benefit evident? and who is the advocate? Is the evaluation more intuitive? and to what extent is an internal sales process undertaken? Is the decision also largely intuitive? and does it require a higher level of approval? In the post-decision, to what extent does the negotiation of benefits take place? While these questions reflect characteristics of these stages, they are also influenced by the multilevel context. Stakeholders, the company and the individuals, all within the context of society, influence the identification of the opportunity and benefits, the recognition and role of an advocate, the extent of intuition involved, internal processes and approvals, and the extent of post-decision negotiation.

This multilevel view builds from the revised framework. This view has noted the levels or contexts, elements within and interactions between levels, which then influence the decision process. Through this arrangement it is clear that these decisions are made within a multilevel context. These findings and those of earlier chapters clearly have implications for and contributions to theory. 
Figure 8.1 A Multilevel Perspective on Arts Sponsorship Decisions

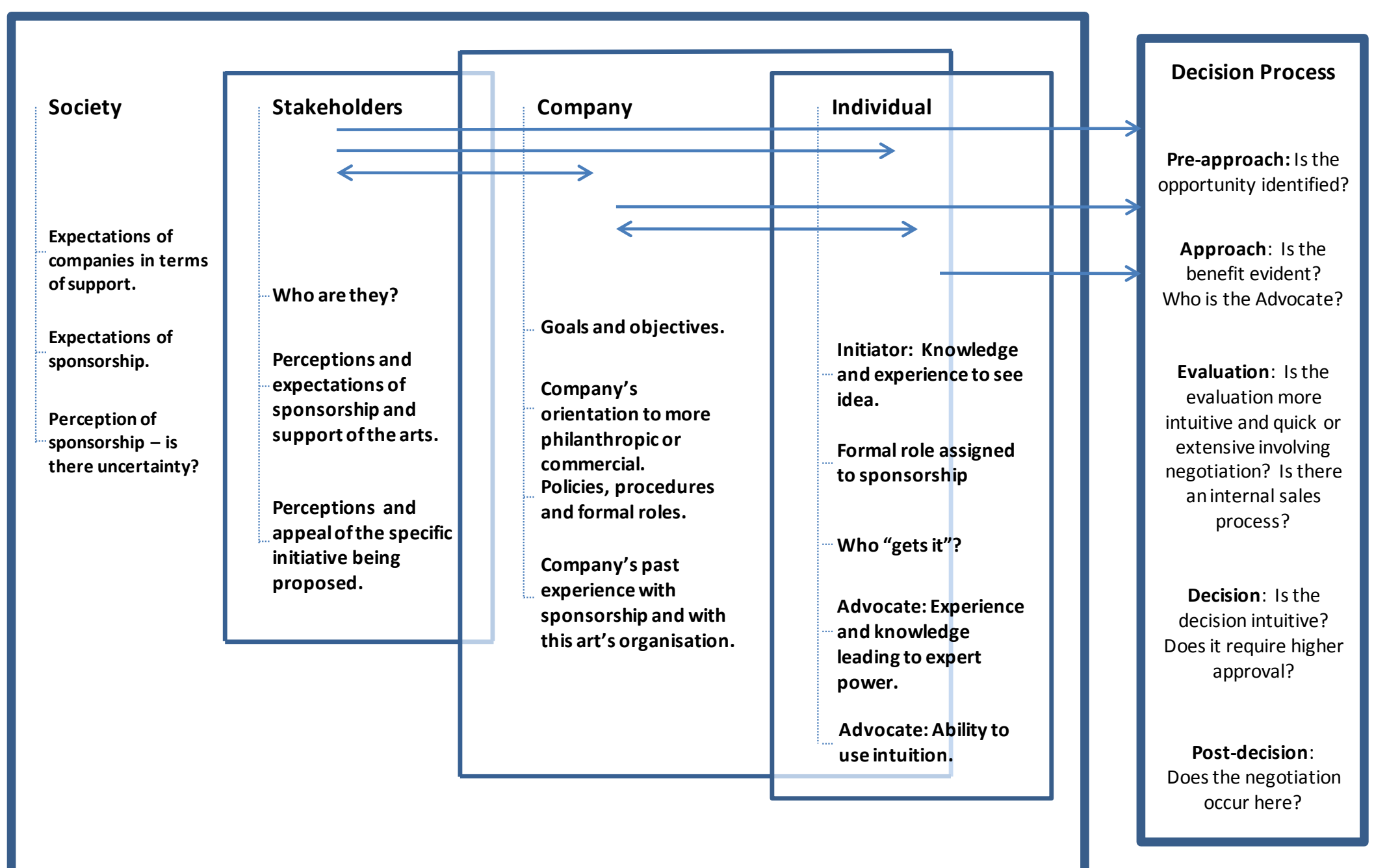




\subsection{Implications and Contributions to Theory}

This study of arts sponsorship has contributed to the literature firstly in examining decisions and decision processes in particular. As noted, the philanthropy and sponsorship literature has not focused upon this area. In addition, previous studies have not examined these decisions making use of a case approach, with multiple informants and representation from both sides of the relationship. In studying this area, and using this methodology, much has been revealed about these decisions, and contributions to theory have been noted. This section will summarise main contributions with reference to the areas of literature examined.

\subsubsection{CCl: Sponsorship and Philanthropy}

As identified in chapter 2, CCI has been used to encompass non-profit and business relationships including patronage, philanthropy, commercial and socio-sponsorship, cause-related marketing and partnerships. This study focused on the literature in the management of sponsorship (commercial or socio-sponsorship) and corporate philanthropy (including discussions of Corporate Social Responsibility). The literature review argued for the inclusion of these streams, and this study has benefitted from this perspective, and offered contributions to these areas. The following discussion summarises key contributions.

\section{A Range of Goals}

A key contribution of this study has been the recognition that both philanthropic and commercial goals may exist together in these decisions. While sponsorship and philanthropy literatures offer multiple definitions for various arrangements, this research suggests that these two goals may be sought within one single investment. In other words, arts sponsorship appears not to fall into a pure "commercial sponsorship" or "philanthropy" category. Rather, it would be more accurate to suggest that arts sponsorships may be made with a combination of commercial and philanthropic goals. 
Related to the above, this study also contributes in noting that companies themselves may have a philosophy within this range of commercial and philanthropic desires. Furthermore, in arts sponsorship decisions, a company orientation more towards commercial or philanthropic goals was important. While the idea of multiple objectives has been suggested in the literature, it has not been observed nor addressed in the context of sponsorship decisions. In this study however, this was an important finding and an important influence on the decisions, with the company philosophy related to who was included in the decision-making unit, and the extent to which intuition was accepted as part of the process.

\section{The Expectations and Perceptions of Society}

This study also contributes to the literature in identifying the role and influence of society. Specifically, society's expectations and perceptions of sponsorship will be interpreted by managers, and therefore filter into decisions. Literature in the philanthropy area has touched on this, but it has not been examined in the context of sponsorship decisions. The findings here indicated that there may be an unease in society regarding sponsorship which then influences these decisions. On the other hand, reference to legitimacy suggests that corporate philanthropy decisions especially may be used to manage expectations and perceptions in society. The study here therefore contributes to this discussion in proposing that managers do consider society's perceptions and expectations in terms of arts sponsorship.

\section{The Roles of Individuals}

A focus on individuals and the identification of individual roles in these decisions is an additional contribution from this study. Here it is noted that the views, values and experiences which individuals possess will influence this process. Studies have alluded to this and suggested influence of the board and CCE, but no study has specifically looked at decision-making to identify specific roles. Historically, sponsorship and philanthropy decisions have sometimes been viewed as individual "Chairman's Choice" decisions. Other sponsorship and philanthropy studies have recognised that there is a need in these relationships for particular roles. By looking specifically at decisions, three key roles were identified in this study: initiator, approver and advocate. 
Firstly, the initiator was identified as the individual external to the company who saw that the sponsorship could work, and got the process going. This role has not been investigated in sponsorship or philanthropy literature but was found here as crucial in starting the decision-making process.

Secondly, an approver role was recognised as an individual or individuals within the company who in some cases served as an additional level of approval even after a decision appeared to have been made. While some philanthropy literature raises the idea of CCE's and Board members assuming this type of function, it has not been identified as a role within the DMU and decision-process, and the implications for the process therefore have not been recognised.

Finally, the role of the advocate was observed in this study as the individual within the company who believed in the investment, saw how it would work to benefit the company, and took it upon themselves to advocate for it. The experiences, knowledge and values of the advocate allowed them to apply informed intuition and provided them with expert power. In doing this, they played a significant role. While reference has been made in the literature to key individuals being crucial to sponsorship relationships, this study contributes in identifying this role and the characteristics of the individuals who take on this role in the context of these decisions.

\section{Importance of Intuition}

A further contribution, related to the roles of individuals, is the importance of intuition in these decisions. Intuition, by definition, was referred to as informed intuition, emphasising that it is shaped by experiences, values and knowledge. The idea of informed intuition being important in these decisions suggests that these experiences, values and knowledge, conscious or subconscious, play a role in these decisions. This has not been considered in the literature concerning sponsorship or philanthropy. In fact, it may appear in contrast to many calls in the sponsorship area for more reliance on measureable assessments, and a movement away from individual personal choices. However in examining these decisions it was clear that intuition was not about a personal choice, but about the application of knowledge and experience to better inform the decisions. Through intuition, individuals were able to see how these partnerships would work and to see the benefits to the company; this allowed individuals to further advocate 
for the relationship. In the study, there was variation in the levels of intuition present in decisions, and where in the process it emerged most evident; however, informed intuition was certainly a crucial part of these decisions.

\section{Assessing the Investment}

Contributions to the literature also lie in the consideration of the assessment of the particular investment. Much literature has been devoted to identifying objectives and motivations for sponsorship as well as philanthropy. This study contributes in further examining the idea of fit, and its role within the decision process. Here, decisions characterised as "sponsorship" may not be entirely marketing or customer-oriented exercises. They may be opportunities to build the brand and connect with customers, and/or opportunities to develop networks in the business community, with media, suppliers, supporters, communities. While much literature appears to recognise the movement of sponsorship into Marketing, and its use as a tool for reaching customers, this study is a reminder that this may not always be the most appropriate place for considering sponsorships. Having the role in Marketing and examining the fit solely from a marketing perspective may or may not suit the company's best interests. In fact this study has reiterated that corporate-wide goals and objectives may often be served in arts sponsorships.

Also in terms of the investment, this study has revisited the idea of fit, agreeing with the literature that sponsorship is most commonly used for brand-image-transfer. However this study also suggests more attention be drawn to hosting as a use-pattern of sponsorships. Very little sponsorship or philanthropy literature has dealt specifically with the use of sponsorship via hosting. In contrast, hosting was a common use for reaching multiple stakeholder groups. Therefore the recognition of the importance of hosting and use of hosting is a contribution to the literature.

\section{Considering the Process}

Finally, this study has contributed to philanthropy and sponsorship literature in its focus on the decision-making process, and the start of the relationship. While many findings here agree with the literature concerning the sponsorship relationships, this study helps to set the scene for these relationships. This decision-focus has resulted in the recognition of 
an "informed happenstance" leading to these decisions. In these situations, individuals who are informed about the arts initiative, about the company and about the use of sponsorship are able to bring the parties together and instil the sense of fit. An additional contribution is that steps in the process have been identified, as well as variations in the steps; in particular some decisions will move swiftly based on intuition, and others more slowly and based on economic justification. In addition, this study has suggested that in these decisions there is potential for an internal sales process occurring within the company, with the advocate leading the charge. This internal process has not been recognised in the literature to date.

The above has summarised contributions made to sponsorship and philanthropy literature, with three overriding themes evident. Firstly, this study supports that much could be learned from the application of an OBB and decision-making context in light of arts sponsorship and possibly all CCI decisions. Secondly, this suggests that studies which separate ideas of sponsorship and philanthropy may be limiting their perspective. This does not argue against the call for sponsorship to be a confirmed tool in the marketing mix, but supports that a more integrated approach may be necessary to better understand many of these relationships. Thirdly, this study proposes that these decisions need to be understood at a variety of levels, from the societal level, to the stakeholder, corporate and individual.

\subsubsection{Organisational Buying Behaviour and Decision-making}

It is evident that the application of decision-making and Organisational Buying Behaviour (OBB) lenses have added to knowledge of these decisions. Overall, this study also contributes to these areas in providing greater in-depth understanding of how a particular type of decision is made - decisions of arts sponsorship.

\section{In Light of Organisational Buying Behaviour}

As well as borrowing from OBB literature, this study contributes to OBB in revealing the specific nature of buying decisions for arts sponsorship. The OBB literature tends to focus on the purchase of tangible products, and while arts sponsorships do not come with 
specifications and requests for proposals, it was evident that these decisions could be considered in this OBB context.

This study firstly contributes to this literature in offering up a new area to be considered: sponsorship and even other decisions within Corporate Community Involvement. Secondly, while OBB has suggested categories in the external environment which may impact decisions, this study proposes specific elements of this environment hold influence: the perceptions and expectations of society with respect to Corporate Community Involvement. Thirdly, moving to the corporate environment OBB also proposes a number of factors which will influence decisions; this study finds that the recognition of corporate objectives, the relevant stakeholders and a corporate philosophy towards CCI were crucial to the decision. The fourth area of contribution is to the discussion of the DMU, noted and studied in OBB literature, but not taken into the CCI context. This study contributed to this area in identifying particular roles within and characteristics of these decision-making units in arts sponsorship decisions. In particular the identification of the role of the advocate makes a contribution in identifying this key individual, influential in the buying process. Finally, while OBB notes the role and backgrounds of individuals as important in the buying process, this study has revealed the significance of intuition and expert power; although these decisions are business decisions, it is individuals with their knowledge, experience and intuition, who ultimately make the call.

This view of a sponsorship which a company purchases or invests in has not been presented in the literature, but is an important perspective. The contributions to the OBB area suggest that decisions related to other CCI initiatives may hold similar characteristics, and may be worthy of future investigation.

\section{In Light of Decision-making}

Theories from decision-making have also contributed to this study, and in turn the findings contribute back to decision-making by focusing on arts sponsorship decisions. To date, sponsorship and philanthropy decisions have not been considered in the decision-making literature. 
Here, contributions were made particularly in identifying the decision path and characteristics of this path, specific to sponsorship. While a stage of "problem identification" was not found, this was equated to a more subtle context in which needs existed, in the pre-approach phase. Here, emphasis was given to the company's philosophy in the range of orientations, along with the company strategies, both of which influence the decision path. In addition, the idea of "informed happenstance" was presented as an important pre-cursor to these decisions, raising the weight of knowledge and information in the early stages. The consideration of the evaluation stage of a decision path revealed a potential internal sales process, and frequent shortening of the evaluation when higher levels of intuition were present. This later finding concerning intuition also rings true with decision-making literature and contributes in applying this to these decisions. Decision-making literature does note the importance of individuals with their backgrounds, perceptions and knowledge, however this has not been taken into sponsorship decision-making.

Some conjecture on why decision-making literature has not investigated CCI decisions has been offered previously in this thesis. It may be that CCI is seen as more in the realm of Marketing, or less significant decisions. However, the realm of CCI is quite broad, and if companies see their role in society as including CCI, greater study in this area may deserve attention. Certainly, the application of a decision-making lens has served to enhance this study. Furthermore, and as noted, this study has offered a contribution to the decision-making literature, in defining a path which tends to characterise these decisions, and identifying key influencing factors, such as happenstance and intuition.

On a wider scale, contributions may also be present for decision-making in areas outside of CCI, but which hold similarities to these decisions studied. Specifically, while decision-making literature appears to focus on decisions which begin with problem identification, the cases studied were notable in the absence of this stage. Parallels may be possible between this study and other decisions for which a problem is not always initially identified. Findings such as the importance of informed happenstance, intuition and the existence of an advocate may be relevant for these types of decisions.

Therefore, the findings in this study contribute to the OBB and decision-making literature both in the application of sponsorship decisions, but more specifically in revealing the unique aspects of these decisions - the important elements in the 
environment, the company and individuals; and the characteristics of these particular decision paths. Broader contributions to areas outside CCI may also be possible, but would deserve future research.

To conclude, the contribution goes two ways in this study. In applying OBB and decision-making lenses, new insights have been revealed for sponsorship and philanthropy literature related to these decision processes. In investigating decisions of arts sponsorship, a subset of CCI, greater understanding of these types of decisions has been revealed to contribute to $\mathrm{OBB}$ and decision-making literature. In the above discussion it is also evident that future research opportunities exist. These will be addressed following a discussion of limitations.

\subsection{Limitations and Implications for Future Research}

Like all research, this study carries with it certain limitations. This section will first reiterate some delimitations (those within the control of the researcher), and then identify the limitations which have been recognised.

Firstly, delimitations were imposed in order to give boundaries to the study. Specifically, the decisions selected for study were all positive outcome decisions and occurring within New Zealand. While this restricted the data in some ways, it also allowed for positive decisions to be identified and comparison between these decisions to be conducted. The boundary of decisions within New Zealand allowed for a certain amount of control to be achieved for the broader society, and also on a more practical basis, allowed for face-toface interviews to be conducted. Further discussion of these delimitations is also provided in section 1.5.

In terms of the limitations of this study, a number were identified, and steps taken to minimise the impact on the research. Firstly, in conducting interviews on cases for which the decision had already happened, a potential limitation arose in that participants were responding having had opportunity to reflect and perhaps even post-rationalise the decision, which may introduce bias. To limit this effect and to attempt to capture the most accurate description of these decisions, multiple respondents from each relationship were sought, and when appropriate and available other sources of information were used. 
However, there remains the chance that some details of the decisions may not have been captured as accurately as had been hoped.

It is also recognised that while attempts were made to gather information from multiple respondents on each decision, it is impossible to say that all necessary respondents were involved. As authors point out (for example see Olkkonen et al., 2000), and as is evident in these cases, these decisions exist within a much more complex environment than may be depicted in a study such as this.

As far as future research, the results of this study have multiple implications. Firstly, this study's purpose was related to theory-building, and has therefore presented propositions. These propositions would thus benefit from further research to test their validity in situations such as this, and in other related contexts.

Future research could examine these decisions in other countries/cultures, with other CCI tools and in other recipient sectors. With the recognition that these decisions are influenced by society, there would be benefit in researching decision-making in different countries, especially in those who appear to hold varying values on the role of the corporation in society. In addition, this study was built on ideas from both philanthropy and sponsorship areas within CCI. It is suggested that further study of decisions in the realm of CCI would yield additional comparison and insight. These could be both made on the basis of the CCI tool (such as cause-related marketing and partnerships), as well as on the basis of other recipients (such as sport, and social causes).

There are also opportunities in studying these decisions over time. Considering multiple decisions within a company, and the company's changing context over time would allow for greater insight into the influences of the changing elements within the company. This could allow for investigation of decisions, for example, as priorities and objectives change, or as key individuals change within a company. A longitudinal investigation could also consider changes in society, such as the global recession (which occurred during the analysis of this research), subsequent changes in society expectations, and how this is interpreted by companies in making CCI decisions.

More specific topics highlighted in this study also deserve greater attention. Of particular interest could be the deeper understanding of society's perception of CCI in its 
various guises (philanthropy, sponsorship, cause-related marketing, partnerships), society's perception of government vs business vs individual support of these initiatives and the effect this may have on decisions. This area relates to ideas of legitimacy theory to which attention could be given to better understand CCI in this light. Furthermore, greater measurement and investigation into the idea of a company philosophy and its effect on CCI decisions could be made to highlight both how these philosophies are formed and directions companies take in other CCI decisions. In addition, the recognition of an advocate role in particular suggests research opportunities in better understanding this role, perhaps establishing a more systematic measurement of the backgrounds, values, and actions of these individuals as suggested in innovation literature (Howell \& Higgins, 1990).

Future research may also focus on differences recognised between individuals within companies, and between the arts organisations and the sponsoring companies. For example, in this study it was noted that senior level executives appeared more certain in their belief that these sponsorships would benefit society and therefore would benefit the company. Much could be learned in this area with studies comparing the sensemaking of senior executives with that of CSM/CMM roles, in terms of these decisions.

Furthermore, this study noted that at times there were differences between how the arts organisation perceived the decision and how the company perceived the decision, including differences in the importance of motives. Further investigation into these differences would be of interest to this area.

In summary, this study has suggested many areas of further investigation, both in testing the propositions raised, but also in delving further into CCI decisions across varying contexts. Elements of these decisions noted here, could also be areas for further investigation, including the exploration of legitimacy, company philosophies, the advocate role, and the differences in views between recipients and sponsors and between levels within organisations.

\subsection{Implications for Managers}

This study has been driven by both a gap in the literature, as well as the recognition that arts organisations would benefit from insight into these decisions. Returning to an earlier argument, if understanding our customers assists us in reaching them, and if an arts 
sponsorship is really selling a "product" or investment, then understanding how companies make decisions about this investment is going to benefit arts managers. It is also hoped that managers in sponsoring companies may benefit from this study in understanding more about processes which may be going on within their company/sector. Therefore this study has implications for managers on both sides of the relationship.

\subsubsection{Implications for Arts Managers and Arts Board Members}

Through the interviews conducted, it was evident that some arts managers/board members (from here on the term "arts managers" will be used for both groups purely for simplicity) were very aware of how decisions might proceed, and others were not. Therefore, it is important to say that the implications here may not be epiphanies for many. However, if they "ring true" to these well-informed individuals, this is a reassuring outcome.

For the arts, on a macro scale this study suggests that there may be more to these decisions than is revealed or perceived. This study also suggests that taking an Organisational Buying Behaviour perspective on these decisions, where the sponsorship is viewed as a product or investment by the company, may be a useful approach. The more specific implications could be considered in view of the themes identified.

Firstly it is important for arts managers to recognise that these decisions are likely to be influenced by the views of society, the perspective of the company and the experiences of individuals. They will need to be as "tuned-in" as possible to the individuals they are approaching, the objectives and needs of the companies and the perceptions of customers and other stakeholders. This is often the role of many board members as their connections to the business sector may be greater, so their involvement and empowerment is crucial.

Secondly, arts managers need to appreciate the range of commercial and philanthropic orientations which may form part of the background of these decisions. While elements of philanthropy and doing good for society may be a motivation for company managers, there is also a need for commercial justification. Those in decision-making units need to be able to see what the benefit will be and how it will flow to the company. As a result 
arts managers need to be prepared to demonstrate that the sponsorship will benefit on a commercial scale.

Related to the above point is the idea of fit. The sponsorship proposed needs to fit the company in a way which will clearly benefit the company. The two main avenues of fit are (1) a fit with the brand such that the company might communicate a message to its target market(s) and/or stakeholder groups, and (2) a fit with consumers and/or stakeholder groups such that these individuals are enticed to attend a hosted event. Importantly, someone in or connected to the arts organisation needs to be able to effectively communicate this fit to the potential sponsor.

In communicating the fit, the advocate must be identified. Arts managers need to be aware that in order for their sponsorship proposal to move forward in the decisionmaking process, there needs to be an individual within the sponsoring company who has the experience and knowledge to see that this will be a success, and has the ability to gather support within the company. An arts manager may only be able to influence this through their communication of the opportunity, however it is important to recognise that intuition plays a role in these decisions, and it is often the intuition of the advocate which is most important. This emphasises the importance of identifying the advocate.

Taking the above ideas further, check-list could be proposed for arts managers seeking sponsorship.

Knowledge is key.

- Be knowledgeable about your own organisation, your reputation, what you can offer, who your audiences are, who your business audiences are, who finds your art/company appealing, and how you could benefit a company by appealing to these groups.

- Be knowledgeable about the business community and climate. Be alert and tuned-in to try to understand the goals and objectives of companies and to be open to potential relationships which might then work.

- Be knowledgeable about individuals in the business community. Try to understand who might be the advocate in various companies, make attempts to find these people by searching attendance records, or even 
inviting companies to offer tickets to interested employees (and therefore they will identify themselves).

Be pro-active in identifying and cultivating individuals who may potentially be advocates. Make attempts to introduce key business people to your art form and the potential opportunities which exist in sponsorship.

* Ensure any initiative put forward is in fact a good fit with the company, meaning that it will appeal to the consumers/stakeholders which this company is seeking, and appeal with the intended message.

Ensure that the person who makes the initial approach to the company is able to communicate the fit and instil a sense of enthusiasm and a sense that it will be a success.

* Be able to provide and support the commercial benefit, and be supportive of further requests for clarification as this may be part of an internal sales effort.

Be mindful of the role of your reputation and that of the event/organisation, as this may well be part of the evaluation.

The above implications for arts managers emphasize the importance of knowledge, as well as being empathetic to companies, understanding their situation and their needs. At the same time, arts managers need to be pro-active in converting these opportunities into a successful sponsorship.

\subsubsection{Implications for Managers in Companies}

While this study focused on decision processes largely for the purpose of gaining sponsorship, in understanding of these processes it has also raised some implications for managers in companies considering sponsorship.

Firstly, this study revealed that arts sponsorship in particular may serve a number of purposes, may appeal to a number of stakeholder groups and may be oriented both to commercial and philanthropic ends. This suggests that managers may benefit from not restricting these decisions to a department which may limit them to serving one stakeholder group, or which may limit managers to focusing solely on the commercial gain. The recognition that these partnerships may be considered as means of establishing legitimacy within a community brings a broader perspective to these decisions. 
Secondly this study noted the benefits in many cases of the use of intuition, with academic authors suggesting that informed intuition may be just as important in decisions as the more overt economic justifications. With these decisions revealed as being potentially complex, individuals' experience and knowledge appears to hold a role in recognising opportunities and in seeing how the sponsorship will deliver benefits to the company. For managers this suggests that benefit may be gained from not restricting evaluations solely to economic justifications.

Thirdly, this study noted how managers consider the perceptions and expectations of stakeholders. This suggests that if companies are going to target certain stakeholder groups via sponsorship, they should be aware of what the perceptions and expectations of these groups are. Will the sponsorship appeal to them in the right/intended way?

Overall, this study points to the complexities of these decisions which should be recognised by managers. Specifically, arts sponsorships possess opportunities to appeal to multiple stakeholder groups, may fulfil both commercial and philanthropic goals at play, and may have rationales including both individual intuition and economic justification.

\subsection{Concluding Thoughts}

Part of the rationale in undertaking this study was curiosity about the relationship between the business sector and the non-profit sector. It seems that companies are increasingly taking an interest in their impact on society, under the broader term of sustainability and/or "Corporate Community Involvement." Companies are subscribing to programmes such as the Global Reporting Initiative (2008) and in New Zealand the Sustainable Business Network (2008), which emphasize corporate social responsibility and include involvement in the community. More specifically the international organisation, London Benchmarking Group (2008), focuses directly on CCI. This suggests that expectations of society and business society are changing.

A specific focus on the arts was taken partly due to the lack of study in the literature, but also due to the arts falling between the pure social/charitable causes and the more mediaoriented sports sponsorships. This makes support of the arts perhaps a more tricky 
investment to justify, yet the arts is very much a part of the society in which businesses operate. One respondent made their view of the link between business and the arts clear in stating: "if you want a creative society ... then you have to support the creative people within the society." This was an inspiring remark, but still left unanswered questions. Was this view shared? How do individual views impact the decisions? More to the point, how are these decisions made?

This study has found that this link with society views and individual views is in fact a strong link. These decisions do appear to be investment decisions, made with both the eye to investing in the society in which businesses operate, and investing in the company. Serving two masters, one termed "philanthropic" and one termed "commercial" does not appear to be unusual, nor a problem for these companies, but it may be something to which arts organisations need to be more attuned. In addition, finding these decisions as influenced by the intuition of individuals is a finer point on the idea of an individual making a personal choice. This study has revealed the richness of these decisions - that they are complex, shaped by society, by companies, by the investment itself, and by individuals. The complexity then suggests that personal knowledge, background and experience in fact should play a role.

This study has focused on decisions of arts sponsorship, and in doing so has revealed and examined the "black-box" of decision-making. The study has attempted to bring insight into how these decisions progress, and what the factors are which influence these decisions. This study has also suggested that more research opportunity exists, within arts sponsorship and perhaps in the broader area of Corporate Community Involvement. 


\section{References}

Abratt, R., Clayton, B. C., \& Pitt, L. F. (1987). Corporate objectives in sports sponsorship. International Journal of Advertising, 6(4), 299-311.

Ackoff, R. L. (1981). On the use of models in corporate planning. Strategic Management Journal, 2(4), 353-359.

Amarach Consulting, \& Onside Sponsorship. (2006). National arts sponsorship survey. Dublin: Business2Arts.

Amato, L. H., \& Amato, C. H. (2007). The Effects of Firm Size and Industry on Corporate Giving. Journal of Business Ethics, 72(3), 229-241.

American Express. (2003). American Express launches national campaign to help reopen the Statue of Liberty; Pledges a minimum of $\$ 3$ million with cardmember support. Retrieved 17 August 2006, 2006, from http://home3.americanexpress.com/corp/pc/2003/statue_liberty_.asp

Amis, J., Slack, T., \& Berrett, T. (1999). Sport sponsorship as distinctive competence. European Journal of Marketing, 33(3/4), 250-272.

Anderson, E., Chu, W., \& Weitz, B. (1987). Industrial purchasing: An empirical exploration of the buyclass framework. Journal of Marketing, 51(3), 71-86.

Argus, K., Farrelly, F., \& Quester, P. G. (2004). New insights for managing sport sponsorship: Applying the resource based view of the firm. Paper presented at the Australia \& New Zealand Marketing Academy Conference, Wellington, New Zealand.

Arts Council England. (2010). Annual Review 2010. London: Arts Council England.

Atkinson, L., \& Galaskiewicz, J. (1988). Stock ownership and company contributions to charity. Administrative Science Quarterly, 33(1), 82-100.

Australian Government Department of Family and Community Services. (2005). Giving Australia: Research on philanthropy in Australia, Survey of Business: The Prime Minister's Community Business Partnership.

Barone, M., Norman, A., \& Miyazaki, A. (2007). Consumer response to retailer use of cause-related marketing: Is more fit better? Journal of Retailing, 83(4), 437-445.

Bartkus, B. R., Morris, S. A., \& Seifert, B. (2002). Governance and corporate philanthropy: Restraining Robin Hood? Business and Society, 41(3), 319-344.

Becker-Olsen, K. L., \& Hill, R. P. (2006). The impact of sponsor fit on brand equity: The case of nonprofit service providers. Journal of Service Research : JSR, 9(1), 7383.

Bennett, R. (1998). Corporate philanthropy in France, Germany and the U.K.: International comparisons of commercial orientation towards company giving in European nations. International Marketing Review, 15(6), 458-475.

Bergen, M., Dutta, S., \& Walker, O. C., Jr. (1992). Agency Relationships in Marketing: A Review of the Implications and Applications of Agency and Related Theories. Journal of Marketing, 56(3), 1-24.

Bloom, P. N., Hoeffler, S., Keller, K. L., \& Meza, C. E. B. (2006). How Social-Cause Marketing Affects Consumer Perceptions. MIT Sloan Management Review, 47(2), 49-55.

Boatsman, J. R., \& Gupta, S. (1996). Taxes and corporate charity: Empirical evidence from microlevel panel data. National Tax Journal (1986-1998), 49(2), 193-213.

Brammer, S., \& Millington, A. (2004a). The development of corporate charitable contributions in the UK: A stakeholder analysis. The Journal of Management Studies, 41(8), 1411-1434. 
Brammer, S., \& Millington, A. (2004b). Stakeholder pressure, organizational size, and the allocation of departmental responsibility for the management of corporate charitable giving. Business and Society, 43(3), 268-295.

Brammer, S., Millington, A., \& Pavelin, S. (2006). Is philanthropy strategic? An analysis of the management of charitable giving in large UK companies. Business Ethics, 15(3), 234-245.

Bronn, P. S., \& Vrioni, A. B. (2001). Corporate social responsibility and cause-related marketing: an overview. International Journal of Advertising, 20, 207-222.

Brown, S. (2005). Science, serendipity and the contemporary marketing condition. European Journal of Marketing, 39(11/12), 1229-1234.

Bruch, H., \& Walter, F. (2005). The keys to rethinking corporate philanthropy. MIT Sloan Management Review, 47(1), 49-55.

Bunn, M. D. (1993). Taxonomy of buying decision approaches. Journal of Marketing, 57(1), 38-56.

Bunn, M. D. (1994). Key aspects of organizational buying: Conceptualization and measurement. Academy of Marketing Science. Journal, 22(2), 160-169.

Burlingame, D. (2001). Editorial: Corporate giving. International Journal of Nonprofit and Voluntary Sector Marketing, 6(1), 4-5.

Burlingame, D. F., \& Frishkoff, P. A. (1996). How does firm size affect corporate philanthropy? In D. F. Burlingame \& D. R. Young (Eds.), Corporate Philanthropy at the Crossroads (pp. 86-104). Indiana: Indiana University Press.

Burton, R., Quester, P. G., \& Farrelly, F. J. (1998a). Let the games begin. Marketing Management, 7(1), 31.

Burton, R., Quester, P. G., \& Farrelly, F. J. (1998b). Organizational power games. Marketing Management, 7(1), 27-36.

Cain, J. E., \& Cain, A. S. (1985). An economic analysis of accounting decision variables used to determine the nature of corporate giving. Quarterly Journal of Business and Economics, 24(4), 15-28.

Campbell, D., Moore, G., \& Metzger, M. (2002). Corporate philanthropy in the U.K. 1985-2000: Some empirical findings. Journal of Business Ethics, 39(1/2), 29-41.

Campbell, D., \& Slack, R. (2007). The strategic use of corporate philanthropy: building societies and demutualisation defences. Business Ethics, 16(4), 326-343.

Carroll, A. B. (1991). The pyramid of corporate social responsibility: Toward the moral management of organizational stakeholders. Business Horizons, 34(4), 39-48.

Carroll, R., \& Joulfaian, D. (2005). Taxes and corporate giving to charity. Public Finance Review, 33(3), 300-317.

Chen, J. C., Patten, D. M., \& Roberts, R. W. (2008). Corporate Charitable Contributions: A Corporate Social Performance or Legitimacy Strategy? Journal of Business Ethics, 82(1), 131-144.

Chicago Symphony Orchestra. (2009). 2009 Annual Report. Chicago: Chicago Symphony Orchestra.

Choi, J., \& Wang, H. (2007). The Promise of a Managerial Values Approach to Corporate Philanthropy. Journal of Business Ethics, 75(4), 345-359.

Clark, J. M., Cornwell, T. B., \& Pruitt, S. W. (2002). Corporate stadium sponsorships, signaling theory, agency conflicts, and shareholder wealth. Journal of Advertising Research, 42(6), 16-32.

Clarkson, M. B. E. (1995). A stakeholder framework for analyzing and evaluating corporate social performance. Academy of Management. The Academy of Management Review, 20(1), 92-117.

Collins, M. (1993). Global corporate philanthropy - Marketing beyond the call of duty? European Journal of Marketing, 27(2), 46-58.

Contact Energy Limited. (2006). Annual Report 2005. Wellington. 
Cornwell, B., \& Maignan, I. (1998). An international review of sponsorship research. Journal of Advertising, 27(1), 1-21.

Cornwell, T. B., Pruitt, S. W., \& Clark, J. M. (2005). The relationship between majorleague sports' official sponsorship announcements and the stock prices of sponsoring firms. Academy of Marketing Science. Journal, 33(4), 401-412.

Cornwell, T. B., Roy, D. P., \& Steinard II, A. (2001). Exploring managers' perceptions of the impact of sponsorship on brand equity. Journal of Advertising, 30(2), 41-51.

Cornwell, T. B., Weeks, C. S., \& Roy, D. P. (2005). Sponsorship-linked marketing: Opening the black box. Journal of Advertising, 34(2), 21-42.

Cowan, D. (2005). An evidence based case for arts sponsorship. London: Arts and Business.

Creswell, J. W. (1998). Qualitative inquiry and research design. Thousand Oaks: Sage Publications, Inc.

Creswell, J. W. (2003). Research design: Qualitative, auantitative, and mixed methods approaches (2nd ed.). Thousand Oaks: Sage Publications.

Crowley, M. G. (1991). Prioritising the sponsorship audience. European Journal of Marketing, 25(11), 11-21.

Dacin, P. A., \& Brown, T. J. (1997). The company and the product: Corporate associations and consumer product responses. Journal of Marketing, 61(1), 6884.

Daellenbach, K., Davies, J., \& Ashill, N. J. (2006). Understanding sponsorship and sponsorship relationships-multiple frames and multiple perspectives. International Journal of Nonprofit and Voluntary Sector Marketing, 11(1), 73-87.

Denzin, N. K., \& Lincoln, Y. S. (2005). The handbook of qualitative research (3rd ed.). Thousand Oaks: Sage Publications.

Dholakia, R. R., Johnson, J. L., Della Bitta, A. J., \& Dholakia, N. (1993). Decisionmaking time in organizational buying behavior: An investigation of its antecedents. Academy of Marketing Science. Journal, 21(4), 281-292.

Dolphin, R. R. (2003). Sponsorship: perspectives on its strategic role. Corporate Communications, 8(3), 173-186.

Drumwright, M. E. (1994). Socially responsible organizational buying - Environmental concern as a noneconomic buying criterion. Journal of Marketing, 58(3), 1-19.

Dunn, P. (2004). Professional corporate donation programs in Canada: An exploratory study. Nonprofit and Voluntary Sector Quarterly, 33(2), 334-345.

Dwyer, F. R., \& Tanner, J. F. (2006). Business Marketing: connecting strategy, relationships, and learning (3rd ed. ed.). New York: McGraw-Hill Irwin.

Eisenhardt, K. M. (1989). Building theories from case study research. Academy of Management. The Academy of Management Review, 14(4), 532-550.

Eisenhardt, K. M., \& Graebner, M. E. (2007). Theory building from case studies: Opportunities and challenges. Academy of Management Journal, 50(1), 25- 32.

Eisenhardt, K. M., \& Zbaracki, M. J. (1992). Strategic decision making. Strategic Management Journal, 13, 17-37.

Elicker, P. H. (1978). The business and arts partnership. Vital Speeches of the Day, 45(5), 145-149.

Elms, H. (2006). Corporate (and stakeholder) responsibility in Central and Eastern Europe. International Journal of Emerging Markets, 1(3), 203-211.

Erdogan, B. Z., \& Kitchen, P. J. (1998). Managerial mindsets and the symbiotic relationship between sponsorship and advertising. Marketing Intelligence and Planning, 16(6), 369-374.

Farrelly, F., \& Quester, P. (2003a). The effects of market orientation on trust and commitment: The case of the sponsorship business-to-business relationship. European Journal of Marketing, 37(3/4), 530-553. 
Farrelly, F., \& Quester, P. (2005a). Investigating large-scale sponsorship relationships as co-marketing alliances. Business Horizons, 48(1), 55-62.

Farrelly, F., Quester, P., \& Mavondo, F. (2003b). Collaborative communication in sponsor relations. Corporate Communications, 8(2), 128-138.

Farrelly, F., Quester, P., \& Smolianov, P. (1998). The Australian Cricket Board (ACB): Mapping corporate relations. Corporate Communications, 3(4), 150-155.

Farrelly, F., \& Quester, P. G. (1997, June, 1997). Sports and arts sponsors: Investigating the similarities and differences in management practices. Paper presented at the AMA Conference Proceedings, Dublin.

Farrelly, F., \& Quester, P. G. (2003c). What drives renewal of sponsorship principal/agent relationships? Journal of Advertising Research, 43(4), 353-360.

Farrelly, F. J., \& Quester, P. G. (2005b). Examining important relationship quality constructs of the focal sponsorship exchange. Industrial Marketing Management, 34(3), 211-219.

Farrelly, F. J., Quester, P. G., \& Burton, R. (1997). Integrating sports sponsorship into the corporate marketing function: an international comparative study. International Marketing Review, 14(3), 170-182.

Friedman, M. (1970, September 13, 1970). The social responsibility of business is to increase its profits. New York Times Magazine, September 13, 249-255.

Fry, L. W., Keim, G. D., \& Meiners, R. E. (1982). Corporate contributions: Altruistic or for-profit? Academy of Management Journal (pre-1986), 25(000001), 94-106.

Genest, C. M. (2005). Cultures, organizations and philanthropy. Corporate Communications, 10(4), 315-327.

Ghingold, M., \& Wilson, D. T. (1998). Buying center research and business marketing practice: meeting the challenge of dynamic marketing. The Journal of Business \& Industrial Marketing, 13(2), 96-108.

Gilly, M. C., \& Wolfinbarger, M. (1998). Advertising's internal audience. Journal Of Marketing, 62(1), 69-88.

Global Reporting Initiative. (2008). Global Reporting Initiative. Retrieved 28 September, 2008, from http://www.globalreporting.org/AboutGRI/WhatWeDo/

Godfrey, P. C. (2005). The relationship between corporate philanthropy and shareholder wealth: A risk management perspective. Academy of Management. The Academy of Management Review, 30(4), 777-798.

Godfrey, P. C. (2006). A reply to Bright: Virtousness is necessary for genuineness in corporate philanthropy. Academy of Management. The Academy of Management Review, 31(3), 754-756.

Goncebate, R., \& Hajduk, M. (1996). Business support to the arts and culture in Argentina. In R. Martorella (Ed.), Art and Business: An International Perspective on Sponsorship. Westport, CT: Praeger.

Graebner, M. E. (2004). Momentum and serendipity: how acquired leaders create value in the integration of technology firms. Strategic Management Journal, 25(8/9), 751-777.

Grimes, E., \& Meenaghan, T. (1998). Focusing commercial sponsorship on the internal corporate audience. International Journal of Advertising, 17(1), 51-74.

Gupta, S., \& Pirsch, J. (2006a). The company-cause-customer fit decision in causerelated marketing. The Journal of Consumer Marketing, 23(6), 314-326.

Gupta, S., \& Pirsch, J. (2006b). A taxonomy of cause-related marketing research: Current findings and future research directions. Journal of Nonprofit \& Public Sector Marketing, 15(1,2), 25-43.

Hambrick, D. C., \& Mason, P. A. (1984). Upper Echelons: The organization as a reflection of its top managers. Academy of Management. The Academy of Management Review (pre-1986), 9(000002), 193-206. 
Higgins, K. T. (2002). Marketing with a conscience. Marketing Management, 11(4), 1216.

Hill, R. P., Stephens, D., \& Smith, I. (2003). Corporate social responsibility: An examination of individual firm behavior. Business and Society Review, 108(3), 339-364.

Hitt, M. A., Beamish, P. W., Jackson, S. E., \& Mathieu, J. E. (2007). Building theoretical and empirical bridges across levels: Multilevel research in management. Academy of Management Journal, 50(6), 1385-1399.

Hitters, E. (1996). Art support as corporate responsibility in the postindustrial city of Rotterdam, The Netherlands. In R. Martorella (Ed.), Art and Business: An International Perspective on Sponsorship (pp. 159-168). Westport, CT: Praeger.

Hodgkinson, G., Sadler-Smith, E., Burke, L., Claxton, G., \& Sparrow, P. (2009). Intuition in Organizations: Implications for Strategic Management. Long Range Planning, 42(3), 277-297.

Hoek, J. A., Gendall, P. J., \& West, R. D. (1990). The role of sponsorship in marketing planning selected New Zealand companies. New Zealand Journal of Business(12), 87-95.

Holmes, S., \& Smart, P. (2009). Exploring open innovation practice in firm-nonprofit engagements: a corporate social responsibility perspective. $R \& D$ Management, 39(4), 394-409.

Howell, J. M., \& Higgins, C. A. (1990). Champions of Technological Innovation. Administrative Science Quarterly, 35(2), 317-341.

Jennings, R. G., \& Plank, R. E. (1995). When the purchasing agent is a committee Implications for industrial marketing. Industrial Marketing Management, 24(5), 411-419.

Jocumsen, G. (2004). How do small business managers make strategic marketing decisions? A model of process. European Journal of Marketing, 38(5/6), 659674.

Johnson, G., \& Scholes, K. (1999). Exploring Corporate Strategy (6 ed.). Essex: Pearson Education Limited.

Johnston, W. J., \& Lewin, J. E. (1996). Organizational buying behavior: Toward an integrative framework. Journal of Business Research, 35(1), 1-15.

Johnston, W. J., \& Lewin, J. E. (1997). Advances in industrial marketing theory and research from the Journal of Business and Industrial Marketing. Journal of Business Research, 38(3), 199-209.

Jones, G. R. (2007). Senior executives' personal values: the role personal values play in decisions regarding corporate philanthropy--a theoretical model. International Journal of Management \& Decision Making, 8(2-4), 343-355.

Kelly, A. (2001). Creative partnerships: Fundraising for short film projects. International Journal of Nonprofit and Voluntary Sector Marketing, 6(1), 9-20.

Kenichi, K. (1996). Art and Cultural Policy in Japan. In R. Martorella (Ed.), Art and Business: An International Perspective on Sponsorship (pp. 195-201). Westport, CT: Praeger.

Kenyon. (1996). Corporate involvement in the arts and reproduction of power in Canada. In R. Martorella (Ed.), Arts and Business: An International Perspective on Sponsorship. Westport, CT: Praeger.

Kirchberg, V. (2004). Structures of corporate arts patronage between the world wars: A case study of the corporate leader P. S. du Pont. Journal of Arts Management, Law, and Society, 33(4), 263-280.

Knox, S., \& Maklan, S. (2005). Corporate social responsibility programmes and their impact on business decision-making. Paper presented at the Australia and New Zealand Marketing Academy, Perth, Australia. 
Kohli, A. (1989). Determinants of influence in organizational buying: A contingency approach. Journal of Marketing, 53(3), 50-65.

Kotler, P., \& Lee, N. (2005). Corporate social responsibility: Doing the most good for your company and your cause. New Jersey: John Wiley \& Sons, Inc.

Krapfel, R. E. (1985). An advocacy behavior model of organizational buyers vendor choice. Journal Of Marketing, 49(4), 51-59.

LaFrance, J., \& Lehmann, M. (2005). Corporate awakening - why (some) corporations embrace public-private partnerships. Business Strategy and the Environment, 14(4), 216-229.

Langley, A. (1999). Strategies for theorizing from process data. Academy of Management. The Academy of Management Review, 24(4), 691-710.

LeClair, M. S., \& Gordon, K. (2000). Corporate Support for Artistic and Cultural Activities: What Determines the Distribution of Corporate Giving? Journal of Cultural Economics, 24(3), 225-241.

Lewin, J. E., \& Donthu, N. (2005). The influence of purchase situation on buying center structure and involvement: a select meta-analysis of organizational buying behavior research. Journal Of Business Research, 58(10), 1381-1390.

Locke, E. A. (2007). The case for inductive theory building. Journal of Management, 33(6), 867-890.

London Benchmarking Group. (2008). LBG: Improving the measurement and management of community involvement. Retrieved 7 November, 2008, from http://www.lbg-online.net

Mack, R. W. (1999). Event sponsorship: An exploratory study of small business bbjectives, practises, and perceptions. Journal of Small Business Management, 37(3), 25-30.

Madden, K., Scaife, W., \& Crissman, K. (2006). How and why small to medium size enterprises (SMEs) engage with their communities: an Australian study. International Journal of Nonprofit and Voluntary Sector Marketing, 11(1), 49-60.

Mainfreight. (2004). Annual Report, 2004. Mainfreight.

March, J. G. (1994). A primer on decision making: How decisions happen. New York, New York: The Free Press.

Margolis, J. D., \& Walsh, J. P. (2003). Misery loves companies: Rethinking social initiatives by business. Administrative Science Quarterly, 48(2), 268-305.

McAlister, D. T., \& Ferrell, L. (2002). The role of strategic philanthropy in marketing strategy. European Journal of Marketing, 36(5/6), 689-743.

McCracken, G. (1988). The long interview. Newbury Park: Sage Publications.

McElroy, K. M., \& Siegfried, J. J. (1985). The effect of firm size on corporate philanthropy. The Quarterly Review of Economics and Business., 25(2), 18-26.

McElroy, K. M., \& Siegfried, J. J. (1986). The community influence on corporate contributions. Public Finance Quarterly, 14(4), 394-414.

McNicholas, B. (2004). Arts, culture and business: A relationship transformation, a nascent field. International Journal of Arts Management, 7(1), 57-69.

Meenaghan, J., \& Flood, P. (1983). Commercial sponsorship: The misunderstood corporate art. Dublin: Corporate Image.

Meenaghan, J. A. (1983). Commercial sponsorship. European Journal of Marketing, 17(7), 1-73.

Meenaghan, T. (1991a). The role of sponsorship in the marketing communications mix. International Journal of Advertising, 10(1), 35-47.

Meenaghan, T. (1991b). Sponsorship: Legitimising the medium. European Journal of Marketing, 25(11), 5-10.

Meenaghan, T. (1998). Current developments \& future directions in sponsorship. International Journal of Advertising, 17(1), 3-28. 
Meenaghan, T. (2002). From sponsorship to marketing partnership: The Guinness sponsorship of the GAA All-Ireland Hurling Championship. Irish Marketing Review, 15(1), 3-23.

Meenaghan, T., \& Shipley, D. (1999). Media effect in commercial sponsorship. European Journal of Marketing, 33(3/4), 328-347.

Mescon, T. S., \& Tilson, D. J. (1987). Corporate philanthropy: A strategic approach to the bottom-Line. California Management Review, 29(2), 49-61.

Miles, M. B., \& Huberman, A. M. (1994). Qualitative data analysis: An expanded sourcebook (2nd ed.). Thousand Oaks: Sage Publications.

Moir, L., \& Taffler, R. (2004). Does corporate philanthropy exist?: business giving to the arts in the U.K. Journal of Business Ethics, 54(2), 149-161.

Moorman, C., \& Rust, R. T. (1999). The role of marketing. Journal of Marketing, 63, 180.

Motion, J., Leitch, S., \& Brodie, R. J. (2003). Equity in corporate co-branding: The case of Adidas and the All Blacks. European Journal of Marketing, 37(7/8), 10801094.

Nan, X., \& Heo, K. (2007). Consumer responses to corporate social responsibility (CSR) initiatives: Examining the role of brand-cause fit in cause-related marketing. Journal of Advertising, 36(2), 63-74.

Narayandas, D., \& Rangan, V. K. (2004). Building and sustaining buyer-seller relationships in mature industrial markets. Journal Of Marketing, 68(3), 63-77.

Navarro, P. (1988). Why Do Corporations Give to Charity? The Journal of Business, 61(1), 65-93.

Navarro, P. K. (1986). A Theoretical And Empirical Investigation Of Corporate Charity Motives. Unpublished Ph.D., Harvard University, Massachusetts.

Neuman, W. L. (2006). Social research methods: Qualitative and quantitative approaches (6th ed.). Boston: Pearson Education Inc.

New Zealand Government. (1986). State-owned enterprises act, 1986. Retrieved 12 March, 2009. from http://www.legislation.govt.nz/act/public/1986/0124/latest/viewpdf.aspx.

New Zealand International Festival of the Arts. (2004). Profile (Brochure). Wellington: New Zealand International Festival of the Arts.

O'Hagan, J., \& Harvey, D. (2000). Why do companies sponsor arts events? Some evidence and a proposed classification. Journal of Cultural Economics, 24(3), 205-224.

Olkkonen, R. (2001). Case study: The network approach to international sport sponsorship arrangement. The Journal of Business \& Industrial Marketing, 16(4), 309-329.

Olkkonen, R. (2002). On the same wavelength? A study of the dynamics of sponsorship relationships between firms and cultural organizations. Turku: $\mathrm{PhD}$, Turku School of Economics and Business Administration.

Olkkonen, R., Tikkanen, H., \& Alajoutsijarvi, K. (2000). Sponsorship as relationships and networks: implications for research. Corporate Communications, 5(1), 12-18.

Orlitzky, M., Schmidt, F. L., \& Rynes, S. L. (2003). Corporate social and financial performance: A meta-analysis. Organization Studies, 24(3), 403-441.

Orlitzky, M., \& Swanson, D. L. (2002). Value attunement: Toward a theory of socially responsible executive decision-making. Australian Journal of Management, 27, 119-128.

Park, H., \& Stoel, L. (2005). A model of socially responsible buying/sourcing decisionmaking processes. International Journal of Retail \& Distribution Management, $33(4), 235-248$. 
Parker, K. (1991). Sponsorship: The research contribution. European Journal of Marketing, 25(11), 22-30.

Perry, C. (1998). A structured approach for presenting theses. Australasian Marketing Journal, 6(1), 63-85.

Petro-Canada. (2009). Community Partnerships. Retrieved 24 March, 2009, from http://www.petro-canada.ca/en/environsociety/4408.aspx

Pettigrew, A. M. (1975). The industrial purchasing decision as a political process. European Journal of Marketing, 9(1), 4-19.

Piperno, S. (1996). Sponsorship and patronage in Italy: Some regional cases. In R. Martorella (Ed.), Art and Business: An International Perspective on Sponsorship (pp. 131-149). Westport, CT: Praeger.

Porter, M. E., \& Kramer, M. R. (2002). The competitive advantage of corporate philanthropy. Harvard Business Review, 80(12), 56-68.

Richards, L. (2005). Handling qualitative data: A practical guide. London: Sage Publications.

Ricks, J. M., Jr. (2005). An assessment of strategic corporate philanthropy on perceptions of brand equity variables. The Journal of Consumer Marketing, 22(2/3), 121-134.

Robinson, D. (2006). Public relations comes of age. Business Horizons, 49(3), 247-256.

Robinson, D., \& Hanley, P. (2005). Funding New Zealand 2002: Resource flows to the community non-profit sector in New Zealand. A Report prepared for Philanthropy New Zealand. Wellington: Social and Civic Policy Institute,.

Robinson, P. J., Faris, C. W., \& Wind, Y. (1967). Industrial buying and creative marketintg. Boston: Allyn \& Bacon.

Rodgers, W., \& Gago, S. (2001). Cultural and ethical effects on managerial decisions: Examined in a throughput model. Journal of Business Ethics, 31(4), 355-363.

Royal New Zealand Ballet. (2004). Royal New Zealand Ballet 2004 Annual Report. Wellington: Royal New Zealand Ballet.

Royal Shakespeare Company. (2009). Annual Report and Accounts 2008/2009. Stratfordupon-Avon: Royal Shakespeare Company.

Ryan, A., \& Fahy, J. (2003). A relationship marketing perspective on the sponsorship of the arts in Ireland: A Galway Arts Festival-Nortel Networks case study. Irish Marketing Review, 16(1), 31-42.

Saiia, D. H., Carroll, A. B., \& Buchholtz, A. K. (2003). Philanthropy as strategy when corporate charity "begins at home". Business and Society, 42(2), 169-201.

Sanders, J., O'Brien, M., Tennant, M., Sokolowski, S. W., \& Salamon, L. M. (2008). The New Zealand non-profit sector in comparative perspective. Wellington: Office for the Community and Voluntary Sector, Tari mō te Rāngai a-Hapori, ā-Tūao.

Schuler, D. A., \& Cording, M. (2006). A corporate social performance - corporate financial performance behavioral model for consumers. Academy of Management. The Academy of Management Review, 31(3), 540-558.

Seguin, B., Teed, K., \& O'Reilly, N. J. (2005). National sports organisations and sponsorship: an identification of best practices. International Journal of Sport Management and Marketing, 1(1/2), 69-92.

Seifert, B., Morris, S. A., \& Bartkus, B. R. (2003). Comparing big givers and small givers: Financial correlates of corporate philanthropy. Journal of Business Ethics, 45(3), 195-211.

Seifert, B., Morris, S. A., \& Bartkus, B. R. (2004). Having, giving, and getting: Slack resources, corporate philanthropy, and firm financial performance. Business and Society, 43(2), 135-161.

Seitanidi, M. M., \& Ryan, A. (2007). A critical review of forms of corporate community involvement: from philanthropy to partnerships. International Journal of Nonprofit and Voluntary Sector Marketing, 12(3), 247-266. 
Shaw, B., \& Post, F. R. (1993). A moral basis for corporate philanthropy. Journal of Business Ethics, 12(10), 745-751.

Sheth, J. N. (1973). A model of industrial buyer behavior. Journal of Marketing, 37(4), 50-56.

Siggelkow, N. (2007). Persuasion with case studies. Academy of Management Journal, 50(1), 20-24.

Silk, A. J., \& Kalwani, M. U. (1982). Measuring influence in organizational purchase decisions. JMR, Journal of Marketing Research (pre-1986), 19(000002), 165181.

Simmons, C. J., \& Becker-Olsen, K. L. (2006). Achieving marketing objectives through social sponsorship. Journal of Marketing, 70(4), 154-169.

Smith, C. (1994). The new corporate philanthropy. Harvard Business Review, 72(3), 105-116.

Smith, D., \& Taylor, R. (1985). Organisational Decision Making and Industrial Marketing. European Journal of Marketing, 19(7), 56-61.

Smith, G. (2004). Brand image transfer through sponsorship: A consumer learning perspective. Journal of Marketing Management, 20(3,4), 457-474.

Smith, H. W. (1998). The heroic enterprise: Business and the common good / looking good \& doing good: Corporate philanthropy and corporate power. Nonprofit and Voluntary Sector Quarterly, 27(2), 243-259.

Speed, R., \& Thompson, P. (2000). Determinants of sports sponsorship response. Journal of the Academy of Marketing Science, 28(2), 226-238.

Stake, R. E. (1995). The art of case study research. Thousand Oaks: Sage Publications, Inc.

Stroup, M. A., Neubert, R. L., \& Anderson, J. W., Jr. (1987). Doing good doing better: Two views of social responsibility. Business Horizons, 30(2), 22-25.

Suchman, M. C. (1995). Managing legitimacy: Strategic and institutional approaches. Academy of Management. The Academy of Management Review, 20(3), 571-610.

Sustainable Business Network. (2008). Sustainable Business Network. Retrieved 6 November, 2008, from http://www.sustainable.org.nz/cms/index.php

Swanson, D. L. (1999). Toward an integrative theory of business and society: A research strategy for corporate social performance. Academy of Management. The Academy of Management Review, 24(3), 506-521.

Telecom New Zealand. (2005). Annual Report. Wellington.

Thjømøe, H. M., Olson, E. L., \& Brønn, P. S. (2002). Decision-making processes surrounding sponsorship activities. Journal of Advertising Research, 42(6), 6-15.

Trewin, D., \& Pink, B. (2006). Australian and New Zealand Standard Industrial Classification (ANZSIC) 2006: Australian Bureau of Statistics / Statistics New Zealand.

Tripodi, J. A. (2001). Sponsorship - A confirmed weapon in the promotional armoury. International Journal of Sports Marketing and Sponsorship, March/April, 1-20.

Turgeon, N., \& Colbert, F. (1992). The decision process involved in corporate sponsorship for the arts. Journal of Cultural Economics, 11(1), 41-51.

Urriolagoitia, L., \& Planellas, M. (2007). Sponsorship relationships as strategic alliances: A life cycle model approach. Business Horizons, 50(2), 157-166.

Valor, C. (2006). Why do managers give? Applying pro-social behaviour theory to understanding firm giving. International review on public and non profit marketing, 3(1), 17-28.

Valor, C. (2007). A global strategic plan for corporate philanthropy. Corporate Communications, 12(3), 280-297. 
Varadarajan, P. R., \& Menon, A. (1988). Cause-related marketing: a coalignment of marketing strategy and corporate philanthropy. Journal of Marketing, 52(3), 5874.

Wang, J., \& Coffey, B. S. (1992). Board composition and corporate philanthropy. Journal of Business Ethics, 11(10), 771-778.

Webster, F. E., Jr. (1965). Modeling the industrial buying process. JMR, Journal of Marketing Research (pre-1986), 2(000004), 370-376.

Webster, F. E. J., \& Wind, Y. (1972a). A general model for understanding organizational buying behavior. Journal of Marketing, 36(2), 12-19.

Webster, F. E. J., \& Wind, Y. (1972b). Organizational buying behaviour. Englewood Cliffs, New Jersey: Prentice-Hall.

Webster, F. E. J., \& Wind, Y. (1996). A general model for understanding organizational buying behavior. Marketing Management, 4(4), 52-57.

Weick, K. E. (1989). Theory Construction as Disciplined Imagination. The Academy of Management Review, 14(4), 516-531.

Werbel, J. D., \& Carter, S. M. (2002). The CEO's influence on corporate foundation giving. Journal of Business Ethics, 40(1), 47-60.

Wind, Y., \& Robertson, T. S. (1982). The linking pin role in organizational buying centers. Journal of Business Research, 10(2), 169-184.

Wind, Y., \& Thomas, R. J. (1980). Conceptual and methodological issues in organisational buying behaviour. European Journal of Marketing, 14(5,6), 239263.

Witcher, B., Craigen, J. G., Culligan, D., \& Harvey, A. (1991). The links between objectives and function in organizational sponsorship. International Journal of Advertising, 10(1), 13-33.

Wood, D. J. (1991). Corporate social performance revisited. Academy of Management. The Academy of Management Review, 16(4), 691-717.

Wymer, W. (2006). Special issue on corporate philanthropy. International Journal of Nonprofit and Voluntary Sector Marketing, 11(1), 1-2.

Wymer, W. W., Jr., \& Samu, S. (2003). Dimensions of business and nonprofit collaborative relationships. Journal of Nonprofit \& Public Sector Marketing, 11(1), 3-22.

Yaziji, M. (2004). Turning gadflies into allies. Harvard Business Review, 82(2), 110-115.

Yin, R. K. (2003). Case study research: Design and methods (Vol. 5). Thousand Oaks: Sage Publications, Inc. 


\section{Appendices}

\section{Appendix 1: Decision-Making Approaches}

\begin{tabular}{lll} 
Source & Lit* & Decision Processes \\
\hline Webster (1965) & OBB & $\begin{array}{l}\text { 1. problem recognition, 2. assignment of buying authority \& responsibility, 3. search process, 4. } \\
\text { choice process }\end{array}$ \\
\hline $\begin{array}{l}\text { Robinson Faris \& } \\
\text { Wind (1967) }\end{array}$ & OBB & $\begin{array}{l}\text { 1. recognition of problem and general solution; 2. determination of characteristics and quality of } \\
\text { needed item, 3. description of characteristics \& quality, 4. search for potential sources, 5. acquire } \\
\text { and analyse proposals, 6. evaluation and selection, 7. selection of order routine, 8. performance } \\
\text { feedback and evaluation }\end{array}$ \\
\hline $\begin{array}{l}\text { Webster \& Wind } \\
\text { (1972, p. 31) }\end{array}$ & OBB & $\begin{array}{l}\text { 1. identification of need, 2. establishing objectives \& specifications, 3. identifying buying } \\
\text { alternatives, 4. selecting the supplier }\end{array}$ \\
\hline Sheth (1973) & OBB & $\begin{array}{l}\text { 1. initiation of the decision to buy, 2. gather information, 3. evaluate alternative suppliers, 4. } \\
\text { resolve conflict amoung decision-makers }\end{array}$ \\
\hline $\begin{array}{l}\text { Smith \& Taylor } \\
\text { (1985) }\end{array}$ & OBB & $\begin{array}{l}\text { Proposes 4 different strategies possible, depending on influences/certainly. Strategies would } \\
\text { define processes. Potential strategies are: computational (collect data and evaluate), compromise, } \\
\text { judgement, or inspirational. }\end{array}$ \\
\hline $\begin{array}{l}\text { Johnston \& Lewin } \\
\text { (1996) }\end{array}$ & OBB & $\begin{array}{l}\text { 1. need recognition, 2. determine characteristics, 3. establish specifications, 4. identify potential } \\
\text { sources, 5. request proposals, 6. evaluate proposals, 7. select supplier, 8. post-purchase evaluation } \\
\text { (uses Robinson, Faris \& Wind (1967) as a base) }\end{array}$ \\
\hline Bunn (1993) & OBB & $\begin{array}{l}\text { Process varies but will include a selection and permuation/combination of: 1. search for } \\
\text { information, 2. use of analysis techniques, 3. proactive focusing (considers objectives and long- } \\
\text { term needs), 4. procedural control (evaluation guided by policies and procedures) }\end{array}$ \\
\hline $\begin{array}{l}\text { Rogers \& Gago } \\
\text { (2001) }\end{array}$ & ethics pathways identified including perception, information, judgement and then decision. \\
\hline
\end{tabular}




\begin{tabular}{|c|c|c|}
\hline Ackoff (1978) & $\begin{array}{l}\text { Decn } \\
\text { mkg }\end{array}$ & $\begin{array}{l}\text { Problem solving system: } 1 \text { observation of problem object and enviroment which results in data; } \\
\text { 2. data is converted into information; } 3 \text {. inquiries are made of the information an dmore } \\
\text { information is generated until the problem-solver is satisfied or until the costs of more } \\
\text { information outweigh the benefits; } 4 \text {. a solution (decision) is selected; } 5 \text {. instruction is given } \\
\text { relative to the solution; } 6 \text {. decision is implemented, } 7 \text {. decision is monitored and controlled. }\end{array}$ \\
\hline $\begin{array}{l}\text { Ackoff (1978) cited in } \\
\text { Davies, Mabin \& } \\
\text { Balderstone (2005) }\end{array}$ & $\begin{array}{l}\text { Decn } \\
\text { mkg }\end{array}$ & $\begin{array}{l}\text { 1. identify the problem, } 2 \text {. define objectives, } 3 . \text { determine decision criteria, } 4 \text {. structure problems, } \\
\text { 5. develop alternatives, } 6 \text {. evaluate alternatives, } 7 \text {. recommend courses of action, } 8 \text {. implement } \\
\text { decisions. }\end{array}$ \\
\hline Ackoff (1981) & $\begin{array}{l}\text { Decn } \\
\text { mkg }\end{array}$ & $\begin{array}{l}\text { Three conditions satisfied in a problem: } 1 \text {. decision-maker(s) have choices, } 2 \text {. choices have } \\
\text { effects on decision-maker(s), and 3. the decision maker(s) may have doubts of alternatives. } \\
\text { Problems may be resolved, solved or dissolved (each process slightly different). }\end{array}$ \\
\hline March (1994) & $\begin{array}{l}\text { Decn } \\
\text { mkg }\end{array}$ & $\begin{array}{l}\text { Bounded Rationality - Logic of consequence: (Given problem) 1. discover alternatives; } 2 . \\
\text { consider expectations or consequences associated with likelihood of alternatives; } 3 \text {. preferences } \\
\text { of consequences to decision-maker considered; } 4 \text {. decision rule implemented. }\end{array}$ \\
\hline March (1994) & $\begin{array}{l}\text { Decn } \\
\text { mkg }\end{array}$ & $\begin{array}{l}\text { Bounded Rationality - Logic of appropriateness: (Given problem) 1. decision-maker asks what } \\
\text { kind of situation this is; } 2 \text {. decision-maker asks what kind of person they are and what kind of an } \\
\text { organisation this is? 3. decision-maker considers rules: "what does a person/organisation such as I } \\
\text { am and such as this organisation is, do in this situation? }\end{array}$ \\
\hline $\begin{array}{l}\text { Eisenhardt \& } \\
\text { Zbaracki (1992) }\end{array}$ & $\begin{array}{l}\text { Decn } \\
\text { mkg }\end{array}$ & $\begin{array}{l}\text { Bounded \& Unbounded Rationality: basic phases iterative and often repeat: 1. problem } \\
\text { identification, 2. development, and 3. selection. Process if "intendedly rational with cognitive } \\
\text { limits and loops" (p. 32) }\end{array}$ \\
\hline $\begin{array}{l}\text { Eisenhardt \& } \\
\text { Zbaracki (1992) }\end{array}$ & $\begin{array}{l}\text { Decn } \\
\text { mkg }\end{array}$ & $\begin{array}{l}\text { Politics and Power: "decisions follow the desires and subsequent choices of the most powerful } \\
\text { people" (p. 23). Central to the process is how conflict is resolved. Process is "confilct of interests } \\
\text { dominated by powerful coalitions" (pg. 32). }\end{array}$ \\
\hline $\begin{array}{l}\text { Eisenhardt \& } \\
\text { Zbaracki (1992) }\end{array}$ & $\begin{array}{l}\text { Decn } \\
\text { mkg }\end{array}$ & $\begin{array}{l}\text { Garbage Can Model: Process is "random collisions of problems, solutions, participants and } \\
\text { opportunities" (pg. 32). }\end{array}$ \\
\hline
\end{tabular}

* Literature area: $\quad$ Decn $m k g=$ Decision-making

$\mathrm{OBB}=$ Organisational Buying Behaviour 


\section{Appendix 2: Decision-making Influences}

\begin{tabular}{|c|c|c|}
\hline Source & Lit* $^{*}$ & Decision-making influences identified \\
\hline $\begin{array}{l}\text { Webster \& Wind } \\
(1972, \text { p. 31) }\end{array}$ & OBB & environmental, organisational, buying-centre related, individual characteristics \\
\hline Sheth (1973) & OBB & $\begin{array}{l}\text { psychological world of the decision-makers, joint vs. autonomous decisions, product-specific } \\
\text { factors, company-specific factors; situational factors, conflict resolution (in process as well) }\end{array}$ \\
\hline $\begin{array}{l}\text { Smith \& Taylor } \\
(1985)\end{array}$ & OBB & $\begin{array}{l}\text { Considers the extent of certainty regarding } 1 \text {. beliefs about causation and 2. preferences about } \\
\text { possible outcomes (borrows from Thompson and Tuden (1959) }\end{array}$ \\
\hline Bunn (1994) & OBB & purchase importance, task uncertainty, extensiveness of choice set, perceived buyer power. \\
\hline $\begin{array}{l}\text { Johnston \& Lewin } \\
\text { (1996) }\end{array}$ & OBB & $\begin{array}{l}\text { Purchase-related risk at core with 1. antecedents: environmental characteristicss, organisational } \\
\text { characteristics, purchase characteristics, buyer-seller relationships, communication networks. } 2 . \\
\text { outcomes: group characteristics, participant characteristics, seller characteristics, } \\
\text { conflict/negotiation, informational characteristics, decision rules, role stress, buyer-seller } \\
\text { relationships, communication networks. }\end{array}$ \\
\hline $\begin{array}{l}\text { Rodgers \& Gago } \\
(2001)\end{array}$ & ethics & $\begin{array}{l}\text { could consider the influences equivalent to the nodes on the throughouput model: perception, } \\
\text { judgement and information (leading to decision) }\end{array}$ \\
\hline March (1994) & $\begin{array}{l}\text { Decn } \\
\text { mkg }\end{array}$ & $\begin{array}{l}\text { Bounded Rationality - Logic of consequence: emphasis on the consequences the decision-makers } \\
\text { attribute to the various alternatives. }\end{array}$ \\
\hline March (1994) & $\begin{array}{l}\text { Decn } \\
\text { mkg }\end{array}$ & $\begin{array}{l}\text { Bounded Rationality - Logic of appropriateness: Emphasis is on the identity of the decision- } \\
\text { maker, the organisation, and the rules. How the decision-maker feels they should act within this } \\
\text { organisation, given this situation. }\end{array}$ \\
\hline $\begin{array}{l}\text { Eisenhardt \& } \\
\text { Zbaracki (1992) }\end{array}$ & $\begin{array}{l}\text { Decn } \\
\text { mkg }\end{array}$ & $\begin{array}{l}\text { individual cognitive limits, complexity of problem and conflict amoung decision-makers may } \\
\text { shape path }\end{array}$ \\
\hline Source & Lit* & ecision-making influences identified \\
\hline
\end{tabular}




\begin{tabular}{lll}
\hline $\begin{array}{l}\text { Eisenhardt \& } \\
\text { Zbaracki (1992) }\end{array}$ & $\begin{array}{l}\text { Decn } \\
\mathrm{mkg}\end{array}$ & individual's power and political tactics \\
\hline $\begin{array}{l}\text { Eisenhardt \& } \\
\text { Zbaracki (1992) }\end{array}$ & $\begin{array}{l}\text { Decn } \\
\mathrm{mkg}\end{array}$ & chance \\
\hline Ackoff (1981) & $\begin{array}{l}\text { Decn } \\
\mathrm{mkg}\end{array}$ & $\begin{array}{l}\text { Problem-solving: decision-maker(s), choices, perceived effect of choices, method of problem } \\
\text { solving. Problem resolution (to satisfice) relies heavily on past experience, common sense and } \\
\text { subjective judgements. Problem solving (to optimise) relies on scientific method and } \\
\text { measurement, and aspires to objectivity. Problem dissolution (to idealise) tries to change the } \\
\text { system so the problem does not come about. }\end{array}$ \\
\hline Ackoff (1981) & $\begin{array}{l}\text { Decn } \\
\mathrm{mkg}\end{array}$ & $\begin{array}{l}\text { Mess management / planning (not problem-solving): 3 Approaches. 1. Clinical has emphasis on } \\
\text { participation, but little structure. Relies on individuals and group dynamics. 2. Research } \\
\text { Approach takes the "mess" apart and treats parts independently. 3. Design Approach: formulate } \\
\text { mess (define situation and problem), ends planning (select objectives), means planning (ways to } \\
\text { fill the gap), resource planning (how much resource is required), design of implementation and } \\
\text { control (who does what, when and where) }\end{array}$ \\
\hline
\end{tabular}

* Literature area: $\quad$ Decn mkg = Decision-making

OBB = Organisational Buying Behaviour 
Appendix 3: Lateral and Vertical Involvement in CCI

\begin{tabular}{|c|c|c|c|c|}
\hline Source & $\begin{array}{l}\text { Focus of } \\
\text { CCI Area }\end{array}$ & $\begin{array}{l}\text { Region and } \\
\text { Genre }\end{array}$ & Involvement & Findings \\
\hline $\begin{array}{l}\text { (Burton et al., } \\
\text { 1998b) }\end{array}$ & sponsorship & $\begin{array}{l}\text { Australia and } \\
\text { USA / sports }\end{array}$ & Vertical & $\begin{array}{l}\text { As a corporation increases its level of experience with } \\
\text { sponsorship there is an increased likelihood that decisions will be } \\
\text { made by middle-managers. }\end{array}$ \\
\hline $\begin{array}{l}\text { (Farrelly \& } \\
\text { Quester, 1997) }\end{array}$ & sponsorship & $\begin{array}{l}\text { Australia / } \\
\text { sports and arts }\end{array}$ & Lateral & $\begin{array}{l}\text { Sport sponsorship decisions tend to be controlled by marketing, } \\
\text { while Arts sponsorship decisions tend to be controlled by Public } \\
\text { Relations. }\end{array}$ \\
\hline $\begin{array}{l}\text { (Witcher et al., } \\
\text { 1991) }\end{array}$ & sponsorship & $\begin{array}{l}\text { UK / sports, } \\
\text { arts \& } \\
\text { community }\end{array}$ & Lateral & $\begin{array}{l}\text { Sponsorship decisions tended to fall within Public Relations, } \\
\text { although the management of sport sponsorships was largely } \\
\text { handled by marketing, while other sponsorships remained in the } \\
\text { hands of Public Relations. }\end{array}$ \\
\hline $\begin{array}{l}\text { (Thjømøe et al., } \\
\text { 2002) }\end{array}$ & sponsorship & $\begin{array}{l}\text { Norway / all } \\
\text { sponsorship }\end{array}$ & Lateral & $\begin{array}{l}\text { Sponsorship decisions tended to be made by Marketing, although } \\
\text { "top local management" were the next most likely to manage } \\
\text { these relationships. }\end{array}$ \\
\hline $\begin{array}{l}\text { (Abratt et al., } \\
\text { 1987) }\end{array}$ & sponsorship & $\begin{array}{l}\text { South Africa / } \\
\text { sports }\end{array}$ & $\begin{array}{l}\text { Lateral and } \\
\text { Vertical }\end{array}$ & $\begin{array}{l}\text { The Marketing Manager was the most influential in making } \\
\text { sponsorship decisions, followed by the CEO; the administration of } \\
\text { the relationship was handled mainly by Marketing, with PR the } \\
\text { next most likely department. }\end{array}$ \\
\hline (Dunn, 2004) & philanthropy & $\begin{array}{l}\text { Canada / all } \\
\text { types }\end{array}$ & Vertical & $\begin{array}{l}\text { Found that professional donations programmes were positively } \\
\text { related to senior executives being involved in non-profit } \\
\text { organisations, indicating senior management influence. }\end{array}$ \\
\hline (Bennett, 1998) & Philanthropy & $\begin{array}{l}\text { UK, France \& } \\
\text { Germany }\end{array}$ & Vertical & $\begin{array}{l}\text { Although they find that the decisions are mainly with the Head } \\
\text { Office, they also find that decisions are conducted with a group or } \\
\text { committee, with influence from (in order of influence) the chief } \\
\text { executive, the sponsorship manager (if one is present) and } \\
\text { marketing/public relations managers. }\end{array}$ \\
\hline
\end{tabular}




\begin{tabular}{|c|c|c|c|c|}
\hline Source & $\begin{array}{l}\text { Focus of } \\
\text { CCI Area }\end{array}$ & $\begin{array}{l}\text { Region and } \\
\text { Genre }\end{array}$ & Involvement & Findings \\
\hline $\begin{array}{l}\text { (Wang \& Coffey, } \\
\text { 1992) }\end{array}$ & philanthropy & $\begin{array}{l}\text { USA / all } \\
\text { types }\end{array}$ & Vertical & $\begin{array}{l}\text { Found that as the percentage of inside managers on a corporate } \\
\text { board increased, corporate philanthropy also increased, indicating } \\
\text { executive influence. }\end{array}$ \\
\hline $\begin{array}{l}\text { (Brammer \& } \\
\text { Millington, } \\
\text { 2004b) }\end{array}$ & philanthropy & UK / all types & $\begin{array}{l}\text { Vertical and } \\
\text { Lateral }\end{array}$ & $\begin{array}{l}\text { Found that involvement varied with stakeholder pressure. As } \\
\text { external stakeholder pressure increases, corporate donations was } \\
\text { less likely to be managed by top level executives, and more likely } \\
\text { to be located with an externally-oriented department such as } \\
\text { marketing or PR; "organisations appear to allocate responsibility } \\
\text { for the management of donations to functional departments that } \\
\text { have the capabilities to cope with the particular stakeholder } \\
\text { pressures they face" (Brammer \& Millington, 2004b, p. 289). }\end{array}$ \\
\hline & & & & $\begin{array}{l}\text { Also found that larger organisations were likely to place } \\
\text { management of donations with a CSR department. }\end{array}$ \\
\hline $\begin{array}{l}\text { (Brammer et al., } \\
\text { 2006) }\end{array}$ & philanthropy & UK / all types & Vertical & $\begin{array}{l}\text { Found that CEO influence was ranked the most important } \\
\text { influence in the total level of donations. However, management of } \\
\text { donations was most frequently delegated to an externally-oriented } \\
\text { department, while budgetary control remains centralised. }\end{array}$ \\
\hline $\begin{array}{l}\text { (Werbel \& Carter, } \\
\text { 2002) }\end{array}$ & Philanthropy & USA / all & Vertical & $\begin{array}{l}\text { Found that the interests of the CEOs, as reflected by their } \\
\text { affiliations with non-profit organisations, was significantly } \\
\text { associated with giving - especially to the arts and international } \\
\text { groups; however the CEO influence decreased when the company } \\
\text { had institutionalised the practise of donations. }\end{array}$ \\
\hline $\begin{array}{l}\text { (LeClair \& } \\
\text { Gordon, 2000) }\end{array}$ & Philanthropy & USA / Arts & Vertical & $\begin{array}{l}\text { Found personal interests of CEO were noted as the second most } \\
\text { important motivation for giving to the arts, following promotion } \\
\text { of the firm. }\end{array}$ \\
\hline
\end{tabular}




\begin{tabular}{|c|c|c|c|c|}
\hline Source & $\begin{array}{l}\text { Focus of } \\
\text { CCI Area }\end{array}$ & $\begin{array}{l}\text { Region and } \\
\text { Genre }\end{array}$ & Involvement & Findings \\
\hline $\begin{array}{l}\text { (Bartkus et al., } \\
\text { 2002) }\end{array}$ & Philanthropy & USA / all & Vertical & $\begin{array}{l}\text { In a quantitative study of secondary data found no significant } \\
\text { relationship between board composition and philanthropy. }\end{array}$ \\
\hline $\begin{array}{l}\text { (Wang \& Coffey, } \\
\text { 1992) }\end{array}$ & Philanthropy & USA / all & Vertical & $\begin{array}{l}\text { Finds some support for a positive relationship between the } \% \text { of } \\
\text { inside managers on the board and increased corporate } \\
\text { philanthropy. }\end{array}$ \\
\hline (Navarro, 1988) & Philanthropy & USA / Arts & Vertical & $\begin{array}{l}\text { Did not find extensive support that contributions were used to } \\
\text { benefit management. }\end{array}$ \\
\hline
\end{tabular}


Appendix 4: Methodology in CCI

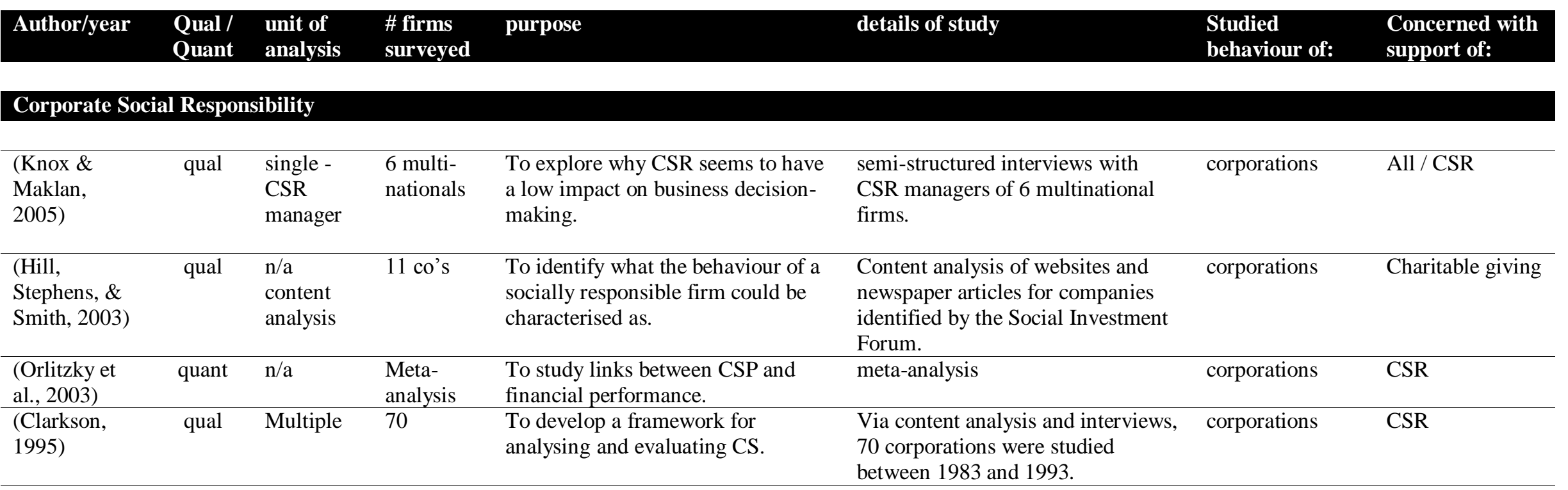

\begin{tabular}{|c|c|c|c|c|c|c|c|}
\hline \multicolumn{8}{|l|}{ Philanthropy } \\
\hline $\begin{array}{l}\text { (Amato \& } \\
\text { Amato, 2007) }\end{array}$ & quant & $\begin{array}{l}\text { Secondary } \\
\text { data }\end{array}$ & 719 & $\begin{array}{l}\text { To explore relationship between } \\
\text { company size and industry on } \\
\text { charitable giving. }\end{array}$ & $\begin{array}{l}\text { USA study included a data set of } 11 \\
\text { asset sizes and } 83 \text { ITS industry } \\
\text { classifications. }\end{array}$ & corporations & Charitable giving \\
\hline $\begin{array}{l}\text { (Campbell \& } \\
\text { Slack, 2007) }\end{array}$ & mixed & $\begin{array}{l}\text { Secondary } \\
\text { data/ } \\
\text { content }\end{array}$ & 31 & $\begin{array}{l}\text { To examine the motivations behind } \\
\text { corporate philanthropy, within the } \\
\text { building society sector of the UK. }\end{array}$ & $\begin{array}{l}31 \text { building societies studied with } \\
\text { data gathered mainly from annual } \\
\text { reports and media clippings. }\end{array}$ & corporations & Charitable giving \\
\hline $\begin{array}{l}\text { (Brammer et } \\
\text { al., 2006) }\end{array}$ & quant & $\begin{array}{l}\text { single } \\
\text { (don'ns } \\
\text { manager) }\end{array}$ & 200 & $\begin{array}{l}\text { To address how strategic is } \\
\text { philanthropy in the UK. }\end{array}$ & $\begin{array}{l}\text { Postal survey of } 200 \mathrm{UK} \\
\text { companies. Surveyed appropriate } \\
\text { senior manager. }\end{array}$ & corporations & Charitable giving \\
\hline $\begin{array}{l}\text { (Madden et } \\
\text { al., 2006) }\end{array}$ & qual & $\begin{array}{l}\text { Multiple: } \\
\text { SME } \\
\text { owners } \\
\text { and CE's }\end{array}$ & 52 & $\begin{array}{l}\text { Examine why SME's give, how they } \\
\text { give and obstacles perceived. }\end{array}$ & $\begin{array}{l}\text { Qualitative study of } 52 \text { SMEs in } \\
\text { Australia; } 5 \text { focus groups and } 15 \\
\text { interviews with owners and CE's. }\end{array}$ & corporations & Charitable giving \\
\hline
\end{tabular}




\begin{tabular}{|c|c|c|c|c|c|c|c|}
\hline Author/year & $\begin{array}{l}\text { Qual / } \\
\text { Quant }\end{array}$ & $\begin{array}{l}\text { unit of } \\
\text { analysis }\end{array}$ & $\begin{array}{l}\text { \# firms } \\
\text { surveyed }\end{array}$ & purpose & details of study & $\begin{array}{l}\text { Studied } \\
\text { behaviour of: }\end{array}$ & $\begin{array}{l}\text { Concerned with } \\
\text { support of: }\end{array}$ \\
\hline $\begin{array}{l}\text { (Carroll \& } \\
\text { Joulfaian, } \\
\text { 2005) }\end{array}$ & quant & $\begin{array}{l}\text { n/a } \\
\text { second'y }\end{array}$ & 26,634 & $\begin{array}{l}\text { To determine the effect of taxes on } \\
\text { corporate giving to charity. }\end{array}$ & $\begin{array}{l}\text { Analysed } 26,634 \text { corporate income } \\
\text { tax returns. }\end{array}$ & corporations & Charitable giving \\
\hline $\begin{array}{l}\text { (Genest, } \\
\text { 2005) }\end{array}$ & qual & $\begin{array}{l}\text { assumed } \\
\text { single }\end{array}$ & 5 & $\begin{array}{l}\text { "To examine the influence of } \\
\text { corporate culture on the practise of } \\
\text { corporate philanthropy in a global } \\
\text { environment" p. } 315\end{array}$ & $\begin{array}{l}\text { Content analysis of web sites and } \\
\text { annual reports for five companies. } \\
\text { Supplemented by interviews. }\end{array}$ & corporations & Charitable giving \\
\hline $\begin{array}{l}\text { (Brammer \& } \\
\text { Millington, } \\
\text { 2004b) }\end{array}$ & quant & $\begin{array}{l}\text { single } \\
\text { (don'ns } \\
\text { manager) }\end{array}$ & 180 & $\begin{array}{l}\text { To consider stakeholder pressures } \\
\text { on a firm, and how these pressures } \\
\text { might influence corporate donation } \\
\text { management. }\end{array}$ & $\begin{array}{l}\text { Survey supplemented by FTSE } \\
\text { data. }\end{array}$ & corporations & Charitable giving \\
\hline (Dunn, 2004) & quant & $\begin{array}{l}\text { single - } \\
\text { senior } \\
\text { execs }\end{array}$ & 209 & $\begin{array}{l}\text { To study the antecedents } \\
\text { contributing to a firm developing a } \\
\text { professional donation program, and } \\
\text { the relationship between a donation } \\
\text { program and the level of donations. }\end{array}$ & $\begin{array}{l}\text { Surveyed } 299 \text { companies. Matched } \\
\text { these with ownership and financial } \\
\text { data. }\end{array}$ & corporations & Charitable giving \\
\hline $\begin{array}{l}\text { (Seifert et al., } \\
\text { 2004) }\end{array}$ & quant & $\begin{array}{l}\mathrm{n} / \mathrm{a} \\
\text { second'y }\end{array}$ & 157 & $\begin{array}{l}\text { To study the relationship between } \\
\text { slack resource availability and } \\
\text { corporate philanthropy. }\end{array}$ & $\begin{array}{l}\text { Data from } 157 \text { firms taken from } \\
\text { Fortune } 1000 \text { (1998), and data in } \\
\text { Corporate Giving Directory. }\end{array}$ & corporations & Charitable giving \\
\hline $\begin{array}{l}\text { (Saiia et al., } \\
\text { 2003) }\end{array}$ & quant & $\begin{array}{l}\text { Single: } \\
\text { corp } \\
\text { giving } \\
\text { mangr }\end{array}$ & 125 & $\begin{array}{l}\text { to examine "whether and how } \\
\text { corporate philanthropy is becoming } \\
\text { more strategic" p. } 170\end{array}$ & $\begin{array}{l}\text { Surveyed } 125 \text { corporate giving } \\
\text { managers in the USA. }\end{array}$ & corporations & Charitable giving \\
\hline $\begin{array}{l}\text { (Bartkus et } \\
\text { al., 2002) }\end{array}$ & quant & $\begin{array}{l}\mathrm{n} / \mathrm{a} \\
\text { second'y }\end{array}$ & 66 & $\begin{array}{l}\text { To study the relationship between } \\
\text { corporate governance and corporate } \\
\text { philanthropy, comparing large and } \\
\text { small givers. }\end{array}$ & $\begin{array}{l}\text { Data from the Directory of } \\
\text { Corporate Giving for matched pairs } \\
\text { of firms in similar industry.. }\end{array}$ & corporations & Charitable giving \\
\hline $\begin{array}{l}\text { (Campbell et } \\
\text { al., 2002) }\end{array}$ & quant & $\begin{array}{l}\mathrm{n} / \mathrm{a} \\
\text { second'y }\end{array}$ & 598 & $\begin{array}{l}\text { To describe the corporate giving } \\
\text { trends in the UK. }\end{array}$ & $\begin{array}{l}\text { Analysis of FTSE index from } 1985 \\
-2000 .\end{array}$ & corporations & Charitable giving \\
\hline $\begin{array}{l}\text { (Werbel \& } \\
\text { Carter, 2002) }\end{array}$ & quant & $\begin{array}{l}\text { n/a } \\
\text { second'y }\end{array}$ & 163 & $\begin{array}{l}\text { To examine whether personal } \\
\text { interests of CEO's affect corporate } \\
\text { giving of corporate foundations. }\end{array}$ & $\begin{array}{l}\text { Data from secondary sources: } \\
\text { corporate foundation profiles and } \\
\text { Who's Who. }\end{array}$ & corporations & Charitable giving \\
\hline $\begin{array}{l}\text { (LeClair \& } \\
\text { Gordon, } \\
\text { 2000) }\end{array}$ & quant & $\begin{array}{l}\text { n/a } \\
\text { second'y }\end{array}$ & $\mathrm{n} / \mathrm{a}$ & $\begin{array}{l}\text { To study antecedents of corporate } \\
\text { giving levels for arts and cultural } \\
\text { activities. }\end{array}$ & $\begin{array}{l}\text { Data from Conference Board's } \\
\text { annual survey }\end{array}$ & corporations & arts \\
\hline
\end{tabular}




\begin{tabular}{|c|c|c|c|c|c|c|c|}
\hline Author/year & $\begin{array}{l}\text { Qual / } \\
\text { Quant }\end{array}$ & $\begin{array}{l}\text { unit of } \\
\text { analysis }\end{array}$ & $\begin{array}{l}\text { \# firms } \\
\text { surveyed }\end{array}$ & purpose & details of study & $\begin{array}{l}\text { Studied } \\
\text { behaviour of: }\end{array}$ & $\begin{array}{l}\text { Concerned with } \\
\text { support of: }\end{array}$ \\
\hline $\begin{array}{l}\text { (Bennett, } \\
\text { 1998) }\end{array}$ & quant & single & 281 & $\begin{array}{l}\text { To compare the approaches to } \\
\text { corporate philanthropy in UK, } \\
\text { France and Germany. }\end{array}$ & $\begin{array}{l}\text { Questionnaires from } 281 \\
\text { companies. }\end{array}$ & Corporations & Charitable giving \\
\hline $\begin{array}{l}\text { (Boatsman \& } \\
\text { Gupta, 1996) }\end{array}$ & quant & $\begin{array}{l}\mathrm{n} / \mathrm{a} \\
\text { second'y }\end{array}$ & & $\begin{array}{l}\text { To study philanthropic motivations } \\
\text { by considering the relationship } \\
\text { between giving and tax rates. }\end{array}$ & $\begin{array}{l}\text { Uses longitudinal secondary data } \\
\text { from The Directory of Corporate } \\
\text { Philanthropy, and IRS sources. }\end{array}$ & corporation & Charitable giving \\
\hline $\begin{array}{l}\text { (Burlingame } \\
\text { \& Frishkoff, } \\
\text { 1996) }\end{array}$ & quant & single & 1382 & $\begin{array}{l}\text { How does firm size affect } \\
\text { philanthropy? }\end{array}$ & $\begin{array}{l}\text { Interviews with } 182 \text { firms, and mail } \\
\text { survey of } 1200 \text { (US based). }\end{array}$ & corporations & Charitable giving \\
\hline $\begin{array}{l}\text { (Wang \& } \\
\text { Coffey, 1992) }\end{array}$ & quant & $\begin{array}{l}\mathrm{n} / \mathrm{a} \\
\text { second'y }\end{array}$ & 500 & $\begin{array}{l}\text { To investigate influence of board } \\
\text { composition on corporate } \\
\text { philanthropy. }\end{array}$ & $\begin{array}{l}\text { Secondary data from } 78 \text { Fortune } \\
500 \text { firms from } 1984 \text {. }\end{array}$ & corporations & Charitable giving \\
\hline $\begin{array}{l}\text { (Atkinson \& } \\
\text { Galaskiewicz, } \\
\text { 1988) }\end{array}$ & qual & uncertain & 69 & $\begin{array}{l}\text { To study the effect of company } \\
\text { ownership patterns on corporate } \\
\text { contributions to charities. }\end{array}$ & $\begin{array}{l}\text { Interviews with } 69 \text { companies from } \\
\text { Minneapolis-St. Paul, plus content } \\
\text { analysis. }\end{array}$ & corporations & Charitable giving \\
\hline $\begin{array}{l}\text { (Navarro, } \\
1988)\end{array}$ & quant & $\begin{array}{l}\mathrm{n} / \mathrm{a} \\
\text { second'y }\end{array}$ & 1000 & $\begin{array}{l}\text { To investigate why corporations } \\
\text { give to charity considering profit- } \\
\text { maximisation and managerial } \\
\text { discretion }\end{array}$ & $\begin{array}{l}\text { Data from American Council for the } \\
\text { Arts' guide to Corporate Giving } \\
\text { (survey of } 1000 \text { companies). }\end{array}$ & corporations & arts \\
\hline $\begin{array}{l}\text { (McElroy \& } \\
\text { Siegfried, } \\
1986)\end{array}$ & quant & $\begin{array}{l}\text { Single - } \\
\text { corp } \\
\text { giving } \\
\text { mmgrs }\end{array}$ & 229 & $\begin{array}{l}\text { To develop a model of giving and } \\
\text { consider the influence of the } \\
\text { community in corporate giving. }\end{array}$ & $\begin{array}{l}\text { Interviewed corporate contributions } \\
\text { officers, combined with secondary } \\
\text { statistics, for } 229 \text { companies. }\end{array}$ & corporations & Charitable giving \\
\hline $\begin{array}{l}\text { (Cain \& Cain, } \\
\text { 1985) }\end{array}$ & quant & $\begin{array}{l}\text { n/a } \\
\text { second'y }\end{array}$ & & $\begin{array}{l}\text { To test whether the profit motive or } \\
\text { philanthropic motive is at play in } \\
\text { corporate giving. }\end{array}$ & $\begin{array}{l}\text { Secondary data. Quantitative } \\
\text { analysis. }\end{array}$ & corporations & Charitable giving \\
\hline $\begin{array}{l}\text { (McElroy \& } \\
\text { Siegfried, } \\
1985)\end{array}$ & quant & $\begin{array}{l}\text { n/a } \\
\text { second'y }\end{array}$ & & $\begin{array}{l}\text { To estimate the relationship } \\
\text { between contributions and pretax } \\
\text { net income in USA firms. }\end{array}$ & $\begin{array}{l}\text { Data collected from IRS source } \\
\text { book. Quantitative analysis. }\end{array}$ & corporations & Charitable giving \\
\hline $\begin{array}{l}\text { (Fry, Keim, \& } \\
\text { Meiners, } \\
\text { 1982) }\end{array}$ & quant & $\begin{array}{l}\text { n/a } \\
\text { second'y }\end{array}$ & & $\begin{array}{l}\text { To advance understanding of the } \\
\text { rationale for corporate giving. }\end{array}$ & $\begin{array}{l}\text { Aggregated data from IRS statistics, } \\
1946-1973\end{array}$ & corporations & Charitable giving \\
\hline
\end{tabular}




\begin{tabular}{|c|c|c|c|c|c|c|c|}
\hline $\begin{array}{l}\text { (Farrelly \& } \\
\text { Quester, } \\
\text { 2005a) }\end{array}$ & qual & $\begin{array}{l}\text { key } \\
\text { informant }\end{array}$ & $\begin{array}{l}28 \\
\text { relation'ps }\end{array}$ & $\begin{array}{l}\text { To analyse the sport sponsorship } \\
\text { relationship as a co-marketing } \\
\text { alliance, and to discover the factors } \\
\text { deemed critical to alliance success. }\end{array}$ & $\begin{array}{l}\text { In-depth interviews of } 28 \\
\text { relationships in the Australian } \\
\text { Football League and the } \\
\text { corresponding sponsors. }\end{array}$ & both & arts \\
\hline $\begin{array}{l}\text { (Farrelly \& } \\
\text { Quester, } \\
\text { 2005b) }\end{array}$ & quant & $\begin{array}{l}\text { assumed } \\
\text { single - } \\
\text { key } \\
\text { informant }\end{array}$ & $\begin{array}{l}46 \\
\text { relation'ps }\end{array}$ & $\begin{array}{l}\text { Examine the effects of trust and } \\
\text { commitment on economic and non- } \\
\text { economic satisfaction with the } \\
\text { protected sponsors of the AFL. }\end{array}$ & $\begin{array}{l}\text { Questionnaire for } 46 \text { relationships } \\
\text { involving sponsors of the Australian } \\
\text { Football League. Investigated } \\
\text { "protected relationships" (large } \\
\text { money) }\end{array}$ & both & arts \\
\hline $\begin{array}{l}\text { (Cornwell, } \\
\text { Pruitt et al., } \\
\text { 2005) }\end{array}$ & quant & $\begin{array}{l}\mathrm{n} / \mathrm{a}-\text { web } \\
\text { and stock } \\
\text { price info }\end{array}$ & $\begin{array}{l}5 \text { sponsor- } \\
\text { ships }\end{array}$ & $\begin{array}{l}\text { To study relationship major-league } \\
\text { sports official product sponsorships } \\
\text { and stock prices of sponsoring } \\
\text { companies }\end{array}$ & $\begin{array}{l}\text { used data from web re } \\
\text { announcements and stock price data }\end{array}$ & both & sports \\
\hline $\begin{array}{l}\text { (Seguin, } \\
\text { Teed, \& } \\
\text { O'Reilly, } \\
\text { 2005) }\end{array}$ & qual & Multiple & $\begin{array}{l}3 \text { relation- } \\
\text { ships }\end{array}$ & $\begin{array}{l}\text { To identify best practises of } \\
\text { Canadian national sports } \\
\text { organisations and their sponsorship } \\
\text { relationships. }\end{array}$ & $\begin{array}{l}\text { Case study approach. Interviews } \\
\text { with sports organisations, and } \\
\text { individual responsible for } \\
\text { sponsorship in corporation. }\end{array}$ & both & sports \\
\hline $\begin{array}{l}\text { (Argus, } \\
\text { Farrelly, \& } \\
\text { Quester, } \\
\text { 2004) }\end{array}$ & qual & $\begin{array}{l}\text { Appears } \\
\text { to be } \\
\text { single }\end{array}$ & 15 & $\begin{array}{l}\text { To prove that the "adoption of the } \\
\text { resource based view of the firm } \\
\text { assists our understanding of ... } \\
\text { sports sponsorship." (p.1) }\end{array}$ & $\begin{array}{l}\text { Interviews with } 15 \text { major sponsor } \\
\text { organisations, 2001-2003. }\end{array}$ & corporations & sports \\
\hline $\begin{array}{l}\text { (McNicholas, } \\
\text { 2004) }\end{array}$ & qual & uncertain & $\begin{array}{l}2 \text { co's, } \\
\text { multiple } \\
\text { sponsor- } \\
\text { ships }\end{array}$ & $\begin{array}{l}\text { To identify trends and shifts in arts } \\
\text { sponsorship approach }\end{array}$ & $\begin{array}{l}\text { Case-based study of two Australian } \\
\text { companies, 1992-93. }\end{array}$ & corporations & arts \\
\hline $\begin{array}{l}\text { (Farrelly \& } \\
\text { Quester, } \\
\text { 2003c) }\end{array}$ & mixed & $\begin{array}{l}\text { appears } \\
\text { single - } \\
\text { key } \\
\text { informant }\end{array}$ & $\begin{array}{l}46 \\
\text { relation- } \\
\text { ships }\end{array}$ & $\begin{array}{l}\text { To establish and understand } \\
\text { antecedents of sponsorship renewal, } \\
\text { considering market orientation, trust } \\
\text { and commitment. }\end{array}$ & $\begin{array}{l}20 \text { sports sponsors of Australian } \\
\text { Football League studied via } \\
\text { questionnaire. }\end{array}$ & both & sports \\
\hline $\begin{array}{l}\text { (Farrelly \& } \\
\text { Quester, } \\
\text { 2003a) }\end{array}$ & mixed & $\begin{array}{l}\text { appears } \\
\text { single - } \\
\text { key } \\
\text { informant }\end{array}$ & 20 & $\begin{array}{l}\text { To study effect of Market } \\
\text { Orientation of company and the } \\
\text { sports organisation, and the impact } \\
\text { on the sponsorship relationship. }\end{array}$ & $\begin{array}{l}\text { Studied } 20 \text { sponsors of Australian } \\
\text { Football League, using } 20 \text { in-depth } \\
\text { interviews, and mail questionnaire. }\end{array}$ & both & sports \\
\hline
\end{tabular}




\begin{tabular}{|c|c|c|c|c|c|c|c|}
\hline Author/year & $\begin{array}{l}\text { Qual / } \\
\text { Quant }\end{array}$ & $\begin{array}{l}\text { unit of } \\
\text { analysis }\end{array}$ & $\begin{array}{l}\text { \# firms } \\
\text { surveyed }\end{array}$ & purpose & details of study & $\begin{array}{l}\text { Studied } \\
\text { behaviour of: }\end{array}$ & $\begin{array}{l}\text { Concerned with } \\
\text { support of: }\end{array}$ \\
\hline $\begin{array}{l}\text { (Farrelly et } \\
\text { al., 2003b) }\end{array}$ & mixed & $\begin{array}{l}\text { single - } \\
\text { key } \\
\text { inform-ant }\end{array}$ & 20 & $\begin{array}{l}\text { Within sponsorship context, studied } \\
\text { link between market orientation, } \\
\text { collaborative communications, trust } \\
\& \text { commitment }\end{array}$ & $\begin{array}{l}\text { Studied } 20 \text { sponsors of Australian } \\
\text { Football League, using } 20 \text { in-depth } \\
\text { interviews. }\end{array}$ & corporations & sports \\
\hline $\begin{array}{l}\text { (Motion et al., } \\
\text { 2003) }\end{array}$ & Qual & $\begin{array}{l}\text { Limited } \\
\text { multiple }\end{array}$ & $\begin{array}{l}1 \text { relation- } \\
\text { ship }\end{array}$ & $\begin{array}{l}\text { To study the process of } \\
\text { "establishing a co-branded identity." }\end{array}$ & $\begin{array}{l}\text { Case study of Adidas and all Blacks } \\
\text { rugby team. Analyzed advertising } \\
\text { text and used semi-structured } \\
\text { interviews. }\end{array}$ & both & sports \\
\hline $\begin{array}{l}\text { (Ryan \& } \\
\text { Fahy, 2003) }\end{array}$ & qual & $\begin{array}{l}\text { Limited } \\
\text { multiple }\end{array}$ & $\begin{array}{l}1 \text { relation- } \\
\text { ship }\end{array}$ & $\begin{array}{l}\text { To suggest a theoretical framework } \\
\text { taking a relationship marketing } \\
\text { perspective of arts sponsorship. }\end{array}$ & $\begin{array}{l}\text { Case study of Galway Arts Festival } \\
\text { and Nortel Networks, via interviews } \\
\text { and content analysis of documents. }\end{array}$ & both & arts \\
\hline $\begin{array}{l}\text { (Clark, } \\
\text { Cornwell, \& } \\
\text { Pruitt, 2002) }\end{array}$ & quant & $\begin{array}{l}\mathrm{n} / \mathrm{a} \\
\text { second'y }\end{array}$ & 49 & $\begin{array}{l}\text { To study the effect of announcement } \\
\text { of stadium sponsorship on firm } \\
\text { stock prices }\end{array}$ & $\begin{array}{l}\text { Regression analysis on factors } \\
\text { within firm and stock prices. }\end{array}$ & both & sports \\
\hline $\begin{array}{l}\text { (Meenaghan, } \\
\text { 2002) }\end{array}$ & $\begin{array}{l}\text { Case / } \\
\text { theory }\end{array}$ & $\begin{array}{l}\text { Limited } \\
\text { multiple }\end{array}$ & $\begin{array}{l}1 \text { relation- } \\
\text { ship }\end{array}$ & $\begin{array}{l}\text { To investigate the synergies and } \\
\text { alliance of a single sponsorship } \\
\text { relationship. }\end{array}$ & case - Guiness and Hurling & both & sports \\
\hline $\begin{array}{l}\text { (Olkkonen, } \\
\text { 2002) }\end{array}$ & qual & Multiple & $\begin{array}{l}4 \text { relation- } \\
\text { ships }\end{array}$ & $\begin{array}{l}\text { To study the interorganisational } \\
\text { relationships of cultural/arts } \\
\text { sponsorship. }\end{array}$ & $\begin{array}{l}\text { Case, dyadic, longitudinal } \\
\text { (retrospective); } 24 \text { interviews with } \\
17 \text { people. }\end{array}$ & both & arts \\
\hline $\begin{array}{l}\text { (Thjømøe et } \\
\text { al., 2002) }\end{array}$ & quant & Single & 400 & $\begin{array}{l}\text { To study how firms define } \\
\text { sponsorship, how much they spend, } \\
\text { why they sponsor, and how they } \\
\text { manage sponsorship activities. }\end{array}$ & $\begin{array}{l}\text { Telephone survey of } 144 \\
\text { Norwegian firms. }\end{array}$ & corporations & $\begin{array}{l}\text { Sponsorship } \\
\text { activities }\end{array}$ \\
\hline $\begin{array}{l}\text { (Cornwell et } \\
\text { al., 2001) }\end{array}$ & quant & $\begin{array}{l}\text { Single: } \\
\text { sponsor- } \\
\text { ship mngr }\end{array}$ & $\begin{array}{l}146 \text { for } \\
\text { first phase }\end{array}$ & $\begin{array}{l}\text { To study how managers view the } \\
\text { brand-equity building capabilities of } \\
\text { sponsorship }\end{array}$ & $\begin{array}{l}\text { Surveyed managers' perceptions of } \\
\text { sponsorship success }\end{array}$ & corporations & $\begin{array}{l}\text { Sponsorship } \\
\text { activities }\end{array}$ \\
\hline (Kelly, 2001) & $\begin{array}{l}\text { qual - } \\
\text { loose } \\
\text { case }\end{array}$ & $\begin{array}{l}\text { not } \\
\text { detailed }\end{array}$ & $\begin{array}{l}3+\text { non } \\
\text { profit }\end{array}$ & $\begin{array}{l}\text { To review the relationships of } \\
\text { festival with a number of sponsors }\end{array}$ & $\begin{array}{l}\text { Case of Brief Encounters - a short } \\
\text { film festival in Britain }\end{array}$ & both & arts \\
\hline $\begin{array}{l}\text { (Olkkonen, } \\
2001)\end{array}$ & $\begin{array}{l}\text { qual - } \\
\text { case }\end{array}$ & Multiple & $\begin{array}{l}1 \text { relation- } \\
\text { ship }\end{array}$ & $\begin{array}{l}\text { Uses the interorganisational network } \\
\text { approach to look at a sports } \\
\text { sponsorship relationship }\end{array}$ & Case study of sports sponsorship & both & sports \\
\hline $\begin{array}{l}\text { (O'Hagan \& } \\
\text { Harvey, } \\
2000)\end{array}$ & quant & single & 69 & $\begin{array}{l}\text { To study the motivations behind } \\
\text { sponsorship of the arts? }\end{array}$ & $\begin{array}{l}69 \text { companies (129 events) studied } \\
\text { via survey in Ireland. }\end{array}$ & corporations & arts \\
\hline Author/year & $\begin{array}{l}\text { Qual / } \\
\text { Quant }\end{array}$ & $\begin{array}{l}\text { unit of } \\
\text { analysis }\end{array}$ & $\begin{array}{l}\text { \# firms } \\
\text { surveyed }\end{array}$ & purpose & details of study & $\begin{array}{l}\text { Studied } \\
\text { behaviour of: }\end{array}$ & $\begin{array}{l}\text { Concerned with } \\
\text { support of: }\end{array}$ \\
\hline
\end{tabular}




\begin{tabular}{|c|c|c|c|c|c|c|c|}
\hline $\begin{array}{l}\text { (Amis, Slack, } \\
\text { \& Berrett, } \\
\text { 1999) }\end{array}$ & qual & $\begin{array}{l}\text { single - } \\
\text { responsibl } \\
\text { e mngr }\end{array}$ & 28 & $\begin{array}{l}\text { To study the consideration of } \\
\text { sponsorship agreements as strategic } \\
\text { investments. }\end{array}$ & $\begin{array}{l}\text { Case studies and interviews of } \\
\text { sponsors of sports in Canada -- } \\
\text { taken from larger study. }\end{array}$ & corporations & sports \\
\hline (Mack, 1999) & mixed & single & 800 & $\begin{array}{l}\text { To study attitudes towards } \\
\text { sponsorships among US small } \\
\text { business. }\end{array}$ & $\begin{array}{l}\text { Exploratory focus groups with } \\
\text { small business owners (1996), } \\
\text { followed by a survey of businesses } \\
\text { ( } 212 \text { responses). }\end{array}$ & corporations & all \\
\hline $\begin{array}{l}\text { (Burton et al., } \\
\text { 1998b) }\end{array}$ & quant & single & 102 & $\begin{array}{l}\text { To study sports sponsorship } \\
\text { decisions, the department making } \\
\text { the decisions and the strategic } \\
\text { importance placed on the decision. }\end{array}$ & $\begin{array}{l}\text { Survey questionnaire } 102 \\
\text { companies, including Canadian, US } \\
\text { and Australian. }\end{array}$ & corporations & sports \\
\hline $\begin{array}{l}\text { (Grimes \& } \\
\text { Meenaghan, } \\
1998)\end{array}$ & mixed & single & 1 corp & $\begin{array}{l}\text { To consider the effects of a } \\
\text { sponsorship program on internal } \\
\text { staff. }\end{array}$ & $\begin{array}{l}\text { Interviews with key respondents } \\
\text { followed by a survey of } 608 \text { bank } \\
\text { employees. }\end{array}$ & corporations & sports \\
\hline $\begin{array}{l}\text { (Farrelly \& } \\
\text { Quester, } \\
1997)\end{array}$ & mixed & $\begin{array}{l}\text { assume } \\
\text { single }\end{array}$ & 185 & $\begin{array}{l}\text { Considers the differences and } \\
\text { similarities in the management of } \\
\text { arts vs sports sponsorships. }\end{array}$ & $\begin{array}{l}10 \text { in-depth interviews with } 5 \\
\text { companies followed by to arts and } \\
\text { sports sponsorship ( } 185 \text { responses). }\end{array}$ & corporations & arts \& sports \\
\hline $\begin{array}{l}\text { (Turgeon \& } \\
\text { Colbert, } \\
\text { 1992) }\end{array}$ & quant & $\begin{array}{l}\text { n/a } 2^{\text {nd }} \text { ary } \\
\text { data }\end{array}$ & 9 events & $\begin{array}{l}\text { To propose a model of the decision- } \\
\text { making process used by firms } \\
\text { involved in sponsorship. }\end{array}$ & $\begin{array}{l}\text { Literature and content analysis of } \\
\text { reports on nine sponsored arts } \\
\text { events in Canada }\end{array}$ & corporations & arts \\
\hline $\begin{array}{l}\text { (Crowley, } \\
\text { 1991) }\end{array}$ & quant & single & 70 & $\begin{array}{l}\text { To identify the relationship between } \\
\text { audience priority and sponsorship } \\
\text { selection and exploitation. }\end{array}$ & $\begin{array}{l}70 \text { senior marketing personnel } \\
\text { surveyed via questionnaire. }\end{array}$ & corporations & arts \& sports \\
\hline $\begin{array}{l}\text { (Witcher et } \\
\text { al., 1991) }\end{array}$ & quant & single & 54 & $\begin{array}{l}\text { To identify links between } \\
\text { objectives, categories of sponsored } \\
\text { activity and organisational function. }\end{array}$ & $\begin{array}{l}\text { Surveyed } 54 \text { sponsoring companies } \\
\text { in the UK. }\end{array}$ & corporations & arts \& sports \\
\hline $\begin{array}{l}\text { (Hoek et al., } \\
1990)\end{array}$ & qual & $\begin{array}{l}\text { single - } \\
\text { sponsor- } \\
\text { ship mngr }\end{array}$ & 19 & $\begin{array}{l}\text { To examine sponsor practise } \\
\text { concerning sponsorship objective } \\
\text { setting, event appraisal, selection, } \\
\text { budgeting and evaluation. }\end{array}$ & $\begin{array}{l}\text { Interviews with } 19 \text { major sponsors } \\
\text { of sporting, cultural and } \\
\text { community groups. }\end{array}$ & corporations & $\begin{array}{l}\text { Sponsorship } \\
\text { activities }\end{array}$ \\
\hline $\begin{array}{l}\text { (Abratt et al., } \\
1987 \text { ) }\end{array}$ & quant & $\begin{array}{l}\text { Assume } \\
\text { single }\end{array}$ & 45 & $\begin{array}{l}\text { To study why companies sponsor } \\
\text { sport. }\end{array}$ & $\begin{array}{l}\text { Quantitative survey of } 45 \text { South } \\
\text { African companies. Ten companies } \\
\text { were interviewed to check validity. }\end{array}$ & corporations & Sports \\
\hline
\end{tabular}




\section{Appendix 5: Interview Protocol}

\section{Opening:}

To begin, the information sheet and consent form were reviewed with the respondent, any questions were addressed and consent was sought.

\section{Questions and Prompts:}

\begin{tabular}{|c|c|}
\hline Q1: Roles & $\begin{array}{l}\text { Tell me about your roles and responsibilities with respect to sponsorship or } \\
\text { donations? }\end{array}$ \\
\hline $\begin{array}{l}\text { Q2: Decision } \\
\text { process }\end{array}$ & $\begin{array}{l}\text { Arts: Could you walk me through your company's request to gain support } \\
\text { from XXX company? } \\
\text { How did the process begin? } \\
\text { Did they approach you or you approach them? } \\
\text { What happened next? ... and then? } \\
\text { Who was involved, in what way and when? } \\
\text { Corp: Could you walk be through the decision of your company to support } \\
\text { this organisation/event? } \\
\text { How did the process begin? } \\
\text { Did they approach you or you approach them? } \\
\text { What happened next? ... and then? } \\
\text { Who was involved, in what way and when? }\end{array}$ \\
\hline Q2a: Amount & How much were you/they asking for? (if not already noted) \\
\hline $\begin{array}{l}\text { Q2b: } \\
\text { Involvement } \\
\text { of Others }\end{array}$ & $\begin{array}{l}\text { You have noted that a number of others were involved in some way ... (state } \\
\text { who). Were there others involved in the decision? }\end{array}$ \\
\hline $\begin{array}{l}\text { Q2c: } \\
\text { Formality }\end{array}$ & $\begin{array}{l}\text { Arts: Do you have a standard approach to getting sponsorship? And did this } \\
\text { process differ in any way from your usual procedures? } \\
\text { Corp: Do you have formal policies and procedures for allocating } \\
\text { sponsorships?, and did this process differ from this? }\end{array}$ \\
\hline $\begin{array}{l}\text { Q3: } \\
\text { considerations }\end{array}$ & $\begin{array}{l}\text { Arts: In your view, what were the main considerations for XXX around this } \\
\text { decision? (putting yourself in their shoes). (Prompt for elaboration) } \\
\text { Corp: What would you say were the main considerations around this } \\
\text { decision? the options you were exploring? (Prompt for elaboration) }\end{array}$ \\
\hline $\begin{array}{l}\text { Q3a: Ranking } \\
\text { of } \\
\text { considerations }\end{array}$ & What do you feel was the most important consideration here? Second most? \\
\hline $\begin{array}{l}\text { Q3b: } \\
\text { Importance }\end{array}$ & $\begin{array}{l}\text { Do you feel this proposal was potentially an important one for } X X X / \text { for your } \\
\text { company? Why? }\end{array}$ \\
\hline Q3c: Risks & $\begin{array}{l}\text { In your view, did you see any risks associated with this proposal, for XXX / } \\
\text { your company? }\end{array}$ \\
\hline
\end{tabular}




\begin{tabular}{|c|c|}
\hline $\begin{array}{l}\text { Q3d: Frame of } \\
\text { Reference }\end{array}$ & $\begin{array}{l}\text { Arts: Do you feel the corporation has a certain philosophy towards this sort } \\
\text { of activity? Do you think this affected the decision in any way? } \\
\text { Corp: Do you feel your company has a certain philosophy towards this sort } \\
\text { of activity? Do you think this affected the decision in any way? }\end{array}$ \\
\hline Q4: Results & $\begin{array}{l}\text { What would you say has been the result of this decision? Do you view it as } \\
\text { satisfactory? In what way are you satisfied or not? }\end{array}$ \\
\hline $\begin{array}{l}\text { Q5: Decision- } \\
\text { specific } \\
\text { comments }\end{array}$ & Is there anything else you would like to tell me about this decision? \\
\hline $\begin{array}{l}\text { Q6: Proactive } \\
\text { Nature }\end{array}$ & Would you say your company actively seeks out support opportunities? \\
\hline $\begin{array}{l}\text { Q7: Personal } \\
\text { Philosophy }\end{array}$ & $\begin{array}{l}\text { Do you have a personal philosophy about the role of a corporation in } \\
\text { society? }\end{array}$ \\
\hline $\begin{array}{l}\text { Q8: Further } \\
\text { Information }\end{array}$ & Is there anything else you would like to add? \\
\hline
\end{tabular}

\section{Closing:}

- confirming others within or external to the organisation to talk with (gain contact information;

- thanking the individual;

- reiterating that they will receive a copy of the transcript, and should they wish, upon completion of the research they may receive an abstract of the $\mathrm{PhD}$ and summary of findings. 


\section{Appendix 6: Example of a Process Diagram}

Example of an initial depiction of a case using a process diagram

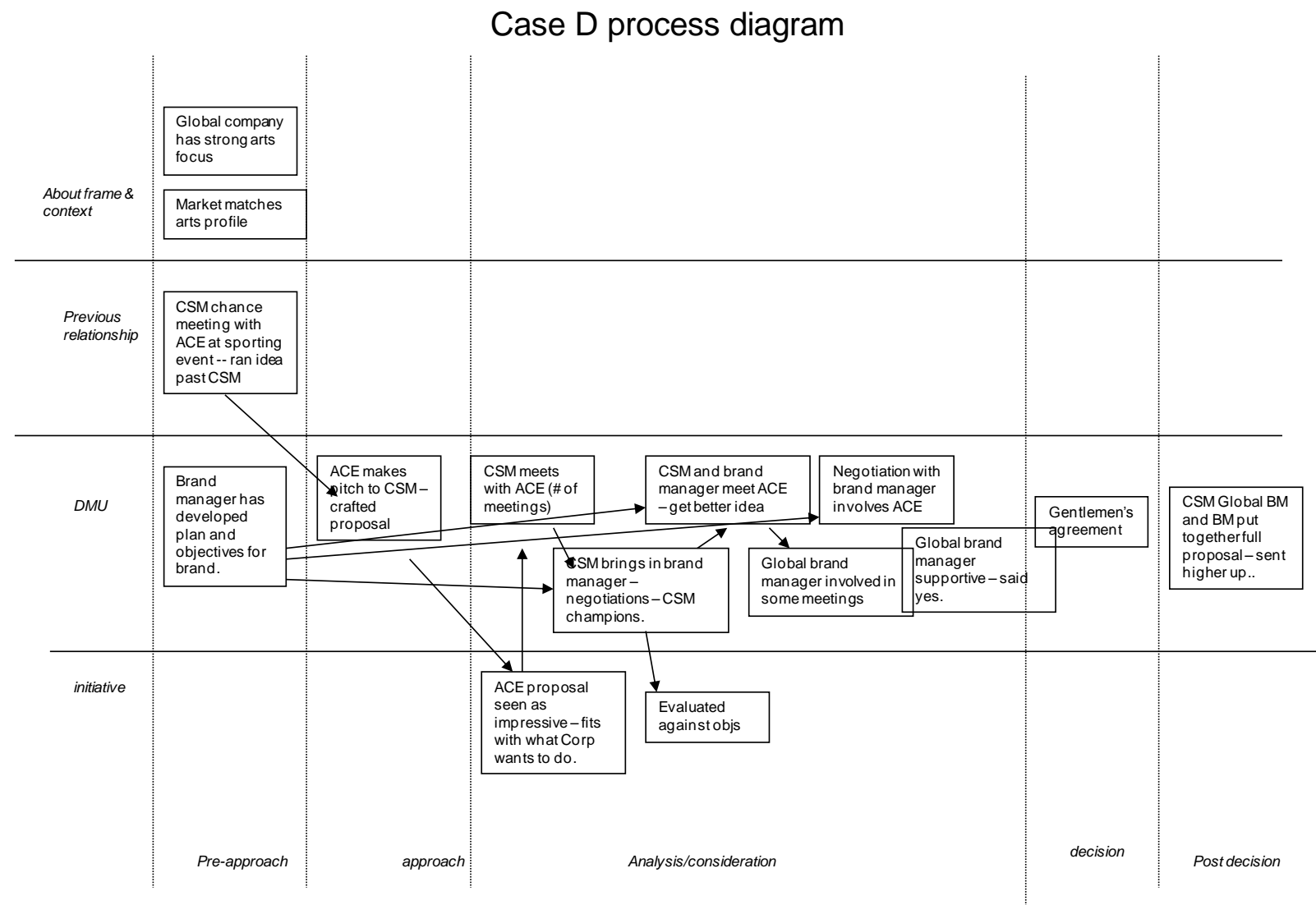




\section{Appendix 7: List of Propositions}

\section{Proposition 1}

In considering arts sponsorship decisions, managers are likely to be influenced by their interpretation of perceptions and expectations held by consumers and other stakeholders with respect to sponsorship and the specific investment.

\section{Proposition 2}

Positive experiences and values in support of arts sponsorship held by a senior level executive are likely to reduce the perception of uncertainty surrounding the use of sponsorship.

\section{Proposition 3(a)}

The more managers feel that sponsorship carries with it uncertainty, the more likely the decision-making unit is to include senior levels of management.

\section{Proposition 3(b)}

The more managers feel that sponsorship carries with it uncertainty, the more likely the evaluation phase is to be extensive and commercially-oriented.

\section{Proposition 4}

Regardless of whether a company is more philanthropic or more commerciallyoriented, arts sponsorship decisions are likely to include goals related to philanthropy along with commercial gain.

\section{Proposition 5 (a)}

Managers in companies who approach sponsorship from a more philanthropic orientation are less likely to perceive uncertainty involving the use of sponsorship.

\section{Proposition 5 (b-d)}

Philanthropic-oriented companies are likely to

b) have fewer formal policies associated with arts sponsorship decisions.

c) make arts sponsorship decisions relying heavily on the intuition of the advocate.

d) negotiate the benefits of arts sponsorships following the decision.

\section{Proposition 6 (a - c)}

Commercially-oriented companies are likely to

a) have more formal policies associated with arts sponsorship decisions.

b) make arts sponsorship decisions with emphasis on the commercial justification, including the formally evaluated fit and benefits to the company.

c) negotiate benefits associated with an arts sponsorship during the evaluation phase of the decision process.

\section{Proposition 7}

A sponsorship needs to provide benefits to the company which are likely to be Proposition 8 realised through hosting and/or brand-image-transfer. 
The more positive experience managers have had with sponsorship, the arts organisation and/or related arts managers, the more likely they are to perceive that the sponsorship will deliver benefits to the company.

\section{Proposition 9 (a)}

If a company is seeking hosting opportunities, a successful outcome for the company is likely to be perceived when the event is judged to appeal to the company's identified stakeholder group (s).

\section{Proposition 9 (b)}

If a company is seeking brand-image-transfer, a successful outcome for the company is likely to be perceived when the arts event's audience and brand image is consistent with the company's target market and desired brand image.

\section{Proposition 10}

The decision-making process is more likely to move forward when an arts representative is able to communicate and instil a strong sense of the benefits to the company within a key individual within the DMU.

\section{Proposition 11}

In successful arts sponsorship decisions there is likely to be an advocate within the sponsoring company who supports the sponsorship internally.

\section{Proposition 12 (a)}

Individuals are likely to become advocates for a sponsorship through the expert power they hold.

\section{Proposition 12 (b)}

The expert power of an advocate is likely to be derived from that individual's personal views and past experiences with the arts and the specific arts initiative, as well as their more formal role to acquire knowledge pertinent to the investment.

\section{Proposition 13}

The more expert power the advocate holds the more likely intuition is to play a strong role in the decision.

\section{Proposition 14 (a)}

Informed intuition concerning sponsorship of the arts is likely to be fostered via the experiences and knowledge of individuals.

\section{Proposition 14 (b)}

Arts sponsorship decisions are likely to be influenced by the informed intuition of individuals within the DMU. 